\title{
MODELING OF FIRE SPREAD IN BUILDINGS AND MODELING OF FIRE SPREAD FROM THE FIRE BUILDING TO ADJACENT BUILDINGS
}

\author{
A thesis submitted to \\ the Faculty of Graduate Studies and Research \\ in Partial Fulfillment of the requirements for the degree \\ Doctor of Philosophy
}

by

Hao Cheng
Department of Civil and Environmental Engineering Carleton University

Ottawa-Carleton Institute of Civil and Environmental Engineering

November, 2010

(C2010 Hao Cheng 
Library and Archives

Canada

Published Heritage

Branch

395 Wellington Street

Ottawa ON K1A ON4

Canada
Bibliothèque et

Archives Canada

Direction du

Patrimoine de l'édition

395 , rue Wellington

Ottawa ON K1A ON4

Canada
Your file Votre référence
ISBN: $978-0-494-79630-6$
Our file Notre référence
ISBN: $978-0-494-79630-6$
NOTICE:

The author has granted a nonexclusive license allowing Library and Archives Canada to reproduce, publish, archive, preserve, conserve, communicate to the public by telecommunication or on the Internet, loan, distribute and sell theses worldwide, for commercial or noncommercial purposes, in microform, paper, electronic and/or any other formats.

The author retains copyright ownership and moral rights in this thesis. Neither the thesis nor substantial extracts from it may be printed or otherwise reproduced without the author's permission.
AVIS:

L'auteur a accordé une licence non exclusive permettant à la Bibliothèque et Archives Canada de reproduire, publier, archiver, sauvegarder, conserver, transmettre au public par télécommunication ou par l'Internet, prêter, distribuer et vendre des thèses partout dans le monde, à des fins commerciales ou autres, sur support microforme, papier, électronique et/ou autres formats.

L'auteur conserve la propriété du droit d'auteur et des droits moraux qui protège cette thèse. $\mathrm{Ni}$ la thèse ni des extraits substantiels de celle-ci ne doivent être imprimés ou autrement reproduits sans son autorisation.
In compliance with the Canadian Privacy Act some supporting forms may have been removed from this thesis.

While these forms may be included in the document page count, their removal does not represent any loss of content from the thesis.
Conformément à la loi canadienne sur la protection de la vie privée, quelques formulaires secondaires ont été enlevés de cette thèse.

Bien que ces formulaires aient inclus dans la pagination, il n'y aura aucun contenu manquant. 


\begin{abstract}
The modeling of fire spread in buildings had been studied for decades. Due to the disadvantages of different models, none of previous models can really be used in practical applications involving large buildings. In this thesis, modeling of fire spread between buildings using Bayesian Network is proposed which can overcome the disadvantages of previous models. In practice, a general fire spread network has firstly to be built according to the floor plan of a building. Once the compartment of fire origin is known, a detailed fire spread model using a directed acyclic graph (DAG) of Bayesian network to express the fire spread process from the initial compartment to any destination compartment on the floor can be constructed. The probability of fire spread from the initial compartment to the destination compartment can be calculated by marginalizing the joint probability distribution of the Bayesian network.

Fire spread in a building is a dynamic process. Therefore, a dynamic fire spread model is proposed. The dynamic fire spread model is built on the basic concepts of dynamic Bayesian network and the static fire spread model proposed. In this model, the algorithms for simulating the fire spread process are developed and corresponding computer codes were developed. The probability of fire spread from the compartment of fire origin to any other compartment, the time of ignition, time of flashover and time of decay in each compartment can be calculated by the computer program. The fire spread dynamic model can be easily used in the application of any building including high rise buildings. In addition, the formulae calculating the input data for the dynamic fire spread model were derived. A user having a very basic knowledge of fire protection engineering will find no trouble using it.

Research on acceptable spatial separations between buildings to prevent fire spread between buildings has been conducted for more than 60 years. Several engineering methods have been presented. The shortcomings of these engineering methods are that there is no detailed description of the background on how the tables or graphs were
\end{abstract}


obtained. There is no universally accepted method and different methods may result in different results.

In this thesis, three basic relationships between window/opening in a fire building and a target point on an exposed building are proposed. The numerical methods of calculation of the configuration factor from the fire building to an adjacent building are presented which are even available for buildings with an irregular distribution of windows, different sizes of openings and recessed portions. By letting the maximum configuration factor be less than the critical configuration factor, the required minimum separation distance between two buildings can be easily calculated.

Furthermore, twelve full-scale fire experiments were conducted to study the emissivity of the external flame and the radiation contribution from the external flame out of the window. Based on the theory of post-flashover compartment fires, the calculations of configuration factor and experimental results, the model of fire spread from the fire building to adjacent buildings by radiation was proposed. The minimum separation distance between buildings could be easily found by computer programming by letting the maximum radiation heat flux equal to the critical ignition heat flux of combustible materials of an adjacent building.

By combining the dynamic model of fire spread in buildings, an example of the calculation of separation distance between buildings as a function of time is presented. The results calculated by the two models of fire spread between buildings are compared with that required by the National Building Code of Canada (NBCC) 2005. 


\section{Acknowledgements}

I would like to thank my supervisor Dr. George Hadjisophocleous for his guidance and help during the course of this work.

I would like to thank Dr. Abhijit Sarkar for guiding me into the field of stochastic, without which I could not solve the problem of fire spread in buildings.

I would like to thank Dr. Jim R. Mehaffey for his great lectures on fire dynamics, and his advice and help during the course of experiments.

I would like to thank Ba Lamthien, Bruce Taber and other technical staff of NRCC's fire lab for their technical support on my experiments. I would like to thank Dr. Ehab Zalok, Dr. Joseph Su and Ineke Van Zeeland for their advice and help during my experiments.

I would like to thank my son Tony Cheng and my wife Lin Yu for their encouragement to improve myself. Last but not least, I would like to thank my brother Gang Cheng and his family for their financial aid, which supported me throughout my study. 


\section{Table of Contents}

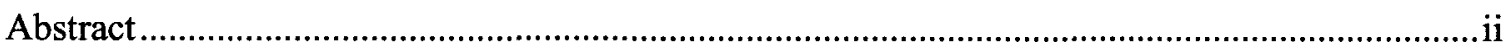

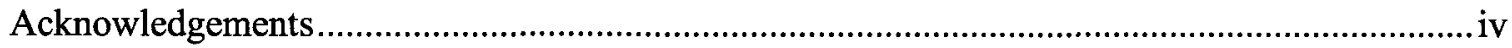

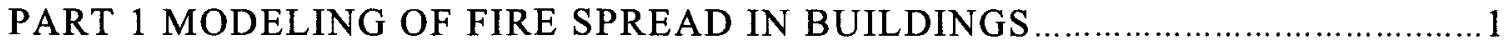

Chapter 1 Introduction to Modeling of Fire Spread in Buildings .............................................. 2

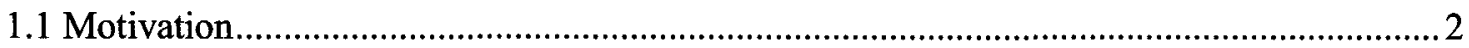

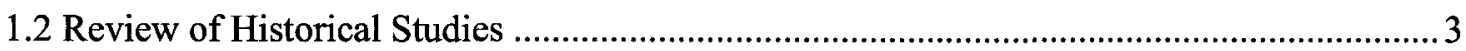

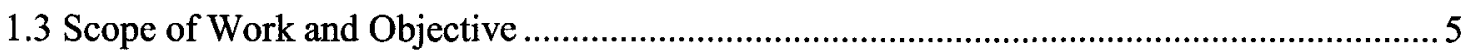

Chapter 2 Literature Review of Modeling Fire Spread in Buildings .............................................

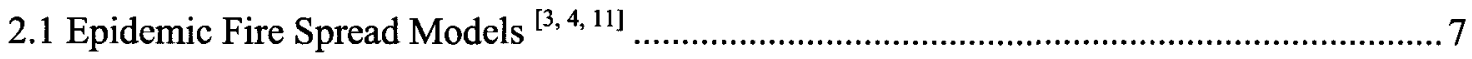

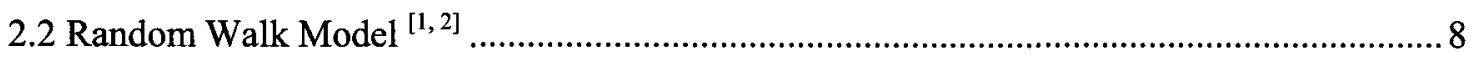

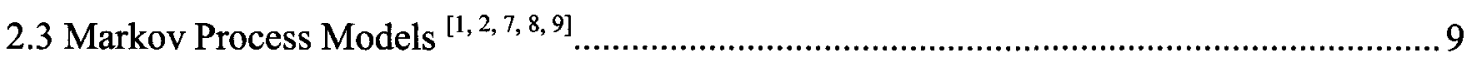

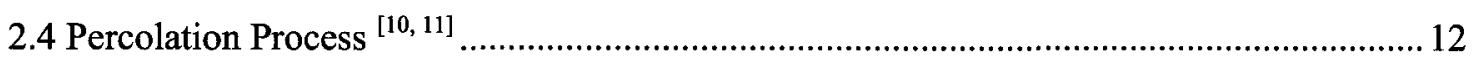

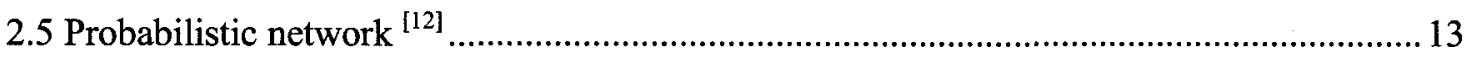

2.6 Probability Model with Time Effect based on Event Tree ${ }^{[13]}$........................................... 17

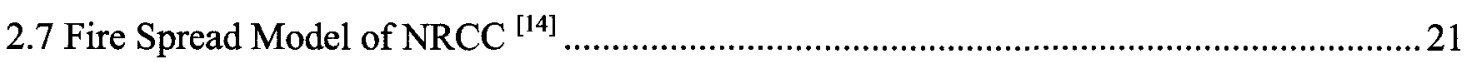

Chapter 3 Fundamentals of Fire Development in Compartments and Fire Spread in Buildings ...25

3.1 Fundamentals of Fire Development in a Compartment .................................................25

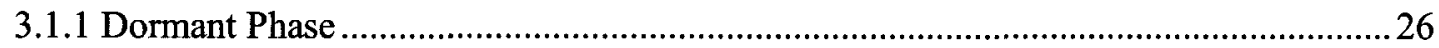

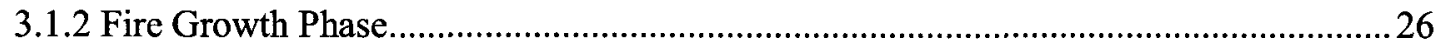

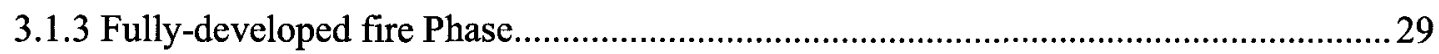

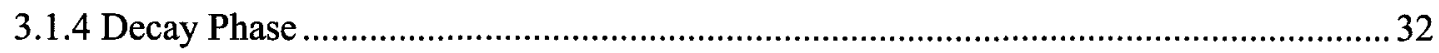

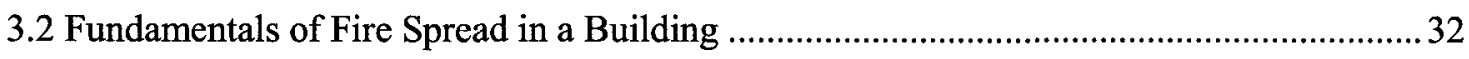

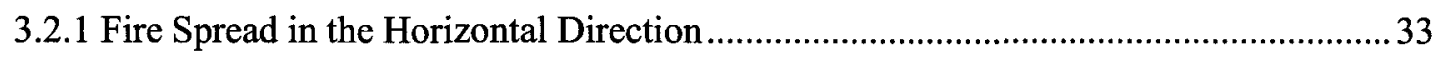

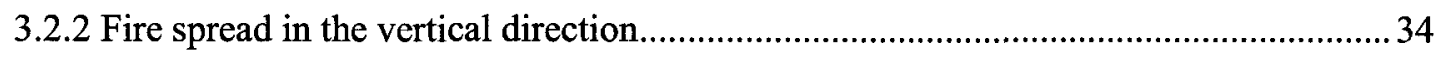

Chapter 4 The Modeling of Fire Spread in Buildings by Bayesian Network .............................. 36

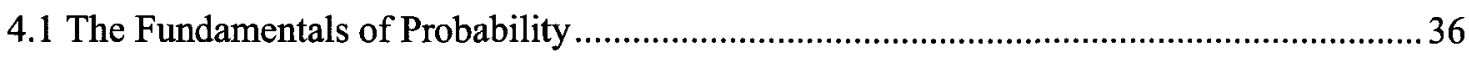

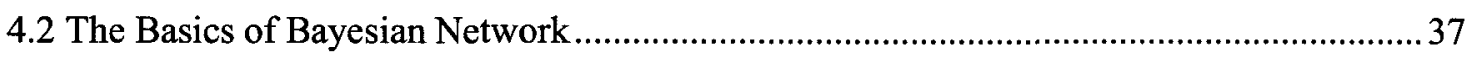

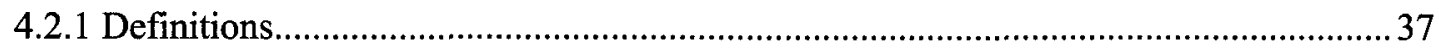

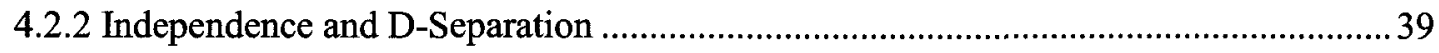

4.2.3 Representation of the Joint Probability Distribution................................................ 41 
4.2.4 Inference and Marginalization in Bayesian Network 42

4.3 A Fire Spread Model for an Office Building Using Bayesian Network .............................42

4.3.1 Transforming the Compartment Floor into the DAG of Bayesian network .................43

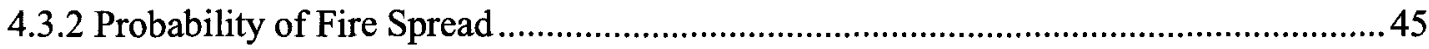

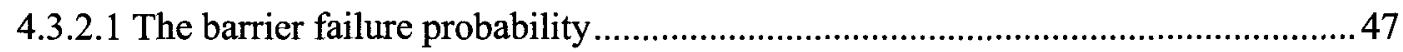

4.3.2.2 Probability of fire growth to fully developed fire ............................................ 47

4.4 Example of a Fire Spread Model Using Bayesian Network .......................................... 49

Chapter 5 Dynamic Modeling of Fire Spread in Buildings ......................................................59

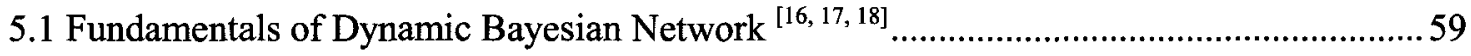

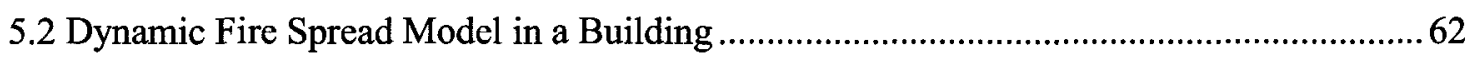

5.2.1 Basic Assumptions for Dynamic Fire Spread Model..............................................62

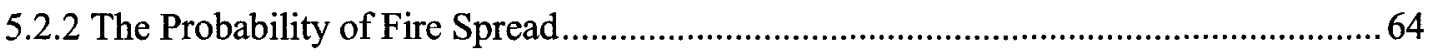

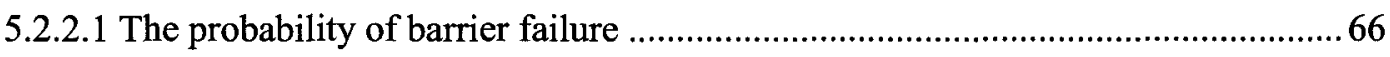

5.2.2.2 Probability of fire growth to a fully-developed fire ..........................................69

5.2.3 Establish the Dynamic Fire Spread Model ................................................................... 71

5.2.3.1 Fire spread in the horizontal direction on a building floor.................................. 73

5.2.4 Fire spreads in the vertical direction in a building ...................................................... 74

5.2.5 Fire spread model of buildings in both horizontal and vertical directions................... 75

5.2.6 Algorithm for Dynamic Fire Spread Model of Bayesian Network ............................... 78

5.3 Example

Chapter 6 Conclusion of Modeling Fire Spread in Buildings ..................................................... 94

6.1 Summary of the Study of Modeling Fire Spread in Buildings........................................... 94

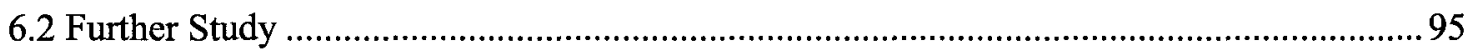

PART 2 MODELING OF FIRE SPREAD FROM THE FIRE BUILDING TO ADJACENT BUILDINGS.

Chapter 7 Introduction of Modeling of Fire Spread from the Fire Building to Adjacent Buildings

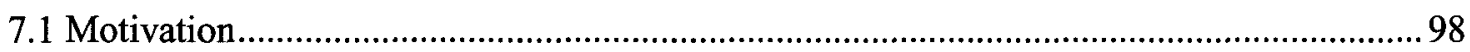

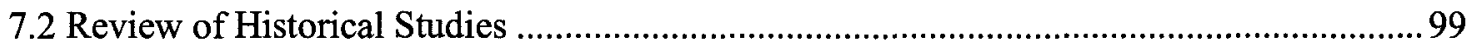

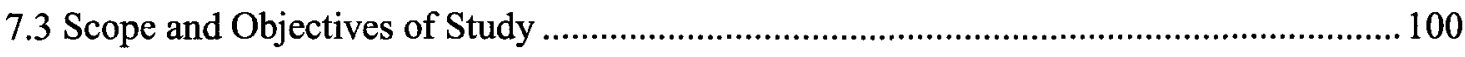

Chapter 8 Literature Review of Modeling Fire Spread from the Fire Building to Adjacent

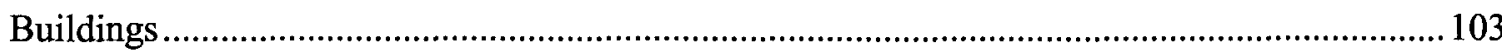


8.1 Experimental Study of Radiation from Fires in Buildings.......................................... 103

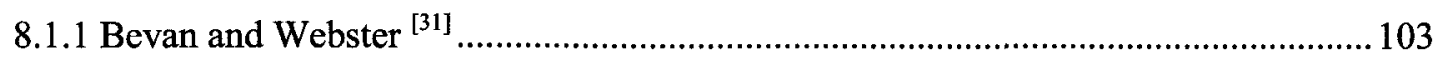

8.1.2 Shorter, McGuire, Hutcheon and Legget ${ }^{[32]}$......................................................... 104

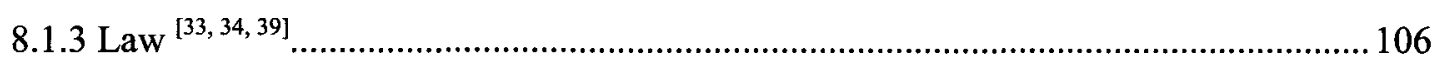

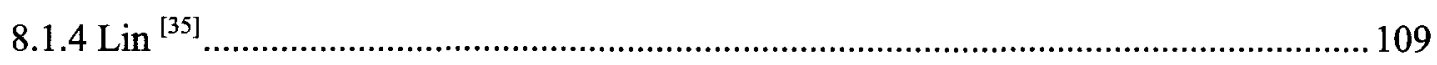

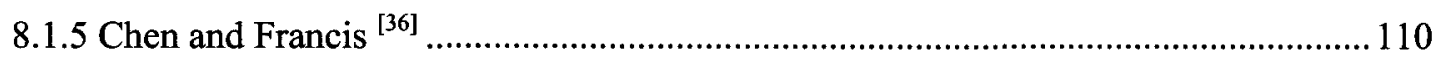

8.2 Calculation of Acceptable Separation Distance between Buildings ................................ 111

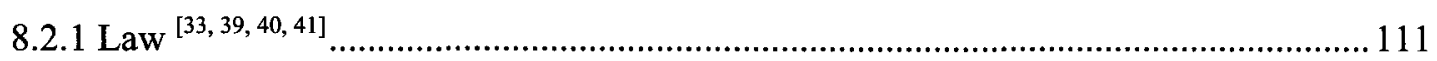

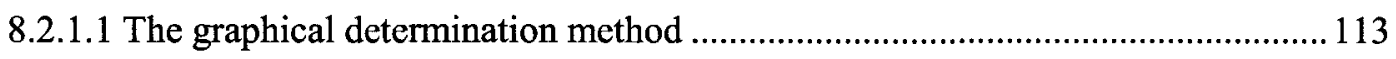

8.2.1.2 The experimental determination method ...................................................... 113

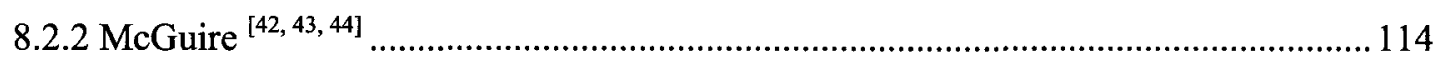

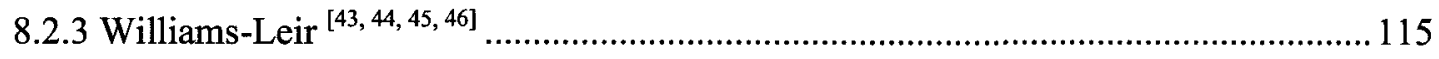

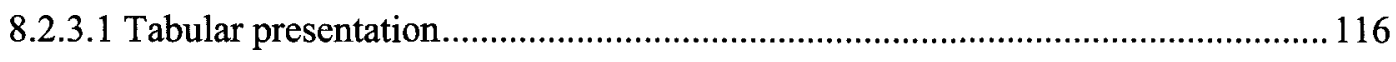

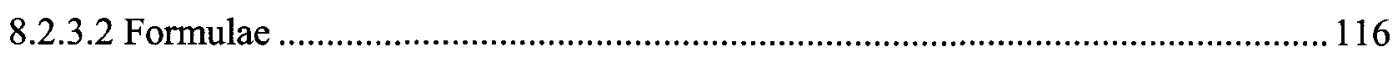

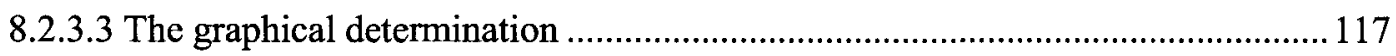

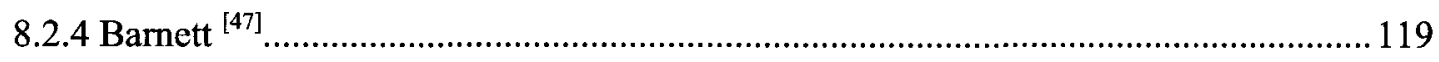

8.2.4.1 The maximum permissible area of openings in the owner's building ................. 120

8.2.4.2 Level of received radiation by the neighboring building ................................... 122

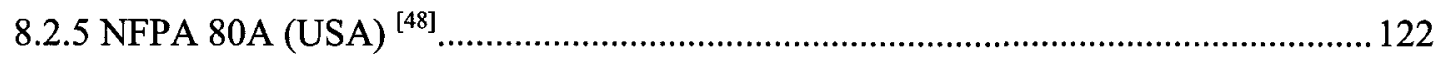

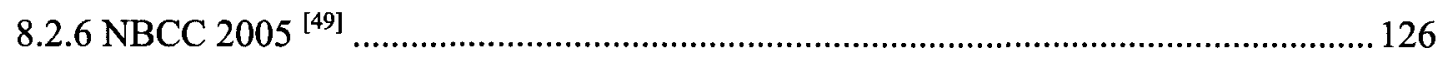

Chapter 9 Fundamentals of Post-Flashover Compartment Fires ............................................. 128

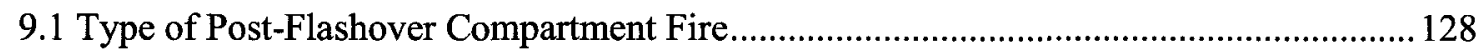

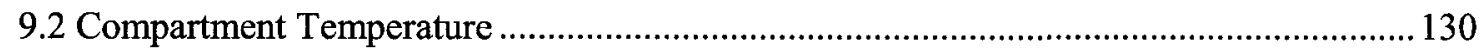

9.3 Burning Rate of Ventilation Controlled Fires.............................................................. 130

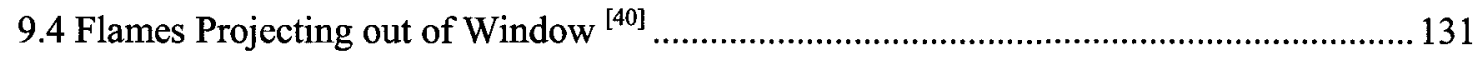

9.4.1 Flame Height above the Soffit of a Window/Opening............................................ 132

9.4.2 Length of Flame along Flame Centerline ${ }^{[40]}$......................................................... 132

9.4.3 Flame Temperature along Flame Centerline.......................................................... 133

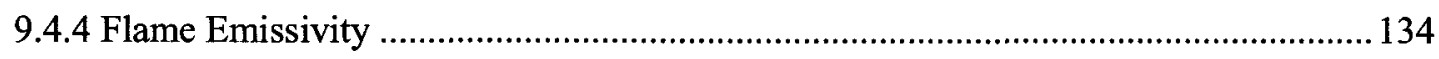

Chapter 10 Experimental Study and Modeling of Radiation from Compartment Fires to Adjacent

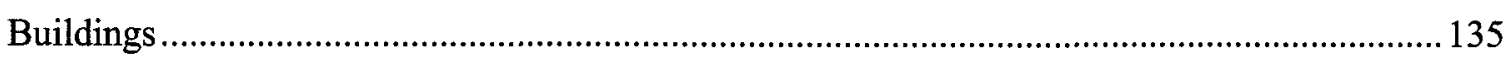

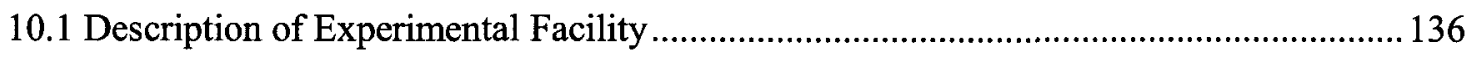

vii 


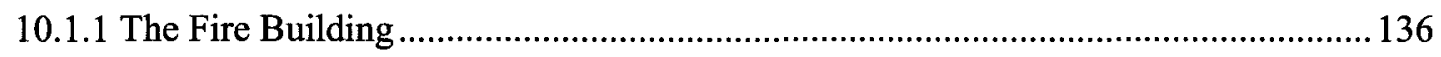

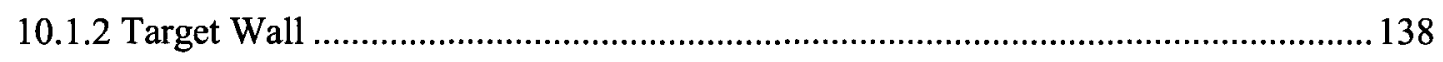

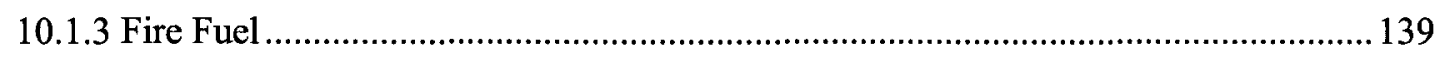

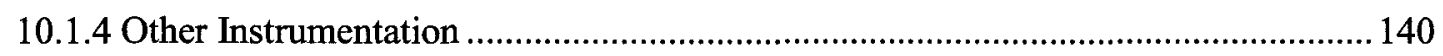

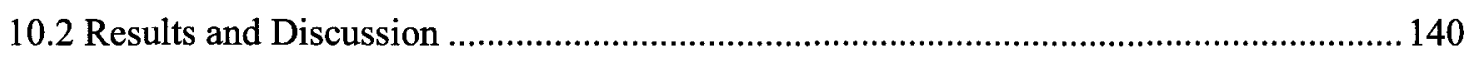

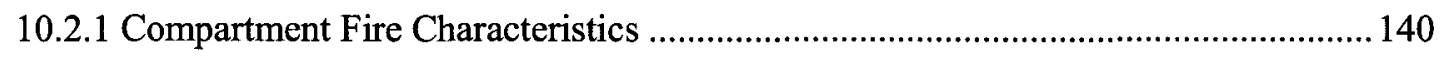

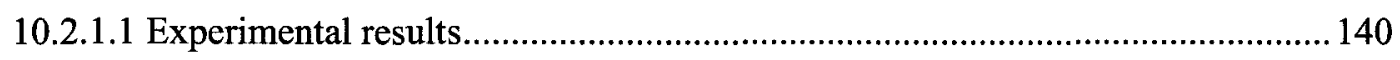

10.2.1.2 Theoretical results of post-flashover compartment fire ................................. 147

10.2.1.3 Comparison of experimental data and theoretical results for post-flashover

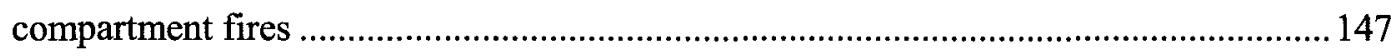

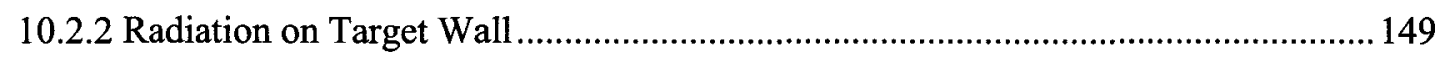

10.2.2.1 Impact of separation distance on radiation and temperature of target wall ....... 150

10.2.2.2 Impact of window size on radiation and temperature of target wall ................. 150

10.2.2.3 Impact of fuel on distribution of radiation and temperature on target wall ....... 153

10.2.2.4 Analysis of radiation heat flux on target wall ................................................ 158

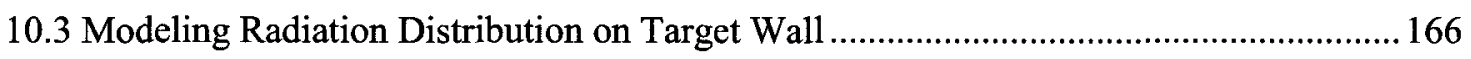

10.3.1 Modeling radiation distribution on target wall based on experimental data ............. 166

10.3.2 Modeling radiation distribution based on the theory of post-flashover compartment

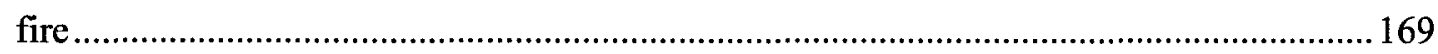

Chapter 11 Modeling Fire Spread from the Fire Building to Adjacent Buildings...................... 176

11.1 Modeling Fire Spread between Buildings by Configuration Factor ............................. 178

11.1.1 Calculation of the Configuration Factor for Buildings with Multiple Openings to a

Target Point on a Parallel Wall of an Adjacent Building.................................................. 178

11.1.1.1 The basic equation for calculation of the configuration factor for a opening to a

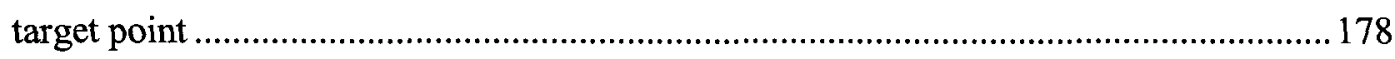

11.1.1.2 Three possible basic types of relationships between an opening of a fire building

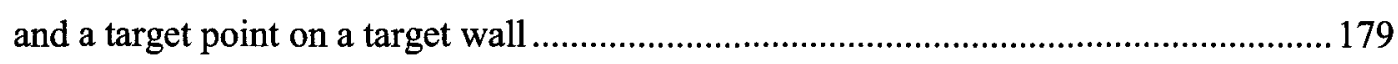

11.1.1.3 The calculation of configuration factor by computer programming ................... 184

11.1.2 The Calculation of Maximum of Configuration Factor ..........................................186

11.1.3 Calculation of Spatial Separation Distance between Buildings .............................. 191

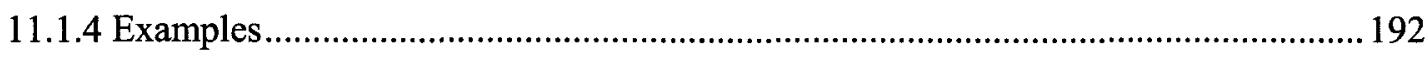

11.1.4.1 Example (11.1): The calculation of maximum configuration factor................. 192 viii 
11.1.4.2 Example (11.2): Calculation of the acceptable separation distance between buildings.. 196

11.2 Modeling Fire Spread between Buildings by Radiation 201

11.2.1 Radiation Heat Flux Emitted from the Fire Building. 201

11.2.1.1 Fire building with one window/opening in the external wall 202

11.2.1.2 Multiple openings in the external wall of the fire building..... 205

11.2.2 The Calculation of the Maximum Radiant Heat Flux from a Fire Building on the Target Wall of an Adjacent Building. 207

11.2.3 Spatial Separation Distance between Buildings. 212

11.2.4 Example (11.3): Calculation of the separation distance between buildings based on radiation heat flux

11.3 Comparison separation distances required by the National Building Code of Canada with

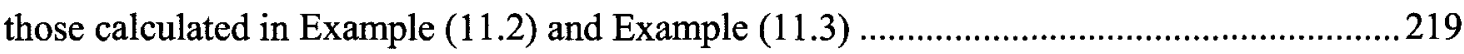
Chapter 12 Conclusion of the Study of Modeling Fire Spread between Buildings .....................223

12.1 Summary of the Study of Modeling Fire Spread between Buildings ............................. 223

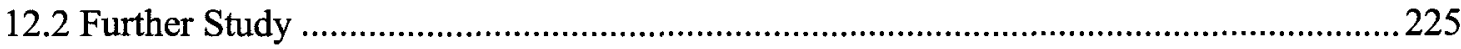

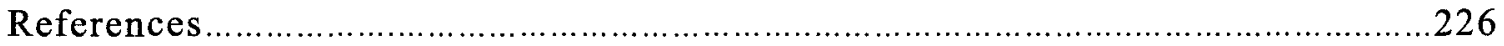

Appendix A The Analysis of Experiments of Radiation from Compartment Fires to Adjacent

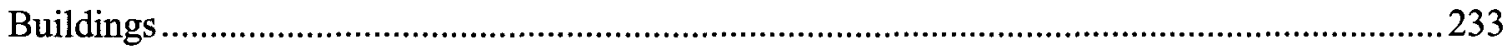

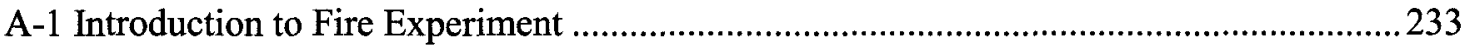

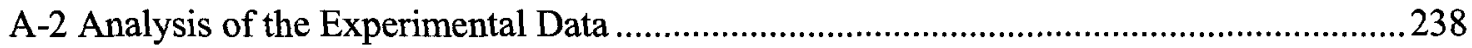




\section{List of Figures}

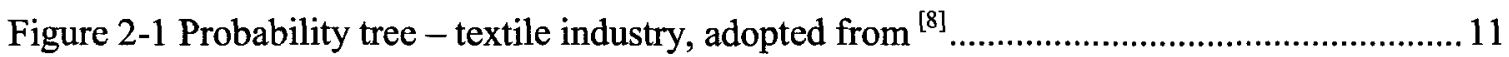

Figure 2-2 (a) A floor plan of an office building and (b) Fire spread network ............................. 14

Figure 2-3 (a) Floor plan of 4 rooms and 1 stairwell (b) Fire spread network.............................. 15

Figure 2-4 Probabilistic network of fire spread from Room 1 to Room 4 .................................. 16

Figure 2-5 Fire spread equivalent network with 5 minute unrated door..................................... 16

Figure 2-6 (a) Plan of a four-compartment building; (b) possible paths by which fire may spread

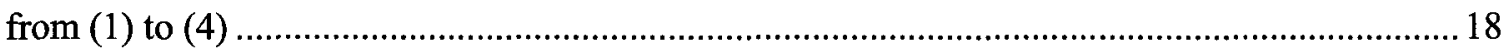

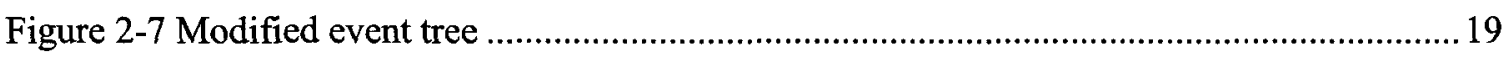

Figure 2-8 Recursive graph searching algorithm flowchart.....................................................22

Figure 2-9 Digraph of 3-store building with1 stairwell, 2 elevator shafts, 1 service duct.............23

Figure 2-10 Paths of fire spread from node 0 to node 1 ..........................................................24

Figure 3-1 The phases of enclosure fire development .............................................................. 25

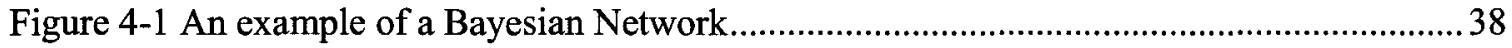

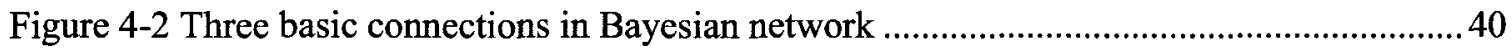

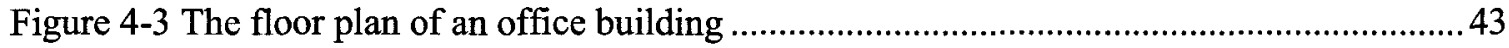

Figure 4-4 The DAG of fire spread model based on Bayesian network ...................................... 44

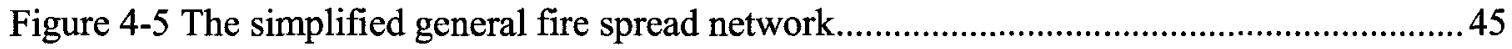

Figure 4-6 The DAG of Bayesian Network for fire to spread from room 1 to room 6 ................50

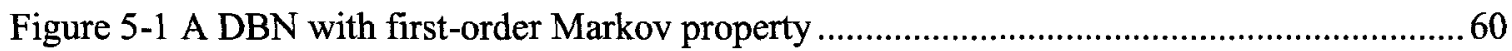

Figure 5-2 The prior network and transition network ..............................................................61

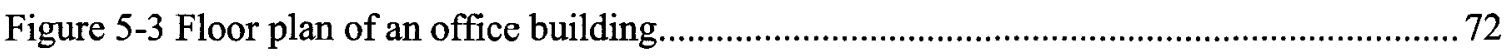

Figure 5-4 General model of fire spread of the building floor................................................. 72

Figure 5-5 The DAG of e Bayesian Network for fire to spread from room 1 to room 6 ..............74

Figure 5-6 (a) A building with four storey (b) The DAG of vertical fire spread network of the

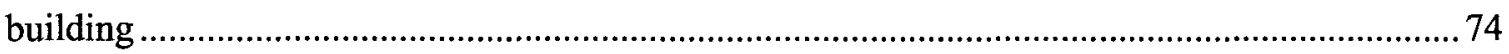

Figure 5-7 Fire spread to a compartment horizontally and vertically ..................................... 75

Figure 5-8 Bayesian network of fire spread from room R1 on the first floor to room R6 on the

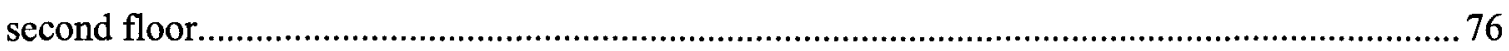

Figure 5-9 Flow char of dynamic Bayesian network ............................................................... 77

Figure 5-10 The assigned number for each compartment of each floor .................................... 85 
Figure 5-11 Probability of fire spread in the compartment during fire growth phase .90

Figure 5-12 Probability of fire spread during fire growth phase ................................................93

Figure 9-1 Dimensions of flames projecting out of a window.............................................. 131

Figure 10-1 Spatial separation fire experiments setting up plan..............................................136

Figure 10-2 Instrumentation on the exposing wall and target wall......................................... 137

Figure 10-3 Pictures and thermal images of experimental propane fires.................................. 141

Figure 10-4 Pictures and thermal images of wood crib fires .................................................. 144

Figure 10-5 Propane fire with same window size but different separation distance....................151

Figure 10-6 Propane fire with same separation distance but different window sizes .................. 152

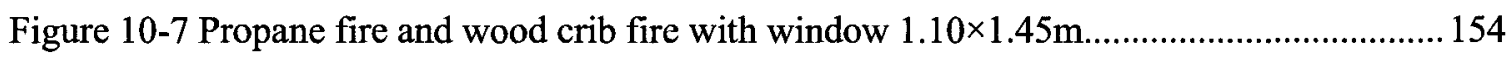

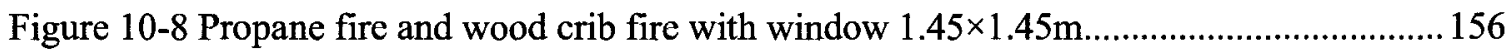

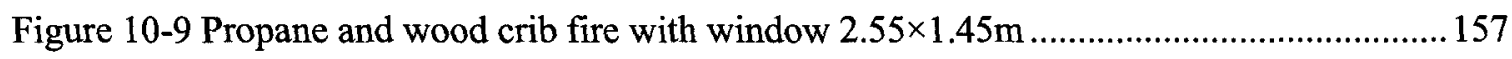

Figure 10-10 Comparison of experimental radiation distribution and modeling results using the

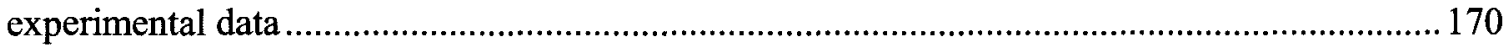

Figure 10-11 Comparison of experimental radiation distribution and modeling results using the theory of compartment fire and experimental emissivity ..... 174

Figure 10-12 Comparison of experimental radiation distribution and modeling results using the

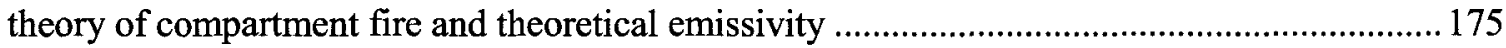

Figure 11-1 Target point is exactly at a corner of the window in vertical plane. ....................... 179

Figure 11-2 Target point is within the boundary of the opening. ............................................ 180

Figure 11-3 Target point is beside one side of the boundary of the opening.............................. 181

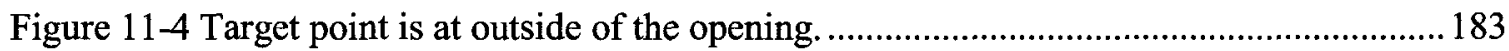

Figure 11-5 Flow chart of calculation of configuration factor.............................................. 185

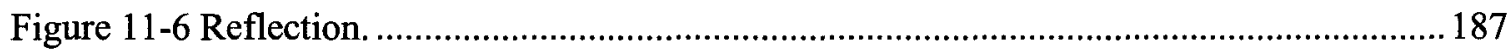

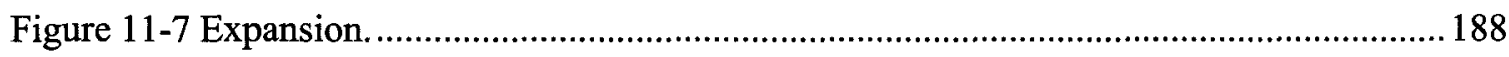

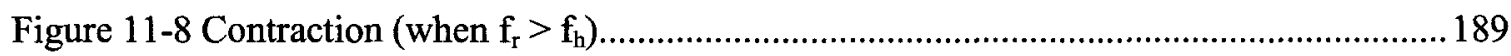

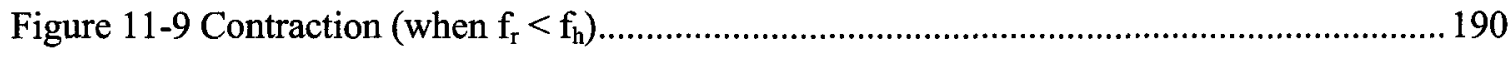

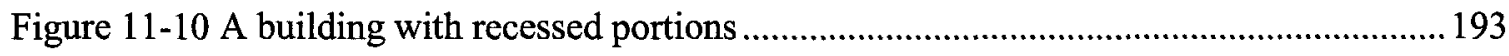

Figure 11-11 A building with irregular distribution of openings............................................ 197

Figure 11-12 Flow chart of calculation of radiation heat flux ................................................206

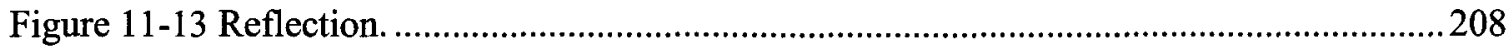

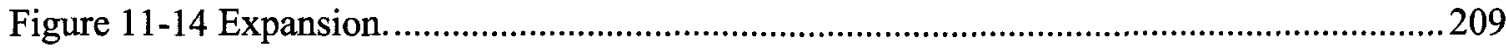




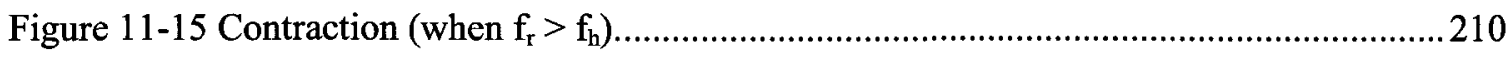

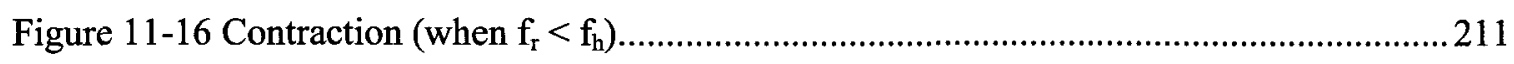

Figure 11-17 Flow char of modeling of fire spread to adjacent buildings................................ 214

Figure 11-18 A building with irregular distribution of openings..............................................215

Figure 11-19 Relation between opening and post-flashover fire with time effect.....................217 


\section{List of Tables}

Table 2-1 Pathways through the example equivalent network assuming 5-minute doors............ 17

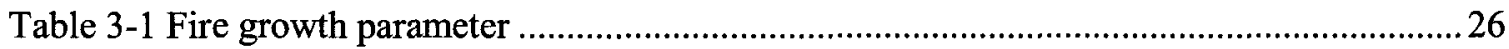

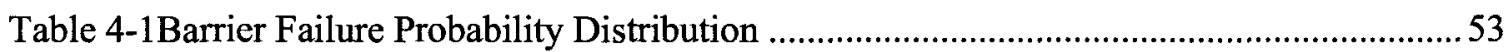

Table 4-2 Fire Spread Probability Distribution Tables without Intervention ...............................55

Table 4-3 Fire Spread Probability Distribution Tables with Sprinklers Installed.........................57

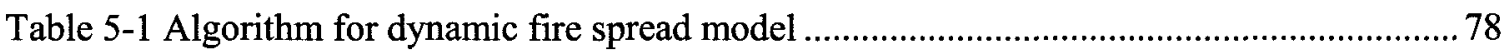

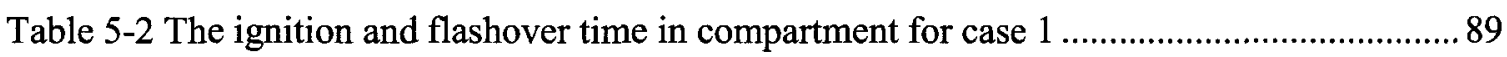

Table 5-3 The ignition and flashover time in compartment for case 2 ..................................... 92

Table 8-1 Classification of fire severity ................................................................................ 123

Table 8-2 Guide numbers for the determination of the minimum separation distances between

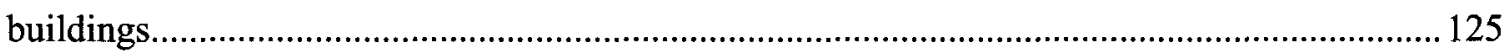

Table 8-3 Minimum separation distance or height of protection for buildings with combustible

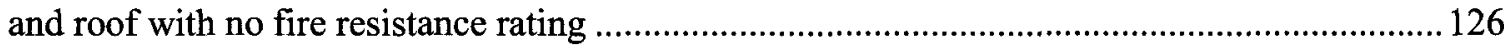

Table 8-4 Maximum Aggregate Area of Unprotected Openings in Exterior Walls .................... 127

Table 10-1 Experimental data of room temperature and external flame temperature ................. 142

Table 10-2 Theoretical study of the impact of fuel load and window size on post-flashover

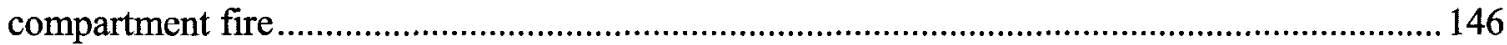

Table 10-3 Theoretical and experimental data for post-flashover compartment fires ................ 148

Table 10-4 The comparisons of the radiation heat flux on target wall due to post-flashover compartment fires

Table 10-5 Radiation contributed from projecting flame above soffit of window during fully-

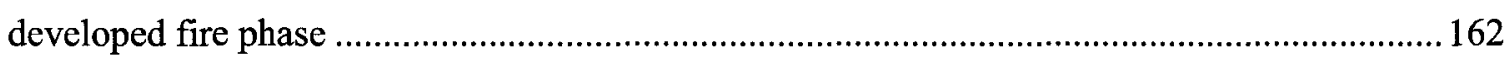

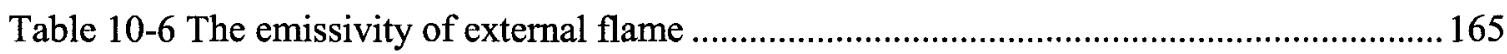

Table 10-7 Experimental data used for calculation of radiation heat flux on target wall ............ 168

Table 10-8 Theoretical data used for calculation of radiation heat flux on target wall ............... 171

Table 11-1 Algorithms for calculation of the maximum configuration factor........................... 187

Table 11-2 Algorithms for the calculation of the separation distance between buildings ........... 192

Table 11-3 Input data of Example (11.1) ................................................................................. 195

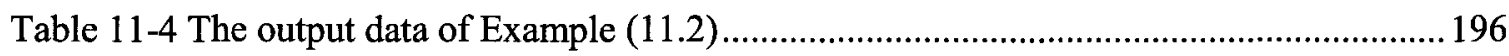

Table 11-5 The dimensions of relative compartments and its openings ................................. 197 
Table 11-6 Times of ignition and flashover in each compartment ...

Table 11-7 The input data of searching minimum separation distance between buildings .........200

Table 11-8 Required minimum separation distance between two buildings ..............................201

Table 11-9 Algorithms of searching maximum radiation heat flux by simplex method .............207

Table 11-10 Algorithms of calculation of separation distance between buildings ......................213

Table 11-11 The output of post-flashover compartment fire ....................................................218

Table 11-12 Minimum separation distance required between two buildings (m)......................220

Table 11-13 Separation distances calculated by NBCC and two models $(\mathrm{m})$...........................221 


\section{Nomenclature}

A

$A^{\prime}$

$\mathrm{A}_{\mathbf{f}}$

$A_{F}$

$A_{0}$

$A_{o} \sqrt{H_{o}}$

$\mathrm{A}_{\mathrm{T}}$

c

$c_{1}$

D

$\mathrm{dA}_{\mathrm{E}}$

$F_{\text {crit }}$

$F_{\mathrm{d} 2-1}$

$F_{\text {dE-EF }}$

$F_{\mathrm{dE}-\mathrm{W}}$

$F_{f}$

$\mathrm{F}_{1}$

$\mathrm{F}_{\max }$

A fully-developed fire occurs in compartment A

A fully-developed fire does not occur in compartment A

Area, $\mathrm{m}^{2}$

Variables describing whether a fully-developed fire occurs in compartment A or not

Variables describing whether an ignition occurs in compartment A or not

Surface area of fuel, $\mathrm{m}^{2}$

Floor surface area of a compartment, $\mathrm{m}^{2}$

Area of the ventilation opening, $\mathrm{m}^{2}$

ventilation factor, $\mathrm{m}^{5 / 2}$

Total area of fire compartment enclosing surface, $\mathrm{m}^{2}$

Separation distance between buildings, $\mathrm{m}$

Specific heat of the boundary material $\mathrm{I}, \mathrm{kJ} /(\mathrm{kg} \cdot \mathrm{K})$

Depth of a compartment, $m$

A target point

Critical configuration factor

Configuration factor from radiator 1 to a target point $\mathrm{d} 2$

Configuration factor from the radiator of external flame to a point on target wall

Configuration factor from window to a point on target wall

Configuration factor of flame radiator to a target point

Configuration factor for opening $i$ to the target point

Maximum configuration factor 


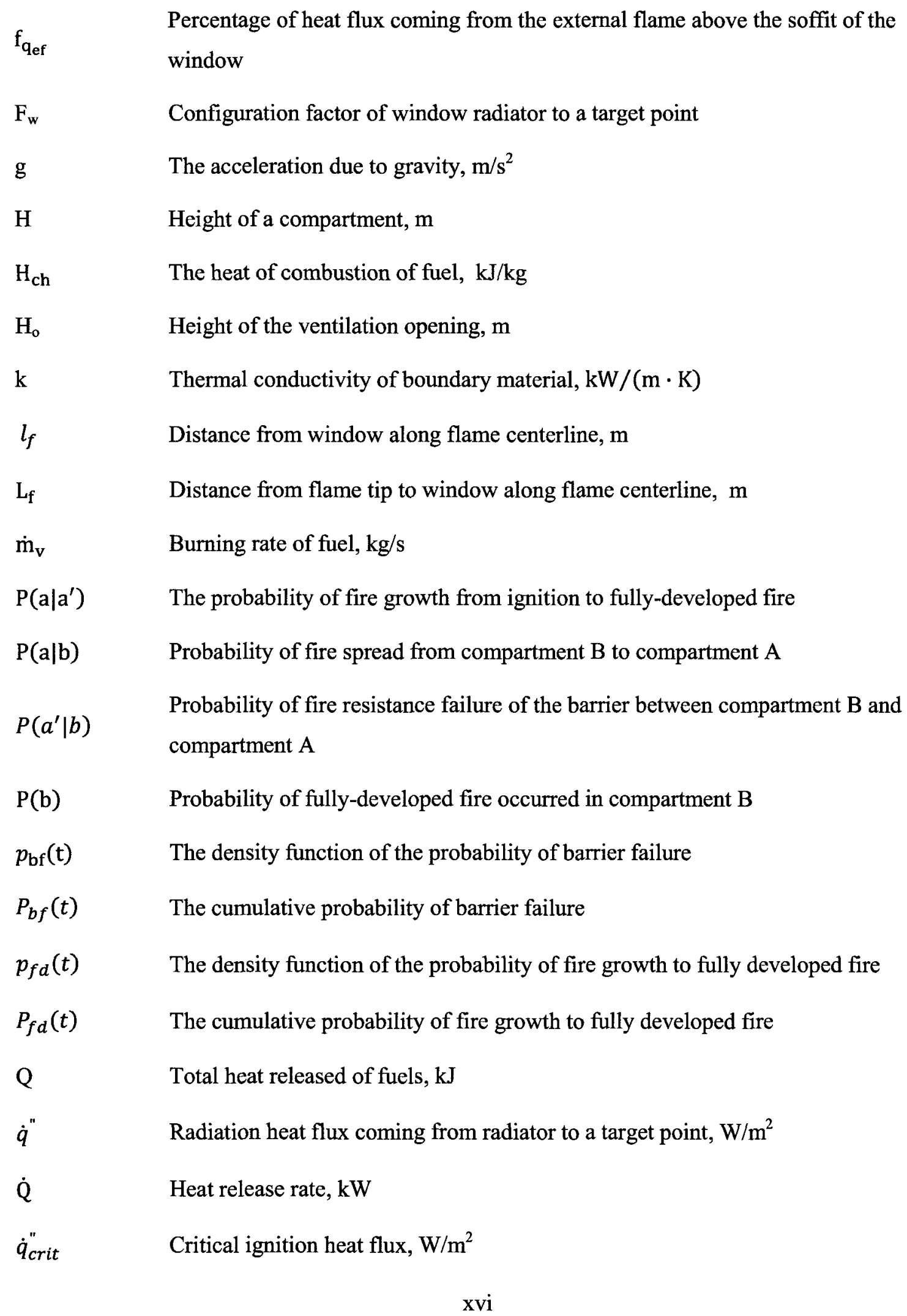




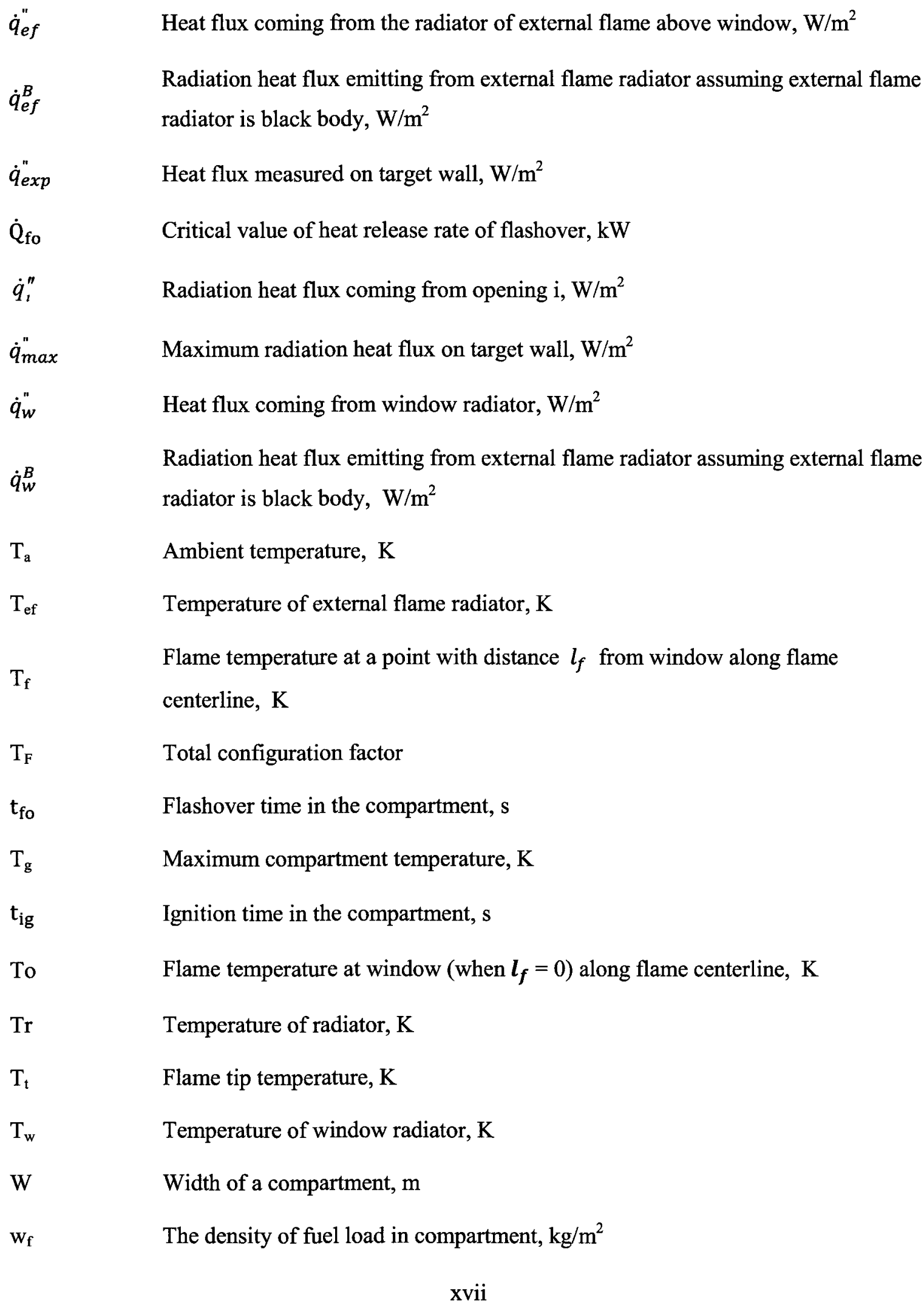




$\begin{array}{ll}\mathrm{W}_{\mathrm{f}} & \begin{array}{l}\text { Equivalent total fire load of wood, } \mathrm{kg} \\ \mathrm{W}_{\mathrm{o}}\end{array} \\ \mathrm{x} & \text { Width of the ventilation opening, } \mathrm{m} \\ (\mathrm{x}, \mathrm{y}) & \text { The coordinate of a target point, } \mathrm{m} \\ \left(\mathrm{x}_{0}, \mathrm{y}_{0}\right) & \text { The coordinate of left and bottom corner of a rectangle window or opening, } \mathrm{m} \\ \left(\mathrm{x}_{1}, \mathrm{y}_{1}\right) & \text { The coordinate of right and top corner of a rectangle, } \mathrm{m} \\ \mathrm{z} & \text { Flame height above soffit of the window/opening, } \mathrm{m} \\ (\mathrm{z} 0, \mathrm{z} 1) & \text { Searching range of separation distance, } \mathrm{m}\end{array}$

\section{Greek}

$\alpha$

Growth coefficient for $\mathrm{t}$-square fire, $\mathrm{kW} / \mathrm{s}^{2}$

$\alpha$

Reflection coefficient

$\beta$

Parameter of Japanese Parametric model for compartment boundaries, $\mathbf{K s}^{\mathbf{- 1 / 6}}$

$\beta$

Contraction coefficient

$\gamma$

Expansion coefficient

$\varepsilon$

Flame emissivity

$\varepsilon_{e f}$

Emissivity of radiator of external flame

$\varepsilon_{f}$

Emissivity of window radiator

$\varepsilon_{w}$

Emissivity of window radiator

$\epsilon$

Tolerance for convergence criterion

$\kappa$

Atténuation coefficient, $\mathrm{m}^{-1}$

$\lambda$

Thickness of the external flame, $m$

$\mu_{\mathrm{bf}} \quad$ The mean time for the fire resistance failure of a barrier to, $\min$

$\mathrm{u}_{\mathrm{f}} \quad$ Mean of fuel load density in compartment, $\mathrm{kg} / \mathrm{m}^{2}$

xviii 


\begin{tabular}{|c|c|}
\hline$\mu_{\mathrm{fd}}$ & Mean of fully-developed fire phase, $\min$ \\
\hline$\mu_{\text {fo }}$ & Mean duration for fire to grow from ignition to flashover, $\min$ \\
\hline$\mu_{F R R}$ & Mean of duration of fire resistance ratings to the standard ISO 834 fire, min \\
\hline$\mu_{g r}^{\max }$ & Mean of maximum duration assume all fuels are burnt in fire growth phase, min \\
\hline$\mu_{\alpha}$ & Mean of fire growth coefficient for $\mathrm{t}$-square fire, $\mathrm{kW} / \mathrm{s}^{2}$ \\
\hline$\rho_{0}$ & Density of air, $\mathrm{kg} / \mathrm{m}^{3}$ \\
\hline$\rho$ & Density of material, $\mathrm{kg} / \mathrm{m}^{3}$ \\
\hline$\sigma$ & Stefan-Boltzmann constant, $\sigma=5.67 \times 10^{-8} \mathrm{~W} /\left(\mathrm{m}^{2} \mathrm{k}^{4}\right)$ \\
\hline$\tau_{f d}$ & The duration of fully-developed fire phase in fire compartment, min \\
\hline$\tau_{\text {eq }}$ & The equivalent duration of the standard fire test in severity, min \\
\hline$\tau_{\mathrm{fd}}$ & Duration of fully-developed fire phase, min \\
\hline$\tau_{\text {fo }}$ & Duration of fire growth phase from ignition to flashover, min \\
\hline$\tau_{g r}$ & Duration of fire growth phase in the compartment, min \\
\hline$\tau_{F R R, i}$ & Duration of fire resistance rating to the standard ISO 834 fire, $\min$ \\
\hline$\tau_{\mathrm{gr}}^{\max }$ & The maximum duration of fire growth phase, $\min$ \\
\hline$\sigma_{\alpha}$ & Standard deviation of the fire growth coefficient for $\mathrm{t}^{2}$ fire \\
\hline$\sigma_{\mathrm{bf}}$ & Standard deviation of barrier fire resistance failure \\
\hline$\sigma_{\mathrm{f}}$ & Standard deviation of fuel load density in compartment \\
\hline$\sigma_{f d}$ & Standard deviation of duration of fully-developed fire phase \\
\hline$\sigma_{\text {fo }}$ & Standard deviation of duration from ignition to flashover \\
\hline & Standard deviation of duration of fire resistance ratings to the standard ISO 834 \\
\hline & for the assemble \\
\hline$\sigma_{g r}^{\max }$ & Standard deviation of maximum duration assume all fuels are bu \\
\hline
\end{tabular}


phase

$\varphi$

Specific surface of fuel, $\mathrm{m}^{2} / \mathrm{kg}$

\section{Subscripts}

dE-A

Area $\mathrm{A}$ to the target point $\mathrm{dE}$

Window or opening $\mathrm{i}$ 
PART 1

MODELING OF FIRE SPREAD IN BUILDINGS 


\section{Chapter 1}

\section{Introduction to Modeling of Fire Spread in Buildings}

\subsection{Motivation}

Fires in buildings pose a significant risk to building occupants and cause property damage. Traditionally, prescriptive-based building codes were used in fire safety design of buildings. Such codes prescribe in detail what is required for a fire-safe building. Because of the limitations inherent in prescriptive-based building codes, such as, not being flexible and inhibiting innovation, performance-based building codes are being adopted and used in more and more countries. To achieve the goals required by performance-based building codes, it is necessary to undertake a fire-risk assessment and fire safety evaluation especially for large buildings. Toward this end, CURisk, a fire-risk model that evaluates the expected-risk-to-life and fire-cost-expectation to property is being developed at Carleton University.

When a fire occurs in a building, the occupants may be injured or killed because of exposure to toxic gases, hot gases, and high heat fluxes. The threat to life and property caused by fire is mainly due to fire spreading from the fire compartment to other areas in the building. Therefore, it is very important to include a fire-spread model in the analysis of risk. 


\subsection{Review of Historical Studies}

A lot of research has been conducted in the recent decades to understand the mechanisms of fire spread in large buildings. Because of the difficulty of including all factors affecting fire growth and fire spread in the input data for fire-spread models, these studies were often done using a probabilistic approach. Ramachanandran ${ }^{[1,2]}$ summarized the previous studies of stochastic fire-spread modeling in recent decades.

In the earlier studies, the epidemic theory ${ }^{[3,4]}$, random walk theory ${ }^{[5,6]}$, Markov process $[7,8$, and 9$]$, percolation process ${ }^{[10,11]}$ and probabilistic network ${ }^{[12,13]}$ were used to model fire spread. These models could successfully describe fire spread in buildings in certain respects. But there are some disadvantages to simulate the fire spread process using these models. The epidemic theory can not explain fire spread due to radiation to combustible materials or compartments which are far away from the fire origin and can not be directly reached by flames. The random walk theory ${ }^{[5,6]}$, and percolation process ${ }^{[10,11]}$ can simulate fire spread from a fire compartment to one of its adjacent compartments, and then from this fire compartment to another adjacent compartment. But they are not good at simulating the scenarios whereby fire may spread from a fire compartment to multiple adjacent compartments or fires from multiple fire compartments spread to their adjacent compartments. The transition probability in the Markov process ${ }^{[7,8, \text { and } 9]}$ is not really the probability of fire spread from the fire compartment to adjacent compartments which are 
affected by the fire severity and time. It only represents the relative probability that fire would spread from the fire compartment to an adjacent compartment, i.e. if there are two similar compartments on each side of a fire compartment, the transition probability of fire spread to each compartment will always be equal to $50 \%$, regardless of the severity of the fire and how long the fire lasts in the compartment. In addition, the fire spread process from one compartment to multiple compartments or from multiple compartments to their adjacent compartments at the same time can not be described by the Markov process.

Ling and Williamson ${ }^{[12]}$ first presented a probabilistic network approach to study roomto-room fire spread. An example of modeling a network for fire spread in a building floor was illustrated. This model did not consider the barrier failure due to radiation. This network is complicated. For each time that the compartment of fire origin is changed, a new network has to be developed. Platt, Elms and Buchanan ${ }^{[13]}$ developed a simple and clear model in which an event tree was used to determine the probability of fire spread form the fire compartment to other compartments. This model is very good in expressing the fire spread process for small buildings. But it is hard to develop a fire-spread event tree for large buildings. If the initial fire compartment is changed, a new event tree has to be developed even for the same building which make the model difficult to program. The digraph (directed graph) approach was used as the fire-spread sub-model of the fire risk evaluation and cost assessment model (FiRECAM) ${ }^{[14]}$. Fire spread from the fire compartment to the compartment on the floor above through the pathway of window to 
window due to external flames out of a window was not included in this model. To simplify the problem, all compartments of the same type such as rooms, corridors, stairwells on one floor were combined as a single node of the network. The developed algorithm searches all possible pathways for fire to spread from one node to another.

\subsection{Scope of Work and Objective}

In this thesis, the Bayesian Network $(\mathrm{BN})^{[15,16, \text { and } 17]}$ is used to simulate the fire spread process. A Bayesian Network can overcome the disadvantages of the earlier models. A Bayesian Network however can not directly describe the fire spread process. To build the fire-spread model, a general fire-spread network has to be built according to the floor plan of a building. Once the compartment of fire origin is known, a detailed fire-spread model using a directed acyclic graph (DAG) of Bayesian network to express the fire spread process from the initial compartment to any destination compartment in the floor can be constructed and the probability of fire spread from the fire compartment to the destination compartment can be calculated by marginalizing the joint probability distribution of the Bayesian network. This model is a static fire spread model which can be used to undertake fire risk analysis of buildings and determine fire prevention strategies.

Fire spread in a building is a dynamic process as the probability of fire spread from a compartment changes with time. Therefore, a dynamic fire-spread model was also 
developed using basic concepts of dynamic Bayesian network ${ }^{[18]}$ and the static firespread model ${ }^{[19]}$. The dynamic fire-spread model considers both horizontal and vertical fire spread in a building. In this model, the algorithms for simulating the fire spread process are developed and corresponding codes are written. The probability of fire spread from the compartment of fire origin to any other compartment, the time of ignition, the time of flashover and the time of fire decay in each compartment and in every time step can be calculated by a purpose-built computer program. In addition, the formulae calculating the input data for the dynamic fire spread model were derived, in order to minimize the level of expertise required for the user. The dynamic fire-spread model can easily be applied for any building including high-rise buildings. 


\section{Chapter 2}

\section{Literature Review of Modeling Fire Spread in Buildings}

\subsection{Epidemic Fire Spread Models ${ }^{[3,4,11]}$}

The essential characteristic of epidemic models is the transfer of infection. In epidemic fire-spread models, the combustible and burning materials are treated as susceptible and infective respectively. The assumptions below were used in epidemic fire spread models.

a) When the fire spreads to a combustible material, the fire is immediately able to spread from the burning material to adjacent combustibles. There is no latent period. That is the fire growth phase is not considered in this model.

b) The combustible materials are homogeneously mixed; therefore all combustible materials are equally combustible and equally capable of spreading the fire.

The burning materials could spread the fire or burn out. The burnt materials are treated as removals and are immune from catching fire again. Fire spread due to contact between burning materials and combustibles will lead to new burning materials.

\section{Comment on epidemic fire spread model:}

The epidemic theory can not explain fire spread to combustible materials or compartments due to radiation when the combustibles are far away from the burning materials and the combustible materials or compartments can not be directly reached by the burning flame. 


\subsection{Random Walk Model ${ }^{[1,2]}$}

In this model, it is assumed that in every short period, the fire takes a random step either to spread with a probability $\lambda$ or to be extinguished (or burnt out) with a probability $\mu$ $(=1-\lambda)$. Based on this random model, the probability that the duration of burning is less than or equal to time $t$ is given

$$
F(t)=1-\exp (-\mu t)
$$

The probability that the duration of burning is greater than time $t$ is

$$
Q(t)=1-F(t)=\exp (-\mu t)
$$

Let $c=\mu-\lambda$, then $\mu=(1+c) / 2$, therefore

$$
Q(t)=\exp [-(1+c) t / 2]
$$

Associated with time, assume there is damage represented by financial loss $\mathrm{x}$ which is approximately proportional to the heat output. Then the logarithm of damage $\mathrm{x}$ is proportional to time $\mathrm{t}$

$$
\ln x=k \cdot t
$$

Where: $\mathrm{k}=$ coefficient

The probability of damage exceeding the value $\mathrm{x}$ can be found by

$$
\phi(x)=x^{-w}, x>1
$$

Where:

$$
\mathrm{w}=\text { coefficient, } w=\mu / k
$$

\section{Comments on the random walk model:}


- The random walk model represents a one-dimensional process describing the damage by a random function of time rather than by a function of time and space.

- The random walk model can not simulate the scenarios in which fire spreads from a fire compartment to multiple adjacent compartments or fire spreads from multiple fire compartments to their adjacent compartments.

\subsection{Markov Process Models ${ }^{[1,2,7,8,9]}$}

Similar to the random walk model, it is assumed that in every time step, the fire spreads with a probability $\lambda$ or is extinguished (or burnout) with a probability $\mu(=1-\lambda)$. In the Markov model, the fire spreading from a state (such as spatial module, phase or realm) to another state is governed by a transition probability which is a function of time since the start of the fire in the building. Usually the transition probabilities are expressed in a matrix form.

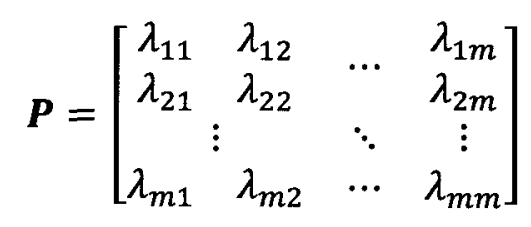

Where:

$$
\sum_{j=1}^{m} \lambda_{i j}=1 \quad i=1,2, \cdots, m
$$

The probability distribution of the system at time $\mathrm{k}$ can be written as a vector

$$
P_{k}=\left(\begin{array}{lllll}
q_{1} & q_{2} & q_{3} & \cdots & q_{m}
\end{array}\right)
$$

Where: 
$q_{i}$ is the probability of fire burning in the $\mathrm{i}^{\text {th }}$ state at time $\mathrm{k}$.

Since a fire can be in one of the $\mathrm{m}$ states at a given time

$$
\sum_{i=1}^{m} q_{i}=1
$$

Then the probability of burning in a different state one transition later is

$$
P_{k+1}=P_{k} \cdot \boldsymbol{P}
$$

Ramachanran ${ }^{[8]}$ proposed an example of the Markov model as shown in Figure 2-1. This model considered following main states in the fire development in a building.

$S_{1}$ - Fire confined to contents first ignited;

$\mathrm{S}_{2}$ - Fire spreading beyond items first ignited but confined to contents of room of fire origin;

$\mathrm{S}_{3}$ - Fire spreading beyond items first ignited and other contents but confined to contents of room and involvement of structure;

$\mathrm{S}_{4}$ - Fire spreading beyond room of fire origin but confined in the buildings

For the example shown in Figure 2-1, fire spreading beyond the building of origin was not considered, therefore $\mu_{4}=1$ and $\lambda_{4}=0$. The detail calculations of the probability of fire in each state are listed in Figure 2-1. 
Sprinklered State Non-sprinklered

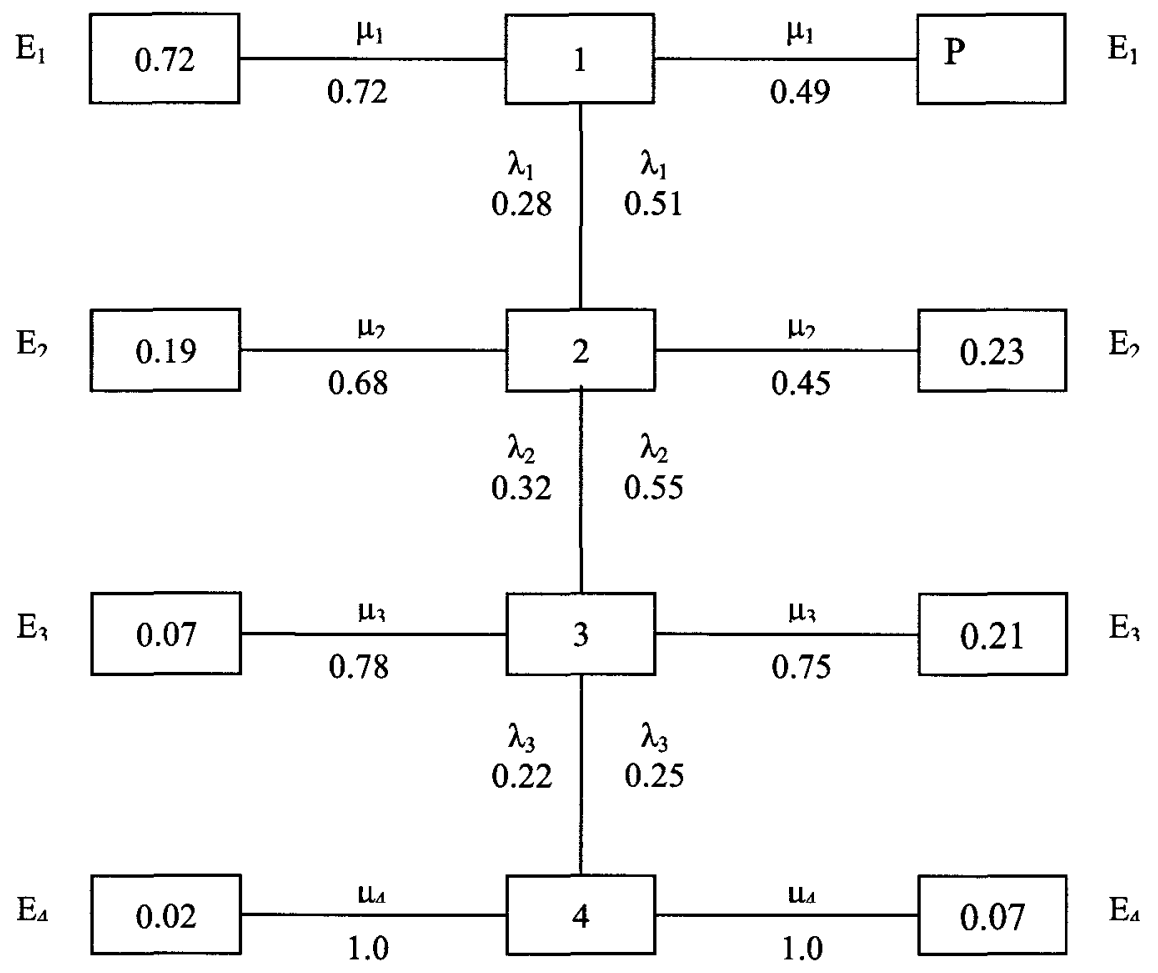

$\mathrm{E}_{1}=$ Probability of confinement to items first ignited $=\mu_{1}$

$E_{2}=$ Probability of spreading beyond items first ignited but confinement to contents of room of fire origin $=\lambda_{1} \mu_{2}$

$E_{3}=$ Probability of spreading beyond items first ignited and other contents but confinement to contents of room and involvement of structure $=\lambda_{1} \lambda_{2} \mu_{3}$ $E_{4}=$ Probability of spreading beyond room of fire origin but confinement in the building $=\lambda_{1} \lambda_{2} \lambda_{3} \mu_{4}\left(\mu_{4}=1\right)$

Figure 2-1 Probability tree - textile industry, adopted from ${ }^{[8]}$ 


\section{Comments on Markov process model}

The transition probability in the Markov process is not really the probability of fire spread from the fire compartment to an adjacent compartment which is affected by the fire severity and time of fire development in the fire compartments. It only presents a relative probability that a fire would spread from the fire compartment to an adjacent compartment, i.e. if there are two similar compartments on each side of a fire compartment, the transition probability of fire spread to each compartment will always be equal to $50 \%$, regardless of the fire severity and the duration of the fire in a compartment.

\subsection{Percolation Process ${ }^{[10,11]}$}

A percolation process is generally used to simulate the spread of a fluid through a medium. When the percolation process was used to simulate fire spread in a building, the building was considered as the medium, the compartment was the atom and the barrier was the bond connecting two atoms. There are two kinds of bonds, the undirected bond which is defined as the barrier with openings which allow the flame easily to spread to its adjacent compartment, and the directed bond which is defined as the barrier through which the fire can not spread to an adjacent compartment until a threshold is reached.

\section{Comments on the percolation process model}

The percolation process is usually studied by asymptotic theory which requires the number of atoms in the model to approach infinity. Therefore, the percolation process is 
not good to simulate fire spread in a building because of the finite number of compartments in a building.

\subsection{Probabilistic network ${ }^{[12]}$}

Because of the uncertainty in fire spread, Ling and Williamson presented a probabilistic network approach to study room-to-room fire spread by transforming the compartments of a building (ship, airplane, or other structures) into nodes of a network. An example of transformation of a floor plan of an office building into a fire spread network is shown in Figure 2-2. The probabilistic network of fire spread in a building floor is presented as a digraph G(N, A) based on PERT (Program Evaluation Review Technique) network. The network consists of nodes and links. Each link represents one event such as fire growth within a compartment, fire breaches a barrier element, or fire spread along a corridor. The length of each link depends on the duration required for the event. A number pair $\left(\mathrm{p}_{\mathrm{i}}, \mathrm{t}_{\mathrm{i}}\right)$ is assigned to each link $i$ in which $p_{i}$ denotes the probability that the fire will go through link $i$ and $t_{i}$ represents the duration the fire will take to go through link $i$.

By enumerating all possible paths from the source node to the sink node, the fire spread network is transformed into an "equivalent network".

The equivalent network has the following properties:

(a) Each link has a Bernoulli probability of success (Bernoulli distribution takes value 1 with success probability $p$ and value 0 with failure probability $q=1-p$ );

(b) The link travel times are deterministic; 
(c) The expected shortest path response time between two points in the emergence network is equal to the expected path response time in the original network.

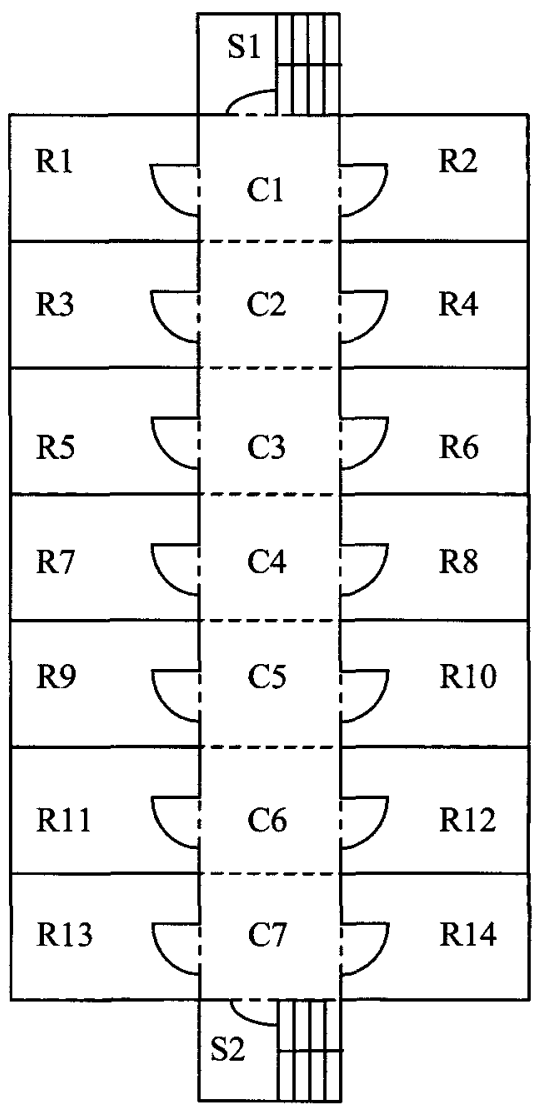

(a)

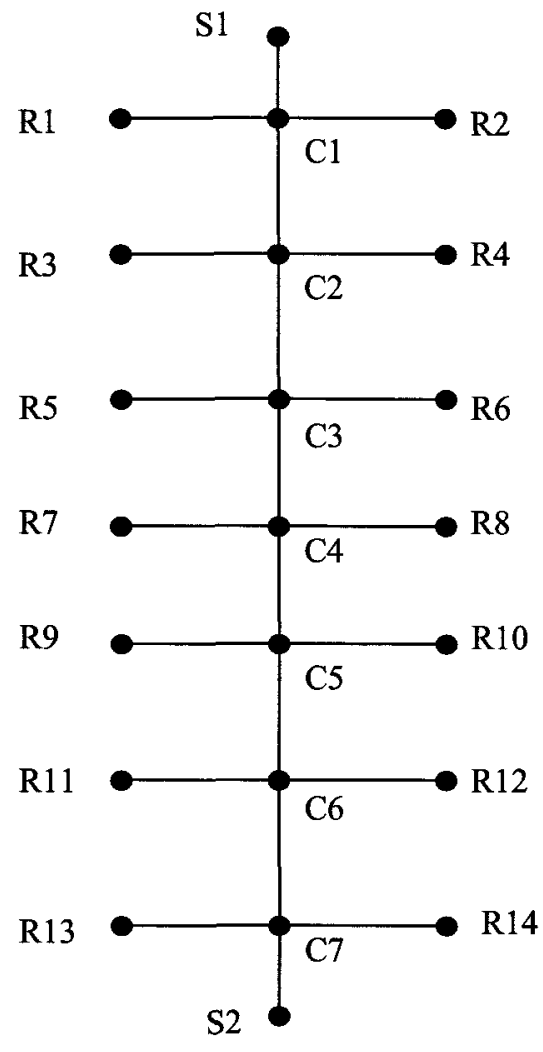

(b)

Figure 2-2 (a) A floor plan of an office building and (b) Fire spread network

By using the McNaughton-Yamada algorithm ${ }^{[20]}$, the expected shortest travel time of fire spread from the source to the sink node could be found. 
Ling and Williamson gave a detailed example of a probabilistic network simulating fire spread from Rooml to Room 4 in an office building as shown in Figure 2-3. Based on the probabilistic network as shown in Figure 2-4, the equivalent network of fire spread from Room 1 to Corridor 2 is presented as shown in Figure 2-5 and the results of every pathway for fire to spread from Room1 to Corridor 2 is listed in Table $2-1$. The $\left(1-U_{i}\right)$ represents the probability that fire spreads from Room 1 to Corridor 2 using less time by the ith pathway than by any other path. $\left(1-U_{i}\right) P_{i}$ represents the ith pathway that is the shortest path by which fire spreads from Room1 to Corridor 2 . Then the expected shortest time for fire to spread from Room 1 to Corridor 2 is

$$
T=\frac{\sum_{i} T_{i} P_{i}\left(1-U_{i}\right)}{\sum_{i} P_{i}\left(1-U_{i}\right)}=t_{f o}+\frac{4.144+P_{f}\left(5.75+0.26 t_{f}\right)}{0.716+0.26 t_{f}}
$$

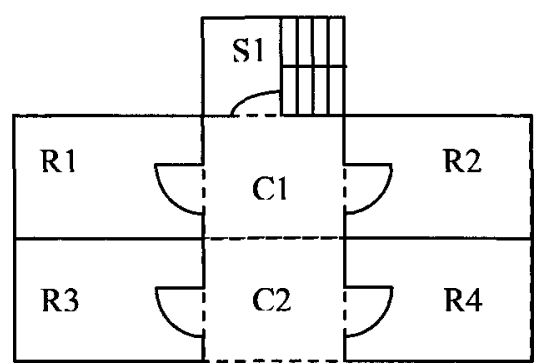

(a)

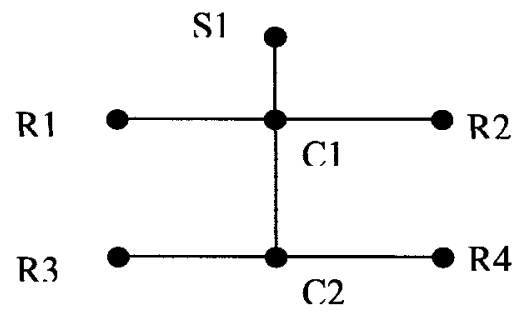

(b)

Figure 2-3 (a) Floor plan of 4 rooms and 1 stairwell (b) Fire spread network 


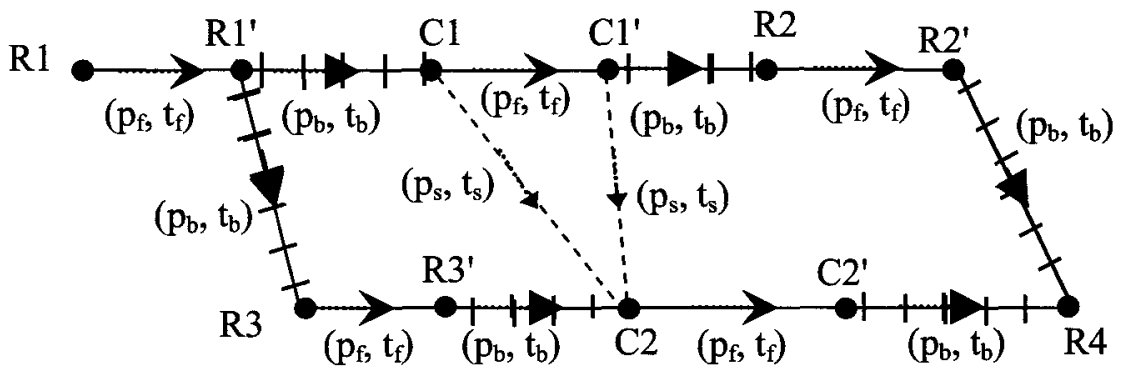

: Fire growth within compartment

$+\uparrow+1+$ : Fire breaches barrier element

------4 : Fire spread along corridor

Figure 2-4 Probabilistic network of fire spread from Room 1 to Room 4

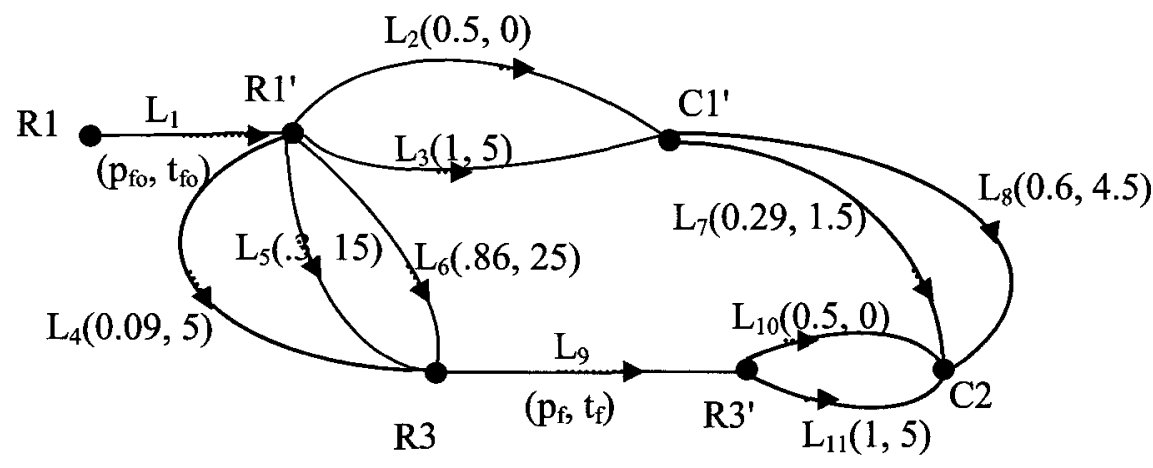

Figure 2-5 Fire spread equivalent network with 5 minute unrated door 
Table 2-1 Pathways through the example equivalent network assuming 5-minute doors

\begin{tabular}{|c|c|c|c|c|c|}
\hline $\mathrm{i}$ & $\begin{array}{c}\text { Component } \\
\text { links }\end{array}$ & $\begin{array}{c}\text { Spread time } \\
\mathrm{T}_{\mathrm{r}}-\mathrm{T}_{\mathrm{fo}}(\mathrm{min})\end{array}$ & $\begin{array}{c}\text { Probability } \\
\mathrm{P}_{1} \mathrm{P}_{\mathrm{fo}}\end{array}$ & $1-\mathrm{U}_{\mathrm{t}}$ & $\begin{array}{c}\text { Probability that path } \mathrm{i} \text { is the } \\
\text { shortest path }\left(1-\mathrm{U}_{\mathrm{f}}\right) \mathrm{P}_{\mathrm{f}}\end{array}$ \\
\hline 1 & $1-2-7$ & 1.5 & 0.145 & 1 & $0.145 \mathrm{P}_{\mathrm{fo}}$ \\
\hline 2 & $1-2-8$ & 4.5 & 0.300 & 0.71 & $0.213 \mathrm{P}_{\mathrm{fo}}$ \\
\hline 3 & $1-3-7$ & 6.5 & 0.290 & 0.50 & $0.145 \mathrm{P}_{\mathrm{fo}}$ \\
\hline 4 & $1-3-8$ & 9.5 & 0.600 & 0.355 & $0.213 \mathrm{P}_{\mathrm{fo}}$ \\
\hline 5 & $1-4-9-10$ & $5.0+\mathrm{t}_{\mathrm{f}}$ & $0.045 \mathrm{P}_{\mathrm{f}}$ & 0.284 & $0.013 \mathrm{P}_{\mathrm{fo}}$ \\
\hline 6 & $1-4-9-11$ & $10+\mathrm{t}_{\mathrm{f}}$ & $0.090 \mathrm{P}_{\mathrm{f}}$ & 0.142 & $0.013 \mathrm{P}_{\mathrm{fo}} \mathrm{P}_{\mathrm{f}}$ \\
\hline 7 & $1-5-9-10$ & $15+\mathrm{t}_{\mathrm{f}}$ & $0.150 \mathrm{P}_{\mathrm{f}}$ & 0.258 & $0.039 \mathrm{P}_{\mathrm{fo}} \mathrm{P}_{\mathrm{f}}$ \\
\hline 8 & $1-5-9-11$ & $20+\mathrm{t}_{\mathrm{f}}$ & $0.300 \mathrm{P}_{\mathrm{f}}$ & 0.129 & $0.039 \mathrm{P}_{\mathrm{fo}} \mathrm{P}_{\mathrm{f}}$ \\
\hline 9 & $1-6-9-10$ & $20+\mathrm{t}_{\mathrm{f}}$ & $0.430 \mathrm{P}_{\mathrm{f}}$ & 0.181 & $0.078 \mathrm{P}_{\mathrm{fo}} \mathrm{P}_{\mathrm{f}}$ \\
\hline 10 & $1-4-9-11$ & $25+\mathrm{t}_{\mathrm{f}}$ & $0.860 \mathrm{P}_{\mathrm{f}}$ & 0.090 & $0.078 \mathrm{P}_{\mathrm{f}_{\mathrm{f}}} \mathrm{P}_{\mathrm{f}}$ \\
\hline
\end{tabular}

\section{Comments on probabilistic network model}

- This model is too complicated to use in big buildings.

- It is very difficult and too expensive to get the discrete distribution used in the equivalent network by fire tests.

\subsection{Probability Model with Time Effect based on Event Tree ${ }^{[13]}$}

Platt, Elms and Buchanan ${ }^{[13]}$ developed a probabilistic model of fire spread with time effect in which an event tree was used to determine pathways of fire spread in a building and the probability of fire spread from the fire compartment to a destination compartment. For a simple four-compartment building as shown in Figure 2-6(a), the 
four possible paths by which the fire would spread from fire initial compartment 1 to the destination compartment 4 are shown in Figure 2-6(b). To find the probability of fire spread from compartment 1 to compartment 4 with this approach requires vast computational effort. Therefore, a modified event tree method was presented as shown in Figure 2-7. The probability of fire spread in pathway 3 shown in Figure 2-6(b) could be expressed as the summation of the two branches as shown in Figure 2-7.

$$
\begin{aligned}
& P[\text { path }(3)]=P[(\text { branch }(01) \cap(12) \cap(23) \cap(\overline{\mathbf{3 4}}) \cap(24)) \cup(\text { branch }(01) \cap \\
& (12) \cap(\overline{\mathbf{2 3}}) \cap(\mathbf{2 4}))
\end{aligned}
$$

The time for fire to spread along path $\mathrm{k}\left(Z_{k}=Z_{k} \mid F S_{l j}\right)$

$$
Z_{k}=\sum_{\text {all } i, j \text { on path } k} T_{i j}
$$
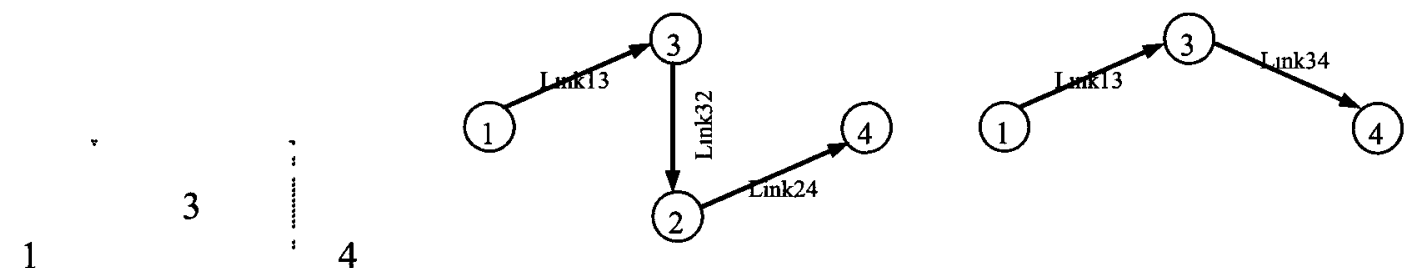

Path 1

$\underline{\text { Path2 }}$

2
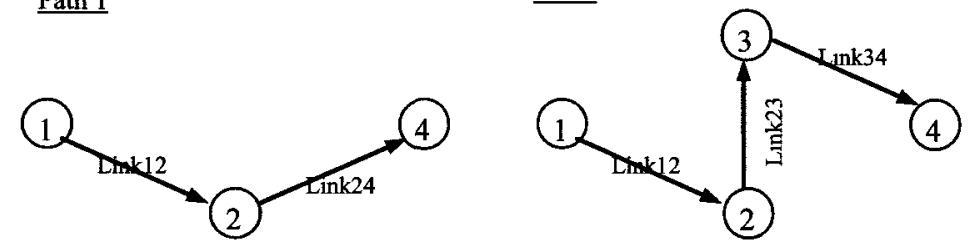

(a)

$\underline{\text { Path } 3}$

Path 4

(b)

Figure 2-6 (a) Plan of a four-compartment building; (b) possible paths by which fire may spread from (1) to (4) 

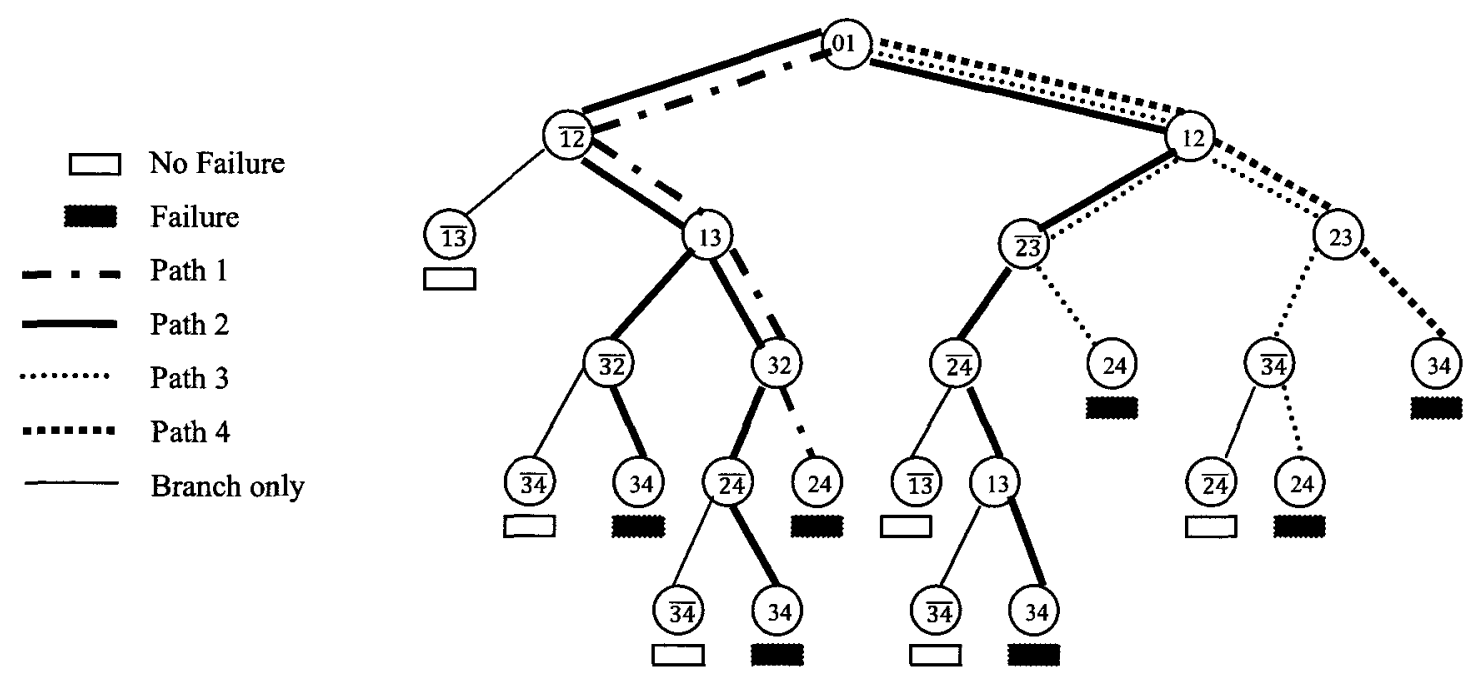

Figure 2-7 Modified event tree

For the case $Z_{k}=T_{i j}$, the probability density function of $Z_{k}$ :

$$
f_{Z_{k}}(t)=f_{T_{i j}}(t)
$$

For the case

$$
Z_{k}=T_{i j}+T_{i k},
$$

Then

$$
f_{Z_{k}}(t)=\int_{-\infty}^{t} f_{T_{i j}}(y) f_{T_{i k}}(t-y) d y
$$

Therefore, the probability that a fire will enter compartment 4 via path 3 at time $t$ is

$$
\begin{aligned}
& \mathrm{P}[(\text { path } 3) \cap \text { (path time to room } 4=t)]= \\
& \mathrm{P}[(\text { path time to room } 4=t) \mid(\text { path } 3)] \cdot \mathrm{P}[(\text { path } 3)]
\end{aligned}
$$

For the case fire spread to compartment $j$ via any path from compartment $i$ at time $t$ 


$$
\mathrm{P}\left[E T_{i j}=t \mid F S_{i j}\right]=\sum_{\text {all paths kfrom i toj }} \mathrm{P}[(\text { path time to } j=\mathrm{t}) \mid(\text { path } \mathrm{k})]
$$

P[path k]

The probability of fire spread from compartment $i$ to compartment $j$ via any path at time $t$

$$
\begin{aligned}
& \mathrm{P}\left[E T_{i j}=t \mid F S_{i j}\right]=\sum_{\text {all paths kfrom i toj }} \mathrm{P}[(\text { path time to } j=\mathrm{t}) \mid(\text { path } \mathrm{k})] \\
& \mathrm{P}[\text { path } \mathrm{k}]
\end{aligned}
$$

Assume that a fire starts in compartment $i$, the probability that the fire will spread to compartment $\mathrm{j}$ via any path before or at time $\mathrm{t}$ is

$$
\mathbf{P}\left[E T_{i j} \leq t \mid F S_{i j}\right]=\int_{-\infty}^{t} f_{E T_{i j}}(t) \mathrm{dt}=\sum_{a l l k} \int_{-\infty}^{\mathrm{t}} f_{Z_{k}}(t) \cdot \mathrm{P}[(\text { path k) }] \mathrm{dt}
$$

\section{Comments on fire spread model using event tree}

This model is very good to express the fire spread process for small buildings. The limitations of this model are

- It is hard to develop a tree for large buildings.

- If the initial fire compartment changes, a new tree has to be developed even for the same building which makes this model difficult to be programmed.

- It is assumed that the fire in a compartment develops linearly after ignition which is not true for real fires. A real fire in a compartment may go through the inception phase, fire growth phase, fully-developed fire phase and fire decay phase. 


\subsection{Fire Spread Model of NRCC ${ }^{[14]}$}

A fire spread model was built by the NRCC (National Research Council of Canada) as a sub-model of the computer program FiRECAM (fire risk evaluation and cost assessment model). A digraph (directed graph) approach was used to build the fire spread submodel. To simplify the problem, all compartments on each floor are combined as one compartment except for the floor with the compartment of fire origin. This floor has the compartment of fire origin and the remaining compartments which are grouped into one compartment. Then the compartment, corridor, stairwell, elevator shaft or duct on a floor is denoted by a node of the network of the building. Two nodes are connected by a bidirectional edge which is considered as the fire spread pathway.

The developed algorithm searches all possible pathways for fire to spread from one node to another. A recursive graph searching routine is used to find out all possible paths from the compartment of fire origin to a destination compartment. The flowchart of the recursive graph searching algorithms is shown in Figure 2-8.

To show how the model works, an example of a building fire spread model of a 3-story building with 1 stairwell, 2 elevator shafts and 1 service duct is illustrated in Figure 2-9. The paths of fire spread from node 0 to node 1 are shown in Figure 2-10. 


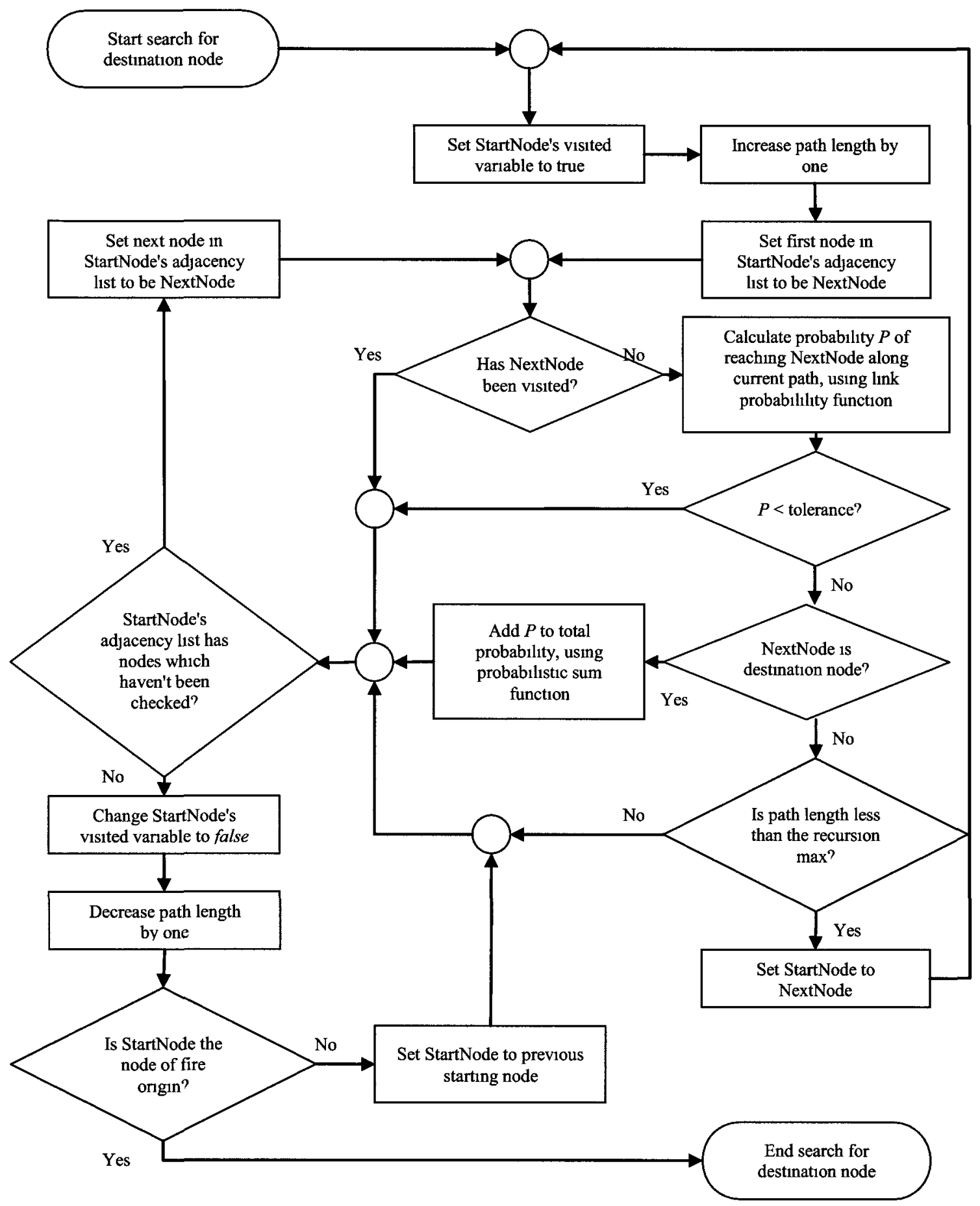

Figure 2-8 Recursive graph searching algorithm flowchart 


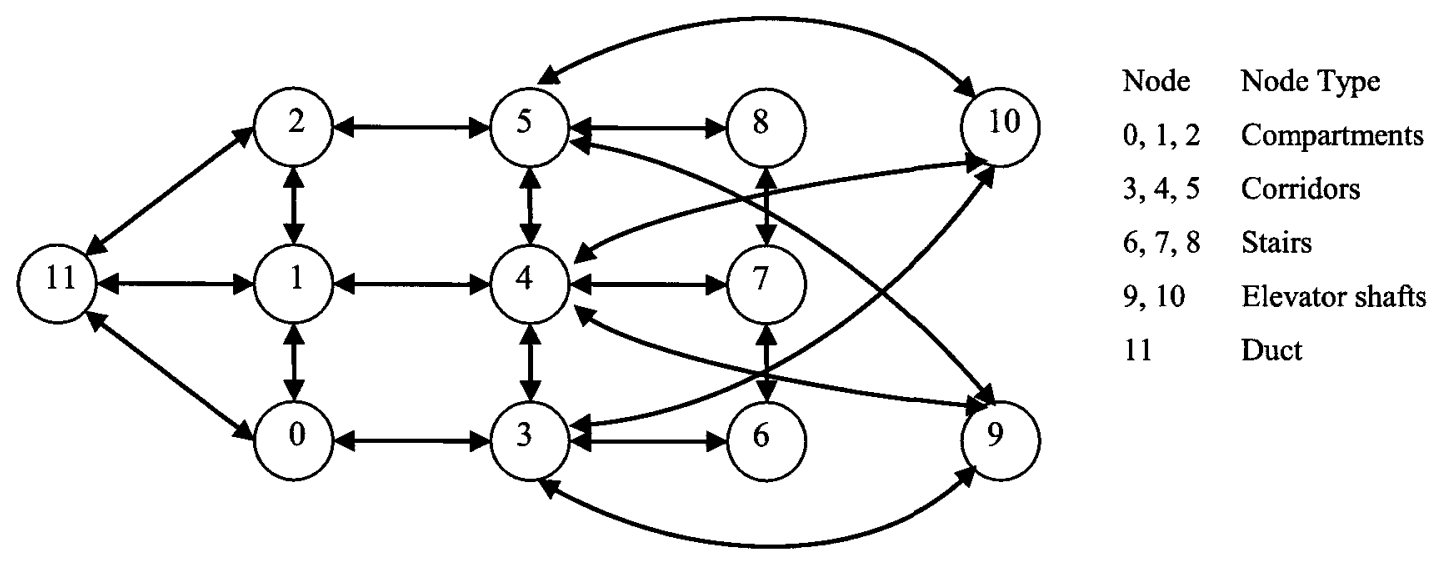

Figure 2-9 Digraph of 3-store building with1 stairwell, 2 elevator shafts, 1 service duct

\section{Comments on fire spread model of NRCC}

This model considers the fire spread to the compartments on the floor above through the ceiling, but does not consider the fire spread by external flames projecting out of the window of the fire compartment; but in real fires, fire spread from a window to a window is also a reason of fire spread to the floor above the fire floor;

All compartments on one floor are combined together, ignoring fire spread between compartments on the same floor. 
- Path of length 1 - Path of length 2 - Path of length 3
(2) (5) (8)
(2) (5) (8)
(2) (5) (8)
(2) (1) (4)
(9) $\rightarrow$ (1) (4) (7)
(9)<smiles>O=COCO</smiles>
(7)

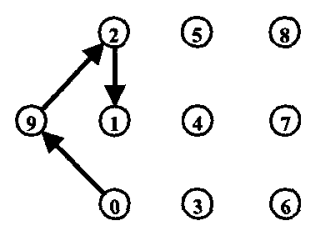

- Path of length 5

- Path of length 6

(2) (5) (8)

(9)

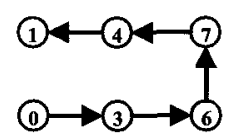

(9)

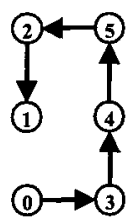

(8)

(7)

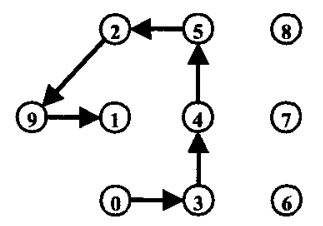

- Path of length 7

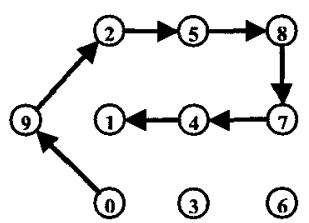

(9)

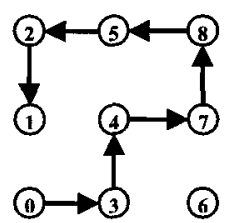

(9)

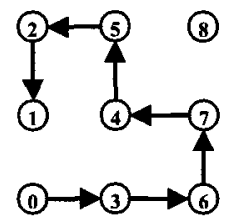

(9)

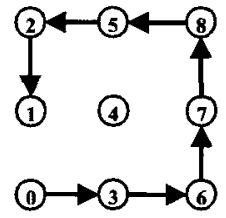

(2)

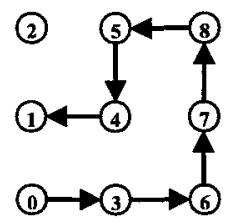

- $\quad$ Path of length 8

- Path of length 9

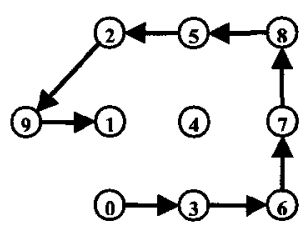

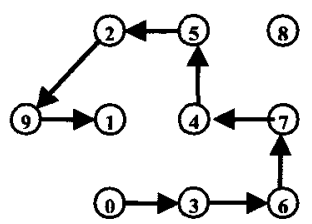

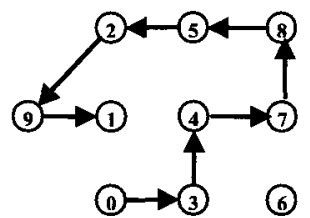

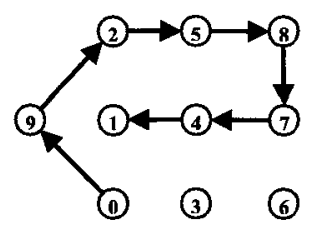

Figure 2-10 Paths of fire spread from node 0 to node 1 


\section{Chapter 3}

\section{Fundamentals of Fire Development in Compartments and Fire Spread in Buildings}

To build a fire-spread model simulating fire spread in buildings, it is important to review some fundamentals of fire development in a compartment and fire spread from the fire compartment to its adjacent compartments.

\subsection{Fundamentals of Fire Development in a Compartment}

If a fire occurs in a compartment, the fire may undergo the phases of growth, development and decay as shown in Figure 3-1.

Temperature/HRR

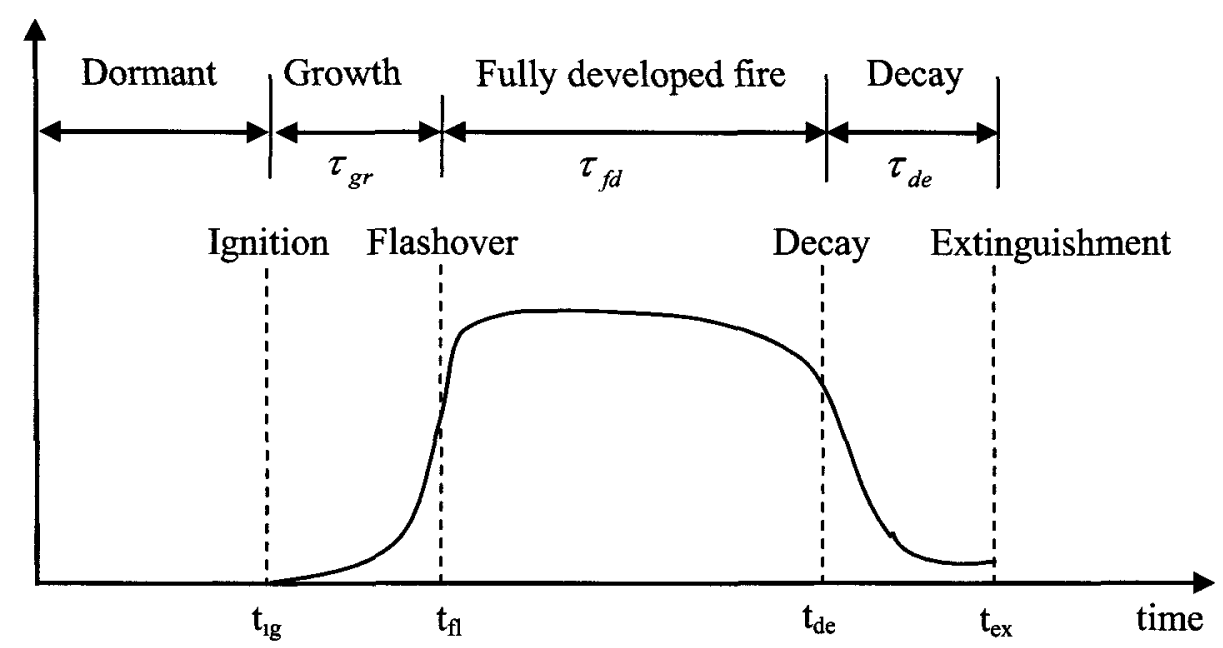

Figure 3-1 The phases of enclosure fire development 


\subsubsection{Dormant Phase}

The phase during which no fire or ignition occurs in the compartment;

\subsubsection{Fire Growth Phase}

Once ignition occurs in the compartment, the fire might grow to a fully sustained fire.

Usually the t-square fire ${ }^{[21]}$ is used to characterize the fire in the fire growth phase

$$
\dot{\mathbf{Q}}=\alpha\left(t-t_{i g}\right)^{2}
$$

Where:

$\dot{\mathrm{Q}}=$ Heat release rate, $(\mathrm{kW})$;

$t_{\text {ig }}=$ The ignition time in the compartment, (s);

$\alpha=$ growth coefficient for $\mathrm{t}$-square fire, $\left(\mathrm{kW} / \mathrm{s}^{2}\right)$. The value of fire growth parameter is shown in Table 3-1.

Table 3-1 Fire growth parameter

\begin{tabular}{|c|c|c|}
\hline $\begin{array}{c}\text { Fire growth } \\
\text { rate }\end{array}$ & $\begin{array}{c}\text { Fire growth parameter } \alpha \\
\left(\mathrm{kW} / \mathrm{s}^{2}\right)\end{array}$ & $\begin{array}{c}\text { Time (s) } \\
\text { (when } \dot{\mathrm{Q}}=1 \mathrm{MW})\end{array}$ \\
\hline Slow & 0.0029 & 600 \\
\hline Medium & 0.012 & 300 \\
\hline Fast & 0.047 & 150 \\
\hline Ultra fast & 0.188 & 75 \\
\hline
\end{tabular}


The fire in the growth phase in the compartment might experience flashover. A criterion for flashover occurring in a compartment is that the heat release rate of the fire must

reach a critical value ${ }^{[22]}$

$$
\dot{\mathrm{Q}}_{\mathrm{fo}}=\mathbf{7 5 0 A}_{\mathbf{0}} \sqrt{\mathbf{H}_{\mathbf{0}}}
$$

Where:

$\dot{\mathrm{Q}}_{\mathrm{fo}}=$ Critical value of heat release rate of fire for flashover, $(\mathrm{kW})$;

$$
\begin{aligned}
& A_{0} \sqrt{H_{0}}=\text { Ventilation factor, }\left(m^{5 / 2}\right) ; \\
& A_{o}=\text { Area of the ventilation opening, }\left(\mathrm{m}^{2}\right) ; \\
& H_{o}=\text { Height of the ventilation opening, }(\mathrm{m}) .
\end{aligned}
$$

\section{a. Fire can flashover in a compartment}

The fire growth phase ends when the heat released rate (HRR) of fire in fire growth phase reaches the critical value for flashover which depends on the ventilation condition, therefore

$$
\dot{Q}_{f o}=\alpha\left(t_{f o}-t_{i g}\right)^{2}=\alpha\left(\tau_{f o}\right)^{2}=750 A_{0} \sqrt{H_{0}}
$$

Where:

$$
\begin{aligned}
& \tau_{f o}=\text { Duration of fire growth phase from ignition to flashover (s); } \\
& t_{f o}=\text { Flashover time in the compartment, (s). }
\end{aligned}
$$

Therefore the duration from ignition to flashover $\tau_{f o}$ can be calculated by 


$$
\tau_{f o}=\sqrt{\frac{750 \mathrm{~A}_{0} \sqrt{\mathrm{H}_{0}}}{\alpha}}
$$

\section{b. Criterion for flashover in a compartment}

If the heat release rate (or temperature) in a compartment during the fire growth phase can not reach the critical value for flashover, a sustained fire could not cause flashover to occur. All fuels in the compartment would burn out during the fire growth phase. The total heat that can be released by fuels in a compartment can be calculated by Equation

$$
\begin{aligned}
& Q=w_{\mathrm{f}} \mathbf{A}_{\mathbf{F}} \mathbf{H}_{\mathrm{ch}}= \\
& \int_{t_{i g}}^{t_{i g}+\tau_{g r}^{\max }} \dot{Q(t)} \mathrm{dt}=\int_{t_{\mathrm{ig}}}^{t_{\mathrm{ig}}+\tau_{g r}^{\max }} \alpha\left(\mathrm{t}-\mathrm{t}_{\mathrm{ig}}\right)^{2} \mathrm{dt}=\int_{0}^{\tau_{g r}^{\max }} \alpha(\tau)^{2} \mathrm{~d} \tau=\frac{1}{3} \alpha\left(\tau_{g r}^{\max }\right)^{3}
\end{aligned}
$$

Where:

$\mathrm{Q}=$ Total heat released of fuels, $(\mathrm{kJ})$;

$\mathrm{w}_{\mathrm{f}}=$ The fuel load density in compartment, $\left(\mathrm{kg} / \mathrm{m}^{2}\right)$;

$A_{F}=$ Floor area of the compartment, $\left(\mathrm{m}^{2}\right)$;

$\mathrm{H}_{\mathrm{ch}}=$ The heat of combustion of fuel $(\mathrm{kJ} / \mathrm{kg})$;

$\tau_{g r}^{\max }=$ The maximum duration of fire growth phase when all fuel would be burnt in fire growth phase, (s).

Therefore the maximum duration of fire growth phase could be calculated by

$$
\tau_{g r}^{\max }=\sqrt[3]{\frac{3 \mathrm{w}_{\mathrm{f}} \mathrm{A}_{\mathrm{F}} \mathrm{H}_{\mathrm{ch}}}{\alpha}}
$$


If $\tau_{g r}^{\max } \leq \tau_{f o}$, then there is no flashover in a compartment

If $\tau_{g r}^{\max }>\tau_{f o}$, then flashover can occur in a compartment

\subsubsection{Fully-developed fire Phase}

Immediately after flashover, the compartment fire becomes a fully developed fire.

During the fully-developed fire phase, the heat release rate of the fire reaches its greatest value. The fully-developed fire might be ventilation controlled or fuel controlled.

The criterion used to distinguish the two regimes of post-flashover compartment fire proposed by Harmathy ${ }^{[23,24]}$ are as follows.

- Ventilation controlled fire:

$$
\frac{\rho_{0} \sqrt{g} A_{o} \sqrt{H_{o}}}{A_{f}}<0.263
$$

- Fuel surface controlled fire:

$$
\frac{\rho_{o} \sqrt{g} A_{o} \sqrt{H_{o}}}{A_{f}} \geq 0.263
$$

Where:

$$
\begin{aligned}
& \rho_{0}=\text { The density of air },\left(\mathrm{kg} / \mathrm{m}^{3}\right) ; \\
& \mathrm{g}=\text { The acceleration due to gravity, }\left(\mathrm{m} / \mathrm{s}^{2}\right) ; \\
& \mathrm{A}_{\mathrm{f}}=\text { The surface area of the fuel, }\left(\mathrm{m}^{2}\right) .
\end{aligned}
$$

Harmathy ${ }^{[25]}$ suggested that the surface area of the fuel can be expressed as

$$
A_{f}=\varphi W_{F}=\varphi w_{f} A_{F}
$$


Where:

$$
\begin{aligned}
& \mathrm{W}_{\mathrm{f}}=\text { Total mass of fuel in compartment, }(\mathrm{kg}) \\
& \varphi=\text { Specific surface of fuel, } 0.1<\varphi<0.4 \frac{\mathrm{m}^{2}}{\mathrm{~kg}}{ }^{[23]} \\
& \mathrm{W}_{\mathrm{f}}=\text { The fuel load density in compartment, }\left(\mathrm{kg} / \mathrm{m}^{2}\right) \\
& \mathrm{A}_{\mathrm{F}}=\text { Floor surface area of the compartment, }\left(\mathrm{m}^{2}\right)
\end{aligned}
$$

Substituting $\rho_{0}=1.2 \mathrm{~kg} / \mathrm{m}^{3}, g=9.81 \mathrm{~m} / \mathrm{s}^{2}$ and Equation (3.9) into Equation (3.7) and (3.8), then the criterion of the two regimes of post-flashover compartment fire becomes

- Ventilation controlled fire:

$$
\frac{A_{0} \sqrt{H_{0}}}{A_{f}}=\frac{A_{0} \sqrt{H_{0}}}{\varphi w A_{F}}<0.07 \mathrm{~m}^{-1 / 2}
$$

- Fuel surface controlled fire:

$$
\frac{A_{0} \sqrt{H_{0}}}{A_{f}}=\frac{A_{0} \sqrt{H_{0}}}{\varphi w A_{F}} \geq 0.07 \mathrm{~m}^{-1 / 2}
$$

For a wide range of conventional furniture $\varphi=0.13 \frac{\mathrm{m}^{2}}{\mathrm{~kg}}[25]$

\section{a. Duration of fully-developed fire phase}

Harmathy ${ }^{[25]}$ presented the following equations to calculate the duration of fullydeveloped fire phase $\tau_{f d}$

- Ventilation controlled fire:

$$
\tau_{f d}=\frac{w_{f}}{\rho_{0} \sqrt{g} A_{0} \sqrt{\mathrm{H}_{0}}}=10.6 \frac{w_{f}}{A_{0} \sqrt{\mathrm{H}_{0}}}
$$


- Fuel surface controlled fire:

$$
\tau_{f d}=\frac{151}{\varphi}(\mathrm{s})
$$

Where:

$$
\tau_{f d}=\text { Duration of fully-developed fire phase, (s). }
$$

For a ventilation controlled fire, its duration depends on both the amount of fuel in the compartment and the size and shape of the opening of the compartment. For a fuel surface controlled fire, its duration is independent of the fuel load in the compartment and only depends on the specific surface of fuel.

\section{b. Flame height above the soffit of the window of the compartment}

- For a fuel surface controlled fire, the fire will be contained in the compartment and flames will not come out of compartment.

- If a fire is ventilation controlled, flames will project outside the compartment through openings such as windows or open doors. The flame height above the soffit of the opening is given by ${ }^{[26]}$

$$
z=12.8\left(\frac{\dot{m}_{v}}{w_{o}}\right)^{2 / 3}-H_{o}
$$

Where:

$z=$ Flame height above the soffit of the opening, (m);

$\dot{m}_{v}=$ Fuel burning rate during fully-developed fire phase for ventilation controlled fire, $(\mathrm{kg} / \mathrm{s})$; 


$$
\mathrm{W}_{\mathrm{o}}=\text { Width of the ventilation opening, }(\mathrm{m}) \text {. }
$$

For the ventilation controlled fire, the burning rate at fully-developed fire phase ${ }^{[27]}$ is

$$
\dot{m}_{v}=0.18 \frac{\left(1-e^{-0.036 \Omega}\right) A_{0} \sqrt{H_{0}}}{\sqrt{D / W}}
$$

Where:

$$
\begin{aligned}
& \mathrm{D}=\text { Depth of the fire compartment, }(\mathrm{m}) ; \\
& \mathrm{W}=\text { Width of the fire compartment, }(\mathrm{m}) ; \\
& \Omega=\text { Coefficient }, \Omega=\frac{A_{T}}{A_{o} \sqrt{H_{o}}} \\
& \mathrm{~A}_{\mathrm{T}}=\text { Total area of fire compartment enclosing surface, }\left(\mathrm{m}^{2}\right) .
\end{aligned}
$$

\subsubsection{Decay Phase}

Decay occurs as fuels are consumed by the fire and the HRR begins to decline. During this phase, the fire in the compartment changes from ventilation controlled fire to fuel surface controlled fire.

\subsection{Fundamentals of Fire Spread in a Building}

The main reason for fire spread from the compartment of fire origin to its adjacent compartments is that the barriers between the compartments fail to contain the fire. The heat in the fire compartment penetrates the barrier and may ignite the combustible materials in the adjacent compartments. After ignition, the fire in the adjacent 
compartments may grow and develop to a fully developed fire. The failure of a barrier to contain the fire depends on three factors:

- The fire severity

- Fire duration

- Fire resistance of the barrier

Fire severity is usually expressed in terms of the heat release rate or temperature in the fire compartment. As shown in Figure 3-1, the heat release rate or temperature during the fire growth phase is much smaller than that of the fully developed phase; therefore, it can be assumed that fire spread can only occur after flashover and during the fully-developed fire phase.

The duration of a fully-developed fire mainly depends on the amount of fire load in the compartment and the fire burning rate.

Fire spreads from the fire compartment to its adjacent compartments always via the weakest parts of the barriers such as doors, windows or other openings, etc. In buildings, fire may spread from the fire compartment to adjacent compartments both in the horizontal direction and in the vertical direction

\subsubsection{Fire Spread in the Horizontal Direction}

The possible pathways for fire to spread from the fire compartment to its adjacent compartments in a horizontal direction are:

- through a wall connecting two compartments 
- through a closed door connecting two compartments

- through an open door connecting two compartments

- through a window connecting two compartments

- from one compartment to another compartment separated by a corridor ( 4 different door opening scenarios)

The mechanisms of fire spread between two compartments in the horizontal direction are:

- Conduction: The heat in the fire compartment is conducted through walls or closed doors separating the two compartments, causing an increase of the temperature on the unexposed side and igniting combustible materials in the adjacent compartment.

- Convection: Hot gases or flames flow through openings such as open doors, windows or cracks to the adjacent compartment and ignite combustible materials in it.

- Radiation: Radiative heat flux from the fire compartment transfers to compartments across the corridor and ignites combustible materials in these compartments.

\subsubsection{Fire spread in the vertical direction}

The possible pathways for fire to spread from the fire compartment to compartments on the floor above: 
- through a ceiling connecting two compartments

- through an opening such as stairwell connecting two compartments

- by outside flames projecting out of windows in the fire compartment entering windows in the compartment above

The mechanisms causing the fire to spread from the fire compartment to compartments above in vertical direction are:

- Conduction: Conduction of heat from the fire compartment through the ceiling or floor, causing an increase of the temperature on the unexposed side and igniting combustible materials in the compartment at the upper or lower floor.

- Convection: Immediately after flashover in the fire compartment, hot gases flow to the compartment above through openings and ignite combustible materials inside.

- Radiation and convection: Heat flux from the flames projecting out of the windows of the fire compartment could break glass windows of the compartments on the upper floor, penetrate the windows, and ignite combustible materials in the upper compartment. 


\section{Chapter 4}

\section{The Modeling of Fire Spread in Buildings by Bayesian Network}

The Bayesian network model is a powerful tool to manage uncertainty using probability. A Bayesian network is a graphical model which combines graph theory and Bayesian probability theory. Bayesian probability theory deals with the problem of reasoning under uncertainty.

\subsection{The Fundamentals of Probability}

If $\mathrm{A}$ is an event, $\mathrm{P}(\mathrm{a})$ represents the probability that event $\mathrm{A}$ is true, and $P(\tilde{a})$ denotes the probability that event $\mathrm{A}$ is not true.

Some basic axioms can be expressed as follows:

$$
\begin{aligned}
& 0 \leq P(A) \leq 1 \\
& P(a)+P(\widetilde{a})=1
\end{aligned}
$$

If event A and event B are mutually exclusive, the probability of the union of event $A$ and $\mathrm{B}$ is

$$
P(A \cup B)=P(A)+P(B)
$$

If events $\mathrm{A}$ and $\mathrm{B}$ are not exclusive

$$
P(A \cup B)=P(A)+P(B)-P(A \cap B)
$$


Where $P(A \cap B)$ is called the joint probability of events $\mathrm{A}$ and $\mathrm{B}$. Usually $P(A \cap B)$ is shorten as $P(A, B)$.

The joint probability $P(A, B)$ can be derived from the following equation

$$
P(A, B)=P(B \mid A) P(A)
$$

Where $P(B \mid A)$ is called the conditional probability, which is the probability that event $\mathrm{B}$ occurs given that event A occurs.

$P(A, B)$ can also be written as

$$
P(A, B)=P(B \mid A) P(A)=P(A \mid B) P(B)
$$

Rearranging the above equation leads to the famous Bayes theorem

$$
\boldsymbol{P}(\boldsymbol{A} \mid \boldsymbol{B})=\frac{P(B \mid A) P(A)}{P(B)}
$$

\subsection{The Basies of Bayesian Network}

\subsubsection{Definitions}

The Bayesian network $(\mathrm{BN})$ is based on the fundamental assumption that the probability distributions in BN are subjected to the Markov condition. A Bayesian network or Bayesian belief network consists of two components:

(a) A graphical structure, called directed acyclic graph $\boldsymbol{G}(\mathrm{DAG}) . \boldsymbol{G}=(\mathrm{V}, \mathrm{E})$ where $\mathrm{V}$ are the set of nodes representing random variables on which the Bayesian 
network is defined and $\mathrm{E}$ are the set of directed edges representing relations among the variables.

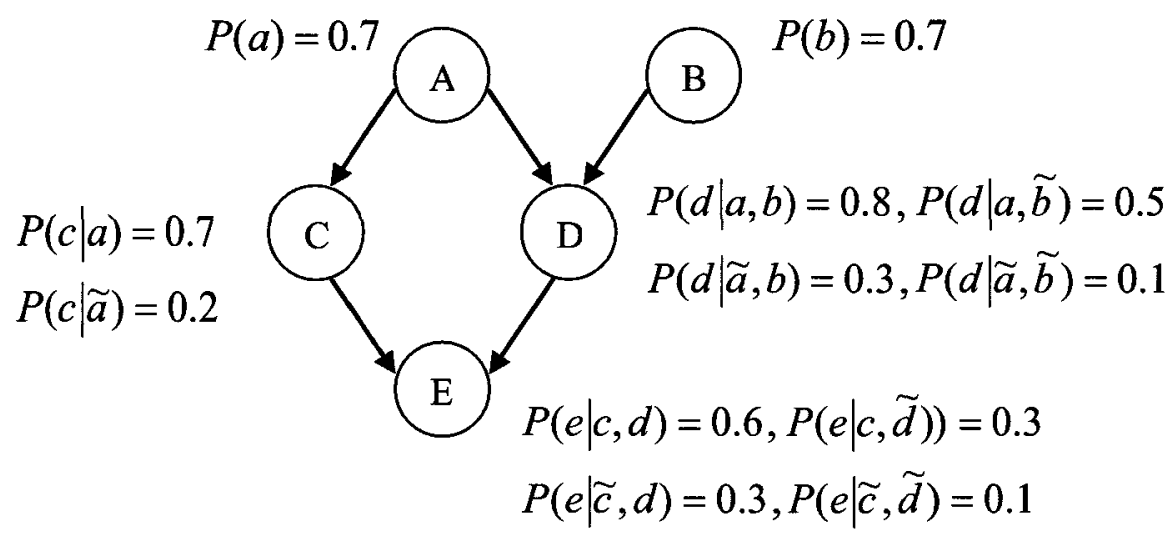

Figure 4-1 An example of a Bayesian Network

An example of a DAG is shown as Figure 4-1. In DAG, the family notation is often used to express the relationships between variables. For $A \in V$, the parents of $A$, or $p a(A)$, are the set of variables from which there is an arrow going to Node A. The children of A are the set of variables which are reached by an arrow from Node A. The ancestors of A are the set of variables who are the parents of A, its parent's parents and so on. The descendents of A are the set of variables who are the children of A, its child's children and so on. The nodes without parents are called root nodes. The nodes without children are called leaf nodes. 
In Figure 4-1, Nodes A and B are root nodes. Node $\mathrm{E}$ is a leaf node. The nodes C, D are the children of Node A, and Nodes A, B are called the parents of Node D. Nodes A, B, C, D are the ancestors of Node E, and Node E is called the descendant of Nodes A, B, C, D. Node $\mathrm{C}$ is a non-descendent of Node $\mathrm{B}$, or ND(B).

(b) A set of probabilities $\boldsymbol{P}$, each of which is associated with a node of the DAG as shown in Figure 4-1. Each root node possesses a prior probability distribution table. Each of the other nodes possesses a Conditional Probability Table (CPT). In this thesis, we assume all variables to be binary, that is, we use $v$ to denote $V=$ True and $\tilde{v}$ to denote $\mathrm{V}=$ False.

\subsubsection{Independence and D-Separation}

Suppose that a conditional probability $P(A \mid B, C)$ has the property that it is always equal to the conditional probability $P(A \mid B)$ as $\mathrm{C}$ varies, therefore $\mathrm{A}$ is conditionally independent of $\mathrm{C}$ given $\mathrm{B}$, written as $\mathrm{A} \amalg \mathrm{C} \mid \mathrm{B}$.

A Bayesian network may have a complicated DAG. No matter how complicated, any Bayesian network can be considered to consist of the following three basic types of connections as shown in Figure 4-2. 


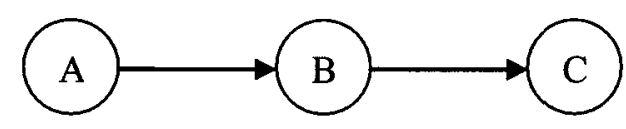

(a) Serial connection

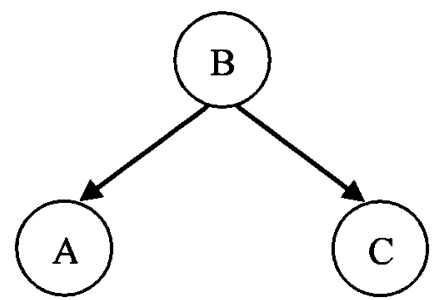

(b) Diverging connection

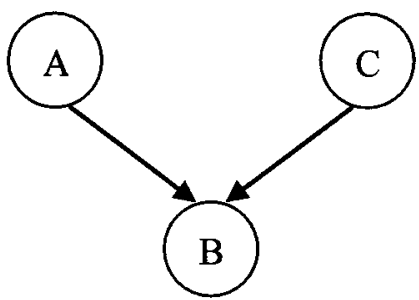

(c) Converging connection

Figure 4-2 Three basic connections in Bayesian network

(a) The serial connection as shown in Figure 4-2(a): There is a directed path from the start node to the end node $\mathrm{A} \rightarrow \mathrm{B} \rightarrow \mathrm{C}$. In Figure 4-2(a), Nodes $\mathrm{A}$ and $\mathrm{C}$ are separated by Node B. If the state B is known, A and C become independent of each other according to the Markov condition, therefore $\mathrm{A}$ and $\mathrm{C}$ are referred to as d-separated by $B$.

(b) The diverging connection as shown in Figure 4-2(b): Node B effectively dseparates Nodes $\mathrm{A}$ and $\mathrm{C}$ from each other, making them conditionally independent.

(c) The converging connection as shown in Figure 4-2(c): If the state of B is known, $\mathrm{A}$ and $\mathrm{C}$ become conditionally dependent. This is known as d-connection. 


\subsection{3 epresentation of the Joint Probability Distribution}

If a $\mathrm{BN}$ contains $\mathrm{n}$ nodes $\mathrm{V}=\left\{\mathrm{X}_{1}, \mathrm{X}_{2}, \ldots, \mathrm{X}_{\mathrm{n}}\right\}$, a particular value in the joint probability distribution can be represented by $P\left(X_{1}=x_{1}, X_{2}=x_{2}, \cdots, X_{n}=x_{n}\right)$, or $P\left(x_{1}, x_{2}, \cdots, x_{n}\right)$. The chain rule in the classical probability theory can be used to factorize it as follows:

$$
\begin{aligned}
& P\left(X_{1}, X_{2}, \cdots X_{n}\right)=P\left(X_{n} \mid X_{1}, X_{2}, \cdots X_{n-1}\right) \cdot P\left(X_{1}, X_{2}, \cdots X_{n-1}\right) \\
& =P\left(X_{1}\right) P\left(X_{2} \mid X_{1}\right) P\left(X_{3} \mid X_{1}, X_{2}\right) \cdots P\left(X_{n} \mid X_{1}, X_{2}, \cdots X_{n-1}\right)
\end{aligned}
$$

Assume that the variables in $\mathrm{V}$ are ordered ancestrally, or in a topological ordering, that is for every node $X_{i} \in \mathrm{V}$; the index of its ancestor $X$, has the property $j<i$. According to the Markov condition, we know that any variable $X_{t}$ is conditionally independent of its non-descents $N D\left(X_{i}\right)$ given its parents $p a\left(X_{\imath}\right)$, which can be stated as $X_{\imath} \amalg N D\left(X_{i}\right) \mid p a\left(X_{\imath}\right)$. Thus the conditional probability distribution of any variable $X_{i}$ may be expressed as

$$
P\left(X_{i} \mid X_{1}, X_{2}, \cdots X_{i-1}\right)=P\left(X_{i} \mid p a\left(X_{i}\right)\right)
$$

Therefore the joint probability distribution over $n$ variables $X_{1}, X_{2}, \ldots, X_{n}$ can be defined as

$$
\begin{aligned}
& P\left(X_{1}, X_{2}, \cdots X_{n}\right)=P\left(X_{1}\right) \cdot P\left(X_{2} \mid p a\left(X_{2}\right)\right) P\left(X_{3} \mid p a\left(X_{3}\right)\right) \cdots P\left(X_{n} \mid p a\left(X_{n}\right)\right)= \\
& \prod_{i=1}^{n} P\left(X_{i} \mid p a\left(X_{i}\right)\right)
\end{aligned}
$$




\subsubsection{Inference and Marginalization in Bayesian Network}

Bayes' rule is one of the fundamental theorems in Bayesian network. Based on the observed evidence of some variables, Bayes' rule can predict the outcome of other variables by providing the posterior probability distribution when these variables are linked in the form of a network. For the random variables $X_{1}, X_{2}, \ldots, X_{n}$, the impact of an observed variable $X_{J}=x_{J}$ on another variable $X_{\imath}=x_{t}$ can be stated as

$$
P\left(x_{i} \mid x_{j}\right)=\frac{P\left(x_{l}, x_{j}\right)}{P\left(x_{j}\right)}
$$

The marginal probability $P\left(X_{i}, X_{j}\right)$ is computed by summing the joint probability distribution $P\left(X_{1}, X_{2}, \cdots X_{n}\right)$ over all instantiations of the variables except $X_{1}$ and $\mathrm{X}_{\mathrm{J}}$. The marginal probabilities can be expressed as

$$
\begin{aligned}
& P\left(X_{i}, X_{j}\right)=\sum_{X /\left[X_{i} \cup X_{j}\right]} P\left(X_{1}, X_{2}, \cdots X_{n}\right) \\
& P\left(X_{j}\right)=\sum_{X_{i}} P\left(X_{i}, X_{j}\right)
\end{aligned}
$$

\subsection{A Fire Spread Model for an Office Building Using Bayesian Network}

A floor of a building may consist of rooms, corridors, stairwells, elevator shafts, and ducts. Due to the different uses and fuel loads, some compartments may have higher probabilities for fire to be initiated in them than other compartments. If a fire occurs in one compartment, the fire may spread from the fire compartment to other compartments in the building. In order to build a fire spread model in a building based on Bayesian 
network, the first step is to transform the building plan into a DAG. To simplify the problem, in this thesis the fire spread model is firstly focused on the case where fire only spreads horizontally on a single floor.

\subsubsection{Transforming the Compartment Floor into the DAG of Bayesian network}

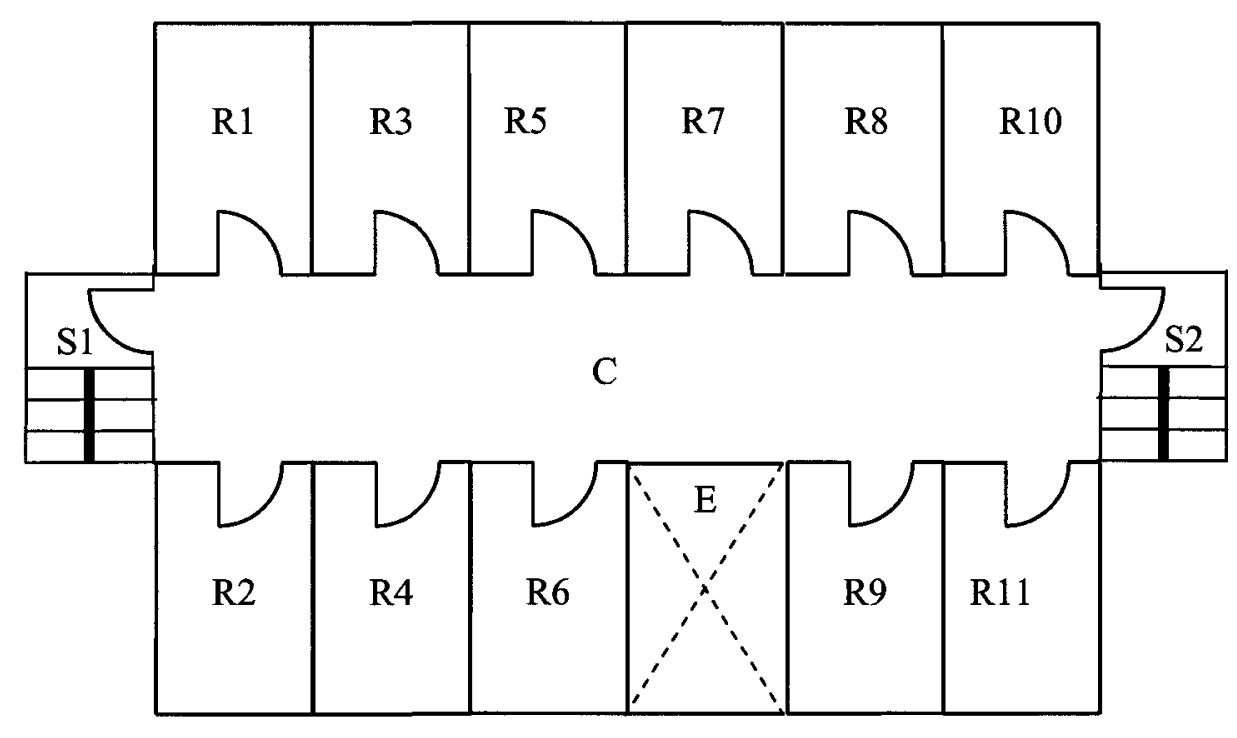

Figure 4-3 The floor plan of an office building

Figure 4-3 shows the floor plan of the office building considered. The floor has eleven rooms, one corridor, two stairwells, and one elevator shaft. We can transform this floor plan into a DAG of Bayesian network as shown in Figure 4-4. 


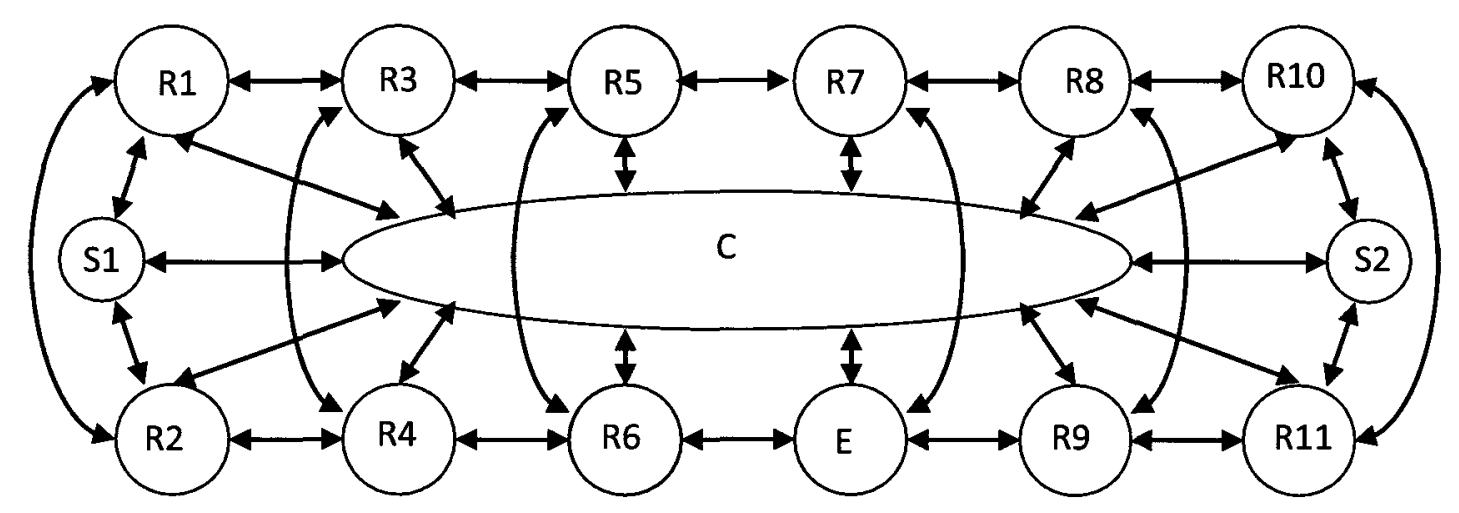

Figure 4-4 The DAG of fire spread model based on Bayesian network

In the DAG of Figure 4-4, there are 15 nodes, each of which represents one compartment such as room, stairwell, elevator shaft, corridor or duct, and edges connecting the 15 nodes. The arrows represent the possible paths and directions of fire spread. The DAG can be considered as the general fire spread model that includes all possible fire spread paths from any compartment of fire origin to any destination compartment in the building. Once the compartment of fire origin is known, the general fire spread network can be immediately converted into a specific fire spread Bayesian network for fire spread from the compartment of fire origin to a specific destination compartment. The probability of fire spread from the compartment of fire origin to the destination compartment can be calculated using Bayesian network theory. 
To further simplify the problem, it is assumed that although it is possible for a corridor fire to occur, a corridor fire will not spread to other compartments because usually there is not enough fuel in the corridor. With this assumption, the fire spread network of Figure 4-4 can be simplified resulting in the fire spread network shown in Figure 4-5.

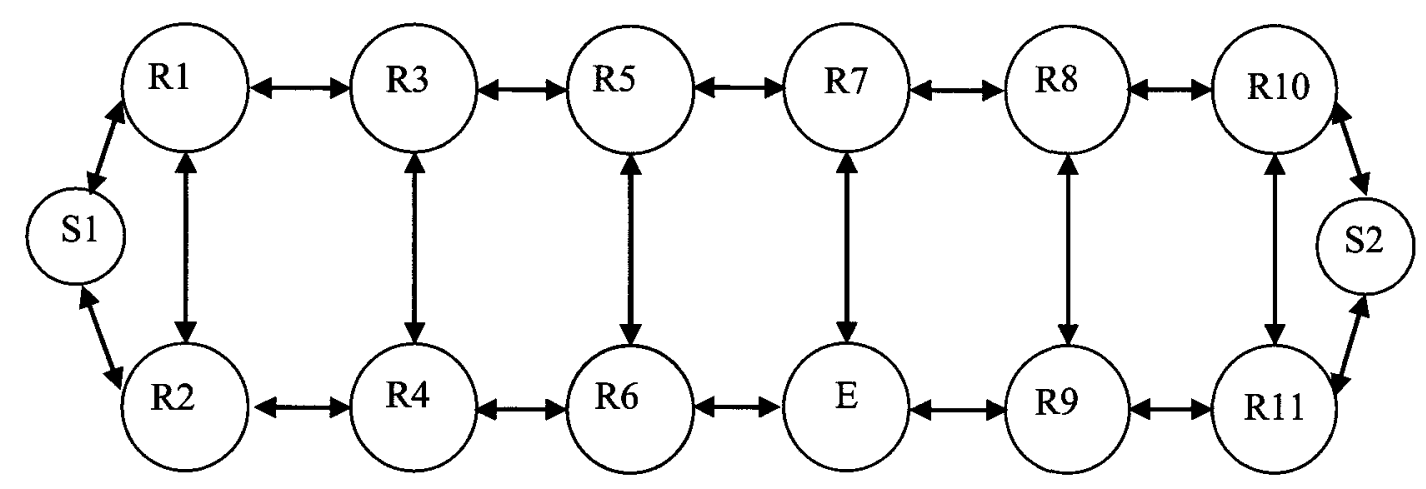

Figure 4-5 The simplified general fire spread network

\subsubsection{Probability of Fire Spread}

Fire spread from the fire compartment to an adjacent compartment includes two processes:

(a) Heat overcomes the fire resistance of the barrier between the two compartments and transfers to the adjacent compartment, igniting combustible material located in the adjacent compartment. 
(b) Following ignition, fire grows into a fully-developed fire in the adjacent compartment.

The main reason a fire spreads from the fire compartment to an adjacent compartment is that the barrier between these two compartments fails to contain the fire. The failure depends on three factors - the fire severity, the duration of the fully-developed fire phase in the fire compartment and the fire resistance of the barrier between the two compartments. Fire penetrates a barrier and spreads to another compartment mainly via the weakest part of the barrier such as a door, a window etc. After ignition, the fire may grow and reach the fully developed phase. The duration of the fully-developed fire phase depends on the amount and type of fuel in the compartment and fire burning rate in the compartment.

The probability of fire spread from compartment B to compartment A is written as $P(a \mid b)$. Therefore

$$
P(a \mid b)=P\left(a \mid a^{\prime}\right) \times P\left(a^{\prime} \mid b\right) \times P(b)
$$

Where:

$P\left(a^{\prime} \mid b\right)=$ Barrier failure probability indicating that heat transfers from the fire compartment $\mathrm{B}$ to the adjacent compartment $\mathrm{A}$ igniting the combustible materials in compartment $\mathrm{A}$. 
$P\left(a \mid a^{\prime}\right)=$ Probability of fire growth to fully-developed fire indicating the fire in compartment A grows from ignition to a fully developed fire;

$P(b)=$ The probability of fire growth to fully-developed fire in compartment B.

\subsubsection{The barrier failure probability}

A barrier failure probability is the probability that heat in the fire compartment overcomes the fire resistance of the barrier, penetrates to an adjacent compartment and ignites the combustible material in the adjacent compartment. The barrier failure probability depends on the fire severity, amount and types of combustible materials, the material and thickness of the barrier, the position of doors or windows and the material and size of the door or window etc. Fire always spreads into adjacent compartments through the weakest part of its barrier, such as door or window. Whether the door or window is open or closed also has a great effect on the speed of fire spread.

\subsubsection{Probability of fire growth to fully developed fire}

Once ignition occurs in a compartment, the fire may or may not grow from ignition to a fully developed fire. The probability of fire growth to a fully-developed fire depends on the following factors:

- The fuel load: fuel amount and fuel types in the compartment;

- The geometry of the compartment and its ventilation condition;

- The presence of a fire suppression system. 
In this thesis, the following assumptions are made for the calculation of the probability of fire spread,

- If a fire has burnt in a compartment and spread to adjacent compartments, the fire can not return to this compartment again.

- When two rooms are separated by a wall, the barrier failure probabilities for fire to spread in both directions through the wall are the same.

- When two similar compartments (such as rooms) are separated by a corridor, the barrier failure probabilities for fire to spread in both directions through the corridor from the fire compartment to the opposite compartment are the same.

- When two similar compartments (such as rooms) are separated only by a door, the barrier failure probabilities for fire to spread in both directions through the door from the fire compartment to the adjacent compartment are the same.

- The barrier failure probability of fire spread to upper floor compartments (upward direction) is greater than that in the downward direction.

- The barrier failure probability for fire in the stairwell, elevator shaft or duct to spread in the upward (vertical) direction is greater than that in the horizontal or downward direction.

- Though fire may occur in a corridor, the probability of barrier failure for fire to spread from the corridor to adjacent compartments can be ignored since there is not enough fuel in the corridor to support fire spread. 
- Though the probability of barrier failure from a corridor to a room is assumed to be zero, heat can spread from one room to a room separated by a corridor due to radiation and convective heat transfer.

- Compartments of the same type have the same probability of fire growth to a fully developed fire.

- The probabilities of fire growth to a fully-developed fire in stairwells, elevator shafts or ducts are lower than that in a compartment (room).

\subsection{Example of a Fire Spread Model Using Bayesian Network}

To calculate the probabilities of fire spread in a building, a general fire spread network has to be built based on the building floor plan. Following that, a Bayesian network can be constructed to calculate the probability of fire spread from the fire compartment to a destination compartment.

As an example, a Bayesian network model for the building, as shown Figure 4-3, will be developed using the principles described above for calculating the probability of fire spread from a fire that starts in Room 1 and spreads to Room 6, both of which are located on the same floor. Once the model is developed, the fire spread probability from Room 1 to Room 6 will be computed for the following two cases:

- Case 1: There is no suppression system in the building or intervention during the fire spread process; 
- Case 2: There is a sprinkler system installed in the rooms of the building.

The steps to calculate the probability of fire spread from Room 1 to Room 6 using the fire spread model based on Bayesian network are listed below:

- Step 1. Build a general fire spread network according to the building floor plan. This general network is shown in Figure 4-5.

- Step 2. Find all the possible pathways, through which fire could spread from Room 1 to Room 6. The possible pathways are shown in Figure 4-6 which represents the directed acyclic graph (DAG) of the Bayesian network.

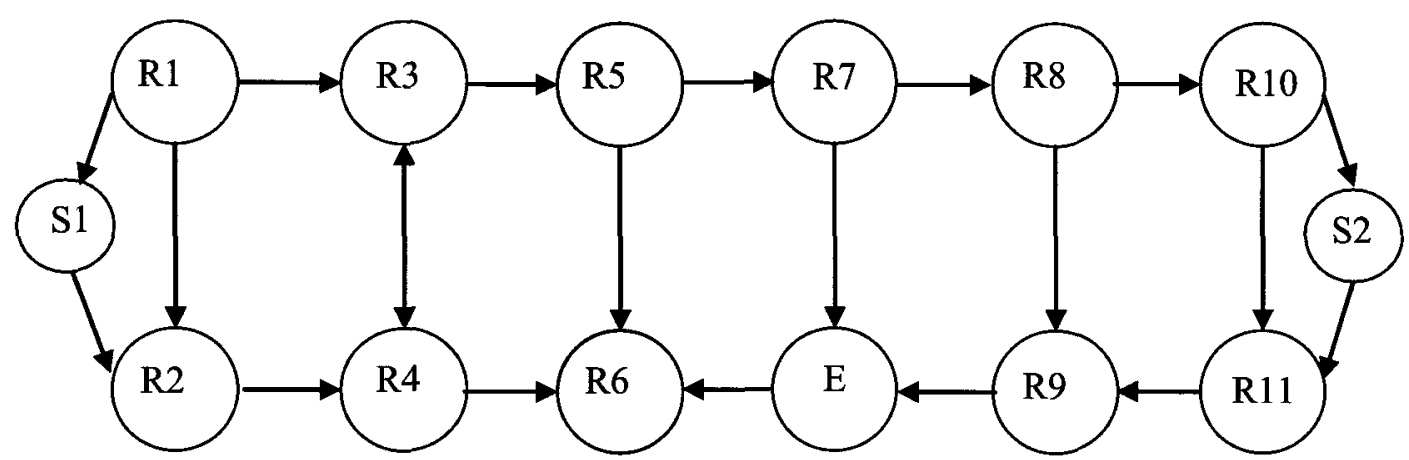

Figure 4-6 The DAG of Bayesian Network for fire to spread from room 1 to room 6

From Figure 4-6, it can be seen that fire can spread from R1 to S1 and R2; from S1 to R2; from R2 to R4; from R4 to R3 and R6; etc. Using this information, the joint probability for the Bayesian network for fire spread from Room 1 to Room 6 can be expressed as 
$P\left(R_{1}, R_{2} \cdots, R_{11}, S_{1}, S_{2}, E\right)=$

$P\left(R_{1}\right) \cdot P\left(S_{1} \mid R_{1}\right) \cdot P\left(R_{2} \mid R_{1}, S_{1}\right) \cdot P\left(R_{3} \mid R_{1}, R_{4}\right) \cdot P\left(R_{4} \mid R_{1}, R_{3}\right) \cdot P\left(R_{5} \mid R_{3}\right) \cdot$

$P\left(R_{6} \mid R_{4}, R_{5}, E\right) \cdot P\left(R_{7} \mid R_{5}\right) \cdot P\left(E \mid R_{7}, R_{9}\right) \cdot P\left(R_{8} \mid R_{7}\right) \cdot P\left(R_{9} \mid R_{8}, R_{11}\right) \cdot P\left(R_{10} \mid R_{8}\right) \cdot$

$P\left(R_{11} \mid R_{10}, S_{2}\right) \cdot P\left(S_{2} \mid R_{10}\right)$

The terms of Equation (4.15) can be re-written to explicitly consider both the probability of barrier failure and the probability of fire growth to fully developed fires in the adjacent compartments, which is a condition for spreading from a fire compartment to the adjacent compartments, as per Equation (4.14).

As described in Equations (4.1) and (4.2), each event (fire spread) in Equations (4.15) can be true or not true, both of which have to be considered in the calculations. Using Equation (4.12) the fire spread probability from Room 1 and Room 6 can be computed by summing the joint probability distribution $P\left(R_{1}, R_{2} \cdots, R_{11}, S_{1}, S_{2}, E\right)$ over all instantiations of the variables except $\mathrm{R} 1$ and $\mathrm{R} 6$ as follows:

$$
P\left(r_{6} \mid r_{1}\right)=\sum_{X / R_{6}} P\left(R_{1}, R_{2} \cdots, R_{11}, S_{1}, S_{2}, E\right)
$$

A computer model can be developed to perform the summations of Equation (4.16). The model requires probabilities of barrier failure and probabilities of fire growth as its input. The probability of fire growth is obtained from paper ${ }^{[28]}$ which was conducted for use in the risk-cost assessment model FireCAM ${ }^{[29]}$. The probability of barrier failure may be calculated by considering the heat transfer through the barrier and structural performance 
of the barrier at elevated temperature. The probabilities of barrier failure were taken from the report ${ }^{[14]}$; however, this report does not provide detail on how they were computed. As no other values were found in the literature, the values of references ${ }^{[14]}$ and ${ }^{[28]}$ are used to demonstrate the ability of the model to compute the probability of fire spread from the compartment of fire origin to other compartments in the building. The model was used to compute the probability of fire spread from Room 1 to Room 6 for two cases: a case without sprinklers in the building, and a case with sprinklers installed in every room in the building. A discussion of the two cases is given below.

\section{Case 1: when there is no intervention during fire spread}

In Case 1, the building has no sprinklers and it is assumed that there is no manual fire suppression intervention. The values of the probabilities of barrier failure shown below are used in the calculations. These values have been obtained from NRCC report ${ }^{[14]}$.

The probabilities of barrier failure between the various building elements ${ }^{[14]}$

- Room to room (separated by wall) 0.81

- Room to room (separated by corridor) 0.84

- Room to stairwell, elevator shaft or duct (separated by wall) $\quad 0.57$

- Room to stairwell, elevator shaft or duct (separated by corridor) 0.28

- Stairwell, elevator shaft or duct to room (separated by wall) $\quad 0.60$ 
Using above data, the barrier failure probability distributions between the adjacent compartments or nodes in Bayesian network in Figure 4-6 were calculated and are shown in Table 4-1 which shows the probabilities of success and failure of all events that lead to barrier failure and fire ignition in the different rooms of the building. (Example of calculation in Table 4-1: $\because P\left(r_{2}^{\prime} \mid r_{1}\right)=0.84, P\left(r_{2}^{\prime} \mid s_{1}\right)=0.60, \quad \therefore P\left(r_{2}^{\prime} \mid r_{1}, s_{1}\right)=$ $\left.P\left(r_{2}^{\prime} \mid r_{1}\right)+P\left(r_{2}^{\prime} \mid s_{1}\right)-P\left(r_{2}^{\prime} \mid r_{1}\right) \times P\left(r_{2}^{\prime} \mid s_{1}\right)=0.84+0.60-0.84 \times 0.60=0.936\right)$. These values are used as input to the fire spread model.

Table 4-1Barrier Failure Probability Distribution

\begin{tabular}{|c|c|}
\hline Node & Barrier Failure Probability \\
\hline $\mathrm{R}_{1}$ & $P\left(r_{1}\right)=1, P\left(\widetilde{r}_{1}\right)=0$ \\
\hline $\mathrm{S}_{1}$ & $P\left(s_{1}^{\prime} \mid r_{1}\right)=0.57, P\left(s_{1}^{\prime} \mid \widetilde{r}_{1}\right)=0$ \\
\hline $\mathrm{R}_{2}$ & $P\left(r_{2}^{\prime} \mid r_{1}, \widetilde{s}_{1}\right)=0.84, P\left(r_{2}^{\prime} \mid \widetilde{r}_{1}, s_{1}\right)=0.60, P\left(r_{2}^{\prime} \mid r_{1}, s_{1}\right)=0.936, P\left(r_{2}^{\prime} \mid \widetilde{r}_{1}, \widetilde{s}_{1}\right)=0$ \\
\hline $\mathrm{R}_{3}$ & $P\left(r_{3}^{\prime} \mid r_{1}, \widetilde{r}_{4}\right)=0.81, P\left(r_{3}^{\prime} \mid \widetilde{r}_{1}, r_{4}\right)=0.84, P\left(r_{3}^{\prime} \mid r_{1}, r_{4}\right)=0.9696, P\left(r_{3}^{\prime} \mid \widetilde{r}_{1}, \widetilde{r}_{4}\right)=0$ \\
\hline $\mathrm{R}_{4}$ & $\begin{array}{l}P\left(r_{4}^{\prime} \mid r_{2}, \widetilde{r}_{3}\right)=0.81, P\left(r_{4}^{\prime} \mid \widetilde{r}_{2}, r_{3}\right)=0.84, P\left(r_{4}^{\prime} \mid r_{2}, r_{3}\right)=0.9696 \\
P\left(r_{4}^{\prime} \mid \widetilde{r}_{2}, \widetilde{r}_{3}\right)=0\end{array}$ \\
\hline $\mathrm{R}_{5}$ & $P\left(r_{5}^{\prime} \mid r_{3}\right)=0.81, P\left(r_{5}^{\prime} \mid \widetilde{r}_{3}\right)=0$ \\
\hline $\mathrm{R}_{6}$ & $\begin{array}{l}P\left(r_{6}^{\prime} \mid r_{4}, \widetilde{r}_{5}, \widetilde{e}\right)=0.81, P\left(r_{6}^{\prime} \mid \widetilde{r}_{4}, r_{5}, \widetilde{e}\right)=0.84, P\left(r_{6}^{\prime} \mid \widetilde{r}_{4}, \widetilde{r}_{5}, e\right)=0.60, \\
P\left(r_{6}^{\prime} \mid r_{4}, r_{5}, \widetilde{e}\right)=0.9696, P\left(r_{6}^{\prime} \mid r_{4}, \widetilde{r}_{5}, e\right)=0.924, P\left(r_{6}^{\prime} \mid \widetilde{r}_{4}, r_{5}, e\right)=0.936,\end{array}$ \\
\hline
\end{tabular}




\begin{tabular}{|c|c|}
\hline & $P\left(r_{6}^{\prime} \mid r_{4}, r_{5}, e\right)=0.98784, P\left(r_{6}^{\prime} \mid \widetilde{r}_{4}, \widetilde{r}_{5}, \widetilde{e}\right)=0$ \\
\hline $\mathbf{R}_{7}$ & $P\left(r_{7}^{\prime} \mid r_{5}\right)=0.81, P\left(r_{7}^{\prime} \mid \widetilde{r}_{5}\right)=0$ \\
\hline $\mathrm{E}$ & $\begin{array}{l}P\left(e^{\prime} \mid r_{7}, \widetilde{r}_{9}\right)=0.28, P\left(e^{\prime} \mid \widetilde{r}_{7}, r_{9}\right)=0.57, P\left(e^{\prime} \mid r_{7}, r_{9}\right)=0.6904 \\
P\left(e^{\prime} \mid \widetilde{r}_{7}, \widetilde{r}_{9}\right)=0\end{array}$ \\
\hline $\mathrm{R}_{8}$ & $P\left(r_{8}^{\prime} \mid r_{7}\right)=0.81, P\left(r_{8}^{\prime} \mid \widetilde{r}_{7}\right)=0$ \\
\hline $\mathbf{R}_{\mathbf{9}}$ & $\begin{array}{l}P\left(r_{9}^{\prime} \mid r_{8}, \widetilde{r}_{11}\right)=0.84, P\left(r_{9}^{\prime} \mid \widetilde{r}_{8}, r_{11}\right)=0.81, P\left(r_{9}^{\prime} \mid r_{8}, r_{11}\right)=0.9696 \\
P\left(r_{9}^{\prime} \mid \widetilde{r}_{8}, \widetilde{r}_{11}\right)=0\end{array}$ \\
\hline $\mathrm{R}_{10}$ & $P\left(r_{10}^{\prime} \mid r_{8}\right)=0.81, P\left(r_{10}^{\prime} \mid \widetilde{r}_{8}\right)=0$ \\
\hline $\mathrm{R}_{11}$ & $\begin{array}{l}P\left(r_{11}^{\prime} \mid r_{10}, \widetilde{s}_{2}\right)=0.84, P\left(r_{11}^{\prime} \mid \widetilde{r}_{10}, s_{2}\right)=0.60, P\left(r_{11}^{\prime} \mid r_{10}, s_{2}\right)=0.936 \\
P\left(r_{11}^{\prime} \mid \widetilde{r}_{10}, \widetilde{s}_{2}\right)=0\end{array}$ \\
\hline $\mathrm{S}_{2}$ & $P\left(s_{2}^{\prime} \mid r_{10}\right)=0.57, P\left(s_{2}^{\prime} \mid \widetilde{r}_{10}\right)=0$ \\
\hline
\end{tabular}

The probabilities of fire growth to fully-developed fire in the compartments without a suppression system and intervention

- $\quad 0.242^{[28]}$

- Stairwell, elevator shaft or duct 0.05

A statistical analysis of Canadian and US fire loss reported in paper ${ }^{[28]}$ shows that $24.2 \%$ of fires in office building grow to become fully developed fire. The probability of a flashover fire in the stairwell, elevator shaft or duct is assumed to be 0.05 as these areas typically have no significant amount of combustible materials. 
Using the barrier failure probability distributions in Table 4-1 and above probabilities of fire growth to fully-developed fire in compartments without suppression system and intervention, the probabilities of fire spread were calculated and are shown in Table 4-2 which shows the probabilities of success and failure of all events that fire spreads from a given fire compartment to its adjacent compartments resulting in fully developed fires in compartments. Using these values, the model computed the probability of fire spread from Room 1 to Room 6 to be $2.2 \times 10^{-2}$.

Table 4-2 Fire Spread Probability Distribution Tables without Intervention

\begin{tabular}{|c|c|}
\hline Node & Fire Spread Probability \\
\hline $\mathrm{R}_{1}$ & $P\left(r_{1}\right)=1, P\left(\widetilde{r}_{1}\right)=0$ \\
\hline $\mathrm{S}_{1}$ & $P\left(s_{1} \mid r_{1}\right)=0.0285, P\left(s_{1} \mid \widetilde{r}_{1}\right)=0$ \\
\hline $\mathrm{R}_{2}$ & $\begin{array}{l}P\left(r_{2} \mid r_{1}, \widetilde{s}_{1}\right)=0.20328, P\left(r_{2} \mid \widetilde{r}_{1}, s_{1}\right)=0.1452, P\left(r_{2} \mid r_{1}, s_{1}\right)=0.226512 \\
P\left(r_{2} \mid \widetilde{r}_{1}, \widetilde{s}_{1}\right)=0\end{array}$ \\
\hline $\mathrm{R}_{3}$ & $\begin{array}{l}P\left(r_{3} \mid r_{1}, \widetilde{r}_{4}\right)=0.19602, P\left(r_{3} \mid \widetilde{r}_{1}, r_{4}\right)=0.20328, P\left(r_{3} \mid r_{1}, r_{4}\right)=0.2346432 \\
P\left(r_{3} \mid \widetilde{r}_{1}, \widetilde{r}_{4}\right)=0\end{array}$ \\
\hline $\mathbf{R}_{4}$ & $\begin{array}{l}P\left(r_{4} \mid r_{2}, \widetilde{r}_{3}\right)=0.19602, P\left(r_{4} \mid \widetilde{r}_{2}, r_{3}\right)=0.20328, P\left(r_{4} \mid r_{2}, r_{3}\right)=0.2346432, \\
P\left(r_{4} \mid \widetilde{r}_{2}, \widetilde{r}_{3}\right)=0\end{array}$ \\
\hline $\mathrm{R}_{5}$ & $P\left(r_{5} \mid r_{3}\right)=0.19602, P\left(r_{5} \mid \widetilde{r}_{3}\right)=0$ \\
\hline $\mathrm{R}_{6}$ & $P\left(r_{6} \mid r_{4}, \widetilde{r}_{5}, \widetilde{e}\right)=0.19602, P\left(r_{6} \mid \widetilde{r}_{4}, r_{5}, \widetilde{e}\right)=0.20328, P\left(r_{6} \mid \widetilde{r}_{4}, \tilde{r}_{5}, e\right)=0.145$ \\
\hline
\end{tabular}




\begin{tabular}{|c|l|}
\hline & $\begin{array}{l}P\left(r_{6} \mid r_{4}, r_{5}, \widetilde{e}\right)=0.2346432, P\left(r_{6} \mid r_{4}, \widetilde{r}_{5}, e\right)=0.223608, \\
P\left(r_{6} \mid \widetilde{r}_{4}, r_{5}, e\right)=0.226512, P\left(r_{6} \mid r_{4}, r_{5}, e\right)=0.23905728, P\left(r_{6} \mid \widetilde{r}_{4}, \widetilde{r}_{5}, \widetilde{e}\right)=0\end{array}$ \\
\hline $\mathrm{R}_{7}$ & $P\left(r_{7} \mid r_{5}\right)=0.19602, P\left(r_{7} \mid \widetilde{r}_{5}\right)=0$ \\
\hline $\mathrm{E}$ & $\begin{array}{l}P\left(e \mid r_{7}, \widetilde{r}_{9}\right)=0.014, P\left(e \mid \widetilde{r}_{7}, r_{9}\right)=0.0285, P\left(e \mid r_{7}, r_{9}\right)=0.03452, \\
P\left(e \mid \widetilde{r}_{7}, \widetilde{r}_{9}\right)=0\end{array}$ \\
\hline $\mathrm{R}_{8}$ & $P\left(r_{8} \mid r_{7}\right)=0.19602, P\left(r_{8} \mid \widetilde{r}_{7}\right)=0$ \\
\hline $\mathrm{R}_{9}$ & $\begin{array}{l}P\left(r_{9} \mid r_{8}, \widetilde{r}_{11}\right)=0.20328, P\left(r_{9} \mid \widetilde{r}_{8}, r_{11}\right)=0.19602, P\left(r_{9} \mid r_{8}, r_{11}\right)=0.2346432, \\
P\left(r_{9} \mid \widetilde{r}_{8}, \widetilde{r}_{11}\right)=0\end{array}$ \\
\hline $\mathrm{R}_{10}$ & $P\left(r_{10} \mid r_{8}\right)=0.19602, P\left(r_{10} \mid \widetilde{r}_{8}\right)=0$ \\
\hline $\mathrm{R}_{11}$ & $\begin{array}{l}P\left(r_{11} \mid r_{10}, \widetilde{s}_{2}\right)=0.20328, P\left(r_{11} \mid \widetilde{r}_{10}, s_{2}\right)=0.1452, P\left(r_{11} \mid r_{10}, s_{2}\right)=0.226512, \\
P\left(r_{11} \mid \widetilde{r}_{10}, \widetilde{s}_{2}\right)=0\end{array}$ \\
\hline $\mathrm{S}_{2}$ & $P\left(s_{2} \mid r_{10}\right)=0.0285, P\left(s_{2} \mid \widetilde{r}_{10}\right)=0$ \\
\hline
\end{tabular}

\section{Case 2: when there is a sprinkler system installed in the building}

When a sprinkler system installed in the building, it is assumed that the effect of sprinkler on the probabilities of barrier failure between the various building elements is limited and the probabilities of barrier failure have the same values as in Case 1. But the sprinkler system will have a great impact on the values of probabilities of fire growth to fully-developed fire in compartments. 
The probabilities of fire growth to fully-developed fire in the compartments with a sprinkler system installed in the building

- Room $0.051^{[28]}$

- Stairwell, elevator shaft or duct 0.005

Using the barrier failure probability distributions in Table 4-1 and above probabilities of fire growth to fully-developed fire in the compartments with the intervention of sprinkler system, the probability of fire spread can be calculated and shown in Table 4-3. Using these probabilities in Table 4-3, the model computed the probability of fire spread from Room 1 to Room 6 to be $2.2 \times 10^{-4}$.

Table 4-3 Fire Spread Probability Distribution Tables with Sprinklers Installed

\begin{tabular}{|c|l|}
\hline Node & \multicolumn{1}{|c|}{ Fire Spread Probability } \\
\hline $\mathrm{R}_{1}$ & $P\left(r_{1}\right)=1, P\left(\widetilde{r}_{1}\right)=0$ \\
\hline $\mathrm{S}_{1}$ & $P\left(s_{1} \mid r_{1}\right)=0.00285, P\left(s_{1} \mid \widetilde{r}_{1}\right)=0$ \\
\hline $\mathrm{R}_{2}$ & $P\left(r_{2} \mid r_{1}, \widetilde{s}_{1}\right)=0.04284, P\left(r_{2} \mid \widetilde{r}_{1}, s_{1}\right)=0.0306, P\left(r_{2} \mid r_{1}, s_{1}\right)=0.047736$, \\
& $P\left(r_{2} \mid \widetilde{r}_{1}, \widetilde{s}_{1}\right)=0$ \\
\hline $\mathrm{R}_{3}$ & $P\left(r_{3} \mid r_{1}, \widetilde{r}_{4}\right)=0.04131, P\left(r_{3} \mid \widetilde{r}_{1}, r_{4}\right)=0.04284, P\left(r_{3} \mid r_{1}, r_{4}\right)=0.0494496$ \\
\hline $\mathrm{R}_{4}$ & $P\left(r_{3} \mid \widetilde{r}_{1}, \widetilde{r}_{4}\right)=0$ \\
& $P\left(r_{4} \mid r_{2}, \widetilde{r}_{3}\right)=0.04131, P\left(r_{4} \mid \widetilde{r}_{2}, r_{3}\right)=0.04284, P\left(r_{4} \mid r_{2}, r_{3}\right)=0.0494496$ \\
\hline
\end{tabular}




\begin{tabular}{|l|l|}
\hline $\mathrm{R}_{5}$ & $P\left(r_{5} \mid r_{3}\right)=0.04131, P\left(r_{5} \mid \widetilde{r}_{3}\right)=0$ \\
\hline $\mathrm{R}_{6}$ & $\begin{array}{l}P\left(r_{6} \mid r_{4}, \widetilde{r}_{5}, \widetilde{e}\right)=0.04131, P\left(r_{6} \mid \widetilde{r}_{4}, r_{5}, \widetilde{e}\right)=0.04284, P\left(r_{6} \mid \widetilde{r}_{4}, \widetilde{r}_{5}, e\right)=0.0306, \\
P\left(r_{6} \mid r_{4}, r_{5}, \widetilde{e}\right)=0.00494496, P\left(r_{6} \mid r_{4}, \widetilde{r}_{5}, e\right)=0.047124, \\
P\left(r_{6} \mid \widetilde{r}_{4}, r_{5}, e\right)=0.047736, P\left(r_{6} \mid r_{4}, r_{5}, e\right)=0.05037984, P\left(r_{6} \mid \widetilde{r}_{4}, \widetilde{r}_{5}, \widetilde{e}\right)=0\end{array}$ \\
\hline $\mathrm{R}_{7}$ & $P\left(r_{7} \mid r_{5}\right)=0.4131, P\left(r_{7} \mid \widetilde{r}_{5}\right)=0$ \\
\hline $\mathrm{E}$ & $\begin{array}{l}P\left(e \mid r_{7}, \widetilde{r}_{9}\right)=0.0014, P\left(e \mid \widetilde{r}_{7}, r_{9}\right)=0.00285, P\left(e \mid r_{7}, r_{9}\right)=0.003452, \\
P\left(e \mid \widetilde{r}_{7}, \widetilde{r}_{9}\right)=0\end{array}$ \\
\hline $\mathrm{R}_{8}$ & $P\left(r_{8} \mid r_{7}\right)=0.04131, P\left(r_{8} \mid \widetilde{r}_{7}\right)=0$ \\
\hline $\mathrm{R}_{9}$ & $\begin{array}{l}P\left(r_{9} \mid r_{8}, \widetilde{r}_{11}\right)=0.04284, P\left(r_{9} \mid \widetilde{r}_{8}, r_{11}\right)=0.04131, P\left(r_{9} \mid r_{8}, r_{11}\right)=0.0494496, \\
P\left(r_{9} \mid \widetilde{r}_{8}, \widetilde{r}_{11}\right)=0\end{array}$ \\
\hline $\mathrm{R}_{10}$ & $P\left(r_{10} \mid r_{8}\right)=0.04131, P\left(r_{10} \mid \widetilde{r}_{8}\right)=0$ \\
\hline $\mathrm{R}_{11}$ & $\begin{array}{l}P\left(r_{11} \mid r_{10}, \widetilde{s}_{2}\right)=0.04284, P\left(r_{11} \mid \widetilde{r}_{10}, s_{2}\right)=0.0306, P\left(r_{11} \mid r_{10}, s_{2}\right)=0.047736 \\
P\left(r_{11} \mid \widetilde{r}_{10}, \widetilde{s}_{2}\right)=0\end{array}$ \\
\hline $\mathrm{S}_{2}$ & $P\left(s_{2} \mid r_{10}\right)=0.00285, P\left(s_{2} \mid \widetilde{r}_{10}\right)=0$ \\
\hline
\end{tabular}




\section{Chapter 5}

\section{Dynamic Modeling of Fire Spread in Buildings}

\subsection{Fundamentals of Dynamic Bayesian Network ${ }^{[16,17,18]}$}

Bayesian network can not model temporal relationships among variables since Bayesian network does not provide the mechanism for representing temporal dependencies. Therefore, it can not represent how the value of some variables may be related to their values and the values of other variables at a previous point in time. But time is a critical factor in modeling the fire spread process in a building because the fire severity in the fire room and the fire resistance of the barrier are functions of time. To capture the dynamic aspects of the problem, dynamic Bayesian network (DBN) is used to build the dynamic fire spread model of buildings.

Let $\mathbf{X}=\left\{\mathrm{X}_{1}, \mathrm{X}_{2}, \ldots, \mathrm{X}_{\mathrm{m}}\right\}$ denote the variables in a Bayesian network. Assume that the variables in $\mathbf{X}$ are ordered ancestrally, or in a topological ordering. That is for every node $X_{l} \in \mathbf{X}$; the index of its ancestor $X$, has the property $j<i$. A dynamic Bayesian network is a Bayesian network with explicitly represented temporal variables. A DBN structure can be treated as having two dimensions: the time line and the variable line, represented in Figure 5-1 on the horizontal axis and vertical axis respectively. On the time line, the time mission $T$ (from $t_{0}=0$ to $t_{n}=T$ ) is divided into $n$ intervals. Each time 
step $\left(t_{0}, t_{1}, t_{2}, \ldots t_{n}\right)$ is called a time-slice. The relationships between variables in the same time slice are represented by the intra-slice arcs. The edges representing the relationships between variables in the different time slices are called inter-slice arcs or temporal arcs. Each variable on the time line forms a sequence $\mathbf{X}_{\mathbf{i}}(t)=\left\{\mathrm{X}_{1}\left(\mathrm{t}_{0}\right), \mathrm{X}_{1}\left(\mathrm{t}_{1}\right), \ldots\right.$, $\mathrm{X}_{1}\left(\mathrm{t}_{\mathrm{n}}\right)$ \} called a temporal variable sequence. The temporal variables measured at the same time slice form a contemporaneous variable set $\mathbf{X}\left(\mathrm{t}_{1}\right)=\left\{\mathrm{X}_{1}\left(\mathrm{t}_{1}\right), \mathrm{X}_{2}\left(\mathrm{t}_{1}\right), \ldots, \mathrm{X}_{\mathrm{m}}\left(\mathrm{t}_{1}\right)\right\}$.

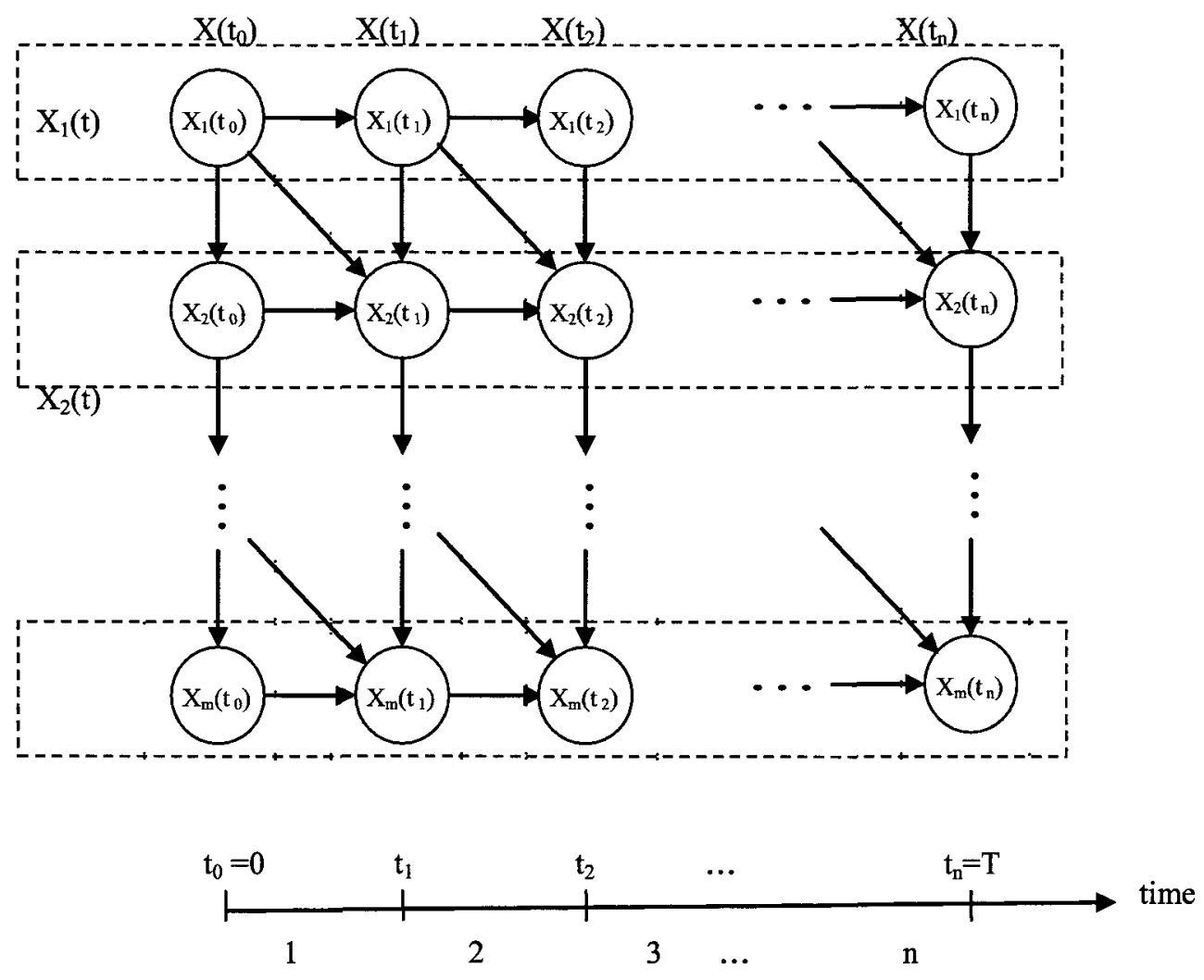

Figure 5-1 A DBN with first-order Markov property

The joint probability distribution of $\mathrm{DBN}$ over all variables can be stated as 


$$
\begin{aligned}
& P\left(X\left(t_{0}\right), X\left(t_{1}\right), X\left(t_{2}\right), \cdots X\left(t_{n}\right)\right)= \\
& P\left(X\left(t_{0}\right)\right) \cdot P\left(X\left(t_{1}\right) \mid X\left(t_{0}\right)\right) \cdot \\
& P\left(X\left(t_{2}\right) \mid X\left(t_{0}\right), X\left(t_{1}\right)\right) \cdots P\left(X\left(t_{n}\right) \mid X\left(t_{0}\right), X\left(t_{1}\right), X\left(t_{2}\right), \cdots, X\left(t_{n-1}\right)\right)
\end{aligned}
$$

Assume that the time slices are so chosen that the states of the DBN satisfy the Markov condition; that is, the state of a DBN at time $t_{i}$ depends only on its immediate past state (the state at time $t_{i-1}$ ). Therefore, the state of a variable of a DBN at time $t_{i}$ depends on its previous state at time $t_{i-1}$ and the current states of its parent's variables of the DBN at time $t_{i}$. Then the joint probability distribution of DBN over all variables can be written as

$$
P\left(X\left(t_{0}\right), X\left(t_{1}\right), X\left(t_{2}\right), \cdots X\left(t_{n}\right)\right)=P\left(X\left(t_{0}\right)\right) \cdot \sum_{i=1}^{n} P\left(X\left(t_{i}\right) \mid X\left(t_{i-1}\right)\right)
$$
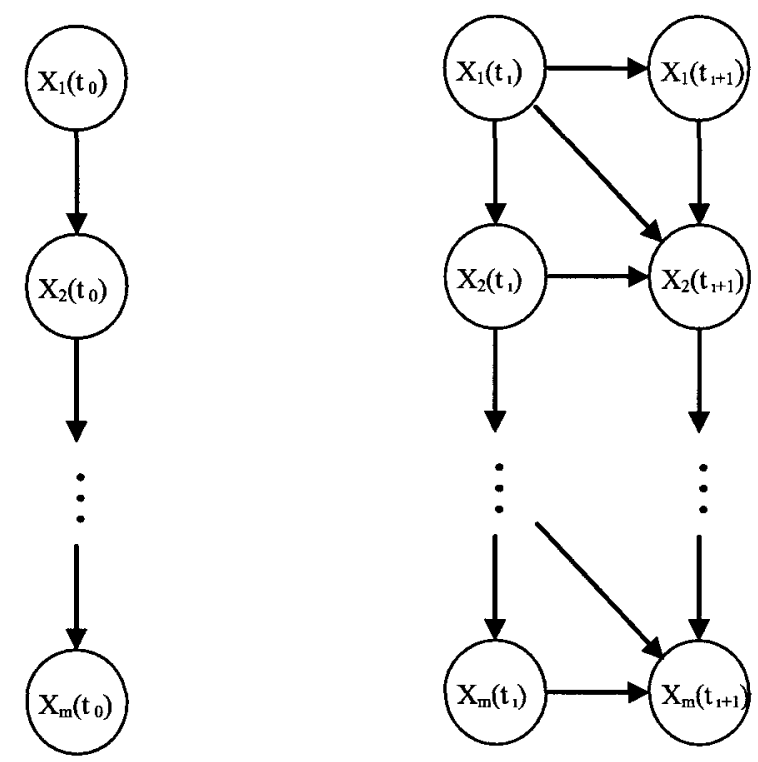

(a) The prior network

(b) The transition network $\boldsymbol{G}$,

Figure 5-2 The prior network and transition network 
In Figure 5-2, there is a transition network $\boldsymbol{G}_{\rightarrow}$ containing the variables in $X\left(t_{t}\right) \cup X\left(t_{t+1}\right)$. Its transition probability distribution is

$$
P_{\rightarrow}\left(X\left(t_{j+1}\right) \mid X\left(t_{j}\right)\right)=\prod_{j=1}^{m-1} P_{\rightarrow}\left(X_{j}\left(t_{j+1}\right) \mid p a\left(X_{j}\left(t_{j+1}\right)\right)\right)
$$

Where $\mathbf{p a}\left(\mathrm{x}_{\mathrm{J}}\left(\mathrm{t}_{1+1}\right)\right)$ denotes the value of the parent node set of $\mathrm{x}_{\mathrm{J}}\left(\mathrm{t}_{1+1}\right)$.

\subsection{Dynamic Fire Spread Model in a Building}

The dynamic fire spread model in a building is based on the static fire spread model using Bayesian network derived in chapter of this thesis ${ }^{[19]}$. To simplify the problem, the following assumptions are made.

\subsubsection{Basic Assumptions for Dynamic Fire Spread Model}

- Fire spread in the building is subjected to the Markov condition. That is the state of a variable of a DBN at time $t_{1}$ depends on its previous state at time $t_{1-1}$ and the current states of its parent's variables of the DBN at time $t_{1}$.

- If a fully-developed fire has occurred in a compartment, fire can not return to the compartment that has already burnt out since there are no combustibles in this compartment to support fire ignition and fire growth.

- Once ignition occurs in a compartment, fire will develop in this compartment independently; that is the fire development in a compartment will not be subjected to the influence of the fire conditions in its adjacent compartments. 
- Fire in a compartment can only spread to its adjacent compartments in the horizontal direction and adjacent compartments on the upper floor; it is assumed that fire spread to compartments on the lower floor can be ignored.

- The probability of fire spread from a corridor to adjacent compartments can be ignored since the fuel density in the corridor is low. Therefore the duration of a fully-developed fire is not long enough for heat to penetrate the barrier to an adjacent compartment and ignite the combustible inside.

- When two compartments are separated just by an open door, open window or there is no barrier between them, if flashover occurs in one of the compartments, the fire will immediately spread to the other compartment. For a large compartment such as a hall in a building, the large compartment can be considered consisting of several virtual compartments without boundary barriers between them.

- When the doors of two compartments are separated by a corridor, the fire can spread from the fire compartment to the other compartment opposite the corridor through the doors of these two compartments by radiation heat flux from the hot gases in the corridor or in the room. If the door of a compartment is far away from the position perpendicular to the door of fire compartment, the radiant heat flux from the fire compartment could be too small to ignite the combustible materials in other compartment since the two doors could be diagonally far away from each other across the corridor. 
- If flashover could occur in a compartment such as stairwell, elevator shaft, or duct, the fire would immediately spread to its upper compartment.

- The common glass of windows in a compartment is assumed to break and fall off once flashover occurs in the compartment.

\subsubsection{The Probability of Fire Spread}

Fire spread from the fire compartment to its adjacent compartment includes two processes:

(a) Heat overcomes the fire resistance of the barrier between the two compartments, is transferred to the adjacent compartment, and ignites combustible material inside it.

(b) After ignition, the fire in the adjacent compartment could grow to a fullydeveloped fire.

Therefore, the probability of fire spread from compartment B to compartment A could be written as

$$
\boldsymbol{P}(\boldsymbol{a} \mid \boldsymbol{b})=\boldsymbol{P}\left(\boldsymbol{a} \mid \boldsymbol{a}^{\prime}\right) \boldsymbol{P}\left(\boldsymbol{a}^{\prime} \mid \boldsymbol{b}\right) \boldsymbol{P}(\boldsymbol{b})
$$

Where:

$P(a \mid b)=$ The probability of fire spread from compartment B to compartment A $P(b)=$ The probability of a fully-developed fire occurred in compartment B. 
$P\left(a^{\prime} \mid b\right)=$ The probability of barrier failure indicating the probability that heat is transferred from the fire compartment B to the adjacent compartment A and ignites the combustible materials in compartment $\mathrm{A}$. $P\left(a \mid a^{\prime}\right)=$ The probability of fire growth from ignition to a fully-developed fire in compartment A.

In this thesis, it is assumed that both the probability of barrier failure and the probability of fire growth to a fully-developed fire follow the properties of a normal distribution $(\mu, \sigma)$. The purpose of this assumption is only to show one kind of calculation of the cumulative probability of barrier failure and the probability of fire growth to a fullydeveloped fire both of which are needed in the fire spread dynamic model. If the probability of barrier failure and the probability of fire growth to a fully-developed fire follow another kind of probability distribution, the results of the cumulative probability of barrier failure and the probability of fire growth to a fully-developed fire could also be used as inputs in the fire spread dynamic model.

The means and standard deviations of the probability of barrier failure and the probability of fire growth could change according to different properties of buildings and other factors such as the presence of a fire suppression system.

- The probabilities of barrier failure mainly depend on the severity of fire and structures, materials and geometry of the building; 
- The probabilities of fire growth to a fully-developed fire mainly depend on fuel load, ventilation, duration of the fully-developed fire phase and on whether fire suppression systems are installed or not.

If a room has several adjacent fire compartments, heat could be transferred to this room simultaneously from all adjacent fire compartments, which will increase the probability of ignition of the combustible materials in the room considering the interaction of heat transfer to this room from more than one barrier. Assume the compartment A has two adjacent fire compartments $B$ and $C$. The probability of fire spread to compartment $A$ due to fire compartments $\mathrm{B}$ and $\mathrm{C}$ is

$$
\begin{aligned}
& P(a \mid b, c)=P\left(a \mid a^{\prime}\right) P\left(a^{\prime} \mid b, \bar{c}\right) P(b) P(\bar{c})+P\left(a \mid a^{\prime}\right) P\left(a^{\prime} \mid \bar{b}, c\right) P(\bar{b}) P(c)+ \\
& P\left(a \mid a^{\prime}\right) P\left(a^{\prime} \mid b, c\right) P(b) P(c)
\end{aligned}
$$

\subsubsection{The probability of barrier failure}

There are four principal ways by which fire spreads between compartments.

- Radiation through a window. If two windows are aligned vertically and the flame projecting out of the lower window is high enough to reach to the window of the compartment on the upper floor, fire may spread to the upper compartment.

- Conduction through a wall, ceiling or closed door.

- Convection through an open door, or window. For example, if the door connecting two rooms is open, the fire would spread to the other room immediately after flashover occurs in one of the rooms. 
- Radiation and convection between rooms connected by a corridor.

The probability density function of barrier failure at the time $t$ can be written as

$$
p_{b f}(t)=\frac{1}{\sigma_{b f} \sqrt{2 \pi}} \exp \left(-\left[\left(t-t_{f o}\right)-\mu_{b f}\right]^{2} / 2 \sigma_{b f}^{2}\right)
$$

The cumulative probability of barrier failure at time $t$ is

$$
P_{b f}(t)=\int_{t_{f o}}^{t} \frac{1}{\sigma_{b f} \sqrt{2 \pi}} \exp \left(-\left[\left(t-t_{f o}\right)-\mu_{b f}\right]^{2} / 2 \sigma_{b f}^{2}\right) d t \quad\left(0 \leq t-t_{f o} \leq \tau_{f d}\right)
$$

Where:

$t_{f o}=$ The time of flashover in fire compartment;

$\mu_{b f}=$ The mean time of failure of a barrier linking the fire compartment to an adjacent compartment;

$\sigma_{b f}=$ The standard deviation time of failure of a barrier linking the fire compartment to an adjacent compartment;

$\tau_{f d}=$ The duration of the fully-developed fire phase in the fire compartment.

- The calculation of the time of barrier failure

Mehaffey ${ }^{[30]}$ used a Japanese fire model to assess the fire resistance of assemblies exposed to a post-flashover fire by expressing the severity of the fire in terms of the standard ISO 834 fire. The duration of the standard ISO 834 fire that is equivalent in severity to the duration of the fully developed ventilation controlled fire is

$$
\tau_{e q}=\left(\frac{\beta}{230}\right)^{3 / 2} \tau_{f d}
$$

Where: 
$\tau_{e q}=$ The equivalent duration of the standard fire test in severity;

$\tau_{f d}=$ Duration of the fully developed ventilation controlled fire;

$\beta=$ Parameter of the Japanese parametric model for compartment boundaries, $\left(K s^{-1 / 6}\right)$

The parameter $\beta$ of the Japanese Parametric model could be written as

$$
\begin{aligned}
& \beta=3.0 T_{0}\left(\frac{A_{o} \sqrt{H_{o}}}{A_{T} \sqrt{k \rho c}}\right)^{1 / 3} \\
& A_{T} \sqrt{k \rho c}=\sum_{i} A_{T, i} \sqrt{k_{i} \rho_{i} c_{i}} \\
& A_{o} \sqrt{H_{o}}=\sum_{i} A_{o, i} \sqrt{H_{o, i}}
\end{aligned}
$$

Where:

$$
\begin{aligned}
& \mathrm{k}_{\mathrm{i}}=\text { Thermal conductivity of boundary material } \mathrm{i}, \mathrm{kW} /(\mathrm{m} \cdot \mathrm{K}) ; \\
& \rho_{\mathrm{i}}=\text { Density of the boundary material } \mathrm{i}, \mathrm{kg} / \mathrm{m}^{3} ; \\
& \mathrm{c}_{\mathrm{i}}=\text { Specific heat of the boundary material } \mathrm{i}, \mathrm{kJ} /(\mathrm{kg} \cdot \mathrm{K}) .
\end{aligned}
$$

In fire safety design, usually the fire resistance ratings of assemblies tested to the standard ISO 834 fire are prescribed by the building codes. From this, the fire resistance of the assembly to fully-developed fire can be calculated by

$$
\tau_{b f, i}=\frac{\tau_{F R R, i}}{\left(\frac{\beta}{230}\right)^{3 / 2}}
$$

Where:

$\tau_{F R R, i}=$ Duration of fire-resistance ratings to the standard ISO 834 fire for assembly $\mathrm{i}$; 
$\tau_{b f, i}=$ Duration of fire-resistance to a fully-developed fire for assembly $\mathrm{i}$.

Based on Equation (5.12), the mean and standard deviation of the fire resistance to a fully developed compartment fire for the assembly could be calculated

$$
\begin{aligned}
& \mu_{b f, i}=\frac{\mu_{F R R, i}}{\left(\frac{\beta}{230}\right)^{3 / 2}} \\
& \sigma_{b f, i}=\frac{\sigma_{F R R, i}}{\left(\frac{\beta}{230}\right)^{3 / 2}}
\end{aligned}
$$

Where:

$\mu_{F R R, i}=$ Mean of the duration of fire resistance ratings to the standard ISO 834 fire for assembly i;

$\sigma_{F R R, i}=$ Standard deviation of the duration of fire resistance ratings to the standard ISO 834 for assembly i;

$\mu_{b f, i}=$ Mean of the duration of fire resistance to a fully developed compartment fire for assembly $\mathrm{i}$;

$\sigma_{b f, i}=$ Standard deviation of the duration of fire resistance to a fully developed compartment fire for assembly $\mathrm{i}$;

\subsubsection{Probability of fire growth to a fully-developed fire}

Once ignition occurs in a compartment, the fire may grow up to a fully developed fire. The probability of fire growth to a fully-developed fire depends on the following factors:

(a) The fuel load: fuel amount and fuel types in the compartment;

(b) The geometry of the compartment and its ventilation conditions; 
(c) The availability of a fire suppression system.

If the maximum heat release rate of the fire in a compartment during the fire growth phase is less than the critical value for flashover in the compartment; that is $\alpha\left(\tau_{g r}^{\max }\right)^{2}$ $<750 \mathrm{~A}_{\mathrm{o}} \sqrt{\mathrm{H}_{\mathrm{o}}}$, flashover would never occur in the compartment. Therefore, the probability of fire growth to a fully-developed fire in the compartment is zero. Otherwise, flashover can occur in the compartment. The density function of the probability of fire growth to a fully-developed fire in the compartment at time $t$ is

$$
p_{f d}(t)=\frac{1}{\sigma_{f o} \sqrt{2 \pi}} \exp \left(-\left[\left(t-t_{i g}\right)-\mu_{f o}\right]^{2} / 2 \sigma_{f o}^{2}\right)
$$

The cumulative probability of fire growth to a fully-developed fire at time $t$ can be calculated by equations below.

- When flashover does not occur in the compartment

$$
\begin{array}{ll}
P_{f d}(t)=\int_{t_{i g}}^{t} \frac{1}{\sigma_{f o} \sqrt{2 \pi}} \exp \left(-\left[\left(t-t_{i g}\right)-\mu_{f o}\right]^{2} / 2 \sigma_{f o}^{2}\right) d t & \left(0 \leq t-t_{i g} \leq \tau_{g r}^{\max }\right) \\
P_{f d}(t)=0 & \text { Otherwise }
\end{array}
$$

- When flashover occurs in the compartment

$$
\begin{array}{ll}
P_{f d}(t)=\int_{t_{i g}}^{t} \frac{1}{\sigma_{f o} \sqrt{2 \pi}} \exp \left(-\left[\left(t-t_{i g}\right)-\mu_{f o}\right]^{2} / 2 \sigma_{f o}^{2}\right) d t \quad\left(0 \leq t-t_{i g} \leq \tau_{g r}+\tau_{f d}\right) \\
P_{f d}(t)=0 & \text { Otherwise }
\end{array}
$$

Where: 
$t_{i g}=$ Ignition time in the compartment;

$\mu_{f o}=$ Mean of duration for fire to develop from ignition to flashover in the compartment;

$\sigma_{f o}=$ Standard deviation of duration for fire to develop from ignition to flashover;

$\tau_{g r}^{\max }=$ The maximum duration of fire growth phase in the compartment;

$\tau_{g r}=$ Duration of fire growth phase in the compartment.

The calculation of the mean time and standard deviation for fire to develop from ignition to flashover in the compartment

$$
\begin{aligned}
& \mu_{f o}=\sqrt{\frac{750 \mathrm{~A}_{0} \sqrt{\mathrm{H}_{0}}}{\mu_{\alpha}}} \\
& \sigma_{f o}=\sqrt{\frac{750 \mathrm{~A}_{0} \sqrt{\mathrm{H}_{0}}}{\mu_{\alpha}^{2}}} \sigma_{\alpha}
\end{aligned}
$$

Where:

$$
\begin{aligned}
& \mu_{\alpha}=\text { Mean of the fire growth coefficient for } \mathrm{at}^{2} \text { fire; } \\
& \sigma_{\alpha}=\text { Standard deviation of the fire growth coefficient for a } \mathrm{t}^{2} \text { fire. }
\end{aligned}
$$

\subsubsection{Establish the Dynamic Fire Spread Model}

In large buildings, fire may spread between compartments simultaneously in both horizontal and vertical directions. To simplify the fire spread model, fire spread model in the horizontal direction and fire spread model in the vertical direction are described separately. A detailed description of the application of Bayesian network to simulate fire 
spread from the compartment of fire origin (Room 1 on the first floor) to a destination compartment (Room 6 on second floor) in a two-storey office building is presented. Also presented are the general algorithms for the dynamic fire spread model that calculate the probabilities of fire spread in a building.

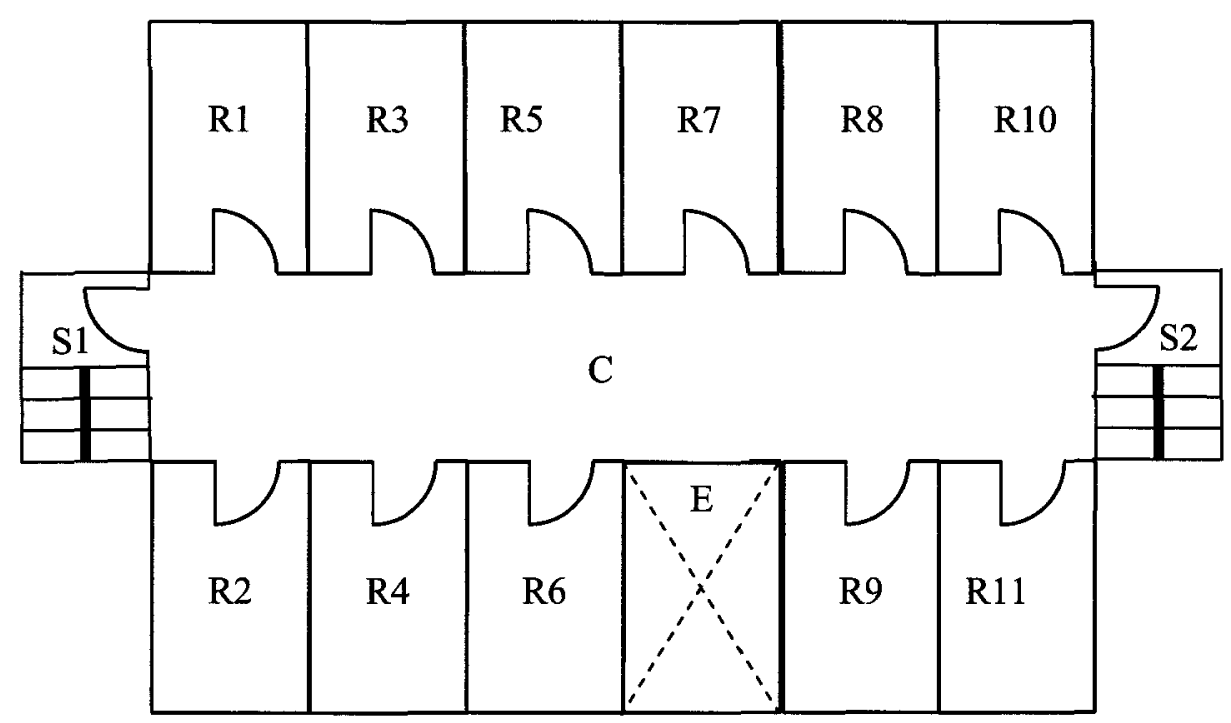

Figure 5-3 Floor plan of an office building

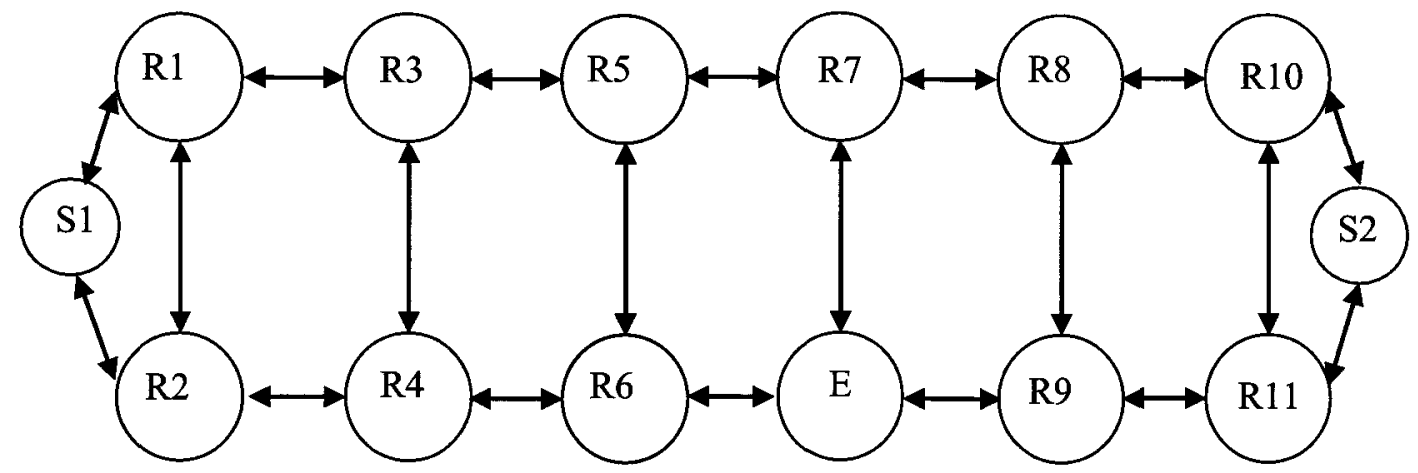

Figure 5-4 General model of fire spread of the building floor 


\subsubsection{Fire spread in the horizontal direction on a building floor}

The floor plan of an office building with two-storey is shown in Figure 5-3. Ignoring the influence of the corridor on fire spread by assuming there is little fuel in the corridor, the general fire spread model of the building floor can be expressed as shown in Figure 5-4. The arrows in both directions in the network mean that the general fire spread model can deal with all the possible fire spread situations for any fire scenario. Once the compartment of fire origin is given, the general fire spread network can be immediately converted into a specific fire spread Bayesian network which can be used to calculate the probability of fire spread from the initial fire compartment to a destination compartment on that floor. A specific example of a fire spread model based on Bayesian network is described below.

To calculate the probability of fire spread from the compartment of fire origin (R1) to the destination compartment (R6), all possible pathways by which fire can spread from R1 to R6 need to be found. The fire spread paths can be found using the directed acyclic graph (DAG) of the fire spread Bayesian network as shown in Figure 4-5. 


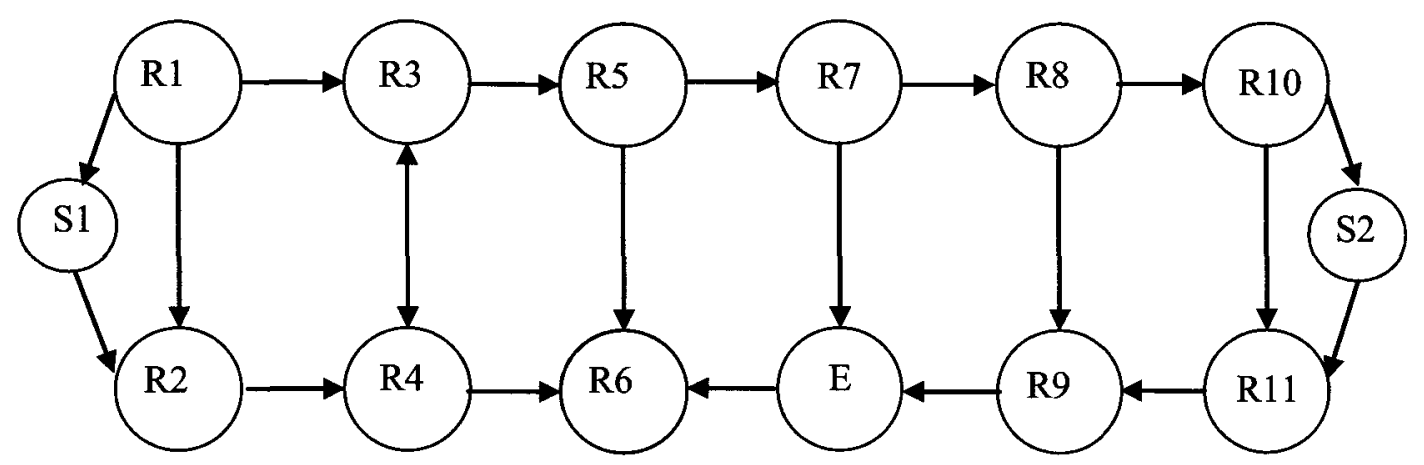

Figure 5-5 The DAG of e Bayesian Network for fire to spread from room 1 to room 6

\subsubsection{Fire spreads in the vertical direction in a building}

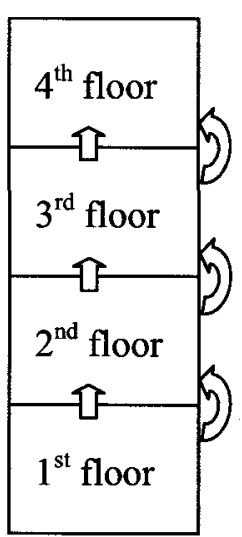

(a)

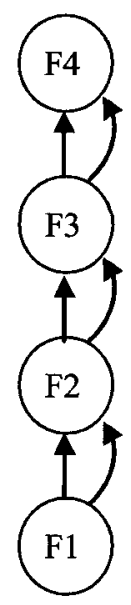

(b)

Figure 5-6 (a) A building with four storey (b) The DAG of vertical fire spread network of the building

Assume that there is a four-storey building with only one compartment on each floor as shown in Figure 5-6 (a). If a fire starts in a room on the first floor, the network for fire 
spread in the vertical direction can be expressed as in Figure 5-6(b). The fire could spread to the upper floors by two possible pathways,

- by conduction, heat transfer to the above compartment through the ceiling;

- by radiation and convection, heat transfer to the above compartment through a window due to the external flame projected out of a window in the fire compartment.

\subsubsection{Fire spread model of buildings in both horizontal and vertical directions}

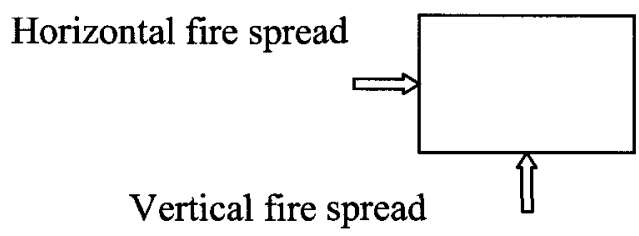

Figure 5-7 Fire spread to a compartment horizontally and vertically

A fire could spread to a compartment simultaneously in both the horizontal and vertical directions as shown in Figure 5-7. The calculation of the probability of fire spread to a compartment must consider the interaction among the probabilities of barrier failure when heat is transferred to the compartment horizontally from adjacent compartments and vertically from the compartment on the lower floor through the ceiling or window. 
For the two-storey office building shown in Figure 5-3, assume that there is a fire in room $\mathrm{R} 1$ on the first floor. We want to determine the probability of fire spread from $\mathrm{R} 1$ to room R6 on the second floor. First the general fire spread compartment network (DAG) for the building has to be converted into a specific Bayesian network as shown in Figure 5-8. To simplify the problem, it is assumed that the probability of barrier failure in the vertical direction for every room has the same density distribution. Then in this model, every floor will have the same DAG of Bayesian network. Based on the Bayesian network of Figure 5-8, the probability of fire spread at each time slice from the compartment of fire origin room $\mathrm{R} 1$ on the first floor to the room R6 on the second floor can be calculated by using the algorithm of the dynamic fire spread model described below.

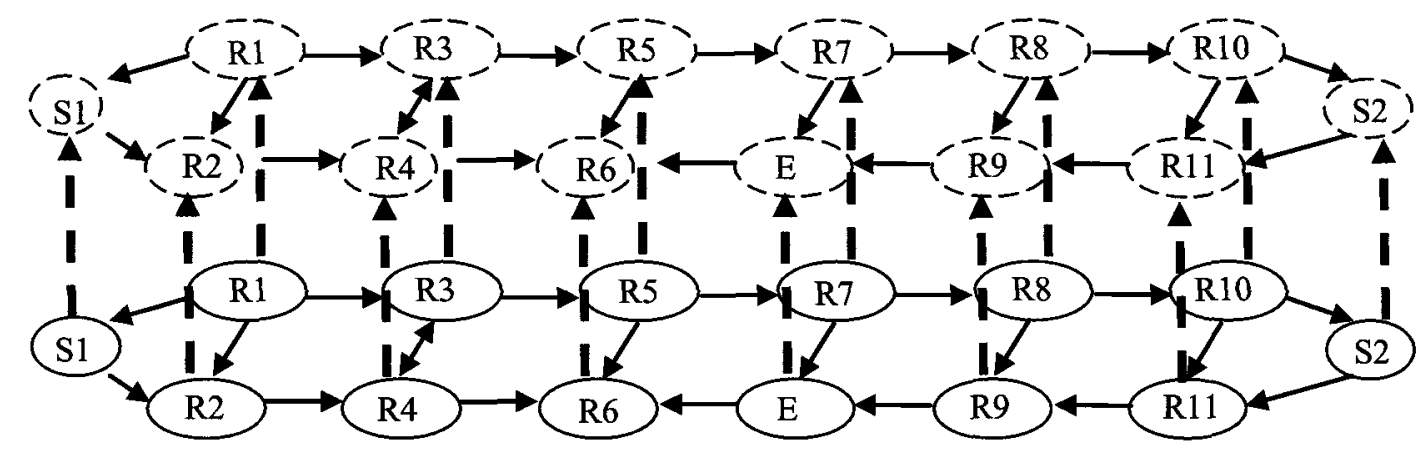

Figure 5-8 Bayesian network of fire spread from room $R 1$ on the first floor to room $R 6$ on the second floor 


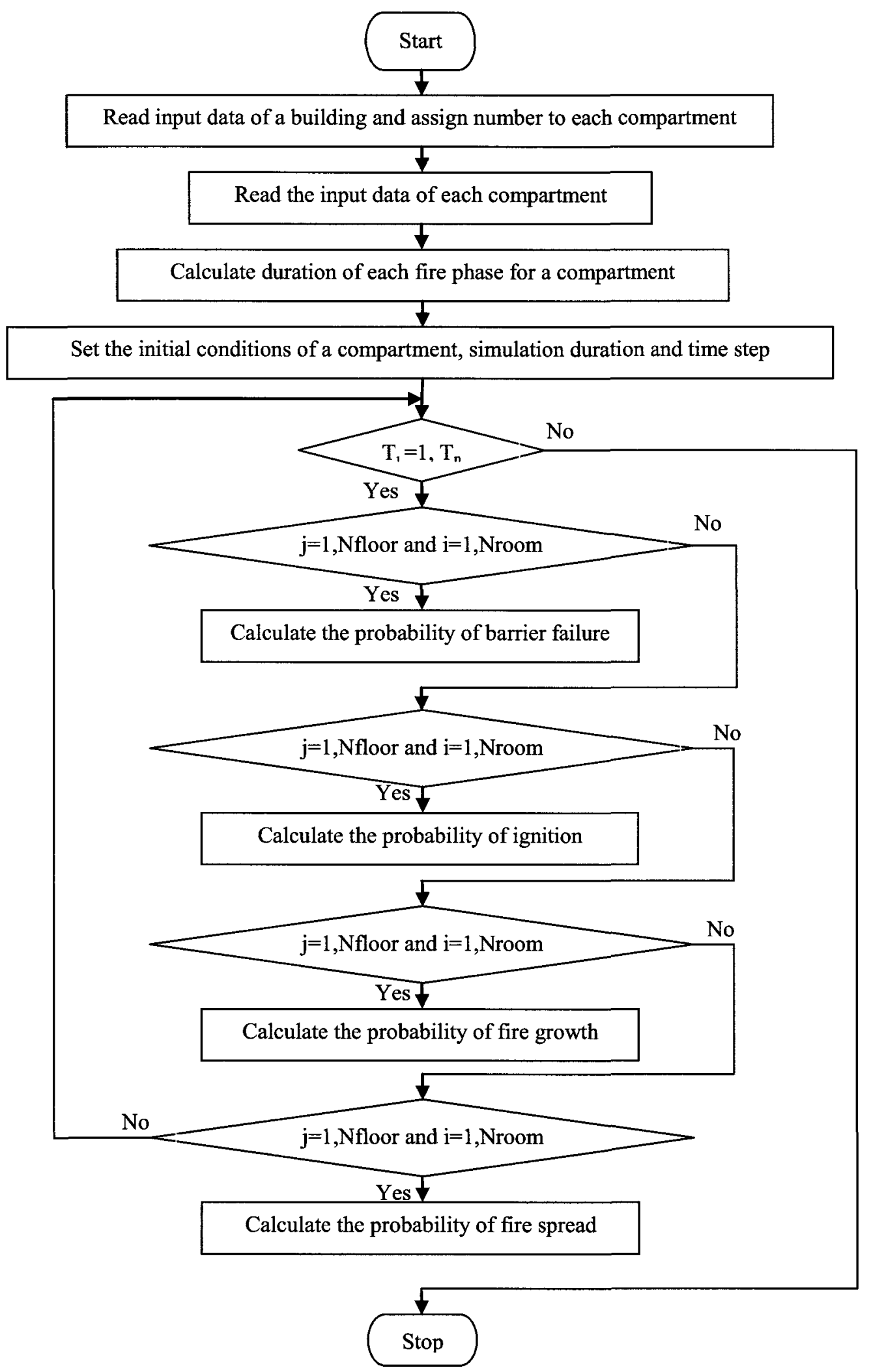

Figure 5-9 Flow char of dynamic Bayesian network 


\subsubsection{Algorithm for Dynamic Fire Spread Model of Bayesian Network}

The flow chart for modeling dynamic fire spread in buildings based on dynamic Bayesian network is shown in Figure 5-9. The algorithm for the dynamic fire spread in buildings based on dynamic Bayesian network which can be used to calculate the dynamic probability of fire spread and fire spread simulation in the building, is described in Figure 5-9 and Table 5-1.

Table 5-1 Algorithm for dynamic fire spread model

1. Set the initial conditions for the compartments and input data for the dynamic fire spread model

Total simulation time $t_{n}=\mathrm{T}$, each simulation time step $\mathrm{dt}=\mathrm{T} / \mathrm{n}$

Set a very large time number $=2 \mathrm{~T}$

1) Assign a room number to each compartment

2) Initial setting for all compartments

$P_{t g}(i, j)=0, t_{t g}=\Xi ; P_{f o}\left(t_{t}\right)=0, t_{f o}= \pm$ No fire (dormant phase)

3) Input initial condition of compartment of fire origin

i. $\quad P_{t g}(i, j)=1, t_{t g}=0 ; P_{f o}\left(t_{t}\right)=1, t_{f o}=0$ Assume flashover occurs in fire compartment

ii. $P_{\imath g}(i, j)=1, t_{t g}=0 ; P_{f o}\left(t_{t}\right)=0, t_{f o}=$ if only ignition occurs in compartment and no flashover occurs 
4) Calculate the duration of fire burning for all compartments

i. duration of fire growth phase

ii. duration of fully-developed fire phase

2. Simulation at time slice $t_{t}\left(t_{0} \leq t_{t} \leq t_{n}\right)$

2.1. Calculate the probability of barrier failure from the fire compartment to its adjacent compartments

1) Loop through all floors: $\mathrm{j}=1$, the total number of floors in the building (Nfloor)

2) Loop through all compartments: $i=1$, the total number of compartments in a floor (Nroom)

3) Check whether a fully-developed fire occurs in compartment $(i, j)$;

a) if $t_{f o}(i, j)>t_{i}$, flashover did not occur in compartment $(i, j)$, go to next $\mathrm{i}$;

b) if $t_{i}-t_{f o}(i, j)>\tau_{f d}(i, j)$, decay occurred in compartment $(i, j)$, go to next i;

4) if $0<t_{i}-t_{f o}(i, j)<\tau_{f d}(i, j)$, then calculate the cumulative probability of barrier failure between this compartment $(i, j)$ and its adjacent compartments at time $t_{\imath}$ in the horizontal direction (same floor $\mathrm{j}$ )

a) Loop through all compartments: $\mathrm{k}=1$, the total number of compartments in a floor 
b) Check whether there is a barrier linking compartment $i$ and $k$
c) If no, next $\mathrm{k}$
d) If yes; check whether decay occurred in the adjacent compartment $(k, j)$, $t_{i}-t_{f o}(k, j)>\tau_{f d}(k, j)$. If yes, next $\mathrm{k}$

e) If no $\left(t_{i}-t_{f o}(k, j)<\tau_{f d}(k, j)\right)$, check kind of barrier linking compartments

f) Calculate the cumulative probability of barrier failure $P_{b f}(k, i, j)$ due to fire spread from compartment $i$ to compartment $k$ using equation (5.7)

g) go to next barrier $\mathrm{k}$

5) Calculate the cumulative probability of fire ignition in compartment (i,j) due to fire spread from its adjacent compartments in the vertical direction $P_{b f}(0, i, j+1)$

a) Check whether it is the top floor of the building $j=\mathrm{Nfloor}$

b) If no, then check whether flashover occurred in the adjacent compartment on the floor above

c) If no, then check the kind of barrier between the two compartments

d) If Vlink $(\mathrm{i}, \mathrm{j})=0$ (there is no barrier between the two compartments), $P_{b f}(0, i, j+1)=1$ next i

e) Calculate the cumulative probability of barrier failure (ceiling) $P_{b f}(0, i, j+1)$ due to fire spread from compartment $(i, \mathrm{j})$ to the 
compartment above $(\mathrm{i}, \mathrm{j}+1)$ at time $t_{t}$ through the ceiling using equation (5.7)

f) If $\operatorname{Vlink}(i, j)=1$ (heat transfer through the ceiling only) next $i$

g) If HFlame $(\mathrm{i}, \mathrm{j})<\mathrm{H}(\mathrm{i}, \mathrm{j})$ (flame height above window $<$ separation distance between the two windows in the vertical direction), next $\mathrm{i}$

h) If Vlink $(i, j)=2$ (flame height above window $>$ separation distance between the two windows in the vertical direction), calculate $\mathrm{P}_{\mathrm{bf}}$ (the cumulative probability of barrier failure due to heat transfer to the above compartment through a closed window) using equation (5.7),

i) then calculate total probability of barrier failure $P_{b f}(0, i, j+1)=$ $P_{b f}(0, i, j+1)+P-P_{b f}(0, i, j+1) \times P$, next i

j) If Vlink $(i, j)=3$ (flame height above window $>$ separation distance between the two windows in the vertical direction), $P_{b f}(0, i, j+1)=1$ (heat transfer to above compartment through open window)

6) Next i

7) Next j

2.2. Calculate the probability of fire ignition $P_{v g}(i, j)$

1) Loop through all floors: $j=1$, the total number of floors in the building

2) Loop through all compartments: $i=1$, the total number of compartments in 


\section{a floor}

3) If flashover $t_{i}>t_{f o}(i, j), P_{i g}(i, j)=1$ go to next compartment $\mathrm{i}$

4) Else $P_{i g}(i, j)=P_{b f}(0, i, j) \times P(i, j-1)$

5) Include the probability of fire ignition in the compartment due to fire spread from the adjacent compartments at time $t_{\imath}$ in the horizontal direction

a) Loop through all compartments: $k=1$, the total number of compartments in a floor

b) Check whether flashover occurred in the adjacent compartment $(k, j)$

c) If yes, calculate the probability of fire ignition using equation

$P_{i g}(i, j)=P_{i g}(i, j)+P_{b f}(i, k, j) \times P(k, j)+P_{i g}(i, j) \times P_{b f}(i, k, j) \times P(k, j)$

d) go to next $\mathrm{k}$

8) If $t_{t g}(i, j)<t_{t}$, ignition already occurred in this compartment, go to next $\mathrm{i}$

9) If $t_{t g}(i, j)>t$, generate a random number $\mathrm{R}$

10) if $R>P_{\mathrm{rg}}\left(t_{i}\right)$, ignition will not occur, go to next compartment $\mathrm{i}$

11) if $R<P_{\imath g}\left(t_{\imath}\right)$, ignition will occur, set $t_{\mathrm{tg}}(i, j)=t_{\imath}$

12) Next $i$

13) Next j

2.3. Calculate the probability of fire growth to a fully-developed fire $P_{f d}(i, j)$ 
1) Loop through all floors: $j=1$, the total number of floors in the building

2) Loop through all compartments: $i=1$, the total number of compartments on a floor

If $t_{l g}(i, j)>t_{t}$, go to the next compartment $\mathrm{i}$, (this compartment $(\mathrm{i}, \mathrm{j})$ is not ignited yet)

If $t_{t g}(i, j)<t_{\imath}$, ignition occurred in this compartment, then

a) if $t_{f o}(i, j)<t_{l}$, flashover occurred in this compartment, calculate $P_{f d}(i, j)$ the cumulative probability of fire growth at time slice $t$, using equation (5.16-5.18), go to the next compartment $i$;

b) if $t_{f_{0}}(i, j)>t_{t}$, flashover did not occur in this compartment, calculate $P_{f d}(i, j)$ the cumulative probability of fire growth at time slice $t_{t}$ using equation (5.16-5.18), then generate a random number $R$;

c) if $R>P_{f d}(i, j)$, flashover will not occur, go to next compartment i;

d) if $R<P_{f d}(i, j)$, flashover will occur in this compartment, set $t_{f o}(i, j)=t_{t}$.

3) Next compartment $i$

4) Next floor $j$

2.4. Calculate the probability of fire spread to compartment $(i, j)$

1) Loop through all floors: $j=1$, the total number of floors in the building 
2) Loop through all compartments: $i=1$, the total number of compartments on a floor

3) Calculate the probability of fire spread to compartment (i,j) using equation $P(i, j)=P_{i g}(i, j) \times P_{f d}(i, j)$

4) Next $\mathrm{i}$

5) Next j

3. Next time slice $t_{i}$

\subsection{Example}

Consider a two-floor office building with only one window in each office room, whose floor plan is shown in Figure 5-3. Assume that the heat release rate of fire during the growth phase follows a slow t-square fire. If a fire starts in Room 1 on the first floor, what is the probability of fire spreading to Room 6 on the second floor?

Case 1: all doors of the compartment are closed during the fire spread process;

Case 2: the doors of Room 5 and 8 are open and all other doors are closed during the fire spread process.

Steps of calculation:

1. First a compartment number is assigned to each compartment on each floor of the building as shown in Figure 5-10. 


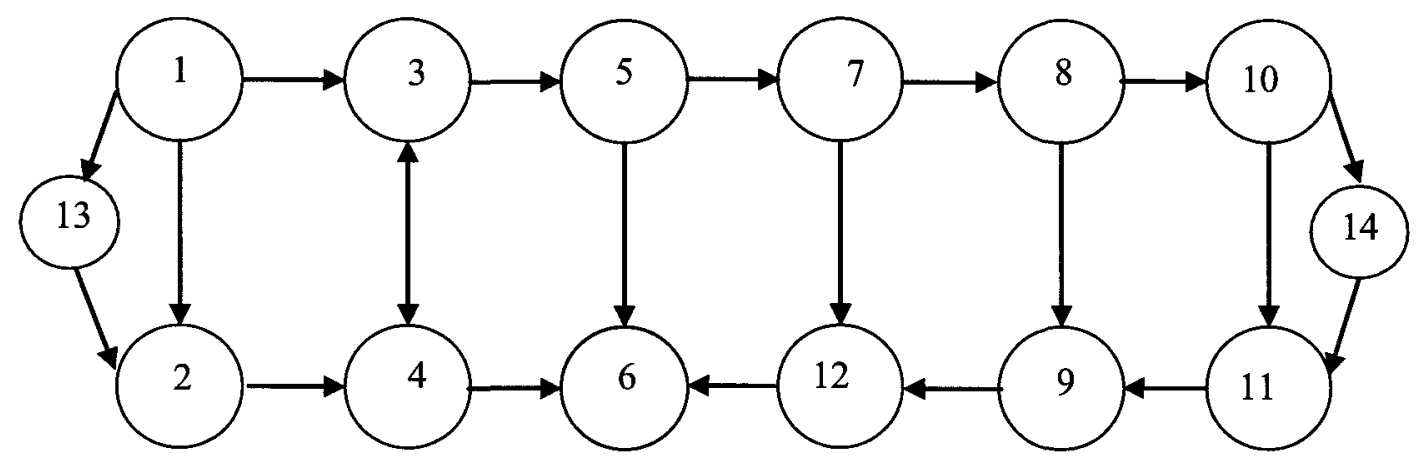

Figure 5-10 The assigned number for each compartment of each floor

2. Read input data for the simulation

Total simulation time: $480 \mathrm{~min}$

Each simulation step time: $1 \mathrm{~min}$

Ambient temperature: $20^{\circ} \mathrm{C}$

3. Read the input data of the compartments

- Office room:

Dimension: $4 \times 5 \times 3 \mathrm{~m}(\mathrm{~W} \times \mathrm{D} \times \mathrm{H})$

The fuel density: mean $=24.8 \mathrm{~kg} / \mathrm{m}^{2}$; standard deviation $=8.6 \mathrm{~kg} / \mathrm{m}^{2}{ }^{[25]}$.

Heat of combustion of fuel $\mathrm{H}_{\mathrm{ch}}=12.4 \mathrm{KJ} / \mathrm{g}^{[27]}$

Fire growth parameter: $\alpha=0.0029 \mathrm{~kW} / \mathrm{s}^{2}$ (slow)

- Window:

Dimension: $1.0 \mathrm{~m} \mathrm{x} 1.0 \mathrm{~m}(\mathrm{~W} \mathrm{x} \mathrm{H})$,

Material: common glass; 
Fire resistance rating to ISO834 fire: mean $=2 \mathrm{~min}$, standard deviation $=0.3 \mathrm{~min}$ (assumed).

- Door:

Dimension: $1.0 \mathrm{~m} \times 2.0 \mathrm{~m}(\mathrm{~W} \times \mathrm{H})$,

Material: wood;

Fire resistance rating to $\mathrm{ISO} 834$ fire: mean $=10 \mathrm{~min}$, standard deviation $=1.5 \mathrm{~min}$ (assumed).

- Wall \& ceiling:

Material: Gypsum board $\sqrt{k \rho c}=0.742 \mathrm{~kJ} / \mathrm{m}^{2} \mathrm{~s}^{0.5} \mathrm{~K}^{[25]}$

Fire resistance rating to ISO 834 fire: mean $=60 \mathrm{~min}$, standard deviation $=9 \mathrm{~min}$ (assumed).

- Floor:

Material: normal weight concrete $\sqrt{k \rho c}=2.192 \mathrm{~kJ} / \mathrm{m}^{2} \mathrm{~s}^{0.5} \mathrm{~K}^{[25]}$

Fire resistance rating to $I S O 834$ fire: mean $=90 \mathrm{~min}$, standard deviation $=13.5$ $\min$ (assumed).

Stairwell:

Dimensions: $5 \times 3 \times 3 \mathrm{~m}(\mathrm{~W} \times \mathrm{D} \times \mathrm{H})$

The fuel density: mean $=0 \mathrm{~kg} / \mathrm{m}^{2}$, standard deviation $=0 \mathrm{~kg} / \mathrm{m}^{2}$.

- Elevator/Duct:

Dimensions: 4 × $5 \times 3 \mathrm{~m}(\mathrm{~W} \times \mathrm{D} \times \mathrm{H})$ 
The fuel density: mean $=0 \mathrm{~kg} / \mathrm{m}^{2}$, standard deviation $=0 \mathrm{~kg} / \mathrm{m}^{2}$.

4. Output of compartment fire model used as input data for fire spread model:

a) Fire growth phase:

Maximum duration of fire growth phase (if all fuel will burn during the fire growth phase without flashover)

$$
\begin{aligned}
& u_{g r}^{\max }=\sqrt[3]{\frac{3 \mathrm{u}_{\mathrm{f}} \mathrm{A}_{\mathrm{F}} \mathrm{H}_{\mathrm{ch}}}{\alpha}}=1853 \mathrm{~s}=30.88 \mathrm{~min} \\
& \sigma_{g r}^{\max }=\sqrt[3]{\frac{3 \mathrm{~A}_{\mathrm{F}} \mathrm{H}_{\mathrm{ch}}}{\alpha\left(\mathrm{u}_{\mathrm{f}}\right)^{2}}} \frac{\sigma_{\mathrm{f}}}{3}=214 \mathrm{~s}=3.57 \mathrm{~min}
\end{aligned}
$$

The duration from ignition to flashover in the room

Mean $\mu_{f o}=\sqrt{\frac{750 \mathrm{~A}_{0} \sqrt{\mathrm{H}_{\mathrm{o}}}}{\alpha}}=508 \mathrm{~s}=8.48 \mathrm{~min}$

Standard deviation $\sigma_{f o}=0.15 \mu_{f o}=1.27 \mathrm{~min}$ (Assumed)

b) The fully-developed fire phase

Check the fire regime during fully-developed fire phase:

$\frac{A_{0} \sqrt{H_{0}}}{\varphi w A_{F}}=0.0155<0.07 \mathrm{~m}^{-1 / 2}$ (the fully-developed fire is ventilation controlled)

Duration of fully-developed fire phase:

Mean $\quad \mu_{f d}=10.6 \frac{\mathrm{A}_{\mathrm{f}} \mu_{\mathrm{f}}}{\mathrm{A}_{0} \sqrt{\mathrm{H}_{0}}}=5258(\mathrm{~s})=87.6 \mathrm{~min}$

Standard deviation $\quad \sigma_{f d}=10.6 \frac{\mathrm{A}_{\mathrm{f}} \sigma_{\mathrm{f}}}{\mathrm{A}_{0} \sqrt{\mathrm{H}_{0}}}=1823(\mathrm{~s})=30.0 \mathrm{~min}$

The mass burning rate for the ventilation controlled fire: 
$\dot{m}_{v}=0.18 \frac{\left(1-e^{-0.036 \Omega}\right) A_{0} \sqrt{H_{0}}}{\sqrt{D / W}}=0.349 \mathrm{~kg} / \mathrm{s}$

Flame height above soffit of window:

$z=12.8\left(\frac{\dot{m}_{v}}{W_{o}}\right)^{2 / 3}-H_{o}=2.70 \mathrm{~m}$, therefore the fire can spread to the room on the floor above by both window and floor

c) The Japanese Parametric model:

The parameter $\beta=3.0 T_{0}\left(\frac{A_{o} \sqrt{H_{o}}}{A_{T} \sqrt{k \rho c}}\right)^{1 / 3}=190.57 \quad K s^{-1 / 6}$

the mean and standard deviation of fire resistance to fully-developed fire can be calculated by equation $5-12$

- Window: Mean=2.65 $\mathrm{min}$, Standard deviation $0.40 \mathrm{~min}$;

- Door: Mean=13.26 min, Standard deviation = $1.99 \mathrm{~min}$;

- Wall \& ceiling: Mean=79.56 min, Standard deviation $=11.93 \mathrm{~min}$;

- Floor: $\mathrm{Mean}=119.33 \mathrm{~min}$, Standard deviation $=17.90 \mathrm{~min}$.

5. The output of two cases based on the results of the dynamic fire spread model:

a) Case 1: all doors are closed during fire spread process

- Based on the calculation of the fire spread model, the ignition time and flashover time in each compartment are listed in Table 5-2. 
Table 5-2 The ignition and flashover time in compartment for case 1

\begin{tabular}{|c|c|c|c|c|c|c|c|}
\hline $\begin{array}{l}\text { Floor } \\
\text { No. }\end{array}$ & Compartment & $\begin{array}{l}\text { Ignition } \\
\text { time } \mathrm{T}_{\mathrm{g}} \\
(\mathrm{min})\end{array}$ & $\begin{array}{l}\text { Flashover } \\
\text { time } \mathrm{T}_{\text {fo }} \\
\text { (min) }\end{array}$ & $\begin{array}{c}\text { Floor } \\
\text { No. }\end{array}$ & Compartment & $\begin{array}{l}\text { Ignition } \\
\text { time } t_{1 g} \\
\text { (min) }\end{array}$ & $\begin{array}{c}\text { Flashover } \\
\text { time } t_{\mathrm{fo}} \\
(\mathrm{min})\end{array}$ \\
\hline 1 & R1 & 0 & 0 & 2 & $\mathrm{R} 1$ & 3 & 12 \\
\hline 1 & $\mathrm{R} 2$ & 26 & 34 & 2 & $\mathrm{R} 2$ & 36 & 44 \\
\hline 1 & R3 & 70 & 78 & 2 & R3 & 82 & 92 \\
\hline 1 & R4 & 100 & 107 & 2 & R4 & 111 & 120 \\
\hline 1 & R5 & 135 & 142 & 2 & R5 & 146 & 155 \\
\hline 1 & R6 & 167 & 176 & 2 & R6 & 179 & 188 \\
\hline 1 & R7 & 208 & 217 & 2 & R7 & 219 & 227 \\
\hline 1 & $\mathrm{R} 8$ & 278 & 285 & 2 & R8 & 289 & 297 \\
\hline 1 & R9 & 312 & 320 & 2 & R9 & 318 & 328 \\
\hline 1 & $\mathrm{R} 10$ & 341 & 350 & 2 & $\mathrm{R} 10$ & 353 & 362 \\
\hline 1 & R11 & 376 & 385 & 2 & $\mathrm{R} 11$ & 384 & 393 \\
\hline 1 & $\mathrm{E}$ & 231 & NF & 2 & $E$ & 248 & NF \\
\hline 1 & S1 & 69 & NF & 2 & S1 & 88 & NF \\
\hline 1 & S2 & 416 & NF & 2 & S2 & 431 & NF \\
\hline
\end{tabular}

- The graphs of probability of fire spread during the fire growth phase for three adjacent compartments of Room 1 on the first floor and the graph of the probability of fire spread during the fire growth phase of Room 6 on the second floor are plotted in Figure 5-11. 


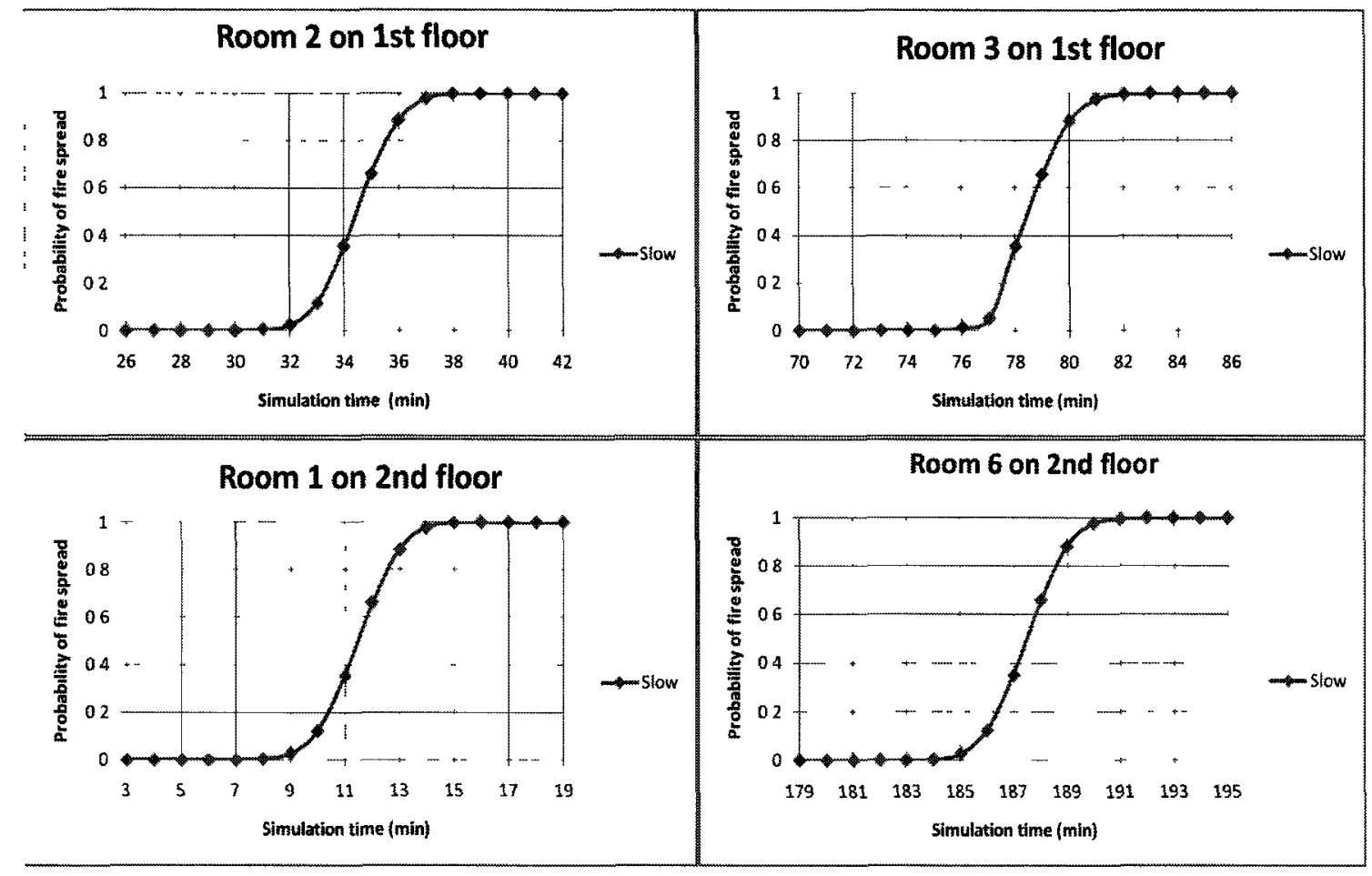

Figure 5-11 Cumulative probability of fire spread in the compartment during fire growth phase

Analysis of the simulation results of fire spread in a building by assuming that a flashover fire occurs in Room 1 on the first floor:

i. Fire spread to Room 6 on the second floor:

- The ignition time is $179 \mathrm{~min}$ and flashover time is $188 \mathrm{~min}$ in Room 6 on the second floor after a flashover fire starts in Room 1 on the first floor (time simulation started); 
- The cumulative probability of fire spread to Room 6 on the second floor is zero before 179 minutes and reaches one after 194 minutes of the simulation time.

ii. Fire spread from Room 1 on the first floor to its adjacent rooms:

- Fire spread from the Room 1 on the first floor to Room 2 on the first floor is due to barrier failure of two closed doors across the corridor. The ignition time in Room 2 is 26 min and flashover time is $34 \mathrm{~min}$ after a flashover fire started in Room 1;

- Fire spread from Room 1 on the first floor to Room 3 on the first floor is due to barrier failure of the wall connecting the two rooms. The ignition time in Room 3 is $70 \mathrm{~min}$ and the flashover time is $78 \mathrm{~min}$ after a flashover fire started in Room 1;

- Fire spread from Room 1 on the first floor to Room 1 on the second floor is due to barrier failure of window glass due to exterior flames. The combustible material in Room 1 on the second floor is ignited by radiation and convection heat flux from the external flame projecting out of the window of Room 1 on the first floor. The ignition time in Room 1 on the second floor is $3 \mathrm{~min}$ and flashover time is 12 min after a flashover fire started in Room 1 on the first floor. 
- Comparing three different kinds of pathways of fire spread in this example shows that fire spreads to a room directly above through windows is much faster that other pathways for this building.

b) Case 2: the doors of Room 5 and 8 are open and all other doors are closed.

1. Based on the results of the fire spread model, the ignition time and flashover time in each compartment in case 2 are listed in Table 5-3.

Table 5-3 The ignition and flashover time in compartment for case 2

\begin{tabular}{|c|c|c|c|c|c|c|c|}
\hline $\begin{array}{c}\text { Floor } \\
\text { No. }\end{array}$ & Compartment & $\begin{array}{c}\text { Ignition } \\
\text { time } \mathrm{T}_{\mathrm{g}} \\
(\mathrm{min})\end{array}$ & $\begin{array}{c}\text { Flashover } \\
\text { time } \mathrm{T}_{\mathrm{fo}} \\
(\mathrm{min})\end{array}$ & $\begin{array}{c}\text { Floor } \\
\text { No. }\end{array}$ & Compartment & $\begin{array}{c}\text { Ignition } \\
\text { time } \mathrm{t}_{\mathrm{gg}} \\
(\mathrm{min})\end{array}$ & $\begin{array}{c}\text { Flashover } \\
\text { time }_{\mathrm{fo}} \\
\text { (min) }\end{array}$ \\
\hline 1 & $\mathrm{R} 1$ & 0 & 0 & 2 & $\mathrm{R} 1$ & 3 & 11 \\
\hline 1 & $\mathrm{R} 2$ & 26 & 34 & 2 & $\mathrm{R} 2$ & 33 & 43 \\
\hline 1 & $\mathrm{R} 3$ & 60 & 70 & 2 & $\mathrm{R} 3$ & 72 & 80 \\
\hline 1 & $\mathrm{R} 4$ & 94 & 104 & 2 & $\mathrm{R} 4$ & 100 & 109 \\
\hline 1 & $\mathrm{R} 5$ & 137 & 146 & 2 & $\mathrm{R} 5$ & 140 & 149 \\
\hline 1 & $\mathrm{R} 6$ & 158 & 167 & 2 & $\mathrm{R} 6$ & 161 & 169 \\
\hline 1 & $\mathrm{R} 7$ & 206 & 214 & 2 & $\mathrm{R} 7$ & 212 & 221 \\
\hline 1 & $\mathrm{R} 8$ & 267 & 275 & 2 & $\mathrm{R} 8$ & 278 & 285 \\
\hline 1 & $\mathrm{R} 9$ & 288 & 296 & 2 & $\mathrm{R} 9$ & 297 & 306 \\
\hline 1 & $\mathrm{R} 10$ & 341 & 349 & 2 & $\mathrm{R} 10$ & 354 & 363 \\
\hline 1 & $\mathrm{R} 11$ & 354 & 363 & 2 & $\mathrm{R} 11$ & 359 & 369 \\
\hline 1 & $\mathrm{E}$ & 223 & $\mathrm{NF}$ & 2 & $\mathrm{E}$ & 237 & $\mathrm{NF}$ \\
\hline 1 & $\mathrm{~S} 1$ & 59 & $\mathrm{NF}$ & 2 & $\mathrm{~S} 1$ & 75 & $\mathrm{NF}$ \\
\hline 1 & $\mathrm{~S} 2$ & 418 & $\mathrm{NF}$ & 2 & $\mathrm{~S} 2$ & 431 & $\mathrm{NF}$ \\
\hline
\end{tabular}


2. The graphs of the probability of fire spread during the fire growth phase of Room 6 on the second floor for both cases are plotted in Figure 5-12.

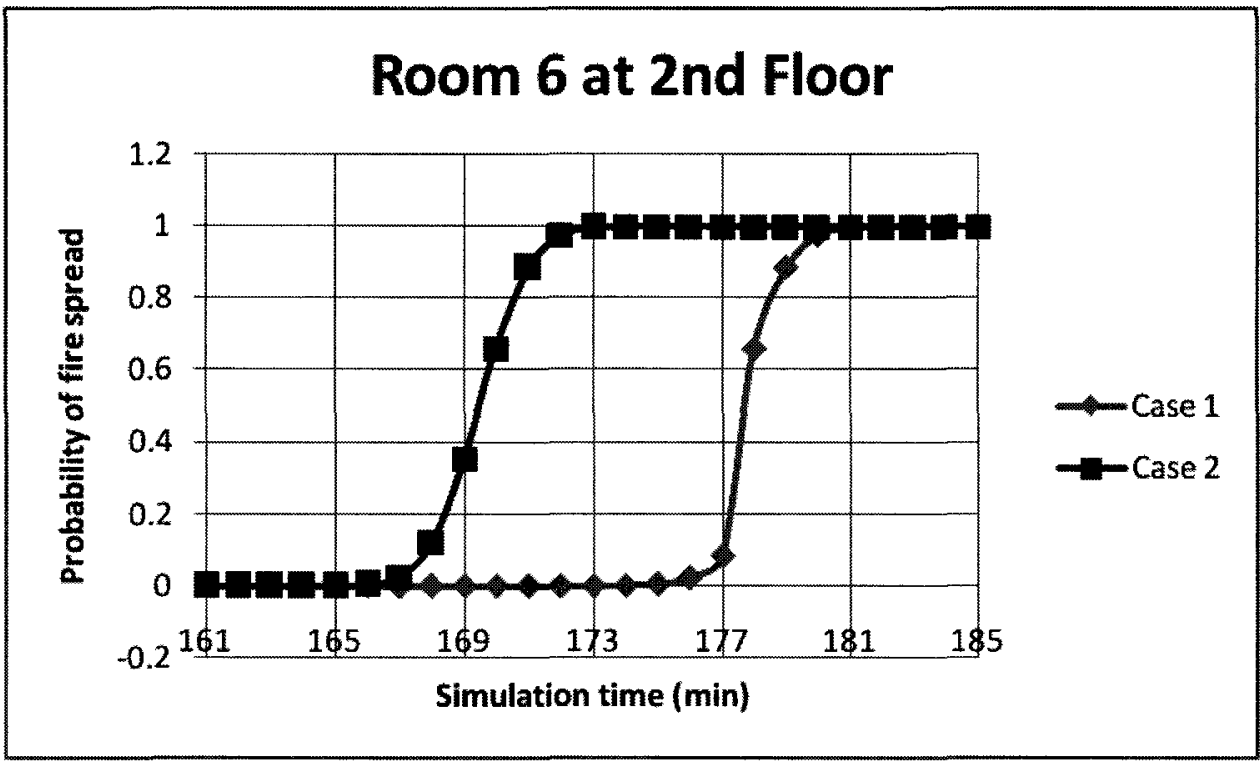

Figure 5-12 Probability of fire spread during fire growth phase

3. Comparing Table 5-2 and Table 5-3 and Figure 5-12, the time needed for fire to spread from Room 1 on the first floor to Room 6 on the second floor in Case 2 is less than that in Case 1. The opening of a door has an influence on the fire spread process. 


\section{Chapter 6}

\section{Conclusion of Modeling Fire Spread in Buildings}

\subsection{Summary of the Study of Modeling Fire Spread in Buildings}

A fire spread model of a building is a key factor of a fire risk analysis used for fire safety designs of large buildings. The probability of fire spread from the compartment of fire origin to other compartments in the building in conjunction with smoke conditions in the building is required to calculate the expected risk to life and expected losses in a building during a fire. The results of a fire spread model can also be used to determine fire protection strategies for buildings. In this work, the following research has been conducted to study fire spread in buildings:

1. A static fire-spread model has been developed to calculate the fire spread probability from the fire compartment to other compartments using a Bayesian network. This model overcomes the drawbacks of previous models and can be used to calculate fire spread in large buildings. To demonstrate the use of the model to calculate fire spread from the compartment of fire origin to a remote compartment in a building, two cases were considered: one without a sprinkler system and one with a sprinkler system installed in the building. The results show that sprinklers reduce fire spread significantly in the building. 
2. Fire spread in a building is a dynamic process. Knowledge of the probability of fire spread with time is very important for a risk analysis. For this, a dynamic fire spread model has been developed. The dynamic fire spread model is built on concepts used in the static fire spread model and the dynamic Bayesian network. The fire spread dynamic model can be easily used for any building including high- rise buildings. In addition, the formulae for calculating the input data for the dynamic fire spread model were derived. The developed model is able to compute the following:

- The probability of fire spread from the compartment of fire origin to any other compartment in the buildings at each time step

- The time of ignition in each compartment

- The time of flashover in each compartment

- The time of fire decay in each compartment

\subsection{Further Study}

To improve the model of fire spread in buildings the following research is recommended:

- Perform a statistical analysis of the probability distribution of barrier failure for different kinds of assemblies and different fire spread pathways, and the probability distribution of fire growth to fully-developed fire in different kinds of compartments; 
- Perform an experimental study of the probability of barrier failure for different kinds of assemblies.

- Undertake an experimental study and computer simulation of the standard deviation of fire growth coefficient for $\mathfrak{t}^{2}$ fires;

- Carry out experiments to verify Equation (5.12);

- Perform a statistical analysis, experimental study and computer simulation of the standard deviation of fire resistance ratings to ISO834 fire for different kinds of assemblies;

- Carry out a statistical analysis, experimental study and computer simulation on the impact of a sprinkler system on probability distribution of fire growth to fullydeveloped fire in different kinds of compartments. 


\section{PART 2}

MODELING OF FIRE SPREAD FROM THE FIRE BUILDING TO ADJACENT BUILDINGS 


\section{Chapter 7}

\section{Introduction of Modeling of Fire Spread from the Fire Building to Adjacent Buildings}

\subsection{Motivation}

During a fire, flame may project out of windows/openings emitting radiation and convection heat flux to the surroundings. Accompanying the hot gases, flying brands from the fire may land on nearby buildings. When the temperature of the exposed combustible materials of adjacent buildings is raised high enough by the heat flux coming from the fire building, combustible materials will ignite and fire will spread to adjacent buildings. Occasionally a disastrous conflagration may occur within a community. When there is no wind and the distance between buildings is larger than the flame projection distance, the convective heat flux is very low compared to the radiative heat flux because of the rapid decrease of the hot gas temperature with increasing horizontal distance from the opening. Therefore, the study of fire spread between buildings can focus on the radiative heat flux from the fire building. 


\subsection{Review of Historical Studies}

The study of spatial separation between buildings to prevent fire spread between buildings has been conducted for more than 50 years ${ }^{[31-51]}$. The main reason for fire spread between buildings is that radiation heat flux coming from a fire building exceeds the critical ignition heat flux of combustible materials on an external wall of an adjacent building. The radiation heat flux received by the wall of the adjacent building in turn is affected by the characteristics of the fire, including the projecting flames out of the window and the window size. A number of experiments have been conducted to study radiation from fire buildings ${ }^{[31-37]}$; however the results of these studies are not consistent. For example, the experimental results of the St. Lawrence burns ${ }^{[32]}$ showed that a major part of the radiation comes from the flames projecting outside the windows, however Law $^{[33,34]}$ stated that the contribution of radiation heat flux due to projecting flames out of the window was not significant and could be ignored. In addition, the value of emissivity of the external flames is an important parameter and needs to be known in order to calculate the radiation heat flux to adjacent buildings. A number of studies have been conducted ${ }^{[38,39,40]}$, however further research is needed to determine an appropriate value of emissivity that can be used for practical engineering applications.

Based on experimental studies, several engineering methods ${ }^{[41-51]}$ have been presented to calculate a safe separation distance between buildings for practical applications. Carlsson 
and Olsson ${ }^{[52]}$ did a literature review of studies on developing engineering methods. Some studies combined a number of openings into a single radiator according to the percentage of opening on the external wall. Some studies proposed charts, tables or simplified formulae to calculate the configuration factor from the fire building to the target building or safe separation distance between two buildings. The shortcomings of these engineering methods are:

- There is no background or detailed description of how these tables or graphs were derived.

- There is no universally accepted method to design buildings against fire spread between buildings. Different methods may result in different results.

\subsection{Scope and Objectives of Study}

To address these problems, an experimental investigation was conducted at the full-scale fire research laboratories of the National Research Council of Canada (NRCC). The aim of this study was to document the radiation heat flux distribution on a target wall when exposed to radiation emitted from flames projecting out of a window. Twelve fire experiments were conducted using a compartment with one window. Three different window sizes were considered by varying the width of the window while maintaining the same height. Other factors considered include the fuel type and size, and separation distance between the external wall of the fire building and a target wall. For each window 
size, four experiments were conducted using three separation distances and two different fuels (propane and wood cribs).

Based on previous studies of spatial separation distance between buildings, a model of calculating a safe separation distance between buildings using configuration factors is proposed. This model is developed using the three basic types of relationships that exist between a rectangular opening and a point on a parallel surface. Corresponding formulae to calculate the configuration factors are proposed. By summing the configuration factors for each window or opening to the target point, the configuration factor for buildings with multiple openings to a target point can easily be calculated even for buildings with an irregular distribution of windows, different sizes of openings and openings having a recessed portion. The algorithms searching for the position and value of the maximum configuration factor between a fire building and an external wall of its adjacent buildings are presented. Once the severity of the hazardous conditions of a fire building is known, the minimum safe separation distance between two buildings can easily be found by letting the maximum configuration factor equal the critical configuration factor, which is defined as the configuration factor that yields the critical heat flux that could ignite the combustibles on the target wall.

Using the theory of post-flashover fires in a compartment, the results of the full-scale fire tests and the modeling the configuration factor described above, a model is proposed for 
calculating the acceptable separation distance between buildings. This model calculates the maximum heat flux from a fire building to the external wall of an adjacent building. Once the critical ignition heat flux of the combustible material of an adjacent building is known, the minimum separation distance required between the buildings can be determined by letting the maximum heat flux equal the critical ignition heat flux by computer programming. 


\section{Chapter 8}

\section{Literature Review of Modeling Fire Spread from the Fire Building to Adjacent Buildings}

\subsection{Experimental Study of Radiation from Fires in Buildings}

\subsubsection{Bevan and Webster ${ }^{[31]}$}

The intensity of radiation falling on an exposed surface from a fire was proposed as

$$
I=\phi \varepsilon T^{4}
$$

Where:

$$
\begin{aligned}
& \mathrm{I}=\text { Intensity of the radiation }\left(\mathrm{W} / \mathrm{m}^{2}\right) ; \\
& \phi=\text { Configuration factor; } \\
& \varepsilon=\text { Emissivity of the radiating surface; } \\
& T=\text { Absolute temperature of the radiating surface, }(\mathrm{K}) .
\end{aligned}
$$

For parallel buildings, the configuration factor can be calculated by

$$
\phi=\frac{S d^{2}}{\pi l^{4}}
$$

Where:

$$
\begin{aligned}
& \mathrm{S}=\text { Area of each window, }\left(\mathrm{m}^{2}\right) \\
& \mathrm{d}=\text { Distance between two buildings, }(\mathrm{m}) ;
\end{aligned}
$$


$1=$ Distance between the center point of the exposing window and a target point, (m).

A gold disc thermocouple was used to find the relationship between the configuration factor and the temperature attained by the exposed surface of the adjacent building. The temperature of the fire building was assumed to be $1000^{\circ} \mathrm{C}$. Based on the experiments, the following conclusions were made:

- The maximum temperature to which timber could safely be heated was $150^{\circ} \mathrm{C}$ and the corresponding critical configuration factor is 0.056 . If the configuration factor from a fire building to a target building is less than 0.056 , the fire can not spread from the fire building to the target building.

- The temperature on the gold disc which was placed behind the glazing was approximately half of that when the gold disc was directly exposed to radiation. Therefore, the critical configuration factor for fire building to a building having no combustible material on the external wall and fire-resisting glazing is 0.16 . If the configuration factor from a fire building to a target window is less than 0.16 , the radiation from the fire building cannot ignite combustible materials behind the window in the target building.

\subsubsection{Shorter, McGuire, Hutcheon and Legget ${ }^{[32]}$}

In January and February 1958, a number of controlled burning experiments (called St.

Lawrence Burns) were conducted by the Division of Building Research, National 
Research Council of Canada. These experiments included six dwellings and two large buildings. One of the objectives of these experiments was to study the spread of fire by radiation between buildings. Three or four radiometers were mounted on movable stands in each experiment. The radiometers near the fire buildings were mounted at a height of $15 \mathrm{ft}(4.57 \mathrm{~m})$ for the dwelling tests and at a height of $20 \mathrm{ft}(6.10 \mathrm{~m})$ for the large building tests. The radiometers were distributed at $10,15,20,30$ or $40 \mathrm{ft}(3.05,4.57,6.10,9.14$ or $12.20 \mathrm{~m}$ ) away from the fire building. In general, two radiometers were located at the leeward side of a building and one on the windward side. One radiometer, called a pyrometer, was mounted on a tripod in front of a window to measure the intensity of radiation $\left(\mathrm{I}_{0}\right)$ at the window opening.

The intensity of radiation $\left(\mathrm{I}_{0}\right)$ was calculated by the equation

$$
I_{0}=\frac{I}{\varphi}
$$

Where:

$$
\begin{aligned}
& I=\text { Measured intensity, }\left(\mathrm{W} / \mathrm{m}^{2}\right) \\
& \Phi=\text { The configuration factor between the window opening and the radiometer }
\end{aligned}
$$
location

The following conclusions were drawn based on the analysis of the experimental data

- The maximum intensity of radiation from the leeward opening of the building could be $40 \mathrm{cal} \mathrm{cm}^{-2} \mathrm{~s}^{-1}\left(1670 \mathrm{~kW} / \mathrm{m}^{2}\right)$ for the buildings with high flammable wall 


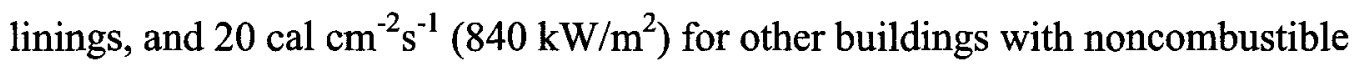
linings.

- The measured maximum temperature in the compartment was $1000^{\circ} \mathrm{C}$. The corresponding intensity of radiation was $3.6 \mathrm{cal} \mathrm{cm}^{-2} \mathrm{~s}^{-1}\left(151 \mathrm{~kW} / \mathrm{m}^{2}\right)$. Compared with the above values of radiation, it was known that only a small radiation was contributed from the window opening, with a major contribution coming from the flames projecting outside the window.

- The maximum intensity of radiation occurred at least 16 minutes after ignition.

\section{Comment on the experimental results of the St. Lawrence Burns}

In the St. Lawrence Burns, the maximum intensity of radiation from the leeward opening of the building was estimated to be $1670 \mathrm{~kW} / \mathrm{m}^{2}$ for the buildings with high flammable wall linings or $840 \mathrm{~kW} / \mathrm{m}^{2}$ for other buildings with noncombustible linings. Because these numbers are not realistic, one-fifth of these values are used in the calculation of spatial separation of buildings

\subsubsection{Law $^{[33,34,39]}$}

In 1963, Law conducted some spatial separation experiments between buildings and concluded that

- The impact of radiation heat flux due to the projecting flame out of the window can be ignored. 
- For fires with restricted ventilation, the intensity of radiation from the compartment fire for the majority of buildings would reach $4 \mathrm{cal} \mathrm{cm}^{-2} \mathrm{~s}^{-1}$ $\left(167 \mathrm{~kW} / \mathrm{m}^{2}\right)$, corresponding to temperatures less than $1100^{\circ} \mathrm{C}$ in the fire compartment. For a compartment with a ventilation factor $A_{o} \sqrt{H_{o}} \leq 5.5 \mathrm{~m}^{5 / 2}$, the intensity of radiation from the compartment fire would have a smaller value due to the reduced size of the window, but its effect on separation distance can be disregarded.

- For a fuel controlled fire or a fire with a fuel load density less than $25 \mathrm{~kg} / \mathrm{m}^{2}$, the intensity of radiation from compartment fire was about $2 \mathrm{cal} \mathrm{cm}^{-2} \mathrm{~s}^{-1}\left(84 \mathrm{~kW} / \mathrm{m}^{2}\right)$, corresponding to temperatures less than $800^{\circ} \mathrm{C}$ in the fire compartment.

- The intensity of radiation emitted by a fire to a point on a vertical façade facing the building on fire should not exceed the minimum value for pilot ignition. The minimum value for pilot ignition for wood equals $0.3 \mathrm{cal} \mathrm{cm}^{-2} \mathrm{~s}^{-1}\left(12.5 \mathrm{~kW} / \mathrm{m}^{2}\right)$ which is used as the critical heat flux for exposed buildings.

In 1968, Law again carried out a series of full-scale fire tests to investigate the levels of radiation from fires in a compartment with dimensions of $7.7 \times 3.7 \times 3 \mathrm{~m}$ (width $\times$ depth $\times$ height). Two identical windows with a distance of $0.7 \mathrm{~m}$ separating them and three window sizes with total area of $11.2 \mathrm{~m}^{2}, 5.6 \mathrm{~m}^{2}$ and $2.8 \mathrm{~m}^{2}$ were used. The amount of fuel in the compartment was distributed with densities of $7.5,15,30$ and $60 \mathrm{~kg} / \mathrm{m}^{2}$, with corresponding total wood crib was $218,436,873$ and $1744 \mathrm{~kg}$ in the compartment. To 
measure the radiation from the fire and the heat flux contributed by the projecting flames, two radiometers were set up 4.6 or $6.1 \mathrm{~m}$ away from the compartment facing the point midway between the two windows. One of them was shielded from the flames above the window so that only the radiation from the window could be measured, and the other was unshielded and measured the total radiation coming from both the window and the flames above the window. The effective intensity of radiation $\left(\mathrm{I}_{0}\right)$ in the plane of the window from the compartment was used to compare the reading for the two compartments.

Based on the analysis of experimental data by Law, the following conclusions were made:

- Higher fire loads would not lead to higher intensity of radiation since the burning rate depends on the ventilation and not on fire load.

- A combustible fiber insulating board lining on walls and ceiling can increase the maximum intensity of radiation by up to $15 \%$.

- A non-combustible fiber insulating board lining on walls and ceiling can increase the intensity of radiation only for the tests with a low fire load.

- The distribution of the fire load had no effect on the intensity of radiation.

- The maximum intensity of radiation emitted from the opening had a close relationship with the maximum temperature within the compartment. 
- For any fire load, the intensity of fire and radiation radiated from the window for the tests with a window size of $11.2 \mathrm{~m}^{2}$ are less than those for the tests with a window size of $5.6 \mathrm{~m}^{2}$.

- For the tests with a window size of $11.2 \mathrm{~m}^{2}$, the intensity of radiation radiated from the flame above the window was not significant. For the tests with the window size $5.6 \mathrm{~m}^{2}$, the intensity of radiation radiated from the flame above the window was significant as it contributes up to $20 \%$ of the total value. For the tests with the highest fire load $(1744 \mathrm{~kg})$, the effect of the flames above the window is significant up to $5 \%$ of total intensity of radiation and the influence of the window size was not significant.

In her report, Law (1968) also mentioned the work done by Webster and Smith (1964). Webster and Smith conducted a full scale test in a $2.4 \mathrm{~m}$ cubical compartment with one side totally open. It was estimated that about two percent of the total amount of the received radiation was contributed by the flames above the opening.

\subsubsection{Lin $^{[35]}$}

Full-scale experiments were conducted in a two-story building to study the fire spread between buildings by radiation from the compartment of fire. Dimensions of the room on the lower floor were $2.64 \times 3.64 \times 3.00 \mathrm{~m}$ and dimensions of the room on the lower floor were $2.64 \times 3.64 \times 2.93 \mathrm{~m}$. The experiments explored the impact of opening of door 
$(0.75 \times 1.8 \mathrm{~m})$ on the spread behavior of a fire in a single room and in upper/lower rooms. Three kinds of load densities of wood crib were used to do the fire experiments: 15 $\mathrm{kg} / \mathrm{m}^{2} ; 25 \mathrm{~kg} / \mathrm{m}^{2}$; and $40 \mathrm{~kg} / \mathrm{m}^{2}$. The compartment fires with fire loads of $25 \mathrm{~kg} / \mathrm{m}^{2}$ and 40 $\mathrm{kg} / \mathrm{m}^{2}$ were ventilation controlled fire. Based on the experiments, the following conclusions were drawn

- For single-room fires, when the window and door were open, the values of the room temperatures, window temperatures, heat fluxes were higher than those when the door was closed.

- For two-room fires, when the door of the upper room was closed, the plume out of the lower room entered the upper room with fresh air. When the door in upper room was open, the door would supply the fresh air for combustion and the flame out of the lower room could not enter the upper room.

\subsubsection{Chen and Francis ${ }^{[36]}$}

33 small-scale fire experiments were conducted to study the radiation heat flux to an external surface from the escaping flame out of an opening. A tenth-scale compartment with internal dimensions of $0.60 \mathrm{~m}$ long by $0.34 \mathrm{~m}$ wide by $0.36 \mathrm{~m}$ high was used in the fire experiments. Based on the experimental results, it was estimated that about $19 \%$ of radiation was from the external flames. 


\title{
8.2 Calculation of Acceptable Separation Distance between Buildings
}

\author{
8.2.1 Law ${ }^{[33,39,40,41]}$
}

Based on the analysis of experimental results, Law concluded that

- The impact of radiation heat flux due to projecting flames out of the window can be ignored.

- For fires with restricted ventilation, the intensity of radiation from the compartment fire for the majority of buildings could reach $167 \mathrm{~kW} / \mathrm{m}^{2}$, corresponding to temperature of less than $1100^{\circ} \mathrm{C}$ in the fire compartment. For a building with a ventilation factor of less than $5.5 \mathrm{~m}^{5 / 2}$, the intensity of radiation from the compartment fire would have a smaller value due to smaller window, but its effect on separation distance was not significant and can be ignored.

- For fuel controlled fires or fires with load density of wood less than $25 \mathrm{~kg} / \mathrm{m}^{2}$, the intensity of radiation from the fire compartment was about $84 \mathrm{~kW} / \mathrm{m}^{2}$, corresponding to a temperature of less than $800^{\circ} \mathrm{C}$ in the fire compartment.

- The intensity of radiation received at a point on a vertical façade facing the building on fire should not exceed the minimum for pilot ignition. The minimum value for pilot ignition for wood is $12.5 \mathrm{~kW} / \mathrm{m}^{2}$ which is used as the critical heat flux for the exposed buildings. 
Based on the above conclusions, the configuration factor of the fire building to an external wall of the adjacent building can be stated as

$$
\emptyset_{n}=\sum \emptyset_{i}=\frac{I}{I_{0}}
$$

Where :

$\emptyset_{n}=$ The configuration factor of the fire building to a point on an external wall of the adjacent building

$\emptyset_{i}=$ The configuration factor of opening $i$ of the fire building to a point on an external wall of the adjacent building

$\mathrm{I}_{0}=$ Intensity of radiation at the source

$\mathrm{I}=$ Intensity of radiation at the receiver

From the above equation, it can be found that, the critical configuration factor is 0.15 for fire load density of equivalent wood less than $25 \mathrm{~kg} / \mathrm{m}^{2}$, the critical configuration factor is 0.075 for fire load density greater than $25 \mathrm{~kg} / \mathrm{m}^{2}$.

Once the critical configuration factor is chosen based on the characteristics of the buildings, the calculation of separation distance between buildings becomes a purely geometrical problem which can be solved by the approach discussed by Bevan and Webster ${ }^{[31]}$. Therefore Law presented two engineering methods, graphical determination and experimental determination, to calculate the acceptable separation distance between buildings described below. 


\subsubsection{The graphical determination method}

For a building with only one radiator, Law presented a graph in which there are several curves based on the relationships of the configuration factor, the ratio of width to height of the radiator, and the ratio of separation distance between buildings to the width of the radiator. Once the former two factors are known, the other can be found from the figure and the separation distance between buildings could be calculated.

For a building with a multiple openings, Law simplified the external wall of the building as one radiator and presented two charts, one for a critical configuration factor of 0.15 and fire load density less than $25 \mathrm{~kg} / \mathrm{m}^{2}$, and the other for a critical configuration factor is 0.075 and fire load density greater than $25 \mathrm{~kg} / \mathrm{m}^{2}$. With the ratio of width to height of the radiator and the percentage of the area of the opening to the radiator, the ratio of the separation distance between two buildings to the width of the radiator could be found from the graph; then the separation distance between buildings can be calculated.

\subsubsection{The experimental determination method}

In this method, the configuration factor for an elevation is approximated by an optical analog which uses the similarity between the transmission of light and thermal radiation.

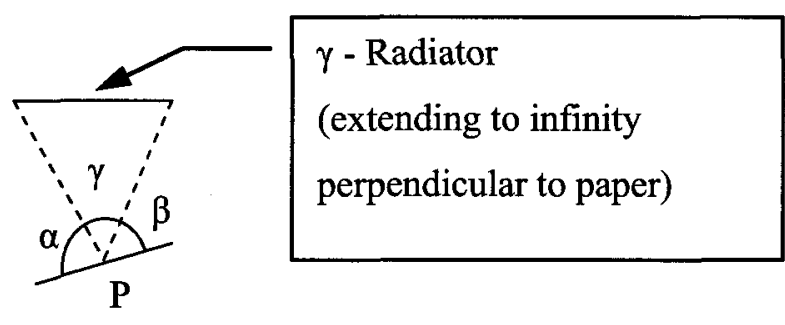


The configuration factor can be calculated by

$$
\phi=\frac{1}{2}(\cos \alpha+\cos \beta)
$$

When the maximum configuration factor of an elevation equals the critical configuration factor, the calculations of the separation distance opposite the center of the radiator and the separation distance opposite the edge of the radiator are proposed according to the value of the configuration factor. For the elevation with multiple openings, two tables were presented based on the percentage of the window area to the external wall. This method can be also used for elevations with uneven distribution of openings, elevations with widely spaced openings and elevations with a set back.

\subsubsection{McGuire ${ }^{[42,43,44]}$}

McGuire summarized the experimental results of the St. Lawrence Burns. It was found that the maximum intensity of radiation from the leeward openings could be as high as $1670 \mathrm{~kW} / \mathrm{m}^{2}\left(40 \mathrm{cal} \mathrm{cm}^{-2} \mathrm{~s}^{-1}\right)$ for the buildings with high flammable wall linings, and 840 $\mathrm{kW} / \mathrm{m}^{2}\left(20 \mathrm{cal} \mathrm{cm}^{-2} \mathrm{~s}^{-1}\right)$ for buildings with noncombustible linings. Though the fires had been arranged to develop very rapidly, the intensity of radiation could not exceed one fifth of the peak values $\left(1670 \mathrm{~kW} / \mathrm{m}^{2}\right.$ and $\left.840 \mathrm{~kW} / \mathrm{m}^{2}\right)$ until at least $16 \mathrm{~min}$ had elapsed. It is reasonable to expect that the fire fighting is in progress within $16 \mathrm{~min}$. Therefore $334 \mathrm{~kW} / \mathrm{m}^{2}$ and $168 \mathrm{~kW} / \mathrm{m}^{2}$ were considered as the critical values of radiation for the calculation of spatial separation. For most materials, the minimum value for pilot ignition 
is more than $12.5 \mathrm{~kW} / \mathrm{m}^{2}\left(0.3 \mathrm{cal} \mathrm{cm}^{-2} \mathrm{~s}^{-1}\right)$. Therefore, the critical values of the configuration factors for the hazardous case (for the buildings with high flammable wall linings) and normal case (for buildings with noncombustible linings) are chosen respectively as 0.035 and 0.07 . Based on the configuration factors of 0.035 and 0.07 , two tables were presented for the hazardous and normal conditions in which the acceptable separation distance between buildings is given based on the dimensions of the compartment and the percent of the window opening to the wall area.

\subsubsection{Williams-Leir ${ }^{\text {[43, 44, 45, 46] }}$}

In 1966, Williams-Leir proposed that the fire building could be treated as a gray radiator with an emissivity equal to the ratio of total opening area to the façade area. Using the conclusions of the St. Lawrence Burns summarized by McGuire; that is the configuration factor for high hazards (for the buildings with high flammable wall linings) is 0.035 and the configuration factor for low hazards (for buildings with noncombustible linings) is 0.07 , a simplified formula to calculate the minimum separation distance between buildings was proposed.

$$
d=B \sqrt{h w}
$$

Where:

$$
\begin{aligned}
& \mathrm{d}=\text { Safe separation distance }(\mathrm{m}) ; \\
& \mathrm{h}=\text { Height of the building }(\mathrm{m})
\end{aligned}
$$




$$
\begin{aligned}
& \mathrm{w}=\text { Width of the building }(\mathrm{m}) ; \\
& \mathrm{B}=\text { Parameter. }
\end{aligned}
$$

If the separation distance between buildings is given, the maximum permissible façade area of the buildings can be calculated using

$$
h w=\left(\frac{d}{B}\right)^{2}
$$

The parameter B can be determined in three ways described below.

\subsubsection{Tabular presentation}

The value of B can easily be obtained from a table based on the ratio of the height to width or width to height and the hazard condition.

\subsubsection{Formulae}

For a parameter $\mathrm{q}$

$$
q=\frac{\pi R F}{\mu}
$$

Where:

$$
\mathrm{R}=\text { Shape factor }
$$

$$
R=\frac{1}{2}\left(\frac{h}{w}+\frac{w}{h}\right)
$$

$\mu=$ Ratio of unprotected opening to façade area

$\mathrm{F}=$ Critical configuration factor according to occupancy and hazard $(\mathrm{F}=0.035$ for high hazards or $\mathrm{F}=0.07$ for low hazards). 
The amount of B can be calculated using following formulae.

- If $\mathrm{q}$ is less than 0.75

$$
B=\sqrt{\frac{R(1+\sqrt{1-q})}{2 q}}
$$

- If $\mathrm{q}$ is greater than 0.75 but less than 3.6

$$
B=0.34 \sqrt[4]{\frac{\mu^{3}}{F^{3} R}}
$$

- If $\mathrm{q}$ is greater than 3.6

$$
B=\frac{\mu}{F \sqrt{8 R}}
$$

\subsubsection{The graphical determination}

Based on the ratio of height to width of the façade of the building and ratio of the $F$ to $u$, the value of B can be obtained from a graph.

In 1972, Williams-Leir presented another engineering method used to calculate the minimum separation distance between buildings. For squarish facades (called floating square) with normal or large opening areas,

$$
d^{2}=\frac{a}{\pi F}
$$

Where:

$$
\begin{aligned}
& a=\text { the aggregate area of openings } \\
& a=\boldsymbol{u h w}
\end{aligned}
$$

For a façade that is elongated rather than square (called floating zone), 


$$
d=\frac{u h}{2 F}
$$

Let

$$
\boldsymbol{d}=\mathbf{2}(\boldsymbol{L}-M)
$$

Where:

$\mathrm{L}=$ Limiting distance, which is the distance from the façade to the lot line, $(\mathrm{ft}$ or $\mathrm{m})$;

$\mathrm{M}=\mathrm{McGuire}$ correction ( $3 \mathrm{ft}$ or $1 \mathrm{~m})$.

Therefore, following definitions and conclusions were stated

- Basic allowance of unprotected openings, (BAUO), is $0.44(\mathrm{~L}-3)^{2} \mathrm{ft}^{2}$ for high hazard condition and $0.88(\mathrm{~L}-3)^{2} \mathrm{ft}^{2}$ for moderate hazard condition.

- Floating-square distance, $\mathrm{K}$, is $3.54(\mathrm{~L}-3) \mathrm{ft}$ and Floating-zone distance, J, is 3.14(L-3) ft.

There are three Rules proposed for practical applications.

- Rule 1: Every exposing building face (EBF) may include one or more basic allowance of unprotected openings. The openings may be distributed in whatever way that is most suitable to the owner, given that the EBF includes a maximum of one BAUO. 
- Rule 2: Where one of the sides of the EBF is greater than $\mathrm{K}$, a floating square of side $\mathrm{K}$ that is parallel to and placed on the EBF can only contain a maximum of one BAUO. The openings shall be distributed to fulfill this requirement.

- Rule 3: Where one of the sides of the EBF is greater than $J$, a suitable direction, generally perpendicular to the longest side of the EBF shall be chosen. A floating zone of side $\mathrm{J}$, unlimited length and that is parallel to the chosen direction can only contain a maximum of one BAUO. The openings shall be distributed to fulfill this demand.

Rule 1 is valid for determining the separation distance or maximum allowed unprotected areas for as much as $90 \%$ of all cases. Rule 2 may be used for facades with a small unprotected areas (approximately less than $15 \%$ of the total area of the facade). Rule 3 is applicable for elongated facades where one of the dimensions is eight times longer than the other.

\subsubsection{Barnett ${ }^{[47]}$}

Barnnet presented the concept "mirror-image" for fire separation calculations between external walls of buildings. The following definitions were used in his paper.

- Radiation distance ( $R$ )

- Separation distance (S)

- Limiting distance (L) 
- Protected limiting distance $\left(\mathrm{L}_{\mathrm{x}}\right)$

- Flame projecting distance $(\mathrm{P})$

Barnett stated that the control of ignition between buildings depends on the selection of the design values of the flame projecting distance $(\mathrm{P})$ and protected limiting distance $\left(\mathrm{L}_{\mathbf{x}}\right)$. Barnett did the comparison of the values of $P$ and $L_{x}$ between the codes of the British system and the Canadian system and made a $4 \times 4$ matrix diagram to illustrate the effect of varying values of $P$ and $L_{x}$. Base on the summary of the different studies by other scientists, Barnett assumed that the average projecting flame temperature is $600^{\circ} \mathrm{C}$, compartment temperatures are between $842^{\circ} \mathrm{C}$ and $1153^{\circ} \mathrm{C}$, the compartment emissivity is 1.00 and flame emissivity as 0.45 for a $2-\mathrm{m}$ thick flame.

Barnett presented the following two methods for calculating separation distance between buildings depending on the maximum permissible area of openings in the owner's building or the level of received radiation on the neighboring building for a given set of openings of the owner's building.

\subsubsection{The maximum permissible area of openings in the owner's building}

The maximum permissible area of openings $A_{V}$

$$
A_{V}=\frac{A_{E} I_{R C}}{\emptyset_{n} I_{E C}}
$$

Where: 
$A_{E}=$ Area of enclosing rectangle, $\left(\mathrm{m}^{2}\right)$. For a building with a number of openings, the enclosing rectangles enclose a combination of openings (large and small cases) in the façade.

$I_{R C}=$ Critical value of received radiation, $\left(\mathrm{kW} / \mathrm{m}^{2}\right)$;

$I_{E C}=$ Critical value of emitted radiation, $\left(\mathrm{kW} / \mathrm{m}^{2}\right)$;

$\emptyset_{n}=$ Configuration factor

(a) The choice of the critical value of received radiation $I_{R C}$

- $I_{R C}=12.5 \mathrm{~kW} / \mathrm{m}^{2}$ if the neighbor's building has combustible materials on the external walls or the neighbor's building has non-combustible materials on the external walls but ordinary windows

- $I_{R C}=50.0 \mathrm{~kW} / \mathrm{m}^{2}$ if the neighbor's building has non-combustible materials on the external walls and the fire resistance windows

(b) The choice of critical value of emitted radiation $I_{E C}$

- for ordinary glazing

$$
I_{E C}=I_{F}=\varepsilon \sigma\left(T_{2}^{4}-T_{1}^{4}\right)
$$

- for fire resistance glazing

$$
I_{E C}=0.5 I_{F}=\frac{\varepsilon \sigma}{2}\left(T_{2}^{4}-T_{1}^{4}\right)
$$

Where:

$T_{1}=$ ambient temperature, $(\mathrm{K})$;

$T_{2}=$ The maximum compartment temperature, $(\mathrm{K})$. 
$\mathrm{T}_{2}$ can be determined from the ISO 834 time-temperature formula

$$
T_{2}=345 \log _{10}(8 t+1)+T_{1}
$$

\subsubsection{Level of received radiation by the neighboring building}

The amount of received radiation by the neighboring building (IR) should not exceed the critical value of received radiation (IRC)

$$
I_{R}=k_{V} \emptyset_{n} I_{E C} \leq I_{R C}
$$

Where:

$$
\begin{aligned}
& k_{V}=\text { Ratio of area of the vertical openings to the area of the enclosing rectangle } \\
& k_{V}=\frac{A_{V}}{A_{E}}
\end{aligned}
$$

\subsubsection{NFPA 80A (USA) ${ }^{[48]}$}

The purpose of the report " NFPA 80A Recommended Practice for Protection of Buildings from Exterior Fire Exposure (NFPA 80A 1996) " is to protect against fire spread between buildings.

\section{- Percentage of openings in exposing wall area}

Percentage of openings in the exposing wall that have to be considered as the percentage of exposing wall made up of doors, windows and other openings that may contribute to the emitted thermal radiation.

Other openings that should be considered are: 
a) Walls with resistance against fire penetration less than 20 minutes should be treated as being a $100 \%$ opening.

b) Walls that can withstand fire penetration for more than 20 minutes but not longer than the estimated fire duration should be treated as being a $75 \%$ opening.

- Severity

Three levels of exposure severity were assumed: light, moderate and severe. The fire severity depends on two properties: the average fire load density and the characteristics of interior finishes as shown in Table 8-1.

Table 8-1 Classification of fire severity

\begin{tabular}{|c|c|c|}
\hline Fire severity & $\begin{array}{c}\text { Fire load density of wood } \\
\left(\mathrm{kg} / \mathrm{m}^{2}\right)\end{array}$ & $\begin{array}{c}\text { Average flame spread rating of } \\
\text { interior wall and ceiling finish * }\end{array}$ \\
\hline Light & $0-34$ & $0-25$ \\
Moderate & $35-73$ & $35-73$ \\
Severe & $\geq 74$ & $\geq 76$ \\
\hline
\end{tabular}

* The flame spread ratings are explained in "NFPA 255 Standard Method of Test of Surface Burning Characteristics of Building Materials".

- Separation distances

The minimum separation distance between buildings can be calculated by

$$
D=g Z+1.52
$$

Where: 
$\mathrm{D}=$ The minimum separation distance between buildings, (m);

$\mathrm{g}=$ Guide number from Table 8-2;

$Z=$ The lesser dimension of width and height of the opening, (m).

The above equation is based on the assumption that the facade of the exposed building is made of cellulosic materials with a critical ignition radiation heat flux of $\mathrm{I}_{\text {crit }}=12.5$ $\mathrm{kW} / \mathrm{m}^{2}$.

For facades with material having different critical ignition radiation heat $\mathrm{I}_{\text {crit }} \neq 12.5 \mathrm{~kW} / \mathrm{m}^{2}$, and no openings, the percentage of openings in the exposing building should be adjusted. The new percentage of openings, $\mathrm{O}_{\text {new }}$, should be obtained by multiplying the old percentage openings of the external wall, $\mathrm{O}_{\text {old }}$, with the ratio between $12.5 \mathrm{~kW} / \mathrm{m}^{2}$ and the critical radiant heat flux for the particular facade material.

$0_{\text {new }}=0_{\text {old }} \times \frac{12.5}{I_{\text {crit }}}$

\section{- Exposure from buildings of lesser height}

a) Where the exposing building is of lesser height than the exposed building, the minimum separation distance between buildings should be firstly calculated by Equation (8-22).

b) Where the roof of the exposing building consists of combustible material without a fire resistance rating, Table 8-3 should be used in order to determine the required separation distance and means of protection necessary above roof level. 
Table 8-2 Guide numbers for the determination of the minimum separation distances between buildings

\begin{tabular}{|c|c|c|c|c|c|c|c|c|c|c|c|c|c|c|c|c|c|c|c|}
\hline \multicolumn{3}{|c|}{ Fire severity } & \multicolumn{17}{|c|}{ Guide number } \\
\hline \multicolumn{3}{|c|}{ Percent of opening } & \multicolumn{17}{|c|}{ Ratio of width to height or height to width } \\
\hline Light & Moderate & Severe & 1.0 & 1.3 & 1.6 & 2.0 & 2.5 & 3.2 & 4 & 5 & 6 & 8 & 10 & 13 & 16 & $\mathbf{2 0}$ & 25 & 32 & 40 \\
\hline 20 & 10 & 5 & 0.36 & 0.40 & 0.44 & 0.46 & 0.48 & 0.49 & 0.50 & 0.51 & 0.51 & 0.51 & 0.51 & 0.51 & 0.51 & 0.51 & 0.51 & 0.51 & 0.51 \\
\hline 30 & 15 & 7.5 & 0.60 & 0.66 & 0.73 & 0.79 & 0.84 & 0.88 & 0.90 & 0.92 & 0.93 & 0.94 & 0.94 & 0.95 & 0.95 & 0.95 & 0.95 & 0.95 & 0.95 \\
\hline 40 & 20 & 10 & 0.76 & 0.85 & 0.94 & 1.02 & 1.10 & 1.17 & 1.23 & 1.27 & 1.30 & 1.32 & 1.33 & 1.33 & 1.34 & 1.34 & 1.34 & 1.34 & 1.34 \\
\hline 50 & 25 & 12.5 & 0.90 & 1.00 & 1.11 & 1.22 & 1.33 & 1.42 & 1.51 & 1.58 & 1.63 & 1.66 & 1.69 & 1.70 & 1.71 & 1.71 & 1.71 & 1.71 & 1.71 \\
\hline 60 & 30 & 15 & 1.02 & 1.14 & 1.26 & 1.39 & 1.52 & 1.64 & 1.76 & 1.85 & 1.93 & 1.99 & 2.03 & 2.05 & 2.07 & 2.08 & 2.08 & 2.08 & 2.08 \\
\hline 80 & 40 & 20 & 1.22 & 1.37 & 1.52 & 1.68 & 1.85 & 2.02 & 2.18 & 2.34 & 2.48 & 2.59 & 2.67 & 2.73 & 2.77 & 2.79 & 2.80 & 2.81 & 2.81 \\
\hline 100 & 50 & 25 & 1.39 & 1.56 & 1.74 & 1.93 & 2.13 & 2.34 & 2.55 & 2.76 & 2.95 & 3.12 & 3.26 & 3.36 & 3.43 & 3.48 & 3.51 & 3.52 & 3.53 \\
\hline- & 60 & 30 & 1.55 & 1.73 & 1.94 & 2.15 & 2.38 & 2.63 & 2.88 & 3.13 & 3.37 & 3.60 & 3.79 & 3.95 & 4.07 & 4.15 & 4.20 & 4.22 & 4.24 \\
\hline - & 80 & 40 & 1.82 & 2.04 & 2.28 & 2.54 & 2.82 & 3.12 & 3.44 & 3.77 & 4.11 & 4.43 & 4.74 & 5.01 & 5.24 & 5.41 & 5.52 & 5.60 & 5.64 \\
\hline- & 100 & 50 & 2.05 & 2.30 & 2.57 & 2.87 & 3.20 & 3.55 & 3.93 & 4.33 & 4.74 & 5.16 & 5.56 & 5.95 & 6.29 & 6.56 & 6.77 & 6.92 & 7.01 \\
\hline - & - & 60 & 2.26 & 2.54 & 2.84 & 3.17 & 3.54 & 3.93 & 4.36 & 4.82 & 5.30 & 5.80 & 6.30 & 6.78 & 7.23 & 7.63 & 7.94 & 8.18 & 8.34 \\
\hline- & - & 80 & 2.63 & 2.95 & 3.31 & 3.70 & 4.13 & 4.61 & 5.12 & 5.68 & 6.28 & 6.91 & 7.57 & 8.24 & 8.89 & 9.51 & 10.05 & 10.50 & 10.84 \\
\hline - & - & 100 & 2.96 & 3.32 & 3.72 & 4.16 & 4.65 & 5.19 & 5.78 & 6.43 & 7.13 & 7.88 & 8.67 & 9.50 & 10.33 & 11.15 & 11.91 & 12.59 & 13.15 \\
\hline
\end{tabular}


Table 8-3 Minimum separation distance or height of protection for buildings with combustible and roof with no fire resistance rating

\begin{tabular}{|c|c|}
\hline $\begin{array}{c}\text { Number of stories likely to contribute } \\
\text { to flaming through the roof }\end{array}$ & $\begin{array}{c}\text { Horizontal separation distance or height } \\
\text { of protection above exposing fire (m) }\end{array}$ \\
\hline 1 & 7.6 \\
2 & 9.8 \\
3 & 12.2 \\
4 & 14.3 \\
\hline
\end{tabular}

\subsubsection{NBCC 2005 ${ }^{[49]}$}

In the National Building Code of Canada (NBCC), limiting distance is defined as the distance from an exposing building face to a property line, to the centre line of a street, lane or public thoroughfare or to an imaginary line between two buildings or fire compartments on the same property, measured at right angles to the exposing building face. Based on the total area of exposing building face and the ratio of aggregate area of unprotected openings to exposing building face area, the limiting distance can be easily found in Table 8-4 (Table 9.10.14.4 NBCC). 
Table 8-4 Maximum Aggregate Area of Unprotected Openings in Exterior Walls

\begin{tabular}{|c|c|c|c|c|c|c|c|c|c|c|c|c|c|c|c|}
\hline \multirow{3}{*}{$\begin{array}{l}\text { Occupancy } \\
\text { Classification } \\
\text { of Building }\end{array}$} & \multirow{3}{*}{$\begin{array}{l}\text { Maximum Total Area of } \\
\text { Exposing Building Face } \\
\qquad\left(\mathrm{m}^{2}\right)\end{array}$} & \multicolumn{14}{|c|}{ Maximum Aggregate Area of Unprotected Openings, $\%$ of Exposing Building Face Area } \\
\hline & & \multicolumn{14}{|c|}{ Limiting Distance, $\mathrm{m}$} \\
\hline & & $\begin{array}{c}\text { Less than } \\
1.2\end{array}$ & 1.2 & 1.5 & 2 & 2.5 & 3 & 4 & 6 & 8 & 10 & 12 & 16 & 20 & 25 \\
\hline \multirow{9}{*}{$\begin{array}{l}\text { Residential, } \\
\text { business and } \\
\text { personal } \\
\text { services and } \\
\text { low-hazard }\end{array}$} & 10 & 0 & 8 & 12 & 21 & 33 & 55 & 96 & 100 & - & - & - & - & - & - \\
\hline & 15 & 0 & 8 & 10 & 17 & 25 & 37 & 67 & 100 & - & - & - & - & - & - \\
\hline & 20 & 0 & 8 & 10 & 15 & 21 & 30 & 53 & 100 & - & - & - & - & - & - \\
\hline & 25 & 0 & 8 & 9 & 13 & 19 & 26 & 45 & 100 & - & - & - & - & - & - \\
\hline & 30 & 0 & 7 & 9 & 12 & 17 & 23 & 39 & 88 & 100 & - & - & - & - & - \\
\hline & 40 & 0 & 7 & 8 & 11 & 15 & 20 & 32 & 69 & 100 & - & - & - & - & - \\
\hline & 50 & 0 & 7 & 8 & 10 & 14 & 18 & 28 & 57 & 100 & - & - & - & - & - \\
\hline & 100 & 0 & 7 & 8 & 9 & 11 & 13 & 18 & 34 & 56 & 84 & 100 & - & - & - \\
\hline & Over 100 & 0 & 7 & 7 & 8 & 9 & 10 & 12 & 19 & 28 & 40 & 55 & 92 & 100 & - \\
\hline \multirow{9}{*}{$\begin{array}{l}\text { Mercantile and } \\
\text { medium-hazard } \\
\text { industrial }\end{array}$} & 10 & 0 & 4 & 6 & 10 & 17 & 25 & 48 & 100 & - & - & - & - & - & - \\
\hline & 15 & 0 & 4 & 5 & 8 & 13 & 18 & 34 & 82 & 100 & - & - & - & - & - \\
\hline & 20 & 0 & 4 & 5 & 7 & 11 & 15 & 27 & 63 & 100 & - & - & - & - & - \\
\hline & 25 & 0 & 4 & 5 & 7 & 9 & 13 & 22 & 51 & 94 & 100 & - & - & - & - \\
\hline & 30 & 0 & 4 & 4 & 6 & 9 & 12 & 20 & 44 & 80 & 100 & - & - & - & - \\
\hline & 40 & 0 & 4 & 4 & 6 & 8 & 10 & 16 & 34 & 61 & 97 & 100 & - & - & - \\
\hline & 50 & 0 & 4 & 4 & 5 & 7 & 9 & 14 & 29 & 50 & 79 & 100 & - & - & - \\
\hline & 100 & 0 & 4 & 4 & 4 & 5 & 6 & 9 & 17 & 28 & 42 & 60 & 10 & - & - \\
\hline & Over 100 & 0 & 4 & 4 & 4 & 4 & 5 & 6 & 10 & 14 & 20 & 27 & 46 & 70 & 100 \\
\hline
\end{tabular}




\section{Chapter 9}

\section{Fundamentals of Post-Flashover Compartment Fires}

The most dangerous scenario by which fire can spread from the fire building to its adjacent buildings is that the fire in the compartment has developed into a fully developed fire. For this case, the radiation heat flux on a target wall of an adjacent building from the fire building reaches its maximum value. Therefore, the study of fire spread between buildings in this thesis concentrates on post-flashover compartment fires.

\subsection{Type of Post-Flashover Compartment Fire}

A post-flashover compartment fire could be a fuel-controlled fire or a ventilation-

controlled fire. Harmathy ${ }^{[23,24, \text { and } 25]}$ recommended a method to distinguish between these two regimes of compartment fires.

For a ventilation-controlled fire:

$$
\frac{\rho_{0} \sqrt{g} A_{0} \sqrt{H_{0}}}{A_{f}}<0.235
$$

For a fuel surface controlled fire:

$$
\frac{\rho_{0} \sqrt{g} A_{0} \sqrt{H_{0}}}{A_{f}}>0.290
$$

Where:

$$
\rho_{0}=\text { Density of air, }\left(\mathrm{kg} / \mathrm{m}^{3}\right)
$$


$\mathrm{g}=$ Acceleration due to gravity, $\left(\mathrm{m} / \mathrm{s}^{2}\right)$

$A_{f}=$ Surface area of fuel, $\left(\mathrm{m}^{2}\right)$.

In the critical regime $0.235<\frac{\rho_{0} \sqrt{\mathrm{g}} \mathrm{A}_{0} \sqrt{\mathrm{H}_{0}}}{\mathrm{~A}_{\mathrm{f}}}<0.290$, it was stated that some characteristics of fire could be poorly predictable ${ }^{[23]}$. Harmathy recommended that the critical value of this critical regime is $0.263^{[23]}$. That is

For a ventilation-controlled fire:

$$
\frac{\rho_{0} \sqrt{g} A_{0} \sqrt{H_{0}}}{A_{f}} \leq 0.263
$$

For a fuel surface controlled fire:

$$
\frac{\rho_{0} \sqrt{g} A_{0} \sqrt{H_{0}}}{A_{f}}>0.263
$$

Harmathy defined the specific surface of wood as:

$$
\varphi=\frac{A_{f}}{W_{f}}
$$

Where:

$\varphi=$ Specific surface of wood with a range of $0.1<\varphi<0.4 \mathrm{~m}^{2} / \mathrm{kg}^{[23]}$; for a wide range of conventional furniture $\varphi=0.13 \mathrm{~m}^{2} / \mathrm{kg}^{[25]}$; . $W_{f}=$ Equivalent weight of wood in a compartment, $(\mathrm{kg})$.

By combining Equations (9.1) and Equations (9.3), the weight of wood needed for a ventilation-controlled fire can be calculated by

$$
W_{f}>\frac{\rho_{0} \sqrt{g} \mathrm{~A}_{0} \sqrt{\mathrm{H}_{0}}}{0.235 \varphi}
$$




\subsection{Compartment Temperature}

The maximum temperature in the compartment ${ }^{[40]}$ is given

$$
T_{g}-T_{a}=6000 \frac{\left(1-e^{-0.10 \Omega}\right)\left(1-e^{-0.05 \Psi}\right)}{\Omega^{0.5}}
$$

Where:

$$
\begin{aligned}
& \mathrm{T}_{\mathrm{g}}=\text { Expected maximum compartment temperature, }(\mathrm{K}) \\
& \mathrm{T}_{\mathrm{a}}=\text { Ambient temperature, }(\mathrm{K}) \\
& \mathbf{\Omega}=\frac{A_{T}}{{A_{0} H_{0}^{1 / 2}}^{1 / 2}} \\
& \Psi=\frac{\mathbf{W}_{\mathrm{f}}}{\left(\mathbf{A}_{0} \mathbf{A}_{\mathrm{T}}\right)^{1 / 2}}=\frac{\mathbf{w}_{\mathrm{f}} A_{\mathbf{F}}}{\left(\mathbf{A}_{0} A_{\mathrm{T}}\right)^{1 / 2}}
\end{aligned}
$$

Where:

$$
\begin{aligned}
& \mathrm{A}_{\mathrm{T}}=\text { Area of fire compartment enclosing surface, }\left(\mathrm{m}^{2}\right) . \\
& \boldsymbol{A}_{T}=2(\boldsymbol{W} \times \boldsymbol{H}+\boldsymbol{D} \times \boldsymbol{H}+\boldsymbol{W} \times \boldsymbol{D})-\boldsymbol{A}_{0}
\end{aligned}
$$

\subsection{Burning Rate of Ventilation Controlled Fires}

For ventilation controlled fire, the burning rate of fuel ${ }^{[27]}$ during the fully-developed fire phase is

$$
\dot{m}_{v}=0.18 \frac{\left(1-e^{-0.036 \Omega}\right) A_{0} H_{0}^{1 / 2}}{(\mathrm{D} / \mathrm{W})^{1 / 2}}
$$

Where:

$$
\dot{m}_{v}=\text { Burning rate of ventilation controlled fire, }(\mathrm{kg} / \mathrm{s}) \text {. }
$$




\subsection{Flames Projecting out of Window ${ }^{[40]}$}

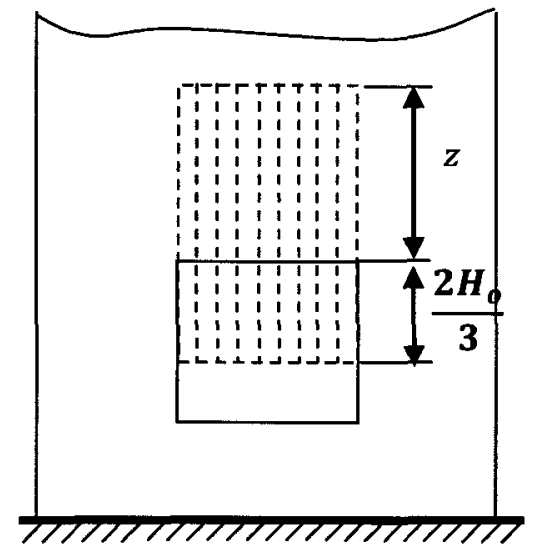

(a) Front view of the flame
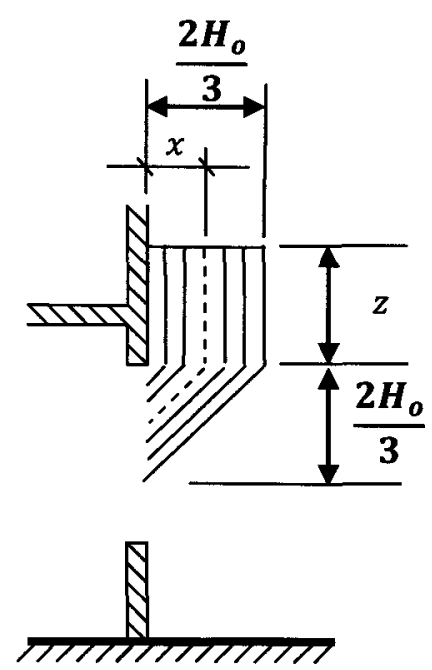

(c) Side view when $\mathrm{Ho}<1.25 \mathrm{Wo}$

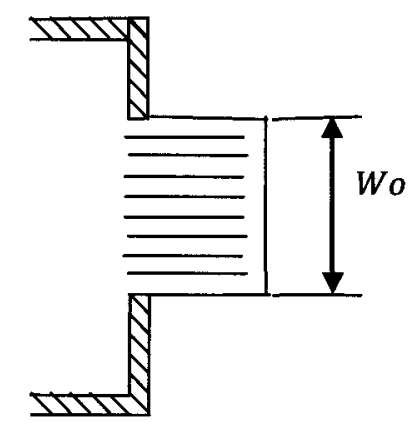

(b)Top view of the flame
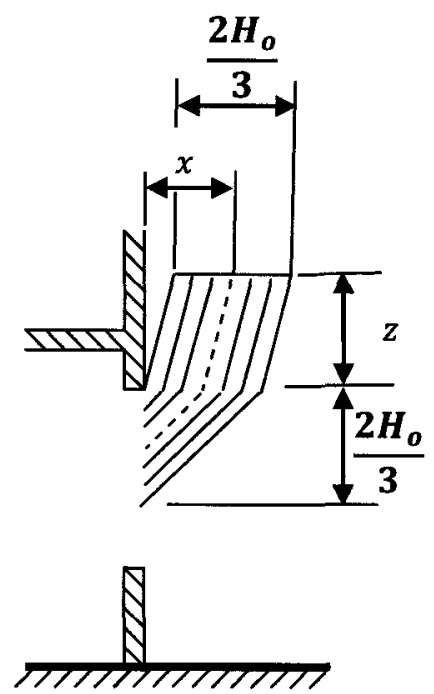

(d) Side view when Ho $>1.25 \mathrm{Wo}$

Figure 9-1 Dimensions of flames projecting out of a window

It is assumed that the front view of the flames projecting out of a window has a rectangular shape ${ }^{[40]}$. The width of the flames equals the width of the window, and the 
thickness of the flame is $2 / 3$ of the height of the window. The dimensions of the flame projecting out from a window under natural ventilation are shown in Figure 9-1.

\subsubsection{Flame Height above the Soffit of a Window/Opening}

The flame height above the soffit of the window is given by ${ }^{[40]}$ :

$$
z=16\left(\frac{\dot{m}_{v} H_{0}}{A_{0} \rho_{0}(g)^{1 / 2}}\right)^{2 / 3}-H_{0}
$$

Where:

$$
\begin{aligned}
& \rho_{0}=\text { The density of air, }\left(\mathrm{kg} / \mathrm{m}^{3}\right) ; \\
& \mathrm{z}=\text { Flame height above the soffit of the window/opening, }(\mathrm{m}) .
\end{aligned}
$$

Assume the density of gas $\rho_{0}=0.45 \mathrm{~kg} / \mathrm{m}^{3}$ at $540^{\circ} \mathrm{C}$ and $\mathrm{g}=9.81 \mathrm{~m} / \mathrm{s}^{2}$, then Equation (9.10) can be simplified as

$$
z=12.8\left(\frac{\dot{m}_{v}}{W_{0}}\right)^{2 / 3}-H_{0}
$$

\subsubsection{Length of Flame along Flame Centerline ${ }^{[40]}$}

As shown in Figure 9-1, the horizontal distance from the flame tip to the wall depends on the aspect ratio of the window/opening. For a window/opening with $\mathrm{H}_{0}<1.25 \mathrm{~W}_{0}$, the horizontal distance $\mathrm{x}$ is given by ${ }^{[40]}$ :

$$
x=\frac{H_{0}}{3}
$$

Where: 
$\mathrm{x}=$ horizontal distance from the flame tip to the external wall, (m).

According to Figure 9-1(c), the flame length along flame centerline is ${ }^{[40]}$ :

$$
L_{f}=z+\sqrt{x^{2}+\left(\frac{H_{0}}{3}\right)^{2}}
$$

Where:

$\mathrm{L}_{\mathrm{f}}=$ Distance from the flame tip to the window along the flame centerline, $(\mathrm{m})$.

If $\mathrm{H}_{0}>1.25 \mathrm{~W}_{0}$, the horizontal distance between the flame centerline at the flame tip and the wall is ${ }^{[40]}$ :

$$
x=0.3 H_{0}\left(\frac{H_{0}}{W_{0}}\right)^{0.54}
$$

According to Figure 9-1(d), the flame length along the flame centerline is ${ }^{[40]}$ :

$$
L_{f}=\sqrt{z^{2}+\left(x-\frac{H_{0}}{3}\right)^{2}}+\sqrt{x^{2}+\left(\frac{H_{0}}{3}\right)^{2}}
$$

\subsubsection{Flame Temperature along Flame Centerline}

Flame temperature at a point with distance $1_{\mathrm{f}}$ from the window along the flame centerline is given by ${ }^{[40]}$ :

$$
\frac{T_{F}-T_{a}}{T_{o}-T_{a}}=1-\frac{0.027 I_{f} W_{0}}{\dot{m}_{v}}
$$

Where:

$\mathrm{T}_{\mathrm{f}}=$ Flame temperature at a point with distance $l_{f}$ from the window along the flame centerline, $(\mathrm{K})$; 


$$
\begin{aligned}
& \mathrm{T}_{\mathrm{o}}=\text { Flame temperature at window }\left(\text { when } l_{f}=0\right) \text { along flame centerline, }(\mathrm{K}) ; \\
& l_{f}=\text { Distance from window along flame centerline, }(\mathrm{m}) .
\end{aligned}
$$

Usually the temperature of the flame tip is known; therefore Equation (9-16) can be rewritten as

$$
T_{o}=T_{a}+\frac{T_{t}-T_{a}}{\left(1-\frac{0027 I_{f} W_{0}}{m_{v}}\right)}
$$

Where:

$$
\mathrm{T}_{\mathrm{t}}=\text { Flame tip temperature }\left(\mathrm{T}_{\mathrm{t}}=540^{\circ} \mathrm{C}\right)^{[40]} \text {. }
$$

The temperature at any point along the flame centerline is:

$$
T_{f}=T_{a}+\left(T_{t}-T_{a}\right) \frac{\dot{m}_{v}-0.027 l_{f} W_{0}}{\dot{m}_{v}-0.027 L_{f} W_{0}}
$$

\subsubsection{Flame Emissivity}

The emissivity of the flames can be calculated by ${ }^{[40]}$

$$
\varepsilon=1-e^{-k \lambda}
$$

Where:

$$
\begin{aligned}
& \varepsilon=\text { Flame emissivity } \\
& \mathrm{k}=\text { Attenuation coefficient },\left(\mathrm{m}^{-1}\right) . \mathrm{k}=0.30 \mathrm{~m}^{-1}[40] ; \mathrm{k}=0.518 \mathrm{~m}^{-1}[37] \\
& \lambda=\text { Flame thickness },(\mathrm{m}) .
\end{aligned}
$$




\section{Chapter 10}

\section{Experimental Study and Modeling of Radiation from Compartment Fires to Adjacent Buildings}

A number of experiments have been conducted to study the problem of radiation emitted from fire buildings ${ }^{[31-37]}$; however the results of these studies are not in agreement. For example, the experimental results of the St. Lawrence burns ${ }^{[32]}$ showed that a major part of the radiation comes from the flames projecting outside the windows, however Law ${ }^{[33,}$ ${ }^{34]}$ stated that the contribution of radiation heat flux due to projecting flames out of the window was not significant and could be ignored. In addition, the value of emissivity of the external flames is an important parameter and needs to be known in order to calculate the radiation heat flux to adjacent buildings. A number of studies have been conducted $[37,38,39,40]$, however further research is needed to figure out which one can give an appropriate value of emissivity that can be used for practical engineering application.

To address these problems, an experimental investigation was conducted at the full-scale fire research laboratories of the National Research Council of Canada (NRCC) to study the amount of radiation heat flux emitted from the flames projecting out of a window. Experiments were conducted in a room with only one window. Three different window sizes were considered by varying the width of the window while maintaining the same 
height. Other parameters considered for these experiments include fuels, and separation distance between the external wall of the fire building and a target wall. For each window size, four experiments were conducted using three separation distances and two different fuels (propane and wood cribs).

\subsection{Description of Experimental Facility}

The experimental facility shown in Figure 10-1 includes a fire building and a target wall.

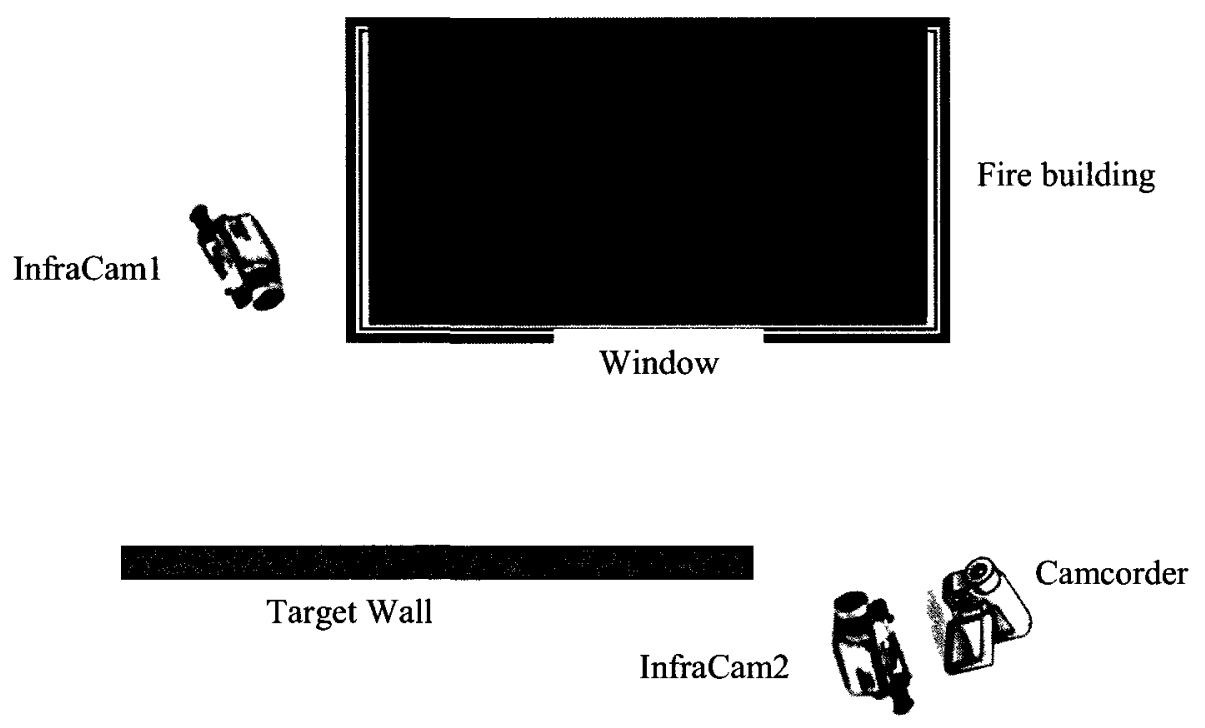

Figure 10-1 Spatial separation fire experiments setting up plan

\subsubsection{The Fire Building}

The size of the fire compartment was $5.95 \times 4.4 \times 2.75 \mathrm{~m}(\mathrm{~W} \times \mathrm{D} \times \mathrm{H})$. The dimensions of the three windows used in the experiments were: $2.55 \times 1.45 \mathrm{~m}, 1.45 \times 1.45 \mathrm{~m}$ and $1.10 \times$ 
$1.45 \mathrm{~m}(\mathrm{~W} \times \mathrm{H})$. The interior walls of the fire compartment were insulated with fiberfrax insulation. The exterior façade of the wall with the window was covered with gypsum board.

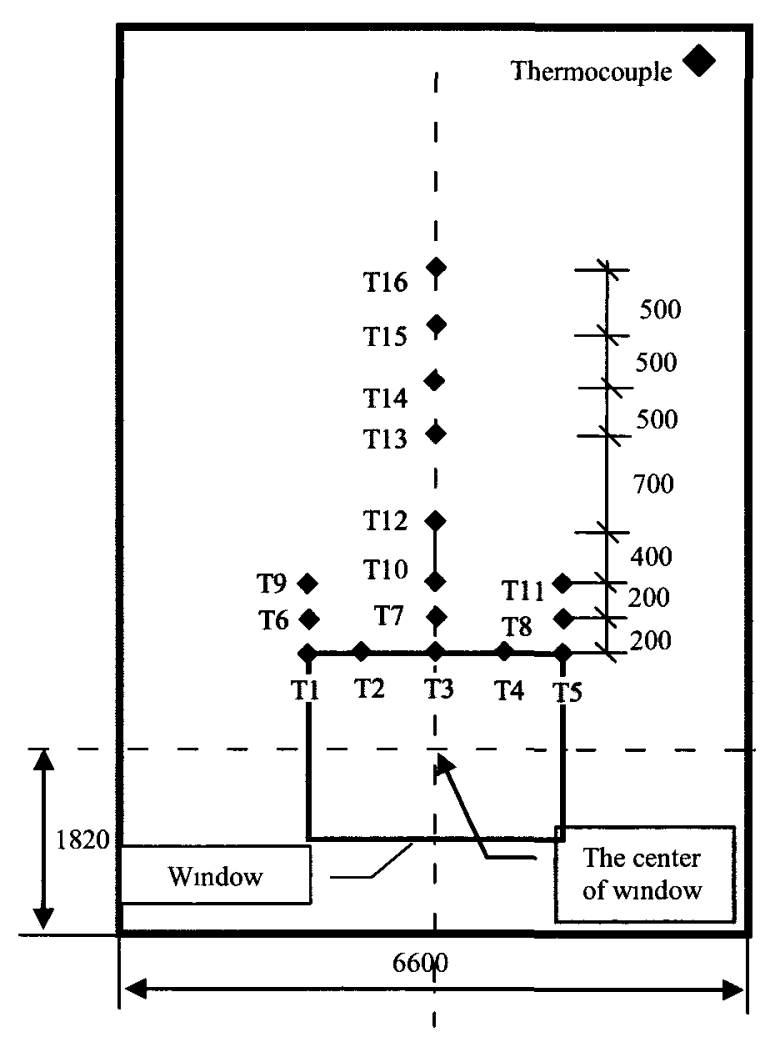

(a) Fire building and its exposing wall

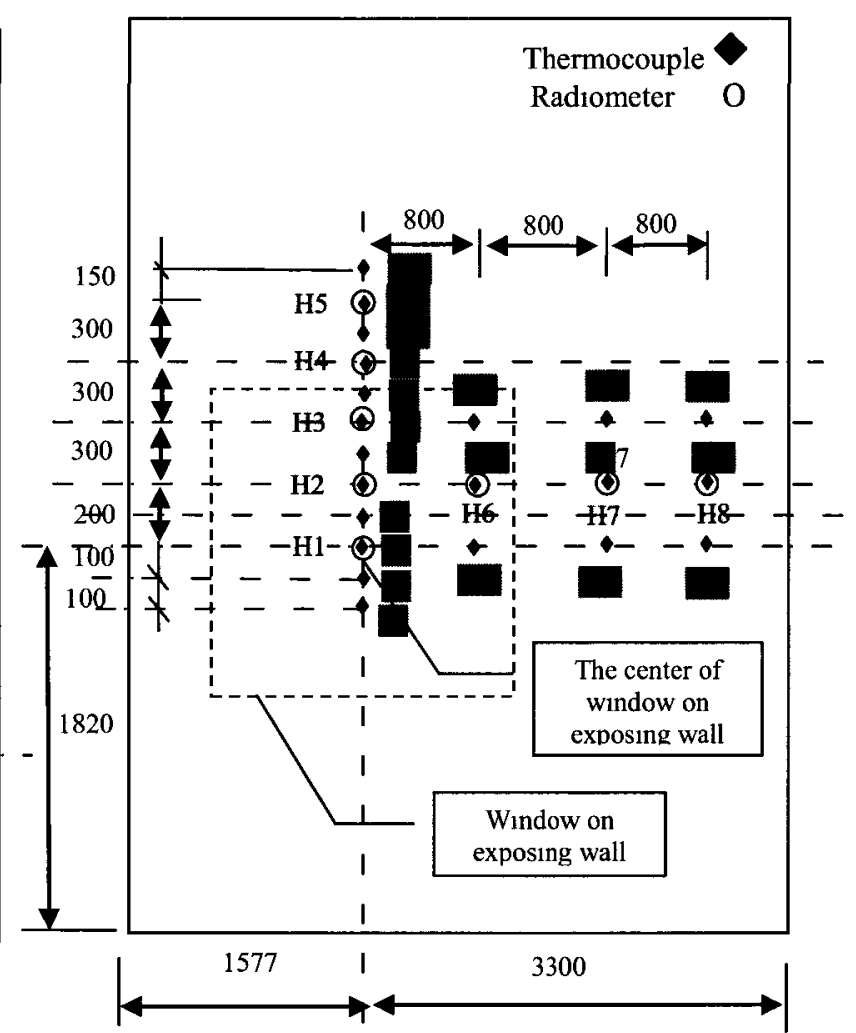

(b) Target wall

Figure 10-2 Instrumentation on the exposing wall and target wall

\section{Instrumentation}

- Three thermocouples were installed inside the fire compartment measuring room temperature (some tests had only two thermocouples); 
- Sixteen thermocouples were installed on the wall above the window. The locations of these thermocouples can be seen in Figure 10-2(a). The tips of five thermocouples located along the soffit of the window were extending just below the soffit of the window to measure the temperature of the flames as they projected out of the window;

- A thermocouple was used to measure flame temperature with its tip $50 \mathrm{~cm}$ above the soffit of the window and $50 \mathrm{~cm}$ from the exterior wall surface.

\subsubsection{Target Wall}

A wood-framed target wall was constructed with a size of $16^{\prime} \times 16^{\prime}(4.88 \times 4.88 \mathrm{~m})$. The target wall was placed away from the fire building at the separation distances of $2.2 \mathrm{~m}$, $3.0 \mathrm{~m}, 3.5 \mathrm{~m}$ or $4.0 \mathrm{~m}$. The exterior façade of the wall was covered with non-combustible cement boards. There were eight or ten radiometers installed on the cement board to measure radiation heat flux. Twenty-one or twenty-five thermocouples were installed to measure the surface temperature of the target wall. The locations of the radiometers $(\mathrm{H})$ and thermocouples (T) on the target wall are shown in Figure 10-2(b). Most radiometers and thermocouples were placed on a vertical line opposite the vertical central line of the window of the fire compartment in order to find the position of maximum radiation heat flux and maximum surface temperature on the target wall. 


\subsubsection{Fire Fuel}

Two kinds of fuels were used in the fire experiments: propane and wood cribs.

\section{a. Propane fire}

Propane was used as the fuel for nine experiments. The propane fire tests were conducted using propane diffusion burners along four pipelines with a length of $3.8 \mathrm{~m}$ evenly distributed in the fire room and elevated $0.6 \mathrm{~m}$ above the floor. The propane mass flow rate was manually controlled. The mass flow rate of the propane was not measured. The most dangerous stage of a compartment fire is the fully-developed fire; therefore, ventilation-controlled fully-developed fires were the focus of this experimental study. During each experiment, the valve controlling the propane flow rate was turned to its maximum position and sustained for at least 10 minutes. It can reasonably be assumed that the maximum mass flow rate of the propane for each fire experiment had the same value.

\section{b. Wood crib fire}

Wood cribs were used as the fuel for three experiments with different windows sizes. In each experiment, $1000-\mathrm{kg}$ wood cribs were put into the fire compartment. This fire load was much higher than the critical value ${ }^{[23]}$ needed for ventilation-controlled fires ensured the duration of the fully-developed fire phase was long enough to do the analysis for the purpose of the experimental study. The density of the fuel load was $38 \mathrm{~kg} / \mathrm{m}^{2}$. Two kinds 
of wood cribs were used in the experiments: 2 " $\times 2$ " $(3.8 \times 3.8 \mathrm{~cm})$ wood cribs were used in the experiment with window size of $2.55 \times 1.45 \mathrm{~m} ; 2$ " $\times 4$ " $(3.8 \times 8.9 \mathrm{~cm})$ wood cribs were used in the two other fire experiments with window sizes of $1.45 \times 1.45 \mathrm{~m}$ and $1.10 \times 1.45$ m.

\subsubsection{Other Instrumentation}

During the test, a camcorder recorded the fire experiment, and two infra-red-cameras were used: one taking the infrared images of the fire building and the other taking the infrared images of the target wall.

\subsection{Results and Discussion}

In experiments 1-9, propane was used as the fuel. The valve controlling the propane flow rate was turned to its maximum position and sustained for more than 10 minutes. It can be assumed that the maximum propane flow rate in every experiment had the same value; however the actual flow rate was not measured.

\subsubsection{Compartment Fire Characteristics}

\subsubsection{Experimental results}



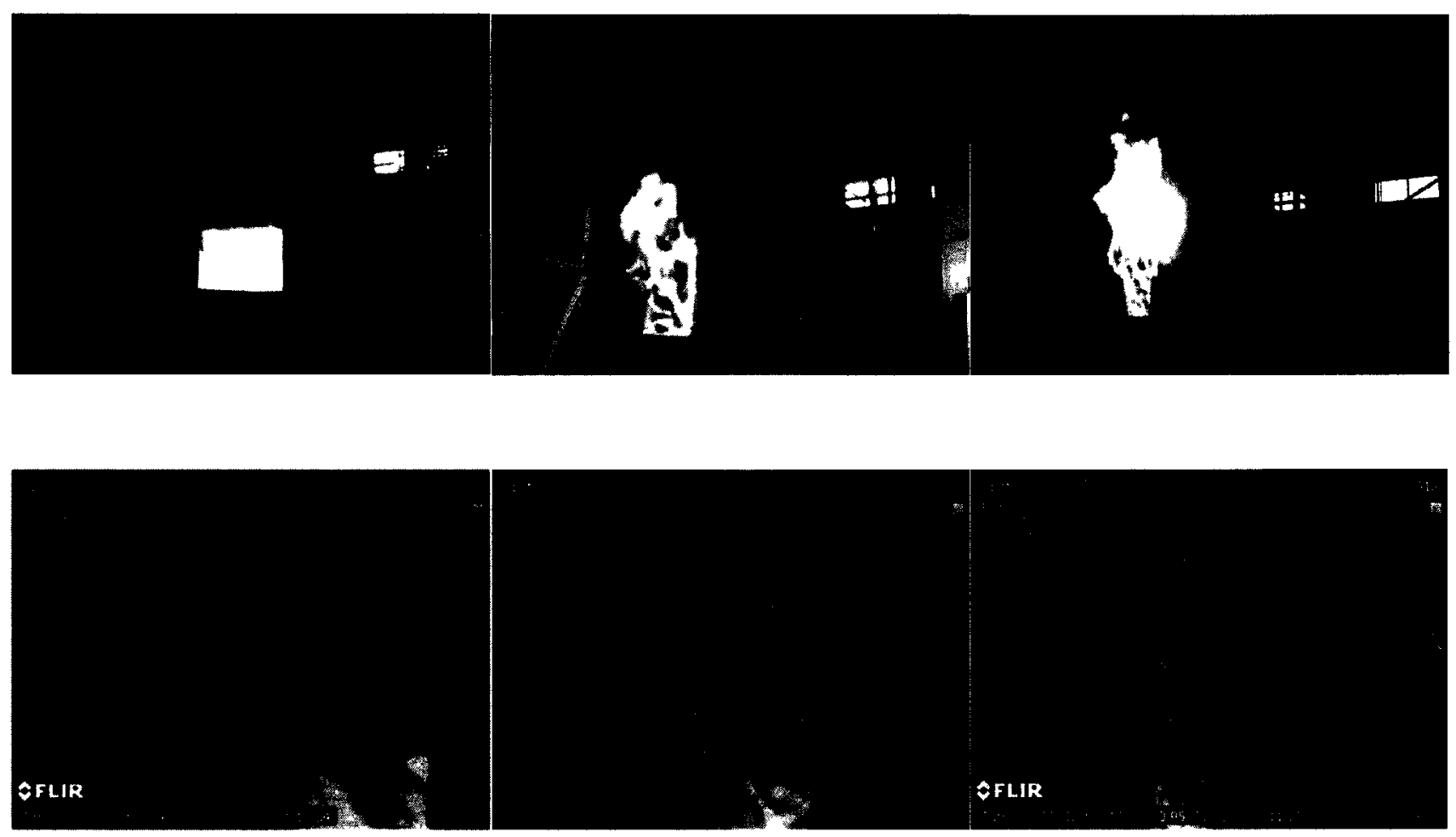

(a) $2.55 \mathrm{~m} \times 1.45 \mathrm{~m}$

(b) $1.45 \mathrm{~m} \times 1.45 \mathrm{~m}$

(c) $1.1 \mathrm{~m} \times 1.45 \mathrm{~m}$

Figure 10-3 Pictures and thermal images of experimental propane fires 
Table 10-1 Experimental data of room temperature and external flame temperature

\begin{tabular}{|c|c|c|c|c|c|c|c|}
\hline No. & Fuel & $\begin{array}{l}\text { Window }(\mathrm{W} \times \mathrm{H}) \\
(\mathrm{m})\end{array}$ & $\begin{array}{l}\text { Separation } \\
\text { distance } \\
\text { (m) }\end{array}$ & $\begin{array}{l}\text { Flame height } \\
\text { above window } \\
\text { ( } \mathrm{m} \text { ) }\end{array}$ & $\begin{array}{c}\text { Maximum room } \\
\text { temperature } \\
\left(\mathrm{C}^{\circ}\right)\end{array}$ & $\begin{array}{c}\text { Maximum flame } \\
\text { temperature at window } \\
\left(\mathrm{C}^{\circ}\right)\end{array}$ & $\begin{array}{c}\text { Flame temperature at } \\
50 \mathrm{~cm} \text { above window } \\
\left(\mathrm{C}^{\circ}\right)\end{array}$ \\
\hline 1 & Propane & $2.55 \times 1.45$ & 3 & 1.5 & 1210 & 1021 & NA \\
\hline 2 & Propane & $2.55 \times 1.45$ & 3.5 & 1.5 & 1215 & 1047 & NA \\
\hline 3 & Propane & $2.55 \times 1.45$ & 4 & 1.5 & 1205 & 1073 & 810 \\
\hline 4 & Propane & $1.45 \times 1.45$ & 3 & 3 & 957 & 993 & 991 \\
\hline 5 & Propane & $1.45 \times 1.45$ & 3.5 & 3 & 918 & 985 & 921 \\
\hline 6 & Propane & $1.45 \times 1.45$ & 2.4 & 3 & 979 & 1022 & 970 \\
\hline 7 & Propane & $1.10 \times 1.45$ & 3.5 & 4 & 879 & 976 & 968 \\
\hline 8 & Propane & $1.10 \times 1.45$ & 3 & 4 & 873 & 1084 & 962 \\
\hline 9 & Propane & $1.10 \times 1.45$ & 4 & 4 & 875 & 1047 & 964 \\
\hline 10 & Wood cribs 2"x4" & $1.10 \times 1.45$ & 3 & 3 & 958 & 942 & 884 \\
\hline 11 & Wood cribs 2"x4" & $1.45 \times 1.45$ & 3 & 2.5 & 1083 & 1010 & 846 \\
\hline 12 & Wood cribs $2 " x 2 "$ & $2.50 \times 1.45$ & 3 & 3.2 & 1050 & 1079 & 956 \\
\hline
\end{tabular}




\section{1) Propane fire experiments}

Table 10-1 and Figure 10-3 show data from the experiments. It can be assumed that the compartment fire for the propane fire experiments with the same window size were similar due to the same propane flow rate. It should be noted that the room temperatures with gypsum board walls instead of fiberfrax walls would be lower than the experimental temperatures.

Comparing the experimental data in Table 10-1 and Figure 10-3, the impact of different window sizes on the compartment fire could be summarized as follows:

a) Room temperature: room temperature decreases as the window size of the fire room decreases as seen in Table 10-1;

b) Height of external flame: external flame height increases as the window width decreases as seen in Figure 10-3;

c) Flame temperature at window: in the test with a window of $2.55 \times 1.45 \mathrm{~m}$, the flame temperature at the window was lower than the room temperature; in the tests with window of $1.45 \times 1.45 \mathrm{~m}$ or $1.10 \times 1.45 \mathrm{~m}$, the flame temperature at the window was higher than the room temperature. This is due to increased combustion taking place outside the room as unburned propane escaped though the window.

d) Flame temperature above window: in the test with a window of $2.55 \times 1.45 \mathrm{~m}$, the flame temperature above the window dropped very fast with height; in the 
tests with window size of $1.45 \times 1.45 \mathrm{~m}$ and $1.10 \times 1.45 \mathrm{~m}$, the flame temperature above the window did not change much with height until reaching the height of about $2 \mathrm{~m}$ below the flame tip which can be seen in Figure 10-3 and Table 10-1. (This is due to the same reason as in (c) above).

\section{2) Wood crib fire experiments}

Three wood crib fire experiments were conducted with three window sizes and two kinds of wood crib sizes ( 2 " $\times 2$ " and 2 " $\times 4$ " or $3.8 \times 3.8 \mathrm{~cm}$ and $3.8 \times 8.9 \mathrm{~cm})$ as shown in Table 10-1. The impact of wood cribs on the fire could be summarized as follows:
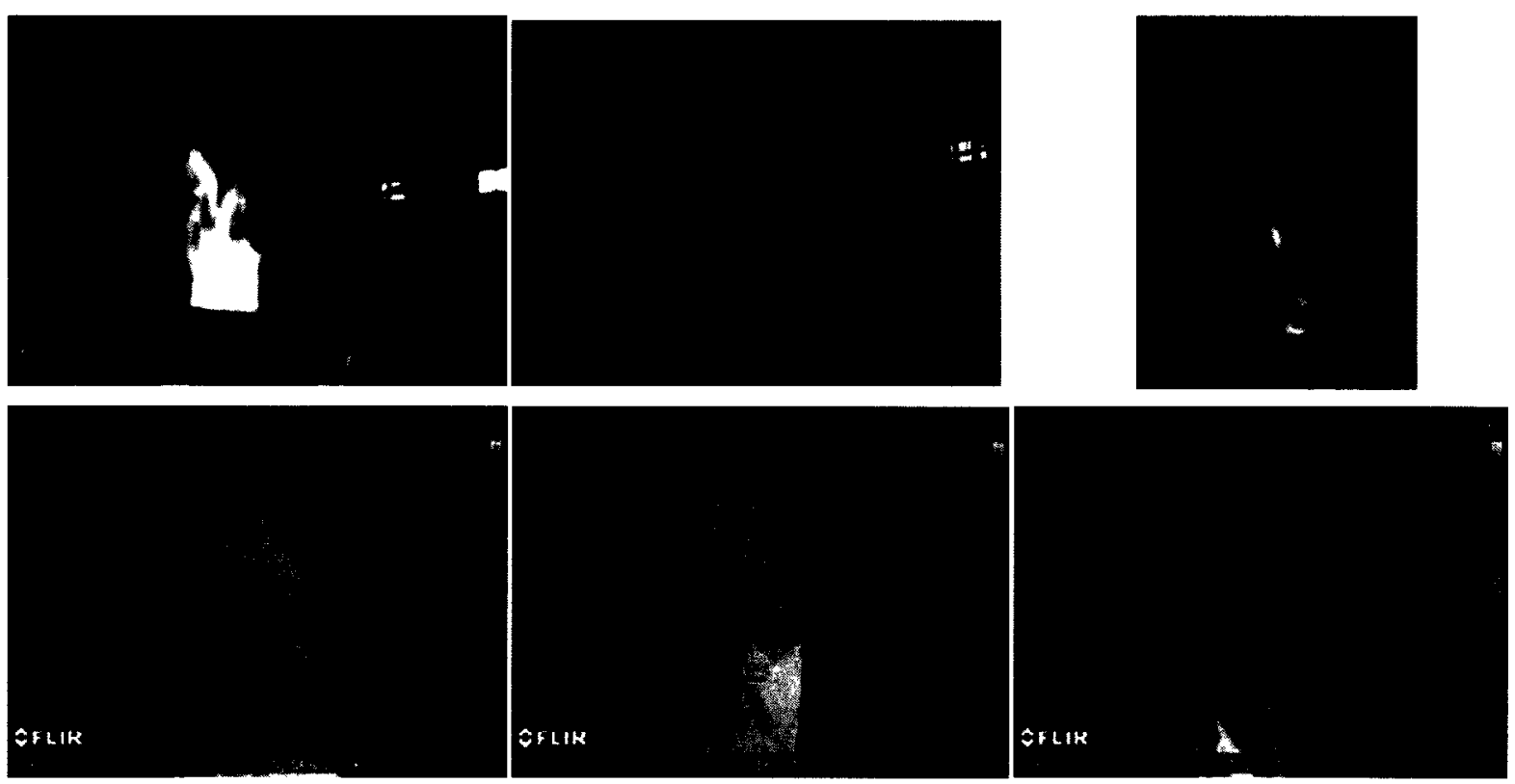
(a) window $2.55 \mathrm{~m} \times 1.45 \mathrm{~m}$ wood crib $2 " \times 2$ "
(b) window $1.45 \mathrm{~m} \times 1.45 \mathrm{~m}$ wood crib 2 " $\times 4$ "
(c) window $1.10 \mathrm{~m} \times 1.45 \mathrm{~m}$ wood crib $2 " \times 4 "$

Figure 10-4 Pictures and thermal images of wood crib fires 
a) Height of external flame: for the two fire experiments using 2"x4" wood cribs as fuel, the external flame height increased as the window width decreased. But for the fire experiment with the $2.55 \times 1.45 \mathrm{~m}$ window using 2 "x2" wood cribs, the flame height was higher than those of the two fire experiments with the smaller size windows and 2"x4" wood cribs as shown in Figure 10-4;

b) Room temperature: for the two fire tests using 2 " $\times 4$ " wood cribs, the room temperature of the test with the $1.45 \times 1.45 \mathrm{~m}$ window was higher than that of the test with the $1.10 \times 1.45 \mathrm{~m}$ window as shown in Table 10-1. However, the room temperature with the $2.55 \times 1.45 \mathrm{~m}$ window and the 2 " $\mathrm{x} 2$ " wood cribs was lower than that of the test with the $1.45 \times 1.45 \mathrm{~m}$ window and the 2 "x 4 "' wood cribs;

c) Flame temperature at window: the flame temperature at the window was almost the same as the room temperature;

d) Flame temperature above the window: for the test with the $1.45 \times 1.45 \mathrm{~m}$ window, the temperature of the external flame above the window decreased fast with height and the flame height above the window was the shortest among the three wood cribs fire tests. For the other two tests, the temperature of the external flame above the window did not change much with height until reaching the height of about $2 \mathrm{~m}$ below the flame tip as shown in the infrared images of Figure 10-4. 
Table 10-2 Theoretical study of the impact of fuel load and window size on post-flashover compartment fire

\begin{tabular}{|c|c|c|c|c|c|c|c|c|c|c|}
\hline \multirow[b]{2}{*}{ No. } & \multirow[b]{2}{*}{$\begin{array}{l}\text { Window } \\
\text { size } \\
(\mathrm{m})\end{array}$} & \multirow[b]{2}{*}{$\begin{array}{c}\text { Ambient } \\
\text { temperature } \\
\left({ }^{\circ} \mathrm{C}\right)\end{array}$} & \multicolumn{4}{|c|}{ Fire load $=1000 \mathrm{~kg}$} & \multicolumn{4}{|c|}{ Fire load $=600 \mathrm{~kg}$} \\
\hline & & & $\begin{array}{l}\text { Burning } \\
\text { rate } \\
(\mathrm{kg} / \mathrm{s})\end{array}$ & $\begin{array}{c}\text { Room } \\
\text { temperature } \\
\left({ }^{\circ} \mathrm{C}\right)^{2}\end{array}$ & $\begin{array}{c}\text { Flame } \\
\text { height above } \\
\text { window } \\
(\mathrm{m})^{3} \\
\end{array}$ & $\begin{array}{l}\text { Flame temperature } \\
\text { at window along } \\
\text { flame centerline } \\
\left({ }^{\circ} \mathrm{C}\right)^{4} \\
\end{array}$ & $\begin{array}{l}\text { Burning } \\
\text { rate } \\
(\mathrm{kg} / \mathrm{s})\end{array}$ & $\begin{array}{c}\text { Room } \\
\text { temperature } \\
\left({ }^{\circ} \mathrm{C}\right)^{2}\end{array}$ & $\begin{array}{c}\text { Flame height } \\
\text { above } \\
\text { window } \\
(\mathrm{m})^{3} \\
\end{array}$ & $\begin{array}{l}\text { Flame temperature } \\
\text { at window along } \\
\text { flame centerline } \\
\left({ }^{\circ} \mathrm{C}\right)\end{array}$ \\
\hline 1 & $2.55 \times 1.45$ & -7 & 0.535 & 1021 & 3.07 & 1051 & 0.535 & 865 & 3.07 & 1051 \\
\hline 2 & $2.55 \times 1.45$ & 6.5 & 0.535 & 1035 & 3.07 & 1038 & 0.535 & 879 & 3.07 & 1038 \\
\hline 3 & $2.55 \times 1.45$ & 0 & 0.535 & 1028 & 3.07 & 1044 & 0.535 & 872 & 3.07 & 1044 \\
\hline 4 & $1.45 \times 1.45$ & -9 & 0.415 & 867 & 4.10 & 993 & 0.415 & 777 & 4.10 & 993 \\
\hline 5 & $1.45 \times 1.45$ & -5.6 & 0.415 & 871 & 4.10 & 990 & 0.415 & 780 & 4.10 & 990 \\
\hline 6 & $1.45 \times 1.45$ & -5.2 & 0.415 & 871 & 4.10 & 990 & 0.415 & 780 & 4.10 & 990 \\
\hline 7 & $1.10 \times 1.45$ & 0 & 0.349 & 781 & 4.50 & 969 & 0.349 & 717 & 4.50 & 969 \\
\hline 8 & $1.10 \times 1.45$ & -7 & 0.349 & 774 & 4.50 & 975 & 0.349 & 710 & 4.50 & 975 \\
\hline 9 & $1.10 \times 1.45$ & 0 & 0.349 & 781 & 4.50 & 969 & 0.349 & 781 & 4.50 & 969 \\
\hline 10 & $1.10 \times 1.45$ & 0 & 0.349 & 781 & 4.50 & 969 & 0.349 & 781 & 4.50 & 969 \\
\hline 11 & $1.45 \times 1.45$ & -4 & 0.415 & 872 & 4.10 & 989 & 0.415 & 782 & 4.10 & 989 \\
\hline 12 & $2.55 \times 1.45$ & 17 & 0.535 & 1045 & 3.07 & 1029 & 0.535 & 889 & 3.07 & 1029 \\
\hline
\end{tabular}

1. Equation (9.9); 2. Equation (9.5); 3. Equation (9.11); 4. Equation (9.17) 


\subsubsection{Theoretical results of post-flashover compartment fire}

The equations presented in Chapter 9 are used to calculate the post-flashover conditions in the compartment for two fire loads: $600 \mathrm{~kg}$ and $1000 \mathrm{~kg}$ of wood. The minimum fire load required for a ventilation-controlled fire in the experimental compartment with the largest window size of $2.55 \times 1.45 \mathrm{~m}$ is $548 \mathrm{~kg}$ which is more than that needed for ventilation controlled fire in the compartment with the smaller window sizes. The window size and ambient conditions were taken from the experimental data. The calculated results for burning rate, room temperature, and flame height and flame temperature are presented in Table 10-2. The experimental ambient temperature was used so that the results of the theoretical calculation of radiation heat fluxes can be compared with the experimental data. The results show that the window has a great impact on all compartment fire characteristics. The larger the window, the higher the compartment temperature, larger burning rate, and higher flame temperature at the window. The flame height however decreases as the window width increases.

\subsubsection{Comparison of experimental data and theoretical results for post-flashover compartment fires}

The experimental data are compared with results of theoretical calculations for postflashover compartment fires. The theoretical results of Table $10-2$ for the $1000 \mathrm{~kg}$ fire load are used for this comparison. The comparison results shown in Table 10-3 can be summarized as follows: 
Table 10-3 Theoretical and experimental data for post-flashover compartment fires

\begin{tabular}{|c|c|c|c|c|c|c|c|c|}
\hline \multirow[t]{2}{*}{ Test } & \multicolumn{2}{|c|}{$\begin{array}{l}\text { Flame height } \\
\text { (m) }\end{array}$} & \multicolumn{2}{|c|}{$\begin{array}{c}\text { Room temperature } \\
\left({ }^{\circ} \mathrm{C}\right)\end{array}$} & \multirow{2}{*}{$\begin{array}{c}\begin{array}{c}\text { Flame temperature at } \\
\text { window along centerline } \\
\left({ }^{\circ} \mathrm{C}\right)\end{array} \\
\text { Theory }^{3}\end{array}$} & \multirow{2}{*}{$\begin{array}{l}\begin{array}{l}\text { Flame temperature out } \\
\text { of the soffit of window } \\
\left({ }^{\circ} \mathrm{C}\right)\end{array} \\
\text { Test }\end{array}$} & \multicolumn{2}{|c|}{$\begin{array}{c}\text { Flame temperature } 0.5 \mathrm{~m} \\
\text { above window along centerline } \\
\left({ }^{\circ} \mathrm{C}\right)\end{array}$} \\
\hline & Test & Theory ${ }^{1}$ & Test & Theory $^{2}$ & & & Test & Theory $^{4}$ \\
\hline 1 & 1.5 & 3.07 & 1210 & 1022 & 1051 & 1021 & NA & 890 \\
\hline 2 & 1.5 & 3.07 & 1215 & 1034 & 1038 & 1047 & NA & 881 \\
\hline 3 & 1.5 & 3.07 & 1205 & 1028 & 1044 & 1073 & 810 & 885 \\
\hline 4 & 3 & 4.10 & 957 & 868 & 993 & 993 & 991 & 881 \\
\hline 5 & 3 & 4.10 & 918 & 871 & 990 & 985 & 921 & 879 \\
\hline 6 & 3 & 4.10 & 979 & 871 & 990 & 1022 & 970 & 879 \\
\hline 7 & 4 & 4.50 & 879 & 781 & 969 & 976 & 968 & 870 \\
\hline 8 & 4 & 4.50 & 873 & 774 & 975 & 1084 & 962 & 875 \\
\hline 9 & 4 & 4.50 & 875 & 781 & 969 & 1047 & 964 & 870 \\
\hline 10 & 3 & 4.50 & 958 & 781 & 969 & 942 & 884 & 870 \\
\hline 11 & 2.5 & 4.10 & 1083 & 872 & 989 & 1010 & 846 & 878 \\
\hline 12 & 3.2 & 3.07 & 1050 & 1045 & 1029 & 1079 & 956 & 874 \\
\hline
\end{tabular}

1. Equation (9.11); 2. Equation (9.5); 3. Equation (9.17); 4. Equation (9.18) 
a) Flame height above soffit of window: For all experiments except experiment 12 , the theoretical flame height above the soffit of the window was higher than the experimental flame height. The experimental flame height for Test 12 was higher than both the theoretical flame height of Tests 1-3 using propane as fuel. It is also higher than the flame heights of Tests 10 and 11 which have smaller window sizes $(1.45 \times 1.45 \mathrm{~m}$ and $1.10 \times 1.45 \mathrm{~m})$ and used the larger wood crib size $2 " \times 4 "$ as fuel;

b) Room temperature: The experimental room temperature is higher than the theoretical value. The theoretical flame temperature at the window along the flame centerline is close to the experimental room temperature;

c) Flame temperature at window: the theoretical value of flame temperature at the window along the flame centerline is very close to the experimental window temperature.

\subsubsection{Radiation on Target Wall}

The amount of radiation heat flux and its distribution on a target wall from a postflashover compartment fire is an important factor affecting fire spread between buildings. Radiation from post-flashover compartment fires can be divided into two parts - radiation from the compartment and radiation from the external flame above the soffit of the window. The impact on radiation of window size, separation distance between the fire building and a target wall, and type of fuel is investigated in this section. 


\subsubsection{Impact of separation distance on radiation and temperature of target wall}

Comparing the results of the three propane fire experiments with a window size

$1.45 \times 1.45 \mathrm{~m}$ shown in Figure 10-5, the followings observation can be made:

a) As expected, the closer the separation distance, the higher the maximum temperature and radiation heat flux on the target wall;

b) The positions of the maximum temperature and radiation heat flux are above the height of the soffit of the window;

c) There is a local maximum temperature and radiation heat flux just above the height of the center of the window.

d) The separation distance has little effect on the shape of the radiation distribution curve on the target wall.

\subsubsection{Impact of window size on radiation and temperature of target wall}

Figure 10-6 shows the results of three propane fire experiments with different window sizes but with the same separation distance of $3.0 \mathrm{~m}$. From the figure, it can be seen that:

a) For the $2.55 \times 1.45 \mathrm{~m}$ window, the points with maximum temperature and heat flux are located just above the center of the window and within the boundary of the window; External flames above the window have little influence on radiation distribution on the target wall due to the radiation from external flame is much smaller than that from window radiator. 

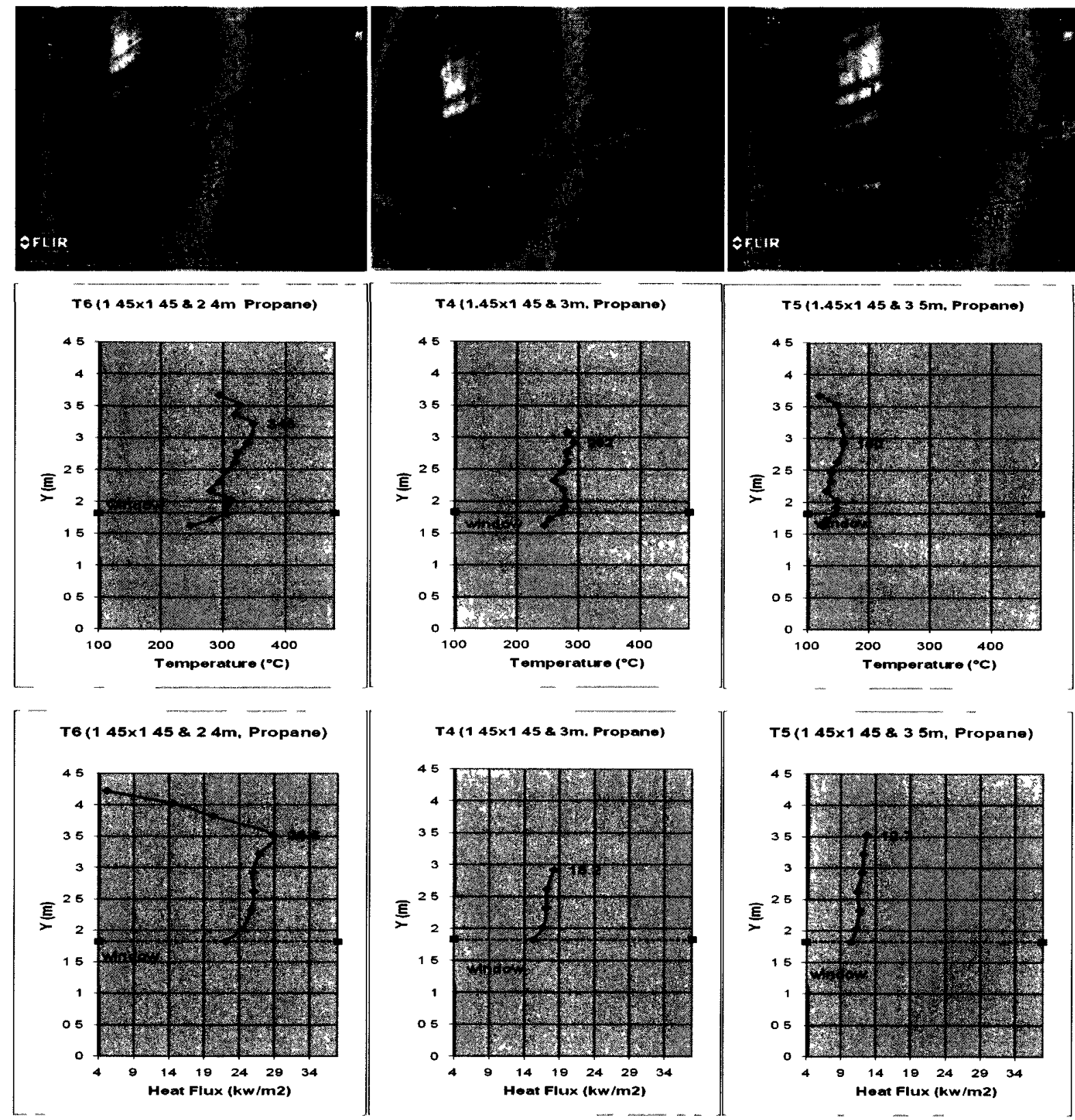

(a) $24 m$

(b) $30 \mathrm{~m}$

T5 (1 45x1 45 \& $3 \mathrm{sm}$, Propane)

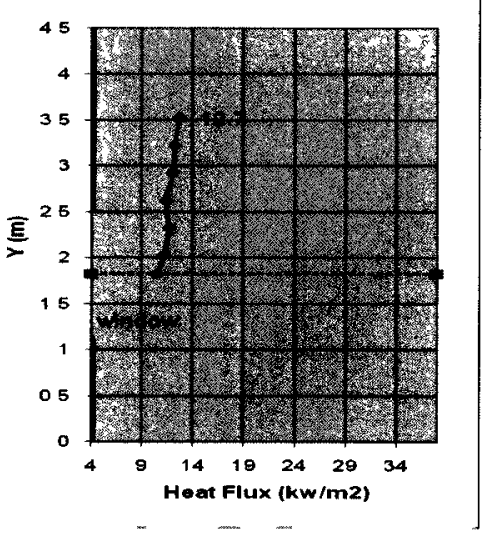

(c) $35 \mathrm{~m}$

Figure 10-5 Propane fire with same window size but different separation distance 

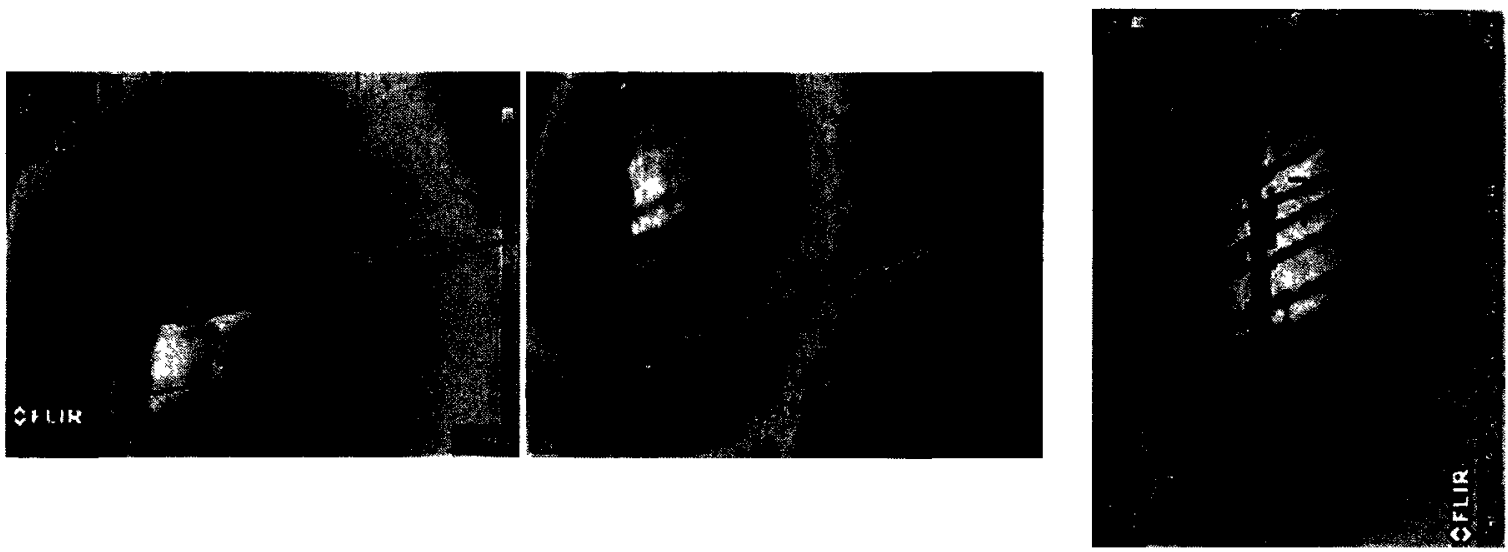

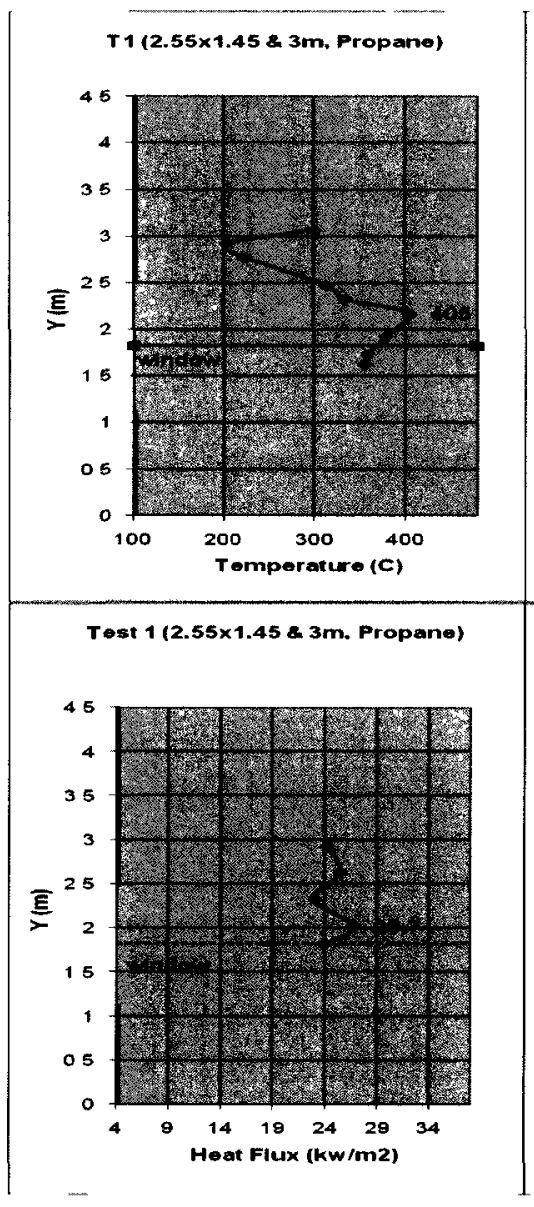

Window $2.55 \times 1.45 \mathrm{~m}$

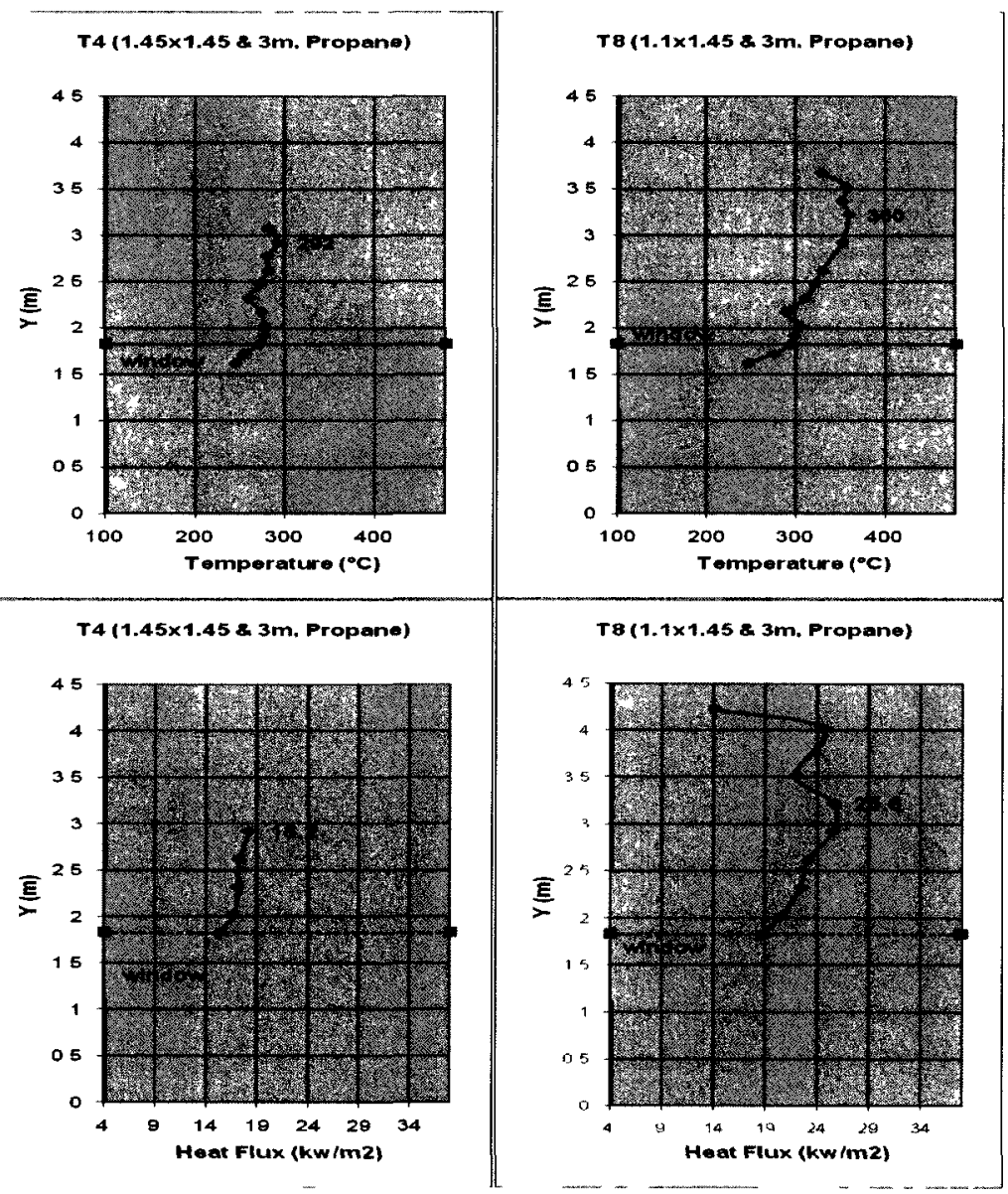

Window $1.45 \times 1.45 m$
Window $1.10 \times 1.45 \mathrm{~m}$

Figure 10-6 Propane fire with same separation distance but different window sizes 
b) For the $1.45 \times 1.45 \mathrm{~m}$ and $1.10 \times 1.45 \mathrm{~m}$ window, the points with maximum temperature and heat flux are located above the soffit of the window. The smaller the window width, the higher the location of the maximum temperature and heat flux; External flames above the window have great influence on radiation distribution on the target wall.

c) For the experiment with the $1.45 \mathrm{~m} \times 1.45 \mathrm{~m}$ window, the maximum temperature and heat flux are smaller than those of the other two experiments with the larger window size and the smaller window size.

The ratio of the height to width of a window has a significant impact on the radiation distribution on a target wall. The location of the maximum heat flux on the target wall goes up as the ratio of the height to width of window increases. For the window with square shape, the maximum heat flux on the target wall is less than those of other two window sizes. It can be concluded that for a window with its width much larger than its height, the radiation on the target wall is mainly from the window on exposing wall and for a window with its width much smaller than its height, the radiation on the target wall is mainly from the external flame above the window on exposing wall.

\subsubsection{Impact of fuel on distribution of radiation and temperature on target wall}

Comparing the experiments with same window size and separation distance but different fire fuels (propane and wood cribs), the following observations can be made: 

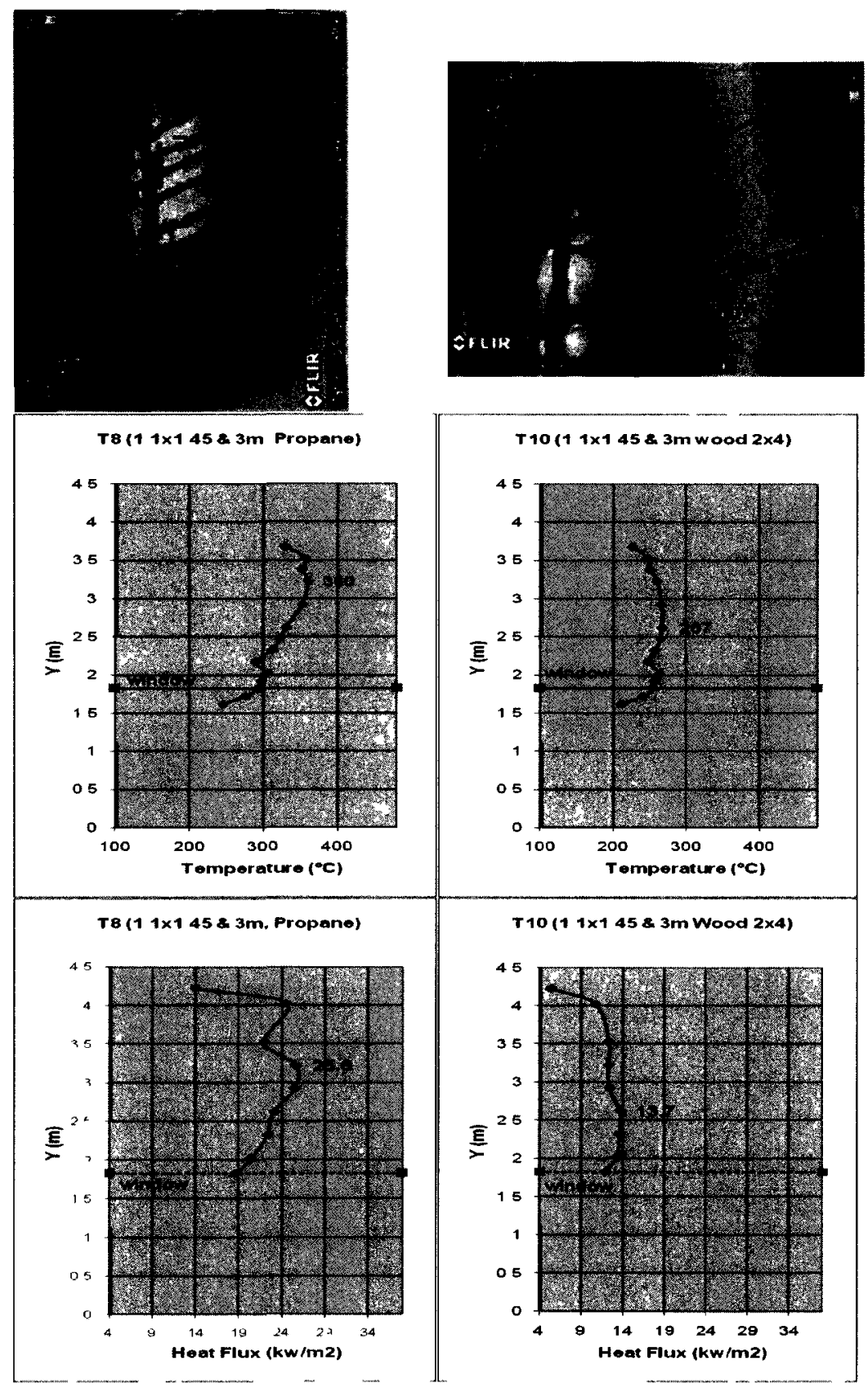

(a) Propane

(b) Wood cribs 2" $\times 4 "$

Figure 10-7 Propane fire and wood crib fire with window $1.10 \times 1.45 \mathrm{~m}$ 
a) The experiments with the $1.10 \times 1.45 \mathrm{~m}$ window as shown in Figure 10-7,

- Propane fire: the global maximum temperature and heat flux are located above the soffit of the window; local maximum values of temperature and heat flux are located at a point just above the center of window;

- $2 " \times 4$ " wood crib fire: the global maximum temperature and heat flux are located above the soffit of the window; local maximum values of temperature and heat flux are located at a point just above the center of window.

- Propane fire posed more severe fire hazard to the target wall.

b) The experiments with the $1.45 \times 1.45 \mathrm{~m}$ as shown in Figure $10-8$,

- Propane fire: the global maximum temperature and heat flux are located above the soffit of the window; local maximum values of temperature and heat flux are located at a point just above the center of window;

- 2" $\times 4$ " wood cribs fire: the global maximum temperature and heat flux are located just above the center of window; local maximum values of temperature and heat flux are located above the soffit of window.

c) Fire experiments with the $2.55 \times 1.45 \mathrm{~m}$ window shown in Figure 10-9,

- Propane fire: the global maximum temperature and heat flux are located just above the center of the window; local maximum values of the temperature and heat flux are located above the soffit of the window; 


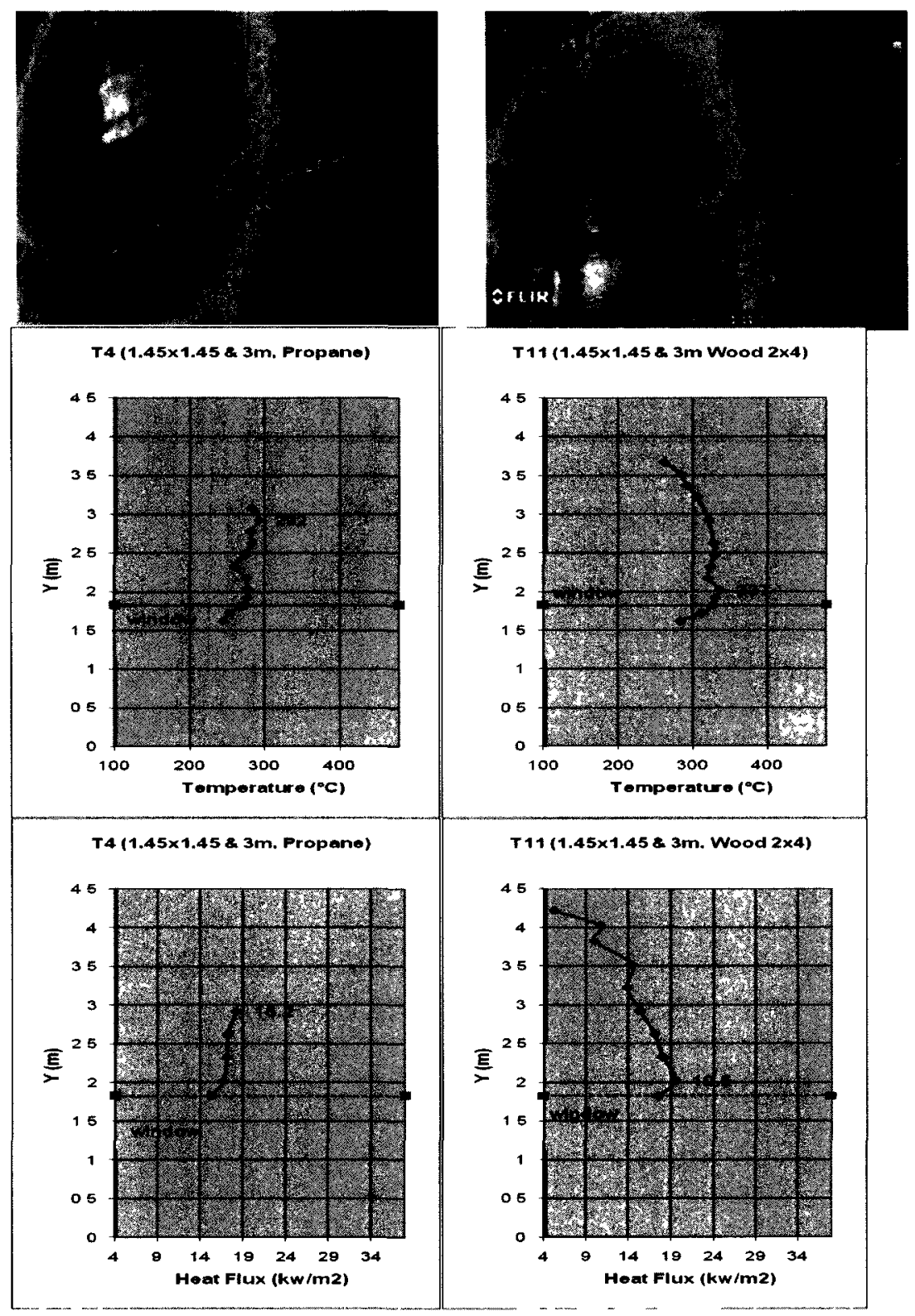

(a) Propane

(b) Wood cribs 2" $\times 4 "$

Figure 10-8 Propane fire and wood crib fire with window $1.45 \times 1.45 \mathrm{~m}$ 

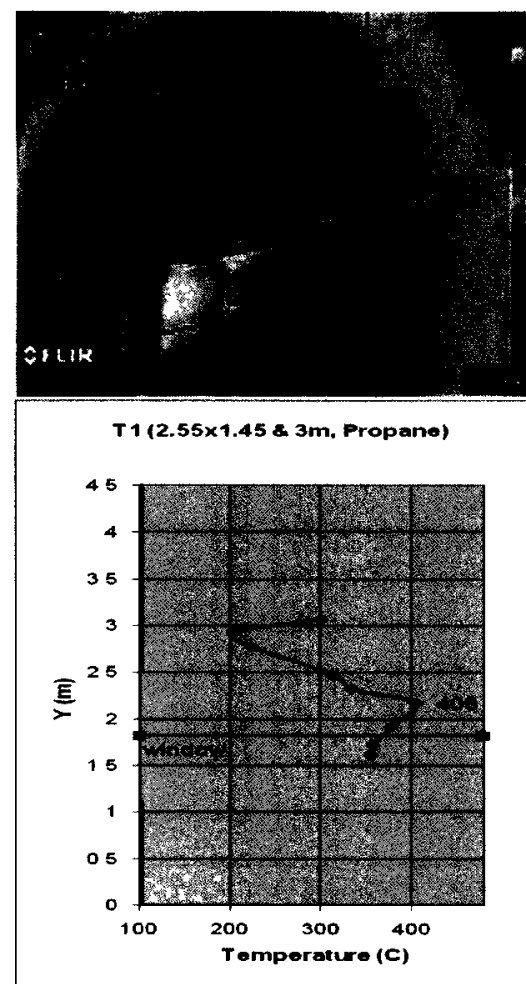

Test 1 (2.55x1.45 a 3m, Propane)

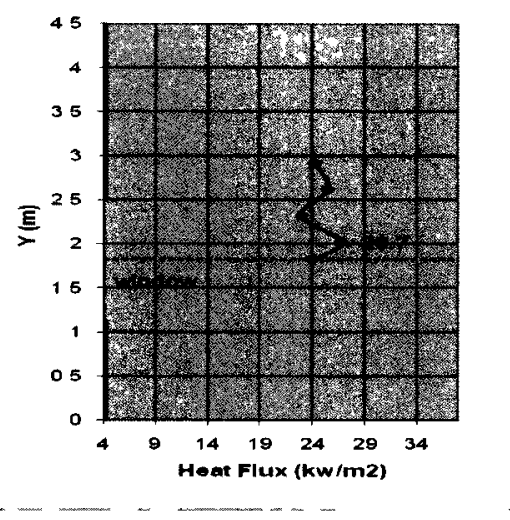

(a) Propane
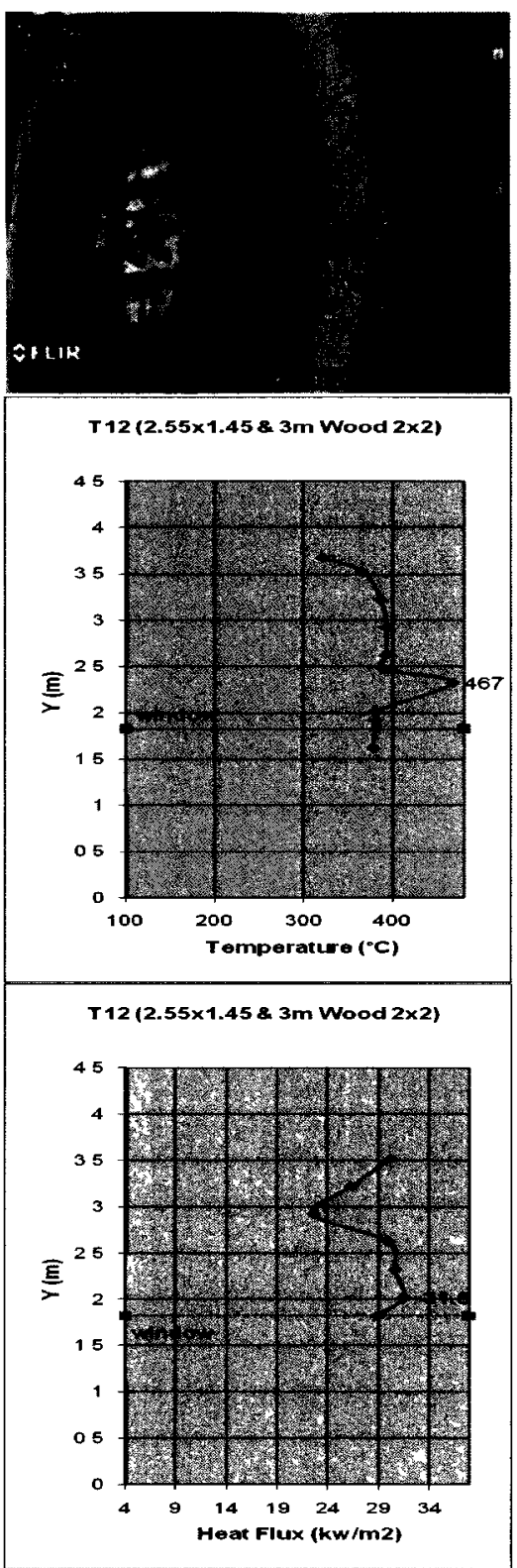

(b) Wood cribs 2" $\times 2 "$

Figure 10-9 Propane and wood crib fire with window $2.55 \times 1.45 \mathrm{~m}$ 
- 2" $\times 2$ " wood cribs fire: the global maximum temperature and heat flux are located just above the center of the window; local maximum values of the temperature and heat flux are located above the soffit of window.

- Wood fire posed more severe fire hazard to the target wall.

By comparison of the locations of the maximum temperature and radiation heat flux on the target wall for the tests with same window size but different fire fuel, the position for the test using propane as fuel was higher than that of the test with wood crib for the two smaller window sizes. This may be due to using the same propane flow rate in every propane test, therefore there was more unburned propane that flows out of the room and burnt outside during the fully-developed fire phase. Although propane fires cannot be found in real fires, this type of fire may be similar to a fire in a compartment with its fire load dominated by plastic materials, in which case a lot of unburned hydrocarbons escape the room of fire and burn outside.

\subsubsection{Analysis of radiation heat flux on target wall}

The influence of the window size, flame height and fuel type on the distribution of radiation heat flux on the target wall are summarized in Table $10-4 . \dot{q}_{c w}^{\prime \prime}$ is the heat flux at the point on the target wall opposite center of the window; $\dot{q}_{\text {Max }}^{\prime \prime}$ is the maximum heat flux on the target wall measured by radiometers during the experiment. The location of 
the maximum heat flux and ratio of $\dot{q}_{M a x}^{\prime \prime}$ to $\dot{q}_{c w}^{\prime \prime}$ reflect the impact of external flame to radiation heat flux on the target wall.

The radiation heat flux is emitted from two radiators - the window radiator and the external flame above the window.

$$
\dot{q}_{\text {exp }}^{\prime \prime}=\dot{q}_{w}^{\prime \prime}+\dot{q}_{e f}^{\prime \prime}
$$

Where:

$$
\begin{aligned}
& \dot{q}_{\text {exp }}^{\prime \prime}=\text { Heat flux measured on target wall, }\left(\mathrm{W} / \mathrm{m}^{2}\right) ; \\
& \dot{q}_{w}^{\prime \prime}=\text { Heat flux coming from the window, }\left(\mathrm{W} / \mathrm{m}^{2}\right) ; \\
& \dot{q}_{e f}^{\prime \prime}=\text { Heat flux coming from the external flame above the window, }\left(\mathrm{W} / \mathrm{m}^{2}\right) .
\end{aligned}
$$

In this thesis, it is assumed that, for post-flashover compartment fires, the window has a constant temperature and its emissivity is 1 . Therefore the radiation heat flux coming from the window is

$$
\dot{q}_{w}^{\prime \prime}=\varepsilon_{w} \sigma F_{d E-W} T_{w}^{4}
$$

Where:

$$
\begin{aligned}
& \left.\varepsilon_{\mathrm{W}}=\text { Emissivity of window radiator (assume } \varepsilon_{\mathrm{w}}=1\right) \\
& \sigma=\text { Stefan-Boltzmann constant, } \sigma=5.67 \times 10^{-8} \mathrm{~W} /\left(\mathrm{m}^{2} \mathrm{~K}^{4}\right) ; \\
& \mathrm{F}_{\mathrm{dE}-\mathrm{W}}=\text { Configuration factor from window to a point on target wall; } \\
& \mathrm{T}_{\mathrm{w}}=\text { Temperature of window radiator, }(\mathrm{K}) .
\end{aligned}
$$


Table 10-4 The comparisons of the radiation heat flux on target wall due to post-flashover compartment fires

\begin{tabular}{|c|c|c|c|c|c|c|c|}
\hline Test & Fuel & $\begin{array}{l}\text { Window } \\
(\mathrm{W} \times \mathrm{H}) \\
(\mathrm{m})\end{array}$ & $\begin{array}{l}\text { Separation } \\
\text { distance } \\
\text { (m) }\end{array}$ & $\begin{array}{l}\text { Heat flux at the point opposite } \\
\text { center of window } \dot{q}_{c w}^{\prime \prime} \\
\qquad\left(\mathrm{kW} / \mathrm{m}^{2}\right)\end{array}$ & $\begin{array}{l}\text { Maximum heat } \\
\text { flux } \dot{q}_{\max }^{\prime \prime} \\
\left(\mathrm{kW} / \mathrm{m}^{2}\right)\end{array}$ & $\frac{\dot{q}_{\max }^{\prime \prime}}{\dot{q}_{c w}^{\prime \prime}}$ & $\begin{array}{c}\text { Position of } \\
\text { maximum heat flux }\end{array}$ \\
\hline 1 & Propane & $2.55 \times 1.45$ & 3 & 23.99 & 26.71 & 1.11 & Within window \\
\hline 2 & Propane & $2.55 \times 1.45$ & 3.5 & 18.70 & 20.23 & 1.08 & Within window \\
\hline 3 & Propane & $2.55 \times 1.45$ & 4 & 15.97 & 17.31 & 1.08 & Within window \\
\hline 4 & Propane & $1.45 \times 1.45$ & 3 & 15.24 & 18.22 & 1.20 & above window \\
\hline 5 & Propane & $1.45 \times 1.45$ & 3.5 & 10.46 & 12.67 & 1.21 & above window \\
\hline 6 & Propane & $1.45 \times 1.45$ & 2.4 & 22.02 & 28.75 & 1.31 & above window \\
\hline 7 & Propane & $1.10 \times 1.45$ & 3.5 & 14.84 & 26.46 & 1.78 & above window \\
\hline 8 & Propane & $1.10 \times 1.45$ & 3 & 18.65 & 25.62 & 1.37 & above window \\
\hline 9 & Propane & $1.10 \times 1.45$ & 4 & 11.50 & 15.93 & 1.39 & above window \\
\hline 10 & Wood cribs 2"x4" & $1.10 \times 1.45$ & 3 & 11.82 & 13.65 & 1.15 & above window \\
\hline 11 & Wood cribs 2"x4" & $1.45 \times 1.45$ & 3 & 17.49 & 19.45 & 1.11 & Within window \\
\hline 12 & Wood cribs 2"x2" & $2.55 \times 1.45$ & 3 & 28.79 & 31.47 & 1.09 & Within window \\
\hline
\end{tabular}


Two different kinds of temperatures could be used as the temperature of the window radiator, one is the maximum room temperature and the other is the maximum flame temperature out of the soffit of window. Substituting the temperature of the window radiator into Equation (10.2), the heat fluxes on the target wall emitted by the window radiator at a point perpendicular to the window center are listed in Table 10-5. The results show that using the maximum room temperature for the calculation of the radiation heat flux from the window to the target wall for some cases gives values greater than the experimental values; using the maximum flame temperature out of the soffit of the window yields more reasonable results.

(a) Radiation contribution from the external flame above the soffit of the window

If the heat flux due to the window radiator is known, the percentage of radiation heat flux coming from the external flame above the soffit of the window could be calculated by

$$
\mathbf{f}_{\mathbf{q}_{\text {ef }}}=\frac{\dot{\boldsymbol{q}}_{\text {ef }}^{\prime \prime}}{\dot{\boldsymbol{q}}_{\text {exp }}} \times 100 \%=\frac{\dot{\boldsymbol{q}}_{\text {exp }}^{\prime \prime}-\dot{\boldsymbol{q}}_{\mathrm{w}}^{\mathrm{n}}}{\dot{\boldsymbol{q}}_{\text {exp }}} \times 100 \%
$$

Where:

$f_{q_{e f}}=$ Percentage of heat flux coming from the external flame above the soffit of the window 
Table 10-5 Radiation contributed from projecting flame above soffit of window during fully-developed fire phase

\begin{tabular}{|c|c|c|c|c|c|}
\hline \multirow{2}{*}{ Test } & \multirow{2}{*}{$\begin{array}{l}\text { Heat flux measured at the point } \\
\text { on target wall opposite to center } \\
\text { of the window } \dot{q}_{\text {exp }}^{\prime \prime}\left(\mathrm{kW} / \mathrm{m}^{2}\right)\end{array}$} & \multicolumn{2}{|c|}{ Results with $\mathrm{T}_{\mathrm{w}}=$ maximum room temperature } & \multicolumn{2}{|c|}{$\begin{array}{l}\text { Results with } T_{w}=\text { maximum external flame } \\
\text { temperature out of the soffit of window }\end{array}$} \\
\hline & & $\begin{array}{l}\text { Heat flux from room } \\
\text { fire } \dot{q}_{w}^{\prime \prime}\left(\mathrm{kW} / \mathrm{m}^{2}\right)\end{array}$ & $\begin{array}{l}\text { Contribution from } \\
\text { external flame } \mathrm{f}_{\mathrm{q}_{\text {ef }}}(\%)\end{array}$ & $\begin{array}{l}\text { Heat flux from room fire } \\
\qquad \dot{q}_{w}^{\prime \prime}\left(\mathrm{kW} / \mathrm{m}^{2}\right)\end{array}$ & $\begin{array}{c}\text { Contribution from } \\
\text { external flame } \mathrm{f}_{\mathrm{q}_{\mathrm{ef}}}(\%)\end{array}$ \\
\hline 1 & 23.99 & 31.01 & 0 & 17.98 & 25 \\
\hline 2 & 18.70 & 23.94 & 0 & 14.85 & 21 \\
\hline 3 & 15.97 & 18.28 & 0 & 12.59 & 21 \\
\hline 4 & 15.24 & 8.96 & 41.2 & 10.05 & 34 \\
\hline 5 & 10.46 & 5.90 & 43.6 & 7.58 & 28 \\
\hline 6 & 22.02 & 14.44 & 34.4 & 16.53 & 25 \\
\hline 7 & 14.84 & 3.96 & 73.3 & 5.48 & 63 \\
\hline 8 & 18.65 & 5.20 & 72.1 & 10.23 & 45 \\
\hline 9 & 11.50 & 3.02 & 73.7 & 5.27 & 54 \\
\hline 10 & 11.82 & 6.92 & 41.4 & 6.58 & 44 \\
\hline 11 & 17.49 & 13.23 & 24.3 & 10.59 & 39 \\
\hline 12 & 28.79 & 19.64 & 31.8 & 21.45 & 25 \\
\hline
\end{tabular}


Based on the temperature in Table 10-3, the percentage of radiation heat flux coming from the external flame above the soffit of the window is shown in Table 10-5. The results in Table 10-5 show that it is better to choose the flame temperature out of the soffit of window as the temperature of the window radiator if the compartment fire is a ventilation controlled fire.

\section{(b) Emissivity of the external flame above the soffit of the window}

If the flame height is less than $2 \mathrm{~m}$, it is assumed that the temperature of the external flame is equal to the average value of the flame tip temperature and the flame temperature out of the soffit of the window.

Then the experimental heat flux could be written as

$$
\dot{q}_{e x p}^{\prime \prime}=\dot{q}_{w}^{\prime \prime}+\dot{q}_{e f}^{\prime \prime}=\varepsilon_{w} \sigma F_{d E-W} T_{w}^{4}+\varepsilon_{e f} \sigma F_{d E-E F} T_{E F}^{4}=\varepsilon_{w} \dot{q}_{w}^{\prime B}+\varepsilon_{e f} \dot{q}_{e f}^{\prime B}
$$

Where:

$\varepsilon_{e f}=$ Emissivity of radiator of external flame;

$\mathrm{F}_{\mathrm{dE}-\mathrm{EF}}=$ Configuration factor from the radiator of external flame to a point on target wall;

$\mathrm{T}_{\mathrm{ef}}=$ Temperature of external flame radiator, $(\mathrm{K})$;

$\dot{q}_{w}^{B}=$ Radiation heat flux received by target wall from window radiator assuming window radiator is black body, $\left(\mathrm{W} / \mathrm{m}^{2}\right)$; 
$\dot{q}_{e f}^{B}=$ Radiation heat flux received by target wall from external flame radiator assuming external flame radiator is black body, $\left(\mathrm{W} / \mathrm{m}^{2}\right)$.

Therefore the emissivity of the external flame radiator can be found using

$$
\varepsilon_{e f}=\frac{\dot{\boldsymbol{q}}_{e x p}-\varepsilon_{w} \dot{q}_{w}^{B}}{\dot{q}_{e f}^{B}}
$$

If the flame height is greater than $2 \mathrm{~m}$, the external flame above the soffit of the window is divided into two parts- bottom part and upper part.

- The bottom part is assumed to start from the soffit of window to the point of $2 \mathrm{~m}$ below flame tip. Within this range, the flame temperature changes little and could be assumed constant. In this paper, it is assumed that the temperature of the bottom part of external flame radiator is equal to the temperature of the flame at a point $50 \mathrm{~cm}$ above the soffit of the window and $50 \mathrm{~cm}$ away from the surface of the fire building.

- The upper part ranges from $2 \mathrm{~m}$ below the flame tip to the flame tip. Within this range, the temperature drops very fast. In this study, it is assumed that the temperature of the upper part of the external flame is equal to the average of the flame tip temperature and the temperature of the bottom part of external flame. To simplify the problem, it is assumed that the external flame has the same thickness in both the upper and bottom parts and the same emissivity. Then the radiation from black body external flame to the target point could be calculated by

$$
\dot{q}_{e f}^{B}=\sigma F_{d E-B P} T_{B P}^{4}+\sigma F_{d E-U P} T_{U P}^{4}
$$


Table 10-6 The emissivity of external flame

\begin{tabular}{|c|c|c|c|c|c|c|c|c|c|c|}
\hline \multirow{3}{*}{ Test } & \multirow{3}{*}{$\begin{array}{l}\text { Width of } \\
\text { radiator } \\
\text { (m) }\end{array}$} & \multirow{2}{*}{\multicolumn{3}{|c|}{ Window radiator }} & \multicolumn{6}{|c|}{ External flame radiator } \\
\hline & & & & & \multicolumn{2}{|c|}{ Bottom part } & \multicolumn{2}{|c|}{ Upper part } & \multicolumn{2}{|c|}{ Emissivity } \\
\hline & & $\begin{array}{l}\text { Height } \\
\text { (m) }\end{array}$ & $\begin{array}{c}\text { Temperature } \\
\left({ }^{\circ} \mathrm{C}\right)\end{array}$ & Emissivity & Height (m) & $\begin{array}{c}\text { Temperature }{ }^{2} \\
\left({ }^{\circ} \mathrm{C}\right)\end{array}$ & $\begin{array}{l}\text { Height } \\
\text { (m) }\end{array}$ & $\begin{array}{c}\text { Temperature }{ }^{3} \\
\left({ }^{\circ} \mathrm{C}\right)\end{array}$ & Test & Average \\
\hline 1 & \multirow{4}{*}{2.55} & \multirow{4}{*}{1.45} & 1021 & \multirow{4}{*}{1.0} & 0 & 1021 & 1.5 & 780.50 & 0.580 & \multirow{8}{*}{0.519} \\
\hline 2 & & & 1047 & & 0 & 1047 & 1.5 & 793.50 & 0.428 & \\
\hline 3 & & & 1073 & & 0 & 1073 & 1.5 & 806.50 & 0.475 & \\
\hline 12 & & & 1079 & & 1.2 & 956 & 2 & 748.00 & 0.629 & \\
\hline 4 & \multirow{4}{*}{1.45} & \multirow{4}{*}{1.45} & 993 & \multirow{4}{*}{1.0} & 1 & 991 & 2 & 765.50 & 0.515 & \\
\hline 5 & & & 985 & & 1 & 921 & 2 & 730.50 & 0.498 & \\
\hline 6 & & & 1022 & & 1 & 970 & 2 & 755.00 & 0.421 & \\
\hline 11 & & & 1010 & & 0.5 & 846 & 2 & 693.00 & 0.607 & \\
\hline 7 & \multirow{4}{*}{1.10} & \multirow{4}{*}{1.45} & 976 & \multirow{4}{*}{1.0} & 2 & 968 & 2 & 754.00 & 0.892 & \multirow{4}{*}{0.820} \\
\hline 8 & & & 1084 & & 2 & 962 & 2 & 751.00 & 0.808 & \\
\hline 9 & & & 1047 & & 2 & 964 & 2 & 752.00 & 0.922 & \\
\hline 10 & & & 942 & & 1 & 884 & 2 & 712.00 & 0.657 & \\
\hline
\end{tabular}

1. the maximum flame temperature out of the soffit of window

2. the temperature of flame at the point $50 \mathrm{~cm}$ above the soffit of window and $50 \mathrm{~cm}$ away from the external wall of fire building

3. the average of the temperature of bottom part and flame tip temperature 
Substituting Equation (10.6) into Equation (10.5), the emissivity of the external flame radiator can be found as shown in Table 10-6. From Table 10-6, it can be seen that the experimental result of emissivity is much larger than the theoretical value calculated by Equation (9.19) which is 0.252 when the attenuation coefficient $\mathrm{k}=0.30 \mathrm{~m}^{-1}{ }^{[40]}$ or 0.394 when $\mathrm{k}=0.518 \mathrm{~m}^{-1}[37]$.

To simplify the problem, it is assumed that the emissivity of the external flame radiator is independent of the type of fuel in the compartment. The results in Table 10-6 show that the emissivity of the external flame depends on window size. For windows with $\mathrm{Ho}<1.25 \mathrm{Wo}(2.55 \times 1.45 \mathrm{~m}$ and $1.45 \times 1.45 \mathrm{~m})$, the mean emissivity of the external flame is 0.519. For the window with Ho $>1.25$ Wo $(1.10 \times 1.45 \mathrm{~m})$, the mean emissivity of the external flame is 0.820 . The reason why there is higher value of the emissivity for window with Ho $>1.25$ Wo is that there was more soot in the external flame due to unburnt propane coming outside.

\subsection{Modeling Radiation Distribution on Target Wall}

\subsubsection{Modeling radiation distribution on target wall based on experimental data}

It can be considered that the radiation on the target wall comes from two radiators: the window radiator and the external flame out of the soffit of the window. To model the radiation on the target wall, the following experimental data are used as shown in Table 10-7: 


\section{a. For the window radiator:}

(a) Separation distance: the separation distance is the distance between the fire building and the target wall;

(b) Emissivity: it is assumed that the emissivity of the window radiator is equal to 1.0 .

(c) Temperature of the window radiator: the maximum flame temperature out of the soffit of window is used as the temperature of the window radiator.

\section{b. For the external flame above window}

(a) Separation distance: the separation distance is the distance between the external wall of the fire building and the target wall minus two third of window height;

(b) Emissivity: for the window $(1.10 \times 1.45 \mathrm{~m})$ with $\mathrm{H}_{0}>1.25 \mathrm{~W}_{0}$, the emissivity of external flame radiator is equal to 0.820 ; for the windows $(2.55 \times 1.45 \mathrm{~m}$ and $1.45 \times 1.45 \mathrm{~m}$ ) with $\mathrm{H}_{\mathrm{o}}<1.25 \mathrm{~W}_{\mathrm{o}}$, the emissivity of external flame radiator is equal to 0.519

(c) Temperature of the radiator of the external flame:

- If the flame height above the soffit of the window is less than $2 \mathrm{~m}$, the average value of the window radiator temperature and the flame tip temperature is used as the temperature of the external flame radiator; 
Table 10-7 Experimental data used for calculation of radiation heat flux on target wall

\begin{tabular}{|c|c|c|c|c|c|c|c|c|c|c|c|}
\hline \multirow{3}{*}{ Test } & \multirow{3}{*}{$\begin{array}{l}\text { Width of } \\
\text { radiator } \\
\qquad(\mathrm{m})\end{array}$} & \multicolumn{4}{|c|}{ Window radiator } & \multicolumn{6}{|c|}{ External flame radiator } \\
\hline & & \multirow{2}{*}{$\begin{array}{l}\text { Height } \\
\text { (m) }\end{array}$} & \multirow{2}{*}{$\begin{array}{c}\text { Temperature }{ }^{1} \\
\left({ }^{\circ} \mathrm{C}\right)\end{array}$} & \multirow[b]{2}{*}{ Emissivity } & \multirow{2}{*}{$\begin{array}{c}\text { Separation } \\
\text { Distance } \\
\text { (m) }\end{array}$} & \multicolumn{2}{|c|}{ Bottom part } & \multicolumn{2}{|c|}{ Upper part } & \multirow[b]{2}{*}{ Emissivity } & \multirow{2}{*}{$\begin{array}{c}\text { Separation } \\
\text { Distance } \\
\text { (m) }\end{array}$} \\
\hline & & & & & & $\begin{array}{c}\text { Height } \\
\text { (m) }\end{array}$ & $\begin{array}{c}\text { Temperature }^{2} \\
\left({ }^{\circ} \mathrm{C}\right)\end{array}$ & $\begin{array}{c}\text { Height } \\
(m)\end{array}$ & $\begin{array}{c}\text { Temperature }^{3} \\
\left({ }^{\circ} \mathrm{C}\right)\end{array}$ & & \\
\hline 1 & 2.55 & 1.45 & 1021 & 1 & 3 & 0 & 1021 & 1.5 & 780.50 & 0.519 & 2.03 \\
\hline 2 & 2.55 & 1.45 & 1047 & 1 & 3.5 & 0 & 1047 & 1.5 & 793.50 & 0.519 & 2.53 \\
\hline 3 & 2.55 & 1.45 & 1073 & 1 & 4 & 0 & 1073 & 1.5 & 806.50 & 0.519 & 3.03 \\
\hline 4 & 1.45 & 1.45 & 993 & 1 & 3 & 1.2 & 956 & 2 & 748.00 & 0.519 & 2.03 \\
\hline 5 & 1.45 & 1.45 & 985 & 1 & 3.5 & 1 & 991 & 2 & 765.50 & 0.519 & 2.53 \\
\hline 6 & 1.45 & 1.45 & 1022 & 1 & 2.4 & 1 & 921 & 2 & 730.50 & 0.519 & 1.43 \\
\hline 7 & 1.1 & 1.45 & 976 & 1 & 3.5 & 1 & 970 & 2 & 755.00 & 0.820 & 2.53 \\
\hline 8 & 1.1 & 1.45 & 1084 & 1 & 3 & 0.5 & 846 & 2 & 693.00 & 0.820 & 2.03 \\
\hline 9 & 1.1 & 1.45 & 1047 & 1 & 4 & 2 & 968 & 2 & 754.00 & 0.820 & 3.03 \\
\hline 10 & 1.1 & 1.45 & 942 & 1 & 3 & 2 & 962 & 2 & 751.00 & 0.820 & 2.03 \\
\hline 11 & 1.45 & 1.45 & 1010 & 1 & 3 & 2 & 964 & 2 & 752.00 & 0.519 & 2.03 \\
\hline 12 & 2.55 & 1.45 & 1079 & 1 & 3 & 1 & 884 & 2 & 712.00 & 0.519 & 2.03 \\
\hline
\end{tabular}

1. the maximum flame temperature out of the soffit of window

2. the temperature of flame at the point $50 \mathrm{~cm}$ above the soffit of window and $50 \mathrm{~cm}$ away from the external wall of fire building

3. the average of the temperature of bottom part and flame tip temperature 
- If the flame height above the soffit of the window is more than $2 \mathrm{~m}$, the external flame above the soffit of the window has to be divided into two parts - a bottom part and an upper part. For the bottom part ranging from the soffit of the window to $2 \mathrm{~m}$ below the flame tip, the temperature of the flame at a point $50 \mathrm{~cm}$ above the soffit of the window and $50 \mathrm{~cm}$ away from the external wall of the fire building is used as the temperature of the bottom part. The average of the temperature of the bottom part and the flame tip temperature is used as the temperature of the upper part of the external flame radiator.

Substituting the experimental temperatures shown in Table 10-7 into Equation (10.4), the distribution of the radiation heat flux on the target wall for each experiment can be plotted as shown in Figure 10-10. The figure shows that the computed values compare well with the experimental data for all tests.

\subsubsection{Modeling radiation distribution based on the theory of post-flashover compartment fire}

For the fire safety designer, it is hard to find experimental data for compartment fires. Therefore, it is very important to develop a simple method to use in the design of an acceptable spatial separation between buildings based on the theory of post-flashover compartment fires. To simplify the problem, it is assumed that the radiation comes from two radiators- window radiator and the radiator of the external flame above the window. The data used to model the radiation on target wall are shown in Table 10-8: 


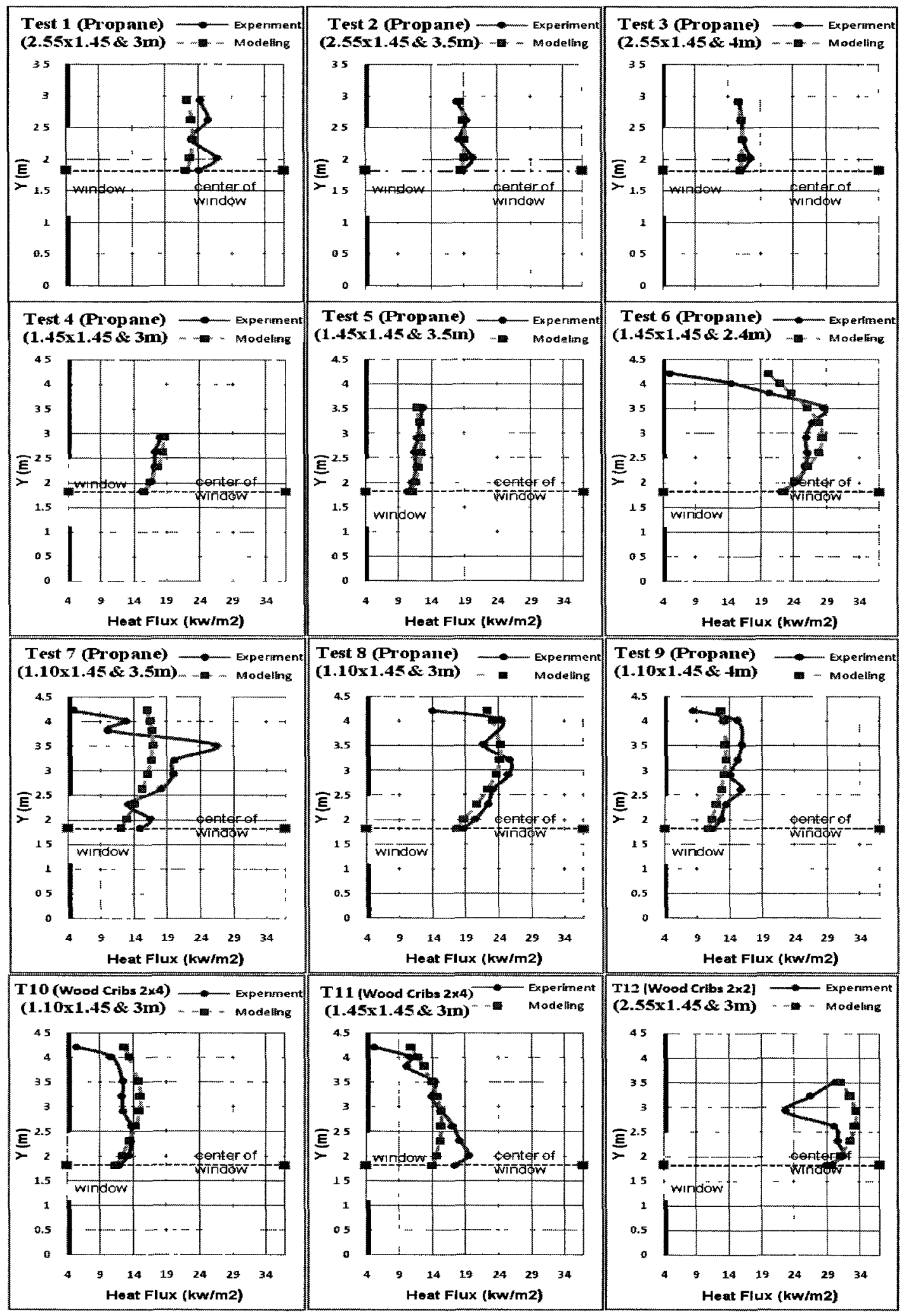

Figure 10-10 Comparison of experimental radiation distribution and modeling results using the experimental data 
Table 10-8 Theoretical data used for calculation of radiation heat flux on target wall

\begin{tabular}{|c|c|c|c|c|c|c|c|c|c|c|c|}
\hline \multirow{3}{*}{ Test } & \multirow{3}{*}{$\begin{array}{l}\text { Width of } \\
\text { radiator } \\
\text { (m) }\end{array}$} & \multicolumn{4}{|c|}{ Window radiator } & \multicolumn{6}{|c|}{ External flame radiator } \\
\hline & & \multirow{2}{*}{$\begin{array}{l}\text { Height } \\
\text { (m) }\end{array}$} & \multirow{2}{*}{$\begin{array}{c}\text { Temperature } \\
{ }^{1} \\
\left({ }^{\circ} \mathrm{C}\right)\end{array}$} & \multirow[b]{2}{*}{ Emissivity } & \multirow{2}{*}{$\begin{array}{l}\text { Separation } \\
\text { distance } \\
\text { (m) }\end{array}$} & \multicolumn{2}{|c|}{ Bottom part } & \multicolumn{2}{|c|}{ Upper part } & \multirow[b]{2}{*}{ Emissivity } & \multirow{2}{*}{$\begin{array}{l}\text { Separation } \\
\text { distance } \\
\text { (m) }\end{array}$} \\
\hline & & & & & & $\begin{array}{l}\text { Height } \\
\text { (m) }\end{array}$ & $\begin{array}{c}\text { Temperature }{ }^{2} \\
\left({ }^{\circ} \mathrm{C}\right)\end{array}$ & $\begin{array}{l}\text { Height } \\
\text { (m) }\end{array}$ & $\begin{array}{c}\text { Temperature }^{3} \\
\left({ }^{\circ} \mathrm{C}\right)\end{array}$ & & \\
\hline 1 & 2.55 & 1.45 & 1051 & 1 & 3 & 0 & 1051 & 1.5 & 795.5 & 0.519 & 2.03 \\
\hline 2 & 2.55 & 1.45 & 1038 & 1 & 3.5 & 0 & 1038 & 1.5 & 789 & 0.519 & 2.53 \\
\hline 3 & 2.55 & 1.45 & 1044 & 1 & 4 & 0 & 1044 & 1.5 & 792 & 0.519 & 3.03 \\
\hline 4 & 1.45 & 1.45 & 993 & 1 & 3 & 1 & 993 & 2 & 766.5 & 0.519 & 2.03 \\
\hline 5 & 1.45 & 1.45 & 990 & 1 & 3.5 & 1 & 990 & 2 & 765 & 0.519 & 2.53 \\
\hline 6 & 1.45 & 1.45 & 990 & 1 & 2.4 & 1 & 990 & 2 & 765 & 0.519 & 1.43 \\
\hline 7 & 1.1 & 1.45 & 969 & 1 & 3.5 & 2 & 969 & 2 & 754.5 & 0.820 & 2.53 \\
\hline 8 & 1.1 & 1.45 & 975 & 1 & 3 & 2 & 975 & 2 & 757.5 & 0.820 & 2.03 \\
\hline 9 & 1.1 & 1.45 & 969 & 1 & 4 & 2 & 969 & 2 & 754.5 & 0.820 & 3.03 \\
\hline 10 & 1.1 & 1.45 & 969 & 1 & 3 & 1 & 969 & 2 & 754.5 & 0.820 & 2.03 \\
\hline 11 & 1.45 & 1.45 & 989 & 1 & 3 & 0.5 & 989 & 2 & 764.5 & 0.519 & 2.03 \\
\hline 12 & 2.55 & 1.45 & 1029 & 1 & 3 & 1.2 & 1029 & 2 & 784.5 & 0.519 & 2.03 \\
\hline
\end{tabular}

1. the maximum value of the room temperature and the flame temperature at the window along the flame centerline

2. the temperature of the window radiator

3. the average of the temperature of bottom part and flame tip temperature 


\section{a. For the window radiator:}

(a) Separation distance: the separation distance is the distance between fire building and target wall;

(b) Emissivity: it is assumed that the emissivity of window radiator is equal to 1.0.

(c) Temperature of the window radiator: the maximum value of the room temperature and the flame temperature at the window along the flame centerline is used as its temperature.

\section{b. For the external flame above window}

(a) Separation distance: the separation distance is the distance between external wall of the fire building and target wall minus two thirds of the window height;

(b) Temperature of the radiator of the external flame:

- If the flame height above the soffit of the window is less than $2 \mathrm{~m}$, the average value of the window radiator temperature and the flame tip temperature is used as the temperature of the external flame radiator;

If the flame height above the soffit of the window is more than $2 \mathrm{~m}$, the external flame above the soffit of the window has to be divided into two parts - a bottom part and an upper part. The temperature of the window radiator is used as the temperature of the bottom part of the external flame ranging from the soffit of the window to $2 \mathrm{~m}$ below the flame tip. The average temperature of the window radiator temperature and the flame tip temperature is used as the temperature of the upper part of external flame radiator. 


\section{(c) Emissivity of the external flame:}

- Case 1: using experimental data of emissivity in the modeling Based on input data obtained by the theory of post-flashover compartment fire in Table 10-8 and experimental emissivity, the graphs of the theoretical modeling are plotted as shown in Figure 10-11. For most cases, the theoretical values are higher than the experimental results; this is due to the much higher theoretical flame height calculated by Equation (9-11) than the experimental flame height.

- Case 2: using theoretical data of emissivity in the modeling The theoretical value of emissivity calculated by Equation (9.19) is 0.252 (when $\mathrm{k}$ $\left.=0.30 \mathrm{~m}^{-1}\right)^{[40]}$ or $0.394\left(\text { when } \mathrm{k}=0.518 \mathrm{~m}^{-1}\right)^{[37]}$

Based on input data obtained by the theory of post-flashover compartment fire in Table 10-8 and emissivity $\varepsilon=0.394$, the graphs of the theoretical modeling are plotted as shown in Figure 10-12. It can be found that for most tests, the theoretical result of modeling radiation distribution is close to the experimental heat flux on the target wall.

For most cases, the values of radiation heat flux calculated by the modeling using experimental results as input data of modeling are close to the experimental distribution; the values of radiation heat flux calculated by the modeling using theoretical results as input data are acceptable in real application if experimental results are not available. 


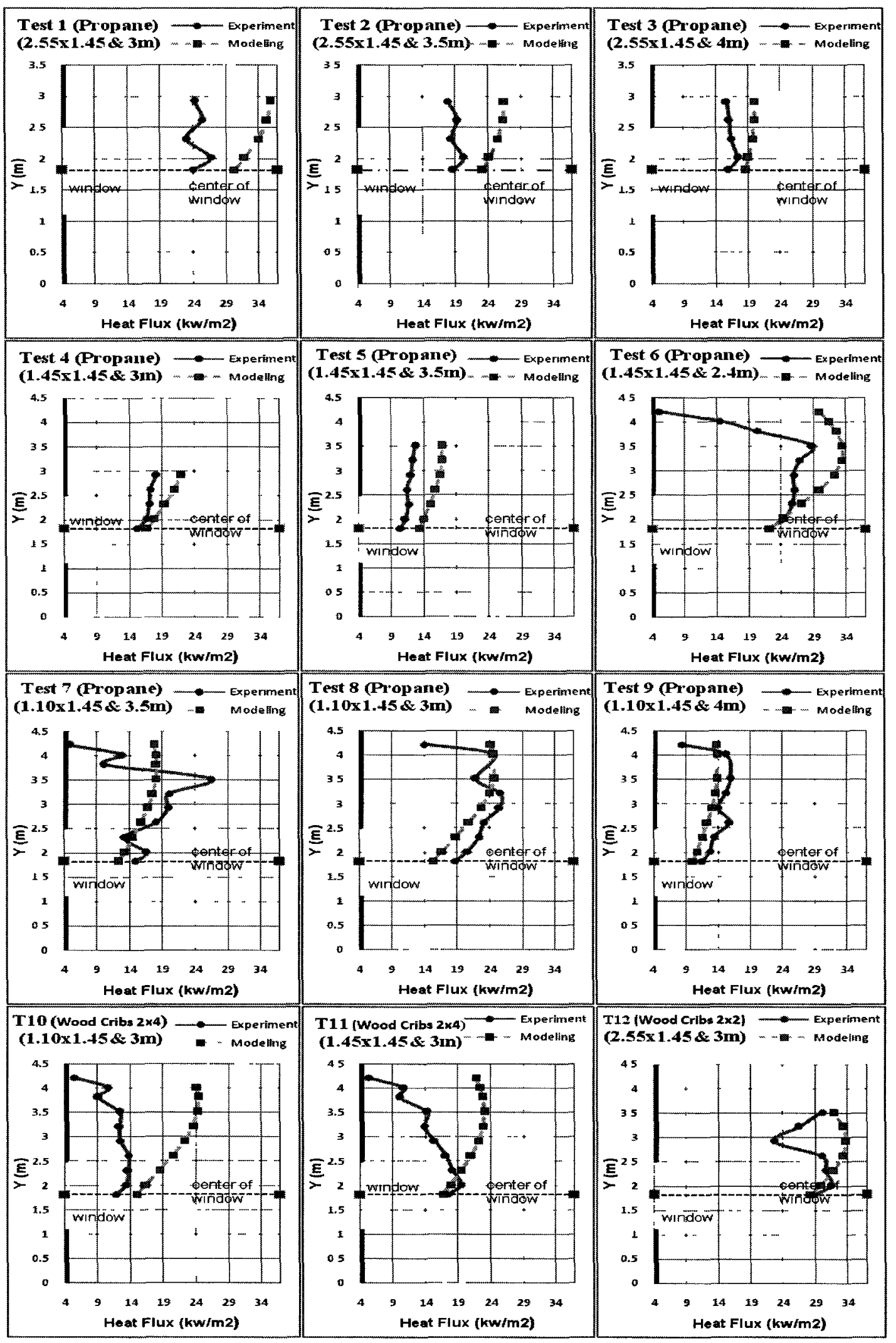

Figure 10-11 Comparison of experimental radiation distribution and modeling results using the theory of compartment fire and experimental emissivity 


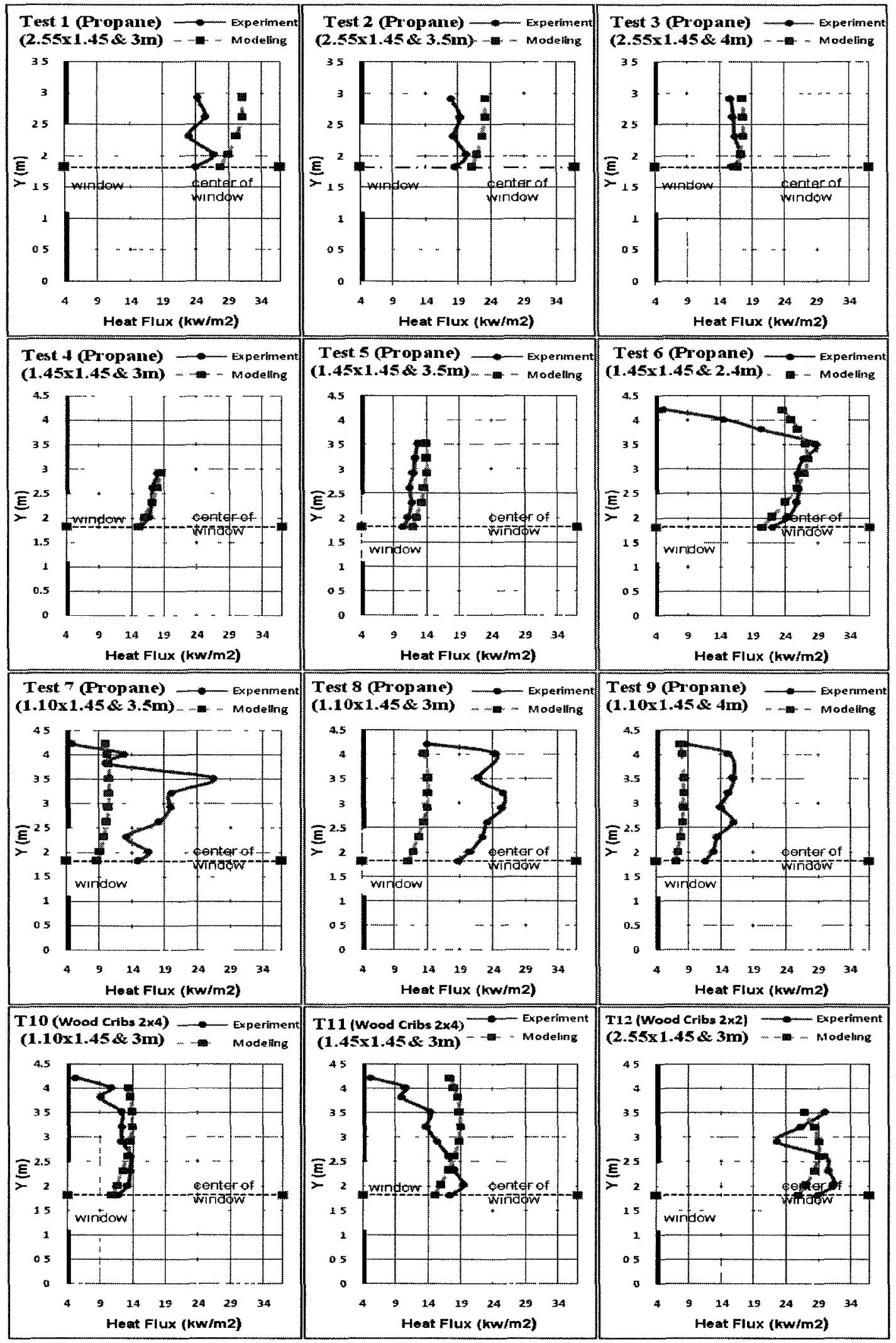

Figure 10-12 Comparison of experimental radiation distribution and modeling results using the theory of compartment fire and theoretical emissivity 


\section{Chapter 11}

\section{Modeling Fire Spread from the Fire Building to Adjacent}

\section{Buildings}

During a fire, flame may project out of windows/openings and heat be transmitted to the surroundings. Accompanying the hot gases, flying brands from the fire may land on nearby buildings. When the temperature of the exposed combustible materials of adjacent buildings is raised high enough by the heat flux coming from the fire building, combustible materials will be ignited and fire will spread to adjacent buildings, sometimes even disastrous conflagration may occur. If there is no wind and the separation distance between the buildings is not too close, the convective heat flux is very low from the fire building compared with the radiation heat flux because of the rapid decrease of hot gas temperature with the increase of horizontal distance between buildings. Therefore, the study of fire spread between buildings can focus on the radiation heat flux from the fire building.

Based on the field fire experiments known as St. Lawrence Burns ${ }^{[32]}$, before fire could spread to the whole building, the buildings could contain the fire for more than 16 minutes after ignition, which provided enough time for the firefighters to arrive to the fire 
scene. Therefore, in this thesis, the purpose of modeling fire spread between buildings is to prevent fire spreading from the fire building to its adjacent building only for the scenario that fire still can be contained in the fire building before the fire spreads to the whole building. The worst situation considered for the model in this thesis is that all compartments in the fire building are on fire, but the radiation heat flux coming from the fire building includes two parts:

- Radiation comes from the compartment fire though its opening such as window or door

- Radiation comes from the external flame out of the window or door.

To simplify the model for fire spread between buildings, in this thesis, following is assumed

(a) Every opening of a building has a rectangular shape;

(b) The external walls are perpendicular to the ground;

(c) The two exterior walls of two adjacent buildings facing each other are parallel.

In this thesis, the relationship between the opening of the fire building and the target point on the adjacent building only considers their relationship on the vertical plane (or in $\mathrm{x}-\mathrm{y}$ plane) by ignoring the separation distance between them. 


\subsection{Modeling Fire Spread between Buildings by Configuration Factor}

In current fire safety codes, engineering methods based on fire experiments are used to do the calculation of acceptable separation distance between buildings. It is assumed that a fire can spread to an adjacent building when the configuration factor for the fire building to an adjacent building exceeds critical configuration factor which yields the critical heat flux that could ignite the combustibles on the target wall.

\subsubsection{Calculation of the Configuration Factor for Buildings with Multiple Openings to a Target Point on a Parallel Wall of an Adjacent Building}

The key of modeling fire spread from the fire building to adjacent buildings is to find a universal method to calculate the configuration factor from the fire building to an adjacent building.

\subsubsection{The basic equation for calculation of the configuration factor for a opening to a target point}

Assume a target point is exactly located across from one corner of an opening in a vertical plane as shown in Figure 11-1. If
a) The position of the left and bottom corner of the opening is $\left(x_{0}, y_{0}\right)$,
b) The position of the right and top corner of the opening is $\left(x_{1}, y_{1}\right)$,
c) The position of the target point is $(x, y)$;
d) The distance between the external wall and the target point is $\mathrm{c}$. 

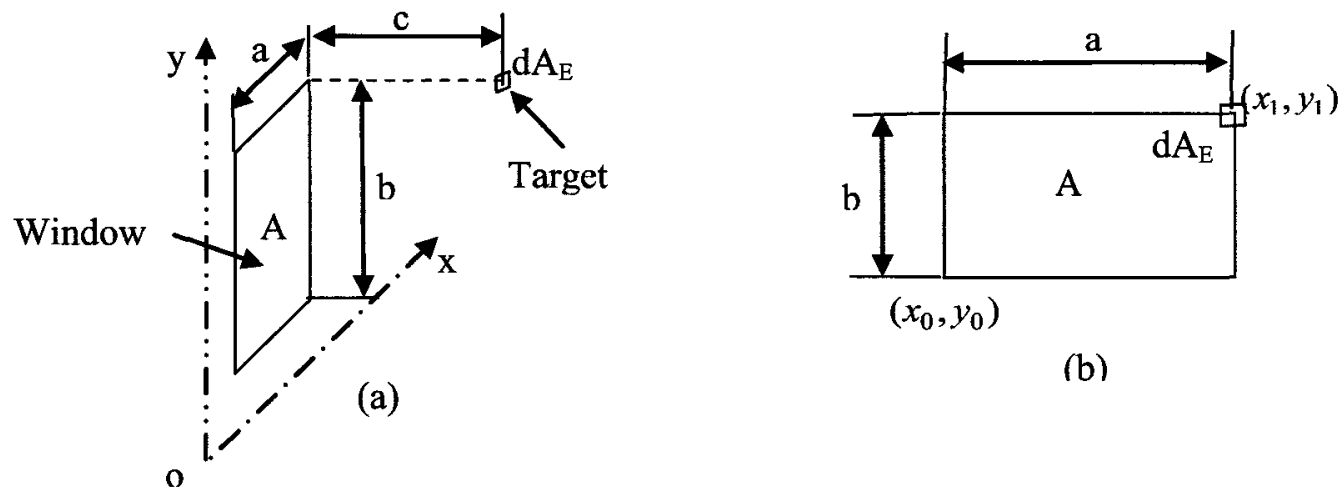

(b)

Figure 11-1 Target point is exactly at a corner of the window in vertical plane.

Then let

$$
M=\frac{a}{c}=\frac{x_{1}-x_{0}}{c}, N=\frac{b}{c}=\frac{y_{1}-y_{0}}{c}
$$

Configuration factor in Figure 11-1 is

$$
\mathbf{F}_{\mathrm{dE}-\mathrm{A}}=\frac{1}{2 \pi}\left\{\frac{M}{\sqrt{1+M^{2}}} \tan ^{-1}\left[\frac{N}{\sqrt{1+M^{2}}}\right]+\frac{N}{\sqrt{1+N^{2}}} \tan ^{-1}\left[\frac{M}{\sqrt{1+N^{2}}}\right]\right\}
$$

\subsubsection{Three possible basic types of relationships between an opening of a fire} building and a target point on a target wall

In this thesis, three basic relationships for calculating the configuration factor between an opening and a target point are presented. With these relationships the configuration factor 
between any opening on the fire building and a target point on an adjacent building can be calculated.

11.1.1.2.1 The target point is located within the inside of the opening projection in vertical plane

When $x_{0} \leq x \leq x_{1}, y_{0} \leq y \leq y_{1}$ as shown in Figure 11-2, the target point is within the boundary of a window if only considering the vertical $x-y$ plane.

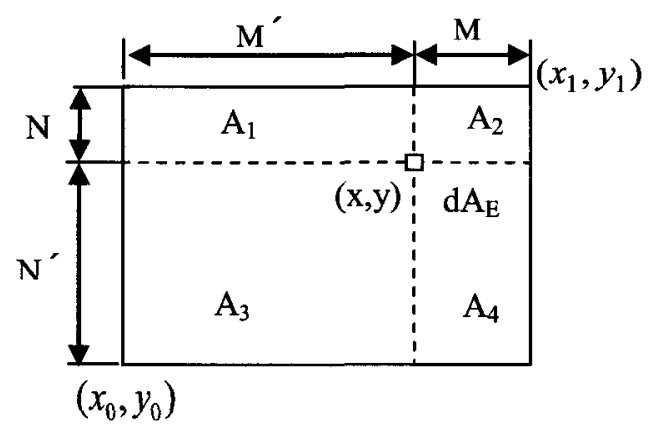

Figure 11-2 Target point is within the boundary of the opening.

Let

$$
M=\frac{x_{1}-x}{c}, M^{\prime}=\frac{x-x_{0}}{c} ; N=\frac{y_{1}-y}{c}, N^{\prime}=\frac{y-y_{0}}{c}
$$

Therefore, the configuration factor is

$$
F_{d E-A_{1}}=\frac{1}{2 \pi}\left\{\frac{M^{\prime}}{\sqrt{1+M^{\prime 2}}} \tan ^{-1}\left[\frac{N}{\sqrt{1+M^{\prime 2}}}\right]+\frac{N}{\sqrt{1+N^{2}}} \tan ^{-1}\left[\frac{M^{\prime}}{\sqrt{1+N^{2}}}\right]\right\}
$$




$$
\begin{aligned}
& F_{d E-A_{2}}=\frac{1}{2 \pi}\left\{\frac{M}{\sqrt{1+M^{2}}} \tan ^{-1}\left[\frac{N}{\sqrt{1+M^{2}}}\right]+\frac{N}{\sqrt{1+N^{2}}} \tan ^{-1}\left[\frac{M}{\sqrt{1+N^{2}}}\right]\right\} \\
& F_{d E-A_{3}}=\frac{1}{2 \pi}\left\{\frac{M^{\prime}}{\sqrt{1+M^{\prime 2}}} \tan ^{-1}\left[\frac{N^{\prime}}{\sqrt{1+M^{\prime 2}}}\right]+\frac{N^{\prime}}{\sqrt{1+N^{\prime 2}}} \tan ^{-1}\left[\frac{M^{\prime}}{\sqrt{1+N^{\prime 2}}}\right]\right\} \\
& F_{d E-A_{4}}=\frac{1}{2 \pi}\left\{\frac{M}{\sqrt{1+M^{2}}} \tan ^{-1}\left[\frac{N^{\prime}}{\sqrt{1+M^{2}}}\right]+\frac{N^{\prime}}{\sqrt{1+N^{\prime 2}}} \tan ^{-1}\left[\frac{M}{\sqrt{1+N^{\prime 2}}}\right]\right\}
\end{aligned}
$$

The total configuration factor

$$
F_{d E-A}=F_{d E-\left(A_{1}+A_{2}+A_{3}+A_{4}\right)}=F_{d E-A_{1}}+F_{d E-A_{2}}+F_{d E A_{3}}+F_{d E-A_{4}}
$$

\subsection{The target point is outside one side of an opening in vertical plane}

When $x<x_{0}$ or $x>x_{1}, y_{0}<y<y_{1}$; or $x_{0}<x<x_{1}, y<y_{0}$ or $y>y_{1}$ as shown in Figure 11-3, the target point is beside one of the boundaries of an opening if only considering the vertical $\mathrm{x}-\mathrm{y}$ plane.

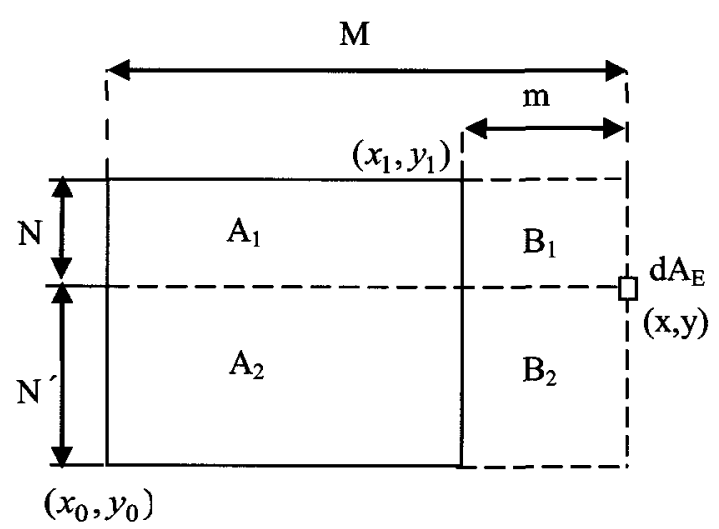

Figure 11-3 Target point is beside one side of the boundary of the opening. 
Let

$$
\begin{aligned}
& M=\frac{\max \left(\left|x_{1}-x\right|,\left|x_{0}-x\right|\right)}{c}, m=\frac{\min \left(\left|x_{1}-x\right|,\left|x_{0}-x\right|\right)}{c} ; \\
& N=\frac{y_{1}-y}{c}, N^{\prime}=\frac{y-y_{0}}{c}
\end{aligned}
$$

Therefore, the configuration factor is

$$
\begin{aligned}
& F_{d E-A_{1} \cup B_{1}}=\frac{1}{2 \pi}\left\{\frac{M}{\sqrt{1+M^{2}}} \tan ^{-1}\left[\frac{N}{\sqrt{1+M^{2}}}\right]+\frac{N}{\sqrt{1+N^{2}}} \tan ^{-1}\left[\frac{M}{\sqrt{1+N^{2}}}\right]\right\} \\
& F_{d E-B_{1}}=\frac{1}{2 \pi}\left\{\frac{m}{\sqrt{1+m^{2}}} \tan ^{-1}\left[\frac{N}{\sqrt{1+m^{2}}}\right]+\frac{N}{\sqrt{1+N^{2}}} \tan ^{-1}\left[\frac{m}{\sqrt{1+N^{2}}}\right]\right\} \\
& F_{d E-A_{2} \cup B_{2}}=\frac{1}{2 \pi}\left\{\frac{M}{\sqrt{1+M^{2}}} \tan ^{-1}\left[\frac{N^{\prime}}{\sqrt{1+M^{2}}}\right]+\frac{N^{\prime}}{\sqrt{1+N^{\prime 2}}} \tan ^{-1}\left[\frac{M}{\sqrt{1+N^{\prime 2}}}\right]\right\} \\
& F_{d E-B_{2}}=\frac{1}{2 \pi}\left\{\frac{m}{\sqrt{1+m^{2}}} \tan ^{-1}\left[\frac{N^{\prime}}{\sqrt{1+m^{2}}}\right]+\frac{N^{\prime}}{\sqrt{1+N^{\prime 2}}} \tan ^{-1}\left[\frac{m}{\sqrt{1+N^{\prime 2}}}\right]\right\}
\end{aligned}
$$

The total configuration factor

$$
F_{d E-A}=F_{d E-\left(A_{1}+A_{2}\right)}=F_{d E-A_{1} \cup B_{1}}-F_{d E-B_{1}}+F_{d E-A_{2} \cup B_{2}}-F_{d E-B_{2}}
$$

\subsection{The target point is outside the opening in vertical plane}

When $x<x_{0}$ or $x>x_{1}, y<y_{0}$ or $y>y_{1}$ as shown in Figure 11-4, it is defined that the target point is at the outside of an opening in vertical plane. 


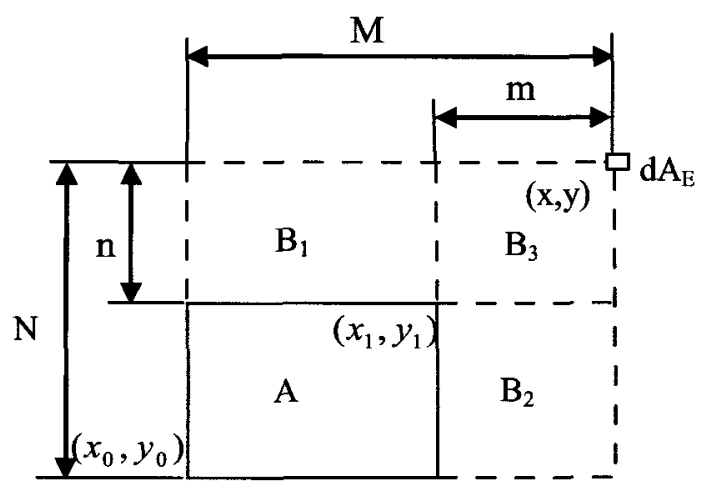

Figure 11-4 Target point is at outside of the opening.

Then let

$$
\begin{gathered}
M=\frac{\max \left(\left|x_{1}-x\right|,\left|x_{0}-x\right|\right)}{c}, m=\frac{\min \left(\left|x_{1}-x\right|,\left|x_{0}-x\right|\right)}{c}, \\
N=\frac{\max \left(\left|y_{1}-y\right|,\left|y_{0}-y\right|\right)}{c}, n=\frac{\min \left(\left|y_{1}-y\right|,\left|y_{0}-y\right|\right)}{c} .
\end{gathered}
$$

Therefore, the configuration factor is

$$
\begin{aligned}
& F_{d E-A_{1} \cup B_{1} \cup B_{2} \cup B_{3}}=\frac{1}{2 \pi}\left\{\frac{M}{\sqrt{1+M^{2}}} \tan ^{-1}\left[\frac{N}{\sqrt{1+M^{2}}}\right]+\frac{N}{\sqrt{1+N^{2}}} \tan 1\left[\frac{M}{\sqrt{1+N^{2}}}\right]\right\} \\
& F_{d E-B_{1} \cup B_{3}}=\frac{1}{2 \pi}\left\{\frac{M}{\sqrt{1+M^{2}}} \tan ^{-1}\left[\frac{n}{\sqrt{1+M^{2}}}\right]+\frac{n}{\sqrt{1+n^{2}}} \tan ^{-1}\left[\frac{M}{\sqrt{1+n^{2}}}\right]\right\} \\
& F_{d E-B_{2} \cup B_{3}}=\frac{1}{2 \pi}\left\{\frac{m}{\sqrt{1+m^{2}}} \tan ^{-1}\left[\frac{N}{\sqrt{1+m^{2}}}\right]+\frac{N}{\sqrt{1+N^{2}}} \tan ^{-1}\left[\frac{m}{\sqrt{1+N^{2}}}\right]\right\}
\end{aligned}
$$




$$
F_{d E-B_{3}}=\frac{1}{2 \pi}\left\{\frac{m}{\sqrt{1+m^{2}}} \tan ^{-1}\left[\frac{n}{\sqrt{1+m^{2}}}\right]+\frac{n}{\sqrt{1+n^{2}}} \tan ^{-1}\left[\frac{m}{\sqrt{1+n^{2}}}\right]\right\}
$$

The total configuration factor is

$$
F_{d E-A}=F_{d E-A_{1} \cup B_{1} \cup B_{2} \cup B_{3}}-F_{d E-B_{1} \cup B_{3}}-F_{d E-B_{2} \cup B_{3}}+F_{d E-B_{3}}
$$

\subsubsection{The calculation of configuration factor by computer programming}

If a building has several openings in one external wall, the relationship between an opening and the target point on an adjacent building will be one of the three basic relationships discussed above. The total configuration factor for buildings with multiple openings to a target point of the external wall can be considered as the summation of the configuration factors for each opening to the target point.

$$
F_{d E-A}=\sum_{i=1}^{n} F_{d E-A_{i}}
$$

Based on equations (11.1-11.11), the configuration factor for the buildings with multiple openings to a target point can be easily calculated by a computer programming. The flow chart of the computer program to calculate the configuration factor for a building to a target point of external wall of an adjacent building is shown in Figure 11-5. 


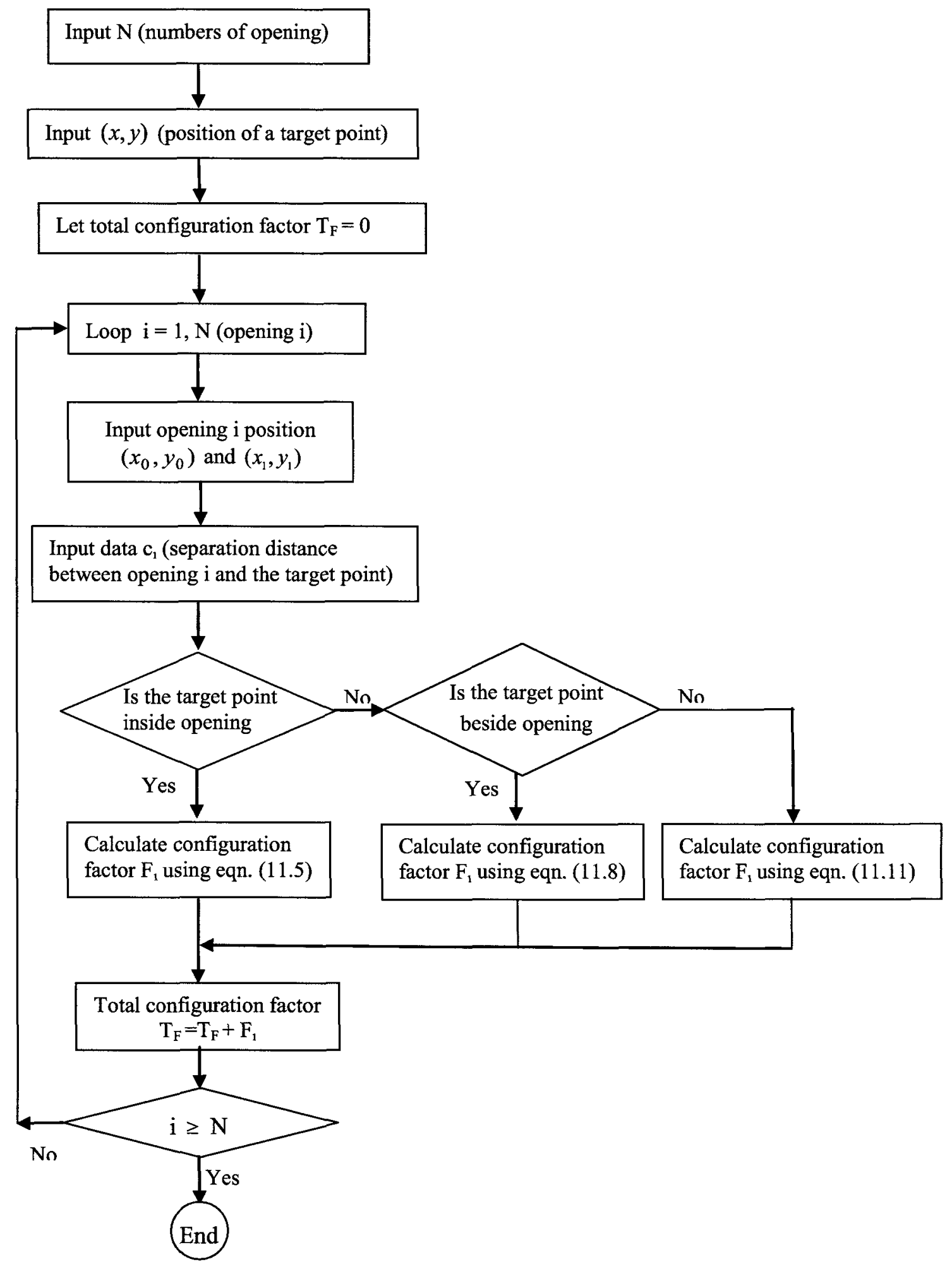

Figure 11-5 Flow chart of calculation of configuration factor 


\subsubsection{The Calculation of Maximum of Configuration Factor}

The reason for fire spread from the fire building to an adjacent building is that the radiation heat flux on the adjacent building exceeds the pilot ignition heat flux of the combustible material on the target wall. The most likely position to be ignited is the point with the maximum configuration factor from openings of the fire building to the external wall of the adjacent building.

If a building has evenly distributed windows or openings and the number of rows and columns of windows or openings are odd, according to the symmetry of windows, the maximum configuration factor can be found at the center point of the middle window or opening. Otherwise, the location of the maximum configuration factor may change depending on the distribution and sizes of the openings and the separation distance between the two external walls of the buildings. Searching for the maximum configuration factor can be done by the numerical method presented below.

Letting $f(X)=-T_{F}(X)$. Therefore the point with the maximum total configuration factor $T_{F}(X)$ is exactly the same as the position with the minimum value of the function $f(X)$. The algorithms using the simplex method ${ }^{[56,57]}$ of searching the position with the minimum value of the function $\mathrm{f}(\mathrm{X})$ are described in Table 11-1. 
Table 11-1 Algorithms for calculation of the maximum configuration factor

1. Let $f(X)=-T_{F}(X)$ and choose the initial point $X_{1}\left(x_{1}, y_{1}\right)$, find its function value

2. Choose the step length $\mathrm{k}$; let $\mathrm{x}_{2}=\mathrm{x}_{1}+\mathrm{k} ; \mathrm{y}_{2}=\mathrm{y}_{1}$ and $\mathrm{x}_{3}=\mathrm{x}_{1} ; \mathrm{y}_{3}=\mathrm{y}_{1}+\mathrm{k}$. Find the point $X_{2}\left(x_{2}, y_{2}\right), X_{3}\left(x_{3}, y_{3}\right)$ and the corresponding $f_{2}=f\left(X_{2}\right), f_{3}=f\left(X_{3}\right)$.

3. Compare $f_{1}, f_{2}$ and $f_{3}$. Then let $f_{h}=\max \left(f_{1}, f_{2}, f_{3}\right), f_{1}=\min \left(f_{1}, f_{2}, f_{3}\right)$ and $f_{m}($ $\left.f_{t} \leq f_{m} \leq f_{h}\right)$, and the corresponding point $\mathrm{X}_{\mathrm{h}}, \mathrm{X}_{\mathrm{l}}$ and $\mathrm{X}_{\mathrm{m}}$

4. Find the point $X_{0}\left(x_{0}, y_{0}\right)$ at the middle of the line connecting points $X_{1}$ and $X_{m}$, and corresponding function $\mathrm{f}_{\mathrm{o}}=\mathrm{f}\left(\mathrm{X}_{\mathrm{o}}\right)$

5. Reflect $X_{h}$ in $X_{o}$ to get point $X_{r}$ and its function $f_{r}=f\left(X_{r}\right)$ as shown in Figure 11-6.

$$
\mathbf{X}_{\mathrm{r}}-\mathbf{X}_{\mathbf{o}}=\alpha\left(\mathbf{X}_{\mathbf{o}}-\mathbf{X}_{\mathrm{h}}\right) \text { or } \mathbf{X}_{\mathrm{r}}=(1+\alpha) \mathbf{X}_{\mathbf{0}}-\alpha \mathbf{X}_{\mathrm{h}}
$$

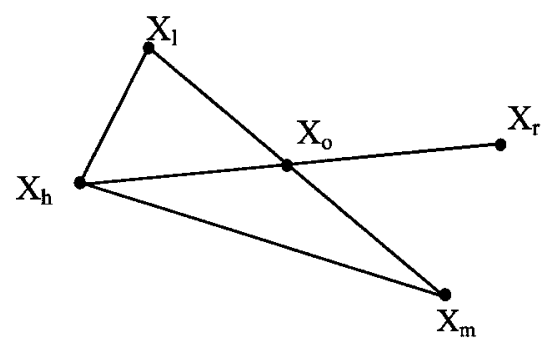

Figure 11-6 Reflection.

6. Compare $f_{r}$ with $f_{m}$ 
1) if $f_{r}<f_{l}$, the new lowest function value is obtained. Make an expansion along the direction from $X_{0}$ to $X_{r}$ to find the point $X_{e}$ and its function value $f_{e}=f$ $\left(\mathrm{X}_{\mathrm{e}}\right)$ as shown in Figure 11-7.

$\mathbf{X}_{\mathbf{e}}-\mathbf{X}_{\mathbf{o}}=\gamma\left(\mathbf{X}_{\mathbf{r}}-\mathbf{X}_{\mathbf{o}}\right)$ or $\mathbf{X}_{\mathbf{e}}=(1-\gamma) \mathbf{X}_{\mathbf{o}}+\gamma \mathbf{X}_{\mathbf{r}}$

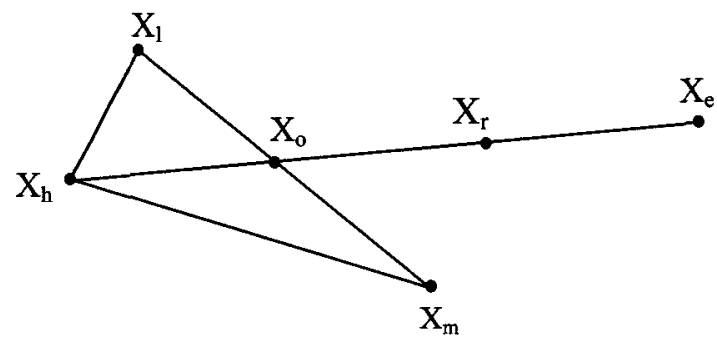

Figure 11-7 Expansion.

a) If $f_{e}<f_{1}$, replace point $X_{h}$ by $X_{e}$. let $X_{1}=X_{e}, X_{2}=X_{1}, X_{3}=X_{m}$ and $f_{1}=f_{e}$, $f_{2}=f_{1}, f_{3}=f_{m}$. Check whether they satisfy the convergence criterion $\sigma=\sqrt{\frac{\left(f_{1}-\bar{f}\right)^{2}+\left(f_{2}-\bar{f}\right)^{2}+\left(f_{3}-\bar{f}\right)^{2}}{3}} \leq \epsilon$

Where:

$\bar{f}=\frac{f_{1}+f_{2}+f_{3}}{3}$

$\epsilon=$ a pre-determined very small value

Check if the convergence criterion is satisfied.

- If yes, all function values are very close, the minimum is found 
- If no, return to step 3 .

b) If $f_{e} \geq f_{l}$, abandon point $X_{e}$ (moved to far) and replace point $X_{h}$ by $X_{r}$. Let $X_{1}=X_{r}, X_{2}=X_{1}, X_{3}=X_{m}$ and $f_{1}=f_{r}, f_{2}=f_{1}, f_{3}=f_{m}$. Then check whether the convergence criterion is satisfied.

- If yes, all function values are very close, the minimum is found

- If no, return to step 3 .

2) if $f_{1}<f_{r}<f_{m}$, replace point $X_{h}$ by $X_{r}$. let $X_{1}=X_{1}, X_{2}=X_{r}, X_{3}=X_{m}$ and $f_{1}=f_{1}$, $f_{2}=f_{r}, f_{3}=f_{m}$. Check whether they satisfy the convergence criterion

- If yes, all function values are very close, the minimum is found

- If no, return to step 3.

3) if $f_{r}>f_{m}$, go to the step 7 .

7. Compare $f_{r}$ with $f_{h}$

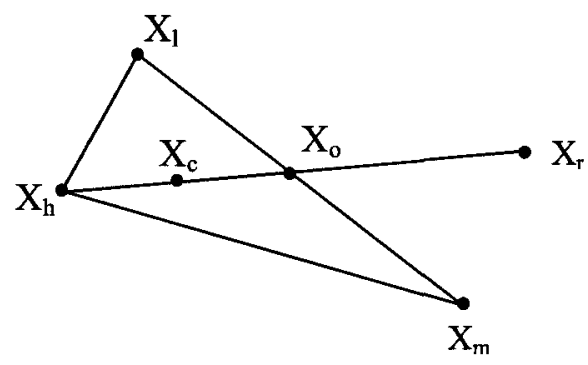

Figure 11-8 Contraction (when $f_{r}>f_{h}$ ). 
1) IF $f_{r}>f_{h}$, do contraction as show in Figure 11-8. Let

$$
\mathbf{X}_{\mathbf{c}}-\mathbf{X}_{\mathbf{o}}=\beta\left(\mathbf{X}_{\mathbf{h}}-\mathbf{X}_{\mathbf{o}}\right) \text { or } \mathbf{X}_{\mathbf{c}}=\beta \mathbf{X}_{\mathbf{h}}+(1-\beta) \mathbf{X}_{\mathbf{o}}
$$

Where: $\beta=$ coefficient $(0<\beta<1)$

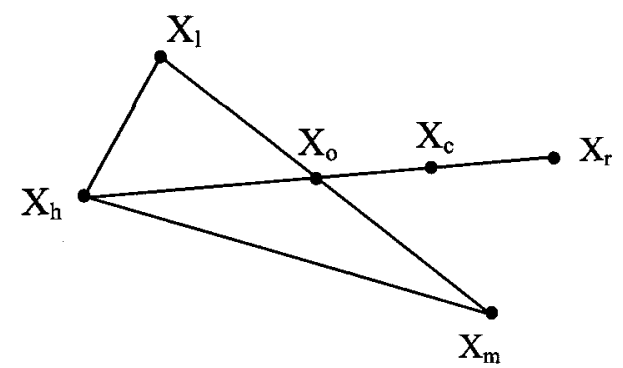

Figure 11-9 Contraction (when $f_{r}<f_{h}$ )

2) IF $f_{r}<f_{h}$, replace point $X_{h}$ by $X_{r}$ and $f_{h}$ by $f_{r}$. Then do contraction as shown in Figure 11-9. Let

$$
\mathbf{X}_{\mathbf{c}}-\mathbf{X}_{\mathbf{o}}=\beta\left(\mathbf{X}_{\mathrm{r}}-\mathbf{X}_{\mathbf{o}}\right) \text { or } \mathbf{X}_{\mathrm{c}}=\beta \mathbf{X}_{\mathbf{r}}+(1-\beta) \mathbf{X}_{\mathbf{o}}
$$

8. Compare $f_{c}$ with $f_{h}$

1) IF $f_{c}<f_{h}$, replace point $X_{h}$ by $X_{c}$. let $X_{1}=X_{c}, X_{2}=X_{1}, X_{3}=X_{m}$ and $f_{1}=f_{c}, f_{2}$

$=f_{1}, f_{3}=f_{m}$. check whether they satisfy the convergence criterion

If yes, all function values are very close, the minimum is found

If no, return to step 3 . 
2) IF $f_{c}>f_{h}$, can not find a function value less than $f_{h}$. We have to reduce the size of simplex by letting

$$
\begin{aligned}
& X_{1}=X_{1,} \\
& X_{2}=X_{1}+0.5\left(X_{2}-X_{1}\right) \\
& X_{3}=X_{1}+0.5\left(X_{3}-X_{1}\right)
\end{aligned}
$$

3) Find corresponding function value $f_{1}, f_{2}$ and $f_{3}$. Then return to step 3

9. If convergence is achieved, the position and maximum configuration factor are $\mathrm{X}_{1}$ and $-f_{1}$ respectively.

10. The maximum configuration factor $F_{\max }(c)=-f_{1}$

\subsubsection{Calculation of Spatial Separation Distance between Buildings}

Based on the field studies called the St. Lawrence Burns, McGuire ${ }^{[43]}$ suggested that the critical configuration factors to prevent fire spread between buildings for the particular hazardous condition and normal hazardous conditions should be 0.035 and 0.07 respectively. Once the severity of fire building is known, the acceptable separation distance between the target building and its adjacent building can be calculated by the algorithms in Table 11-2. 
Table 11-2 Algorithms for the calculation of the separation distance between buildings

1. Input the critical configuration factor $F_{\text {crit }}$

2. Input the tolerance convergence criterion $\epsilon=10^{-9}$

3. Input the search range of separation distance of two buildings $\left(c_{0}, c_{1}\right)$

4. Calculate the $F_{\max }\left(c_{0}\right)$ and $\Delta F_{0}=F_{\max }\left(c_{0}\right)-F_{\text {crit }}$

5. Calculate the $\mathrm{F}_{\max }\left(\mathrm{c}_{1}\right)$ and $\Delta \mathrm{F}_{1}=\mathrm{F}_{\max }\left(\mathrm{c}_{1}\right)-\mathrm{F}_{\text {crit }}$

6. Let $c_{2}=0.5\left(c_{0}+c_{1}\right)$ and calculate the $F_{\max }\left(c_{2}\right)$ and $\Delta F_{2}=F_{\max }\left(c_{2}\right)-F_{\text {crit }}$

7. If $\Delta \mathrm{F}_{2} \leq \epsilon$, then convergence, the separation distance of two buildings is $\mathrm{c}_{2}$

8. Otherwise

- $\Delta \mathrm{F}_{0} \times \Delta \mathrm{F}_{1}<0$ and $\Delta \mathrm{F}_{1} \times \Delta \mathrm{F}_{2}>0$, let $\mathrm{c}_{0}=\mathrm{c}_{0}$ and $\mathrm{c}_{1}=\mathrm{c}_{2}$, return to step 4

- $\Delta \mathrm{F}_{0} \times \Delta \mathrm{F}_{1}>0$ and $\Delta \mathrm{F}_{1} \times \Delta \mathrm{F}_{2}<0$, let $\mathrm{c}_{0}=\mathrm{c}_{2}$ and $\mathrm{c}_{1}=\mathrm{c}_{1}$, return to step 4

- otherwise, enlarge the initial searching range of separation distance $\left(c_{0}, c_{1}\right)$

\subsubsection{Examples}

In the following examples of calculation, the coefficients used for searching the maximum configuration factor in this thesis are recommended by ${ }^{[57]}(\alpha=1, \beta=0.5, \gamma=2)$ and the tolerance used as the convergence criterion is $\epsilon=10^{-9}$.

\subsubsection{Example (11.1): The calculation of maximum configuration factor}

Assume that there is a building with recessed portions. The number and dimensions of openings on one external wall of the fire building and the spatial separation between the 
two buildings are shown in Figure 11-10. The extreme dangerous scenario is that flashover occurs in every room and all glasses of the windows fall out. Considering two scenarios are with the door closed and the door open, calculate the configuration factor at the following target points.

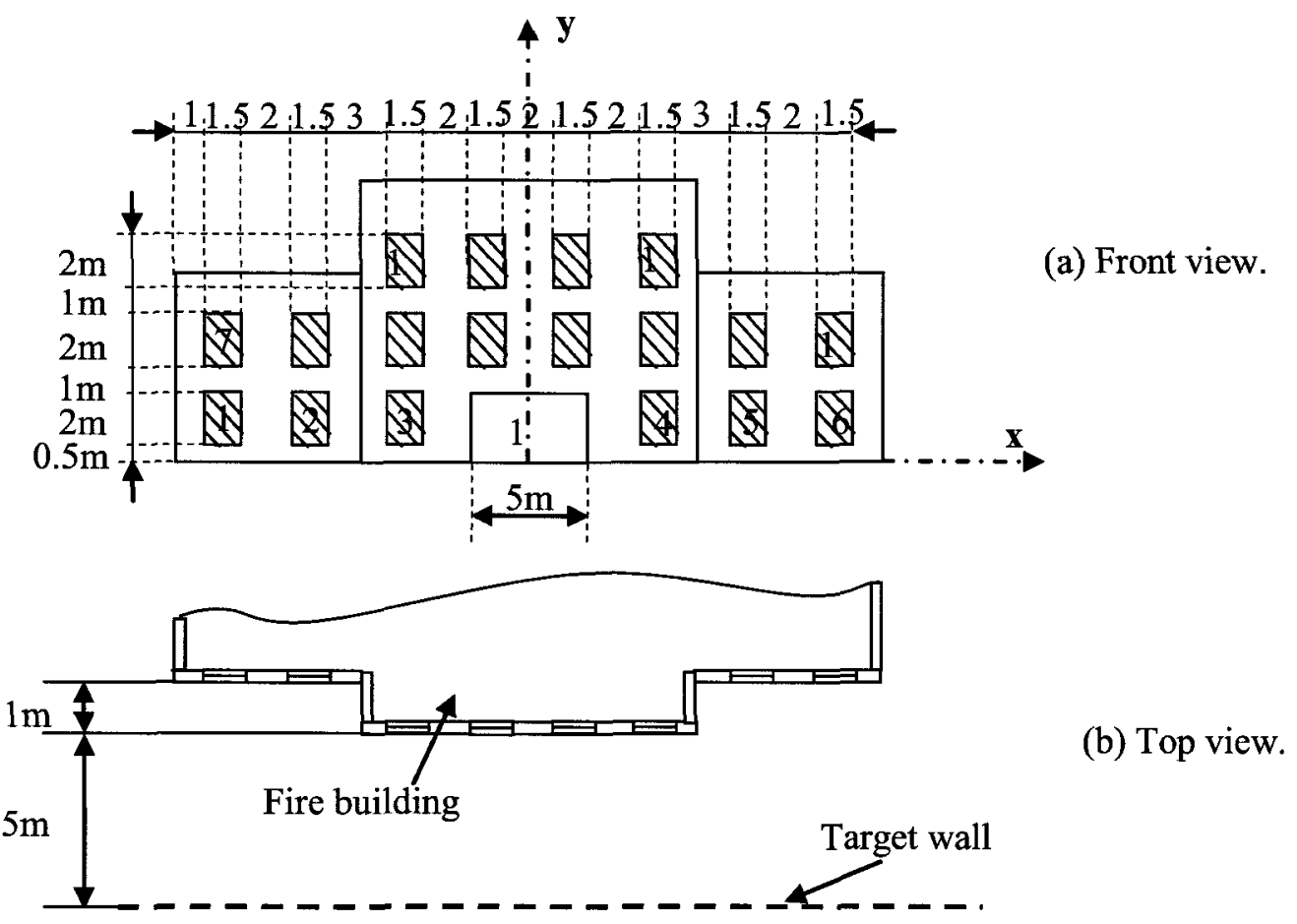

Figure 11-10 A building with recessed portions

Case 1: Calculate the radiation heat flux on the target point located at $(3,7)$ in vertical plane of the external wall of the adjacent building,

Case 2: Calculate the maximum configuration factor on the external wall of the adjacent building. 
Solution:

a) Put input data in Table 11-3 into the computer programming.

b) The outputs of Example (11.1) are listed in Table 11-4.

Table 11-4 shows that

1. Case 1:

- When the door is closed, the configuration factor at the target point located at (3, 7) on the external wall of the adjacent building is 0.142

- When the door is open, the configuration factor at the target point located at $(3,7)$ on the external wall of the adjacent building is 0.165

2. Case 2

- When the door is closed, there are two locations $(1.523,5.611)$ and $(1.523$, 5.611) having the maximum configuration factor when the initial searching points are different, but the values of maximum configuration factors are the same;

- When the door is open, there is only one position $(0,2.63)$ having the maximum configuration factor when the initial searching points are different;

- The maximum configuration factors on the target wall are 0.2336 and 0.1537 respectively for two scenarios that door is open and door is closed. 
Table 11-3 Input data of Example (11.1)

\begin{tabular}{|c|c|c|c|c|c|c|}
\hline \multicolumn{3}{|c|}{ Dimension of openings } & \multirow{3}{*}{$\begin{array}{l}\text { Separation distance } \\
\text { between opening and } \\
\text { target wall }(\mathrm{m})\end{array}$} & \multicolumn{3}{|c|}{ Target point } \\
\hline & \multirow{2}{*}{$\begin{array}{l}\text { Left and bottom } \\
\text { corner }\left(x_{0}, y_{0}\right)(\mathrm{m})\end{array}$} & \multirow{2}{*}{$\begin{array}{l}\text { Right and top } \\
\text { corner }\left(x_{1}, y_{1}\right) \\
\text { (m) }\end{array}$} & & \multirow{2}{*}{$\begin{array}{l}\text { Coordinate of the fixed } \\
\text { point }(\mathrm{m}) \\
\text { (Case } 1)\end{array}$} & \multicolumn{2}{|c|}{$\begin{array}{l}\text { Maximum configuration factor } \\
\text { (Case 2) }\end{array}$} \\
\hline & & & & & $\begin{array}{l}\text { Coordinate of initial } \\
\text { searching point }(\mathrm{m})\end{array}$ & Step length (m) \\
\hline 1 & $(-14,0.5)$ & $(-12.5,2.5)$ & 6 & \multirow{19}{*}{$(3,7)$} & \multirow{19}{*}{$(1,3)$} & \multirow{19}{*}{0.5} \\
\hline 2 & $(-10.5,0.5)$ & $(-9,2.5)$ & 6 & & & \\
\hline 3 & $(-6,0.5)$ & $(-4.5,2.5)$ & 5 & & & \\
\hline 4 & $(4.5,0.5)$ & $(6,2.5)$ & 5 & & & \\
\hline 5 & $(9,0.5)$ & $(10.5,2.5)$ & 6 & & & \\
\hline 6 & $(12.5,0.5)$ & $(14,2.5)$ & 6 & & & \\
\hline 7 & $(-14,3.5)$ & $(-12.5,5.5)$ & 6 & & & \\
\hline 8 & $(-10.5,3.5)$ & $(-9,5.5)$ & 6 & & & \\
\hline 9 & $(-6,3.5)$ & $(-4.5,5.5)$ & 5 & & & \\
\hline 10 & $(-2.5,3.5)$ & $(-1,5.5)$ & 5 & & & \\
\hline 11 & $(1,3.5)$ & $(2.5,5.5)$ & 5 & & & \\
\hline 12 & $(4.5,3.5)$ & $(6,5.5)$ & 5 & & & \\
\hline 13 & $(9,3.5)$ & $(10.5,5.5)$ & 6 & & & \\
\hline 14 & $(12.5,3.5)$ & $(14,5.5)$ & 6 & & & \\
\hline 15 & $(-6,6.5)$ & $(-4.5,8.5)$ & 5 & & & \\
\hline 16 & $(-2.5,6.5)$ & $(-1,8.5)$ & 5 & & & \\
\hline 17 & $(1,6.5)$ & $(2.5,8.5)$ & 5 & & & \\
\hline 18 & $(4.5,6.5)$ & $(6,8.5)$ & 5 & & & \\
\hline 19 & $(-2.5,0)$ & $(2.5,2.5)$ & 5 & & & \\
\hline
\end{tabular}


Table 11-4 The output data of Example (11.2)

\begin{tabular}{|c|c|c|c|c|c|}
\hline \multirow{2}{*}{ Door } & \multicolumn{2}{|c|}{ Fixed Target Point (Case 1) } & \multicolumn{3}{|c|}{ Maximum Configuration Factor (Case 2) } \\
\hline & Position & $\begin{array}{l}\text { Configuration } \\
\text { Factor }\end{array}$ & Initial searching point & Final position & Value \\
\hline \multirow{2}{*}{ Closed } & \multirow{2}{*}{$(3,7)$} & \multirow{2}{*}{0.142} & $(1,3)$ & $(1.523,5.611)$ & 0.1537 \\
\hline & & & $(-3,2)$ & $(-1.528,5.610)$ & 0.1537 \\
\hline \multirow{2}{*}{ Open } & \multirow{2}{*}{$(3,7)$} & \multirow{2}{*}{0.165} & $(4,5)$ & $(0.000,2.628)$ & 0.2336 \\
\hline & & & $(-3,2)$ & $(0.000,2.628)$ & 0.2336 \\
\hline
\end{tabular}

\subsubsection{Example (11.2): Calculation of the acceptable separation distance between buildings}

A residential building with no combustible materials on its external wall will be built on a land lot. If fire occurs in this residential building, the fire may spread from this building to adjacent buildings. On one of the external walls, there are six windows and one open door as shown in Figure 11-11. To protect the adjacent buildings from fire spread, the minimum separation distance required between these two buildings is calculated based on the following scenario:

- A fire starts in compartment 1 of this new building,

- The fire severity in the new building is considered hazardous.

- The dimensions of the relative compartments and openings are listed in Table 11-5. 


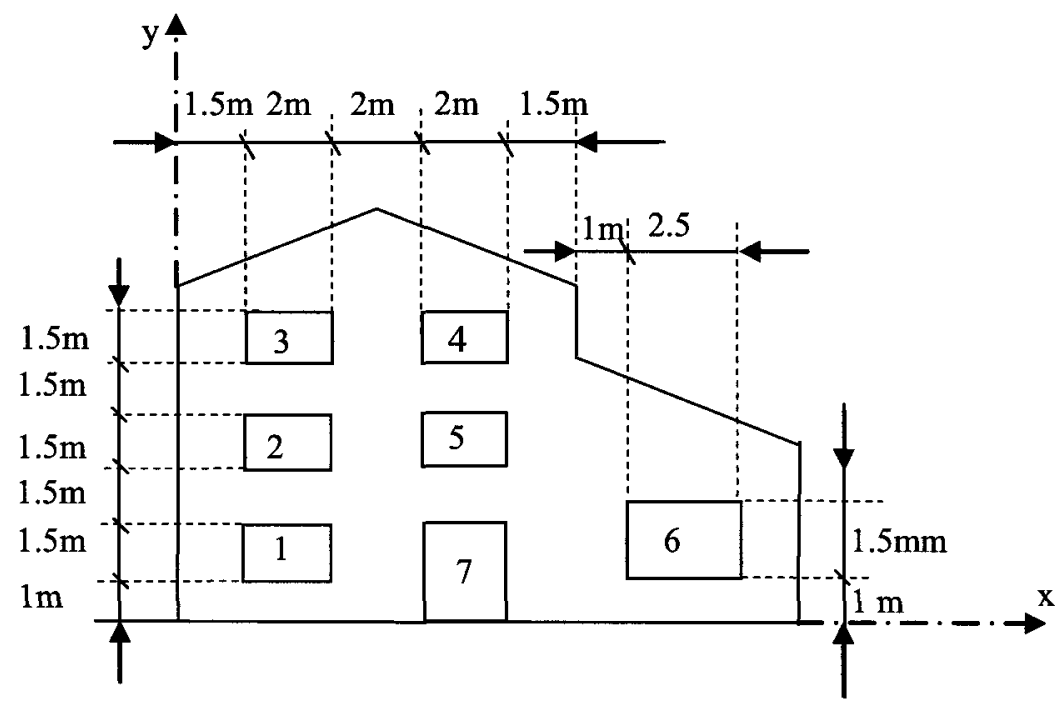

Figure 11-11 A building with irregular distribution of openings

Table 11-5 The dimensions of relative compartments and its openings

\begin{tabular}{|c|c|c|c|c|c|c|c|c|}
\hline Floor & Compartment & $\begin{array}{c}\text { Dimensions } \\
\text { of the } \\
\text { compartment } \\
(\mathrm{W} \times \mathrm{D} \times \mathrm{H}) \\
(\mathrm{m})\end{array}$ & $\begin{array}{c}\text { Relative } \\
\text { opening on } \\
\text { the external } \\
\text { wall }\end{array}$ & $\begin{array}{c}\text { Window } \\
(\mathrm{WxH}) \\
(\mathrm{m})\end{array}$ & $\begin{array}{c}\text { Window } \\
(\mathrm{WxH}) \\
(\mathrm{m})\end{array}$ & $\begin{array}{c}\text { Window } \\
(\mathrm{WxH}) \\
(\mathrm{m})\end{array}$ & $\begin{array}{c}\text { Door } \\
(\mathrm{WxH}) \\
(\mathrm{m})\end{array}$ & $\begin{array}{c}\text { Door } \\
(\mathrm{WxH}) \\
(\mathrm{m})\end{array}$ \\
\hline & 1 & $9 \times 10 \times 3$ & 1 and 7 & $2 \times 1.5$ & $2 \times 1.5$ & $2 \times 1.5$ & $1 \times 2$ & $2 \times 2.5$ \\
\hline \multirow{2}{*}{2} & 2 & $4.5 \times 5 \times 3$ & 6 & $2.5 \times 1.5$ & & & $1 \times 2$ & \\
\cline { 2 - 9 } & 3 & $4.5 \times 5 \times 3$ & 2 & $2 \times 1.5$ & & & $1 \times 2$ & \\
\hline 3 & 5 & $4.5 \times 5 \times 3$ & 5 & $2 \times 1.5$ & & & $1 \times 2$ & \\
\cline { 2 - 9 } & 6 & $4.5 \times 5 \times 3$ & 3 & $2 \times 1.5$ & & & $1 \times 2$ & \\
\hline
\end{tabular}

Other data used in this example:

- Compartment:

The fuel density of wood: mean $=30.1 \mathrm{~kg} / \mathrm{m}^{2} ;$ standard deviation $(\mathrm{sd})=4.4 \mathrm{~kg} / \mathrm{m}^{2}$ [25]. 
Heat of combustion of fuel $\mathrm{H}_{\mathrm{ch}}=12.4 \mathrm{KJ} / \mathrm{g}^{[55]}$

Fire growth parameter $\alpha$ : mean $=0.047 \mathrm{~kW} / \mathrm{s}^{2}$ (fast); $\mathrm{sd}=0.007 \mathrm{~kW} / \mathrm{s}^{2}$ (assumed).

- Window:

Material: common glass;

Fire resistance rating to $\mathrm{ISO} 834$ fire: mean $=2 \mathrm{~min}, \mathrm{sd}=0.3 \mathrm{~min}$ (assumed).

- Door:

Material: wood;

Fire resistance rating to $\mathrm{ISO} 834$ fire: mean=10 $\mathrm{min}, \mathrm{sd}=1.5 \mathrm{~min}$ (assumed).

- Wall \& ceiling:

Material: Gypsum board $\sqrt{k \rho c}=0.742 \mathrm{~kJ} / \mathrm{m}^{2} \mathrm{~s}^{0.5} \mathrm{~K}^{[25]}$

Fire resistance rating to $\mathrm{ISO} 834$ fire: mean $=45 \mathrm{~min}, \mathrm{sd}=6.75 \mathrm{~min}$ (assumed).

- Floor:

Material: wood $\sqrt{k \rho c}=0.436 \mathrm{~kJ} / \mathrm{m}^{2} \mathrm{~s}^{0.5} \mathrm{~K}^{[25]}$

Steps of Solution:

1) Calculation of fire spread in the building

- Assume that the fire starts in Compartment 1 on the first floor and the fire is reported when flashover occurs. The time of simulation of fire spread in the building starts at this moment $(\mathrm{t}=0)$. It is also assumed that the common glasses of windows will break and fall out once flashover occurs in a compartment. The 
fire may spread to adjacent buildings due to the radiation from window 1 and the open door of Compartment 1 on the first floor.

- After flashover, the ventilation controlled fire will project out of Window 1 and the open door on the first floor. The radiation and convective heat flux coming from the projecting flames out of Window 1 and open door may break the glass of the windows of the above compartments and ignite the combustible materials inside the compartments on the second floor. At the same time, heat will transfer from Compartment 1 to its adjacent compartment through conduction.

- The times of ignition and flashover in each compartment based on the computer simulation using the dynamic fire spread modeling are listed in Table 11-6.

Table 11-6 Times of ignition and flashover in each compartment

\begin{tabular}{|c|c|c|c|c|c|c|}
\hline Floor & \multicolumn{2}{|c|}{1} & \multicolumn{2}{c|}{2} & \multicolumn{2}{c|}{3} \\
\hline Compartment & 1 & 2 & 3 & 4 & 5 & 6 \\
\hline $\begin{array}{c}\text { Time of ignition in the } \\
\text { compartment (min) }\end{array}$ & 0 & 6 & 1 & 1 & 6 & 7 \\
\hline $\begin{array}{c}\text { Time of flashover in the } \\
\text { compartment (min) }\end{array}$ & 0 & 11 & 6 & 5 & 11 & 10 \\
\hline $\begin{array}{c}\text { Relative opening on the } \\
\text { external wall }\end{array}$ & $1 \& 7$ & 6 & 2 & 5 & 3 & 4 \\
\hline
\end{tabular}

2) Calculation of the required minimum separation distance between two buildings with time effect

Table 11-6 shows the time of ignition and flashover times in the buildings which can be used to calculate the configuration factor between the fire building and its adjacent 
buildings. Only the openings of compartments where flashover has already occurred are considered in this calculation. If the configuration factor from the fire building to an external wall of an adjacent building is less than the critical configuration factor, it is believed that the fire cannot spread to the adjacent building.

- If the fire severity of a fire building is considered hazardous, the critical configuration factor for fire to spread to its adjacent building is $0.035^{[43]}$.

- If the fire severity of a fire building is considered normal, the critical configuration factor for fire to spread to its adjacent building is $0.07^{[43]}$.

The other data used to do the calculation are listed in Table 11-7.

Table 11-7 The input data of searching minimum separation distance between buildings

\begin{tabular}{|c|c|c|c|c|c|}
\hline \multicolumn{3}{|c|}{ Dimension of openings } & \multirow{2}{*}{$\begin{array}{c}\text { Initial } \\
\text { searching } \\
\text { coordinate } \\
\text { (m) }\end{array}$} & \multicolumn{2}{|c|}{$\begin{array}{l}\text { The initial searching range for separation } \\
\text { distance between two buildings }\end{array}$} \\
\hline & $\begin{array}{l}\text { Left and bottom } \\
\text { corner }\left(x_{0}, y_{0}\right) \\
\text { (m) }\end{array}$ & $\begin{array}{l}\text { Right and top } \\
\text { corner }\left(x_{1}, y_{1}\right) \\
\text { (m) }\end{array}$ & & $\begin{array}{l}\text { Nearest distance } \\
(\mathrm{m})\end{array}$ & $\begin{array}{l}\text { Furthest distance } \\
\text { (m) }\end{array}$ \\
\hline 1 & $(1.5,1.0)$ & $(3.5,2.5)$ & \multirow{7}{*}{$(3,8)$} & \multirow{7}{*}{1} & \multirow{7}{*}{100} \\
\hline 2 & $(1.5,4.0)$ & $(3.5,5.5)$ & & & \\
\hline 3 & $(1.5,7.0)$ & $(3.5,8.5)$ & & & \\
\hline 4 & $(5.5,7.0)$ & $(7.5,8.5)$ & & & \\
\hline 5 & $(5.5,4.0)$ & $(7.5,5.5)$ & & & \\
\hline 6 & $(10,1.0)$ & $(12.5,2.5)$ & & & \\
\hline 7 & $(5.5,0)$ & $(7.5,2.5)$ & & & \\
\hline
\end{tabular}


Using the input data in Table 11-6 and Table 11-7, the required minimum separation distances between the two buildings at different times and severity of the fire building are listed in Table 11-8. If fire fighters can arrive the scene within 10 minutes after fire is reported, the separation distances for the new building should be $11 \mathrm{~m}$ away from its adjacent buildings for hazardous fire severity and $7 \mathrm{~m}$ for normal fire severity.

Table 11-8 Required minimum separation distance between two buildings

\begin{tabular}{|c|c|c|c|c|c|c|}
\hline \multicolumn{2}{|c|}{ Time (min) } & $<5 \mathrm{~min}$ & $5-6 \mathrm{~min}$ & $6-10 \mathrm{~min}$ & $10-11 \mathrm{~min}$ & $>11 \mathrm{~min}$ \\
\hline $\begin{array}{c}\text { Minimum separation } \\
\text { distance based on the } \\
\text { severity of the fire } \\
\text { building (m) }\end{array}$ & $\begin{array}{c}\text { Hazardous } \\
\left(\mathrm{F}_{\text {crt }}=0.035\right)\end{array}$ & 7.99 & 9.38 & 10.61 & 11.60 & 13.56 \\
\cline { 2 - 7 } & $\begin{array}{c}\text { Normal } \\
\left(\mathrm{F}_{\text {crt }}=0.07\right)\end{array}$ & 5.27 & 6.18 & 6.97 & 7.57 & 8.75 \\
\hline
\end{tabular}

\subsection{Modeling Fire Spread between Buildings by Radiation}

\subsubsection{Radiation Heat Flux Emitted from the Fire Building}

The intent of studying radiation in this thesis is to prevent fire spread from a fire building to adjacent buildings within expected fire fighters arrival time. The fire considered in this thesis is assumed to be a fire still contained in the fire building and has not spread to the roof of the building. According to the experiments of St. Lawrence Burns ${ }^{[32]}$, it takes at least sixteen minutes for radiation heat flux from fire building to reach its maximum. For this reason, radiation from the fire building in this thesis is assumed to be emitted from 
windows/openings in an external wall and the flames projecting out of windows/openings.

\subsubsection{Fire building with one window/opening in the external wall}

Assume that there is a building with only one window in the external wall. In the case of fire, the fire may spread to other buildings following flashover. Radiation heat flux to adjacent buildings depends on whether the fire is fuel surface controlled or ventilation controlled.

\subsection{Fuel surface controlled fire}

If the compartment fire is fuel surface controlled, flame burns only inside the compartment; therefore radiation comes from only one radiator - the window radiator.

$$
\dot{q}^{\prime \prime}=\dot{q}_{w}^{\prime \prime}=F_{w} \varepsilon_{w} \sigma T_{w}^{4}
$$

Where:

$$
\begin{aligned}
& \dot{q}_{w}^{\prime \prime}=\text { Radiation heat flux coming from window radiator to a target point, }\left(\mathrm{W} / \mathrm{m}^{2}\right) ; \\
& \mathrm{F}_{\mathrm{w}}=\text { Configuration factor of window radiator to a target point; } \\
& \varepsilon_{w}=\text { Emissivity of window radiator; } \\
& \mathrm{T}_{\mathrm{w}}=\text { Temperature of window radiator, }(\mathrm{K}) .
\end{aligned}
$$

In the calculation, the following are used as input data:

- Dimensions of window radiator is the dimension of window/opening; 
- Separation distance between window radiator and target point is the distance between two buildings;

- Temperature of window radiator is the room temperature calculated by Equation (9.5);

- Emissivity of the window radiator equals $1.0\left(\varepsilon_{w}=1.0\right)$.

\subsection{Ventilation controlled fire}

If the compartment fire is ventilation controlled, the flame will project out of the window; therefore radiation comes from two radiators - the window radiator and the external flame above the window.

$$
\dot{q}^{\prime \prime}=\dot{q}_{w}^{\prime \prime}+\dot{q}_{e f}^{\prime \prime}=\varepsilon_{w} \sigma F_{d E-w} T_{w}^{4}+\varepsilon_{e f} \sigma F_{d E-E F}\left(T_{e f}\right)^{4}
$$

\section{(a) window radiator}

In this calculation, the following are used as input data:

- Dimensions of window radiator are the dimensions of window/opening;

- Separation distance between window radiator and target point is the distance between two buildings, ignoring the impact of the flame projecting beyond window plane on radiation;

- The maximum value of the results of Equation (9.5) and Equation (9.17) is used as the temperature of window radiator;

- Emissivity of the window radiator equals $1.0\left(\varepsilon_{w}=1.0\right)$. 


\section{(b) flame radiator above window}

Based on the results of the full scale experiments on radiation from fires to adjacent buildings conducted in National Research Council of Canada, the following are suggested in the calculation of the radiation from the flame radiator.

- Dimensions of flame radiator above window

The width of flame radiator above the window is the width of window/opening. The height of flame radiator above window is the flame height above the window calculated using Equation (9.11)

- Separation distance

Separation distance between the flame radiator and the external wall of the adjacent building is the distance between the buildings minus two third of the height of window or opening.

- Temperature of flame radiator above window

If the flame height above the soffit of the window is less than $2 \mathrm{~m}$, the average value of the temperature of window radiator and the temperature of the flame tip can be used as the temperature of flame radiator above window.

If the flame height above the soffit of the window is more than $2 \mathrm{~m}$, the flame radiator above window is divided into two parts - top part and bottom part. The height of the top part is 2 meter long ranging from flame tip to 2 meter below it. The average value of the temperature of the window radiator and the temperature of the flame tip is used as the temperature of the top part of the flame radiator. The length of the bottom part equals to 
the flame height above the window minus 2 meters ranging from the soffit of window to 2 meter below the flame tip. The temperature of the window radiator is used as the temperature of bottom part of flame radiator.

- Emissivity

For the external flame, the emissivity can be calculated by the equation given by Law ${ }^{[40]}$.

$$
\varepsilon_{f}=1-e^{-k \lambda}
$$

Where:

$$
\begin{aligned}
& \mathrm{k}=\text { Coefficient, } \mathrm{k}=0.30 \mathrm{~m}^{-1} \\
& \lambda=\text { Thickness of the external flame, } \lambda=\frac{2}{3} H_{o}
\end{aligned}
$$

\subsubsection{Multiple openings in the external wall of the fire building}

For buildings with multiple windows/openings, the radiation heat flux to the target point from the fire building can be considered as the summation of the radiation heat flux from each window/opening calculated by Equation (11.21). Based on the configuration factor calculated by Equations (11.1-11.11), the radiation heat flux coming from the fire building with multiple openings to a target point of an adjacent building can be easily calculated by a computer model. The flow chart of the computer model to calculate the radiation heat flux for a fire building with multiple openings to a target point is shown in Figure 11-12.

$$
\dot{q}^{n}=\sum_{i=1}^{n} \dot{q}_{i}^{\prime \prime}
$$

Where: $\dot{q}_{\imath}^{n}=$ Radiation heat flux coming from opening $i$. 


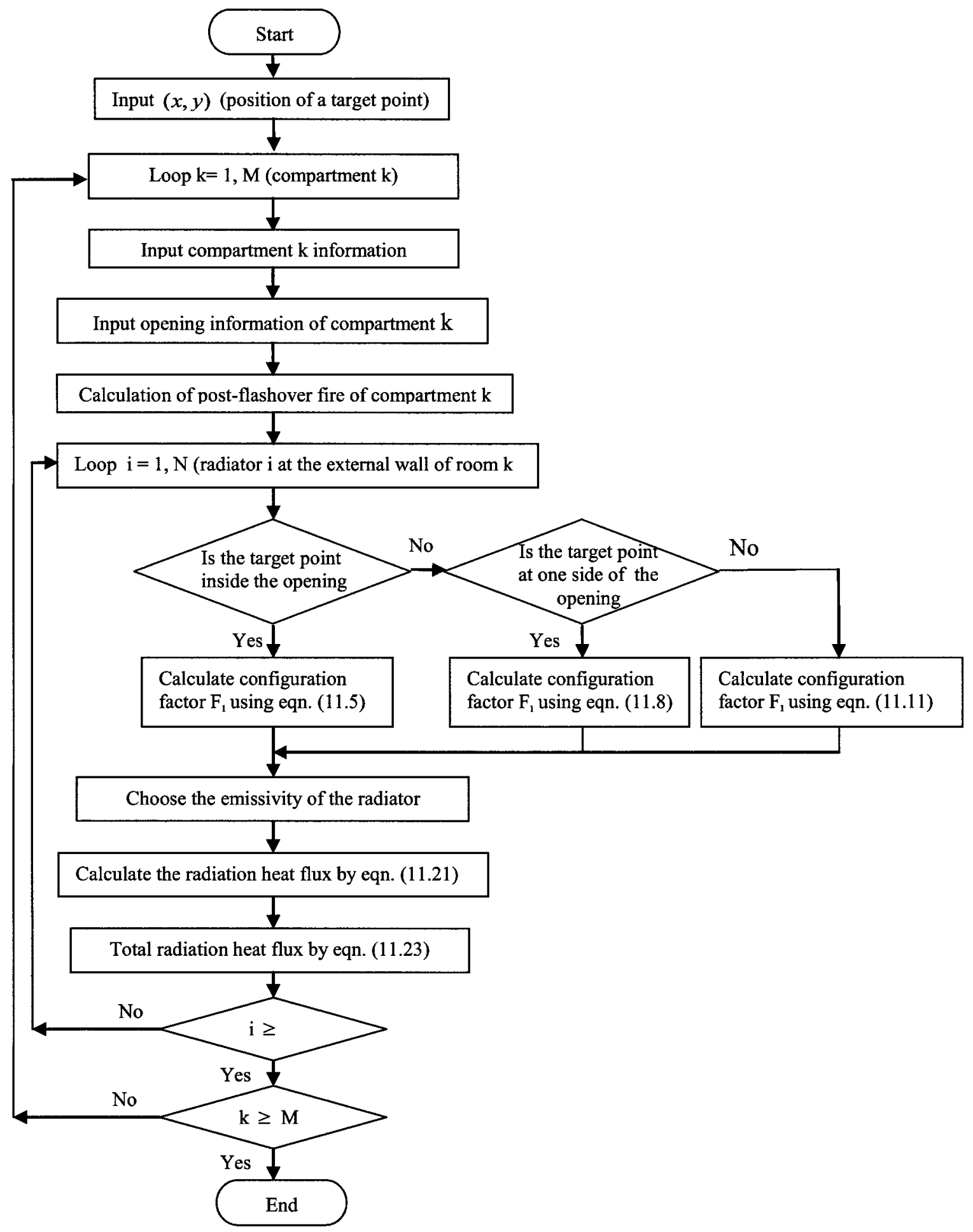

Figure 11-12 Flow chart of calculation of radiation heat flux 


\subsubsection{The Calculation of the Maximum Radiant Heat Flux from a Fire Building on the Target Wall of an Adjacent Building}

The reason for fire spread between buildings is that the radiation heat flux exceeds the pilot ignition heat flux of the combustible material. The most likely ignition point is the point receiving the maximum radiant heat flux from the fire building. The numerical method searching the maximum radiant heat flux is described below.

Assume that $\mathrm{f}(\mathrm{X})=-\dot{q}^{\prime \prime}(\mathrm{X})$, where $\mathrm{X}=(\mathrm{x}, \mathrm{y})$ is the coordinate of target point in $\mathrm{X}-\mathrm{y}$ plane. The point with the maximum value of the radiation heat flux function $\dot{q}^{m}(\mathrm{X})$ is the same as the position with the minimum value of the function $f(X)$. The algorithms of the simplex method ${ }^{[56,57]}$ searching the position with the minimum value of the function $f(X)$ are described in Table 11-9.

Table 11-9 Algorithms of searching maximum radiation heat flux by simplex method

1. Let $f(X)=-T_{F}(X)$ and choose the initial point $X_{1}\left(x_{1}, y_{1}\right)$, find its function value

2. Choose the step length $\mathrm{k}$; let $\mathrm{x}_{2}=\mathrm{x}_{1}+\mathrm{k} ; \mathrm{y}_{2}=\mathrm{y}_{1}$ and $\mathrm{x}_{3}=\mathrm{x}_{1} ; \mathrm{y}_{3}=\mathrm{y}_{1}+\mathrm{k}$. find point $X_{2}\left(x_{2}, y_{2}\right), X_{3}\left(x_{3}, y_{3}\right)$ and corresponding $f_{2}=f\left(X_{2}\right), f_{3}=f\left(X_{3}\right)$.

3. Compare three values $f_{1}, f_{2}$ and $f_{3}$. then let $f_{h}=\max \left(f_{1}, f_{2}, f_{3}\right), f_{t}=\max \left(f_{1}, f_{2}, f_{3}\right)$ and $\mathrm{f}_{\mathrm{m}}\left(f_{l} \leq f_{m} \leq f_{h}\right)$, and corresponding point $\mathrm{X}_{\mathrm{h}}, \mathrm{X}_{1}$ and $\mathrm{X}_{\mathrm{m}}$ 
4. Find the point $X_{0}\left(x_{0}, y_{0}\right)$ at middle of the line connecting points $X_{1}$ and $X_{m}$, and corresponding function $f_{o}=f\left(X_{o}\right)$

5. Reflect $X_{h}$ in $X_{0}$ to get point $X_{r}$ and its function $f_{r}=f\left(X_{r}\right)$ as shown in Figure11.13.

$X_{r}-X_{0}=\alpha\left(X_{0}-X_{h}\right)$ or $X_{r}=(1+\alpha) X_{0}-\alpha X_{h}$

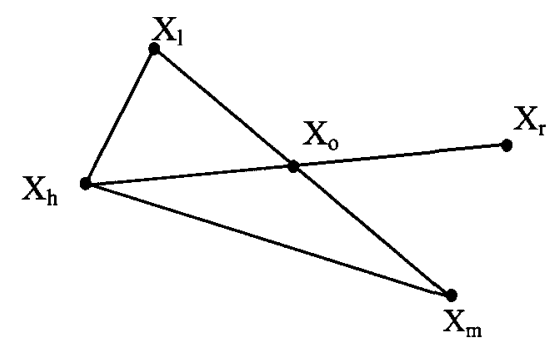

Figure 11-13 Reflection.

6. Compare $f_{r}$ with $f_{m}$

1) if $f_{r}<f_{1}$, the new lowest function value is obtained. Make an expansion along the direction from $X_{o}$ to $X_{r}$ to find the point $X_{e}$ and its function value $f_{e}=f$ $\left(\mathrm{X}_{\mathrm{e}}\right)$ as shown in Figure 11-14.

$\mathbf{X}_{\mathbf{e}}-\mathbf{X}_{\mathbf{o}}=\gamma\left(\mathbf{X}_{\mathrm{r}}-\mathbf{X}_{\mathbf{0}}\right)$ or $\mathbf{X}_{\mathbf{e}}=(\mathbf{1}-\gamma) \mathbf{X}_{\mathbf{o}}+\gamma \mathbf{X}_{\mathbf{r}}$ 


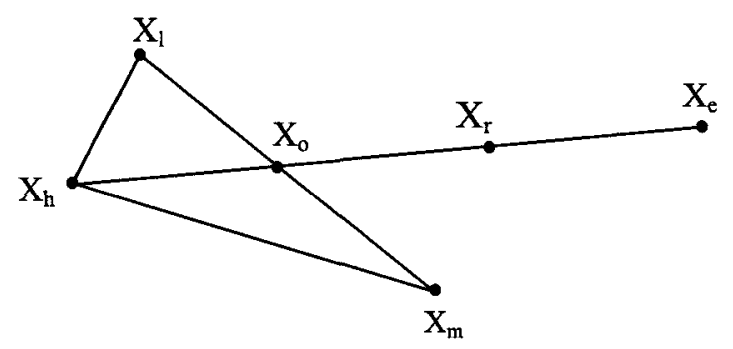

Figure 11-14 Expansion.

a. If $f_{e}<f_{1}$, replace point $X_{h}$ by $X_{e}$. let $X_{1}=X_{e}, X_{2}=X_{1}, X_{3}=X_{m}$ and $f_{1}=f_{e}$, $f_{2}=f_{1}, f_{3}=f_{m}$. Check whether they satisfy the convergence criterion

$\sigma=\sqrt{\frac{\left(f_{1}-\bar{f}\right)^{2}+\left(f_{2}-\bar{f}\right)^{2}+\left(f_{3}-\bar{f}\right)^{2}}{3}} \leq \epsilon$

Where:

$\bar{f}=\frac{f_{1}+f_{2}+f_{3}}{3}$

$\epsilon=$ the pre-determined very small value

Is the convergence criterion satisfied?

- If yes, all function values are very close, the minimum is found

- If no, return to step 3.

b. If $f_{e} \geq f_{1}$, abandon point $X_{e}$ (moved to far) and replace point $X_{h}$ by $X_{r}$. let $X_{1}=X_{r}, X_{2}=X_{1}, X_{3}=X_{m}$ and $f_{1}=f_{r}, f_{2}=f_{1}, f_{3}=f_{m}$. Check whether they satisfy the convergence criterion 
- If yes, all function values are very close, the minimum is found

- If no, return to step 3.

2) If $f_{1}<f_{r}<f_{m}$, replace point $X_{h}$ by $X_{r}$. let $X_{1}=X_{1}, X_{2}=X_{r}, X_{3}=X_{m}$ and $f_{1}=f_{1}$, $f_{2}=f_{r}, f_{3}=f_{m}$. Check whether they satisfy the convergence criterion If yes, all function values are very close, the minimum is found If no, return to step 3.

3) If $f_{r}>f_{m}$, go to step 7 .

7. Compare $f_{r}$ with $f_{h}$

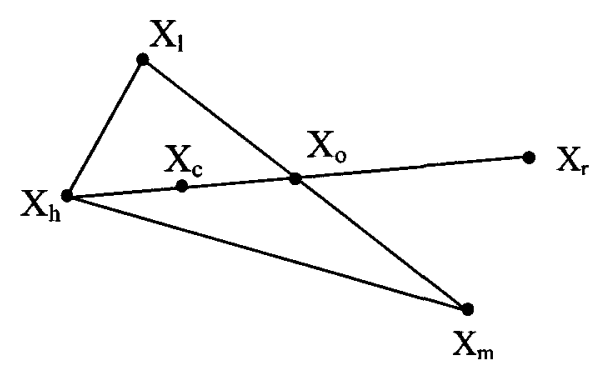

Figure 11-15 Contraction (when $f_{r}>f_{h}$ ).

1) If $f_{r}>f_{h}$, do contraction as show in Figure 11-15.

Let

$$
\mathbf{X}_{\mathrm{c}}-\mathbf{X}_{\mathrm{o}}=\beta\left(\mathbf{X}_{\mathrm{h}}-\mathbf{X}_{\mathrm{o}}\right) \text { or } \mathbf{X}_{\mathrm{c}}=\beta \mathbf{X}_{\mathrm{h}}+(1-\beta) \mathbf{X}_{\mathrm{o}} \quad(0<\beta<1)(11.28)
$$




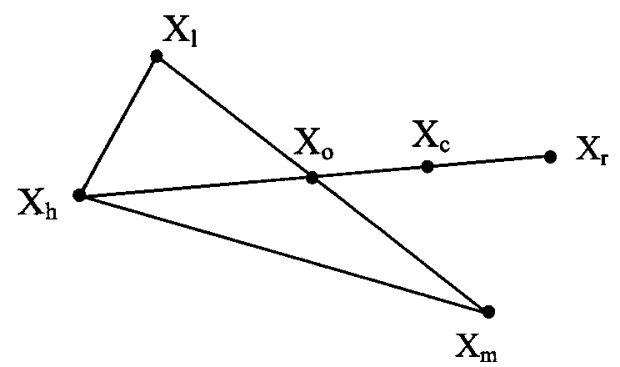

\section{Figure 11-16 Contraction (when $\mathbf{f}_{\mathrm{r}}<\mathrm{f}_{\mathrm{h}}$ )}

2) If $f_{r}<f_{h}$, replace point $X_{h}$ by $X_{r}$ and $f_{h}$ by $f_{r}$. then do contraction as show in Figure 11-16.

Let

$\mathbf{X}_{\mathbf{c}}-\mathbf{X}_{\mathbf{0}}=\beta\left(\mathbf{X}_{\mathbf{r}}-\mathbf{X}_{\mathbf{o}}\right)$ or $\mathbf{X}_{\mathbf{c}}=\beta \mathbf{X}_{\mathbf{r}}+(\mathbf{1}-\beta) \mathbf{X}_{\mathbf{o}}$

8. Compare $f_{c}$ with $f_{h}$

a. If $f_{c}<f_{h}$, replace point $X_{h}$ by $X_{c}$. let $X_{1}=X_{c}, X_{2}=X_{l}, X_{3}=X_{m}$ and $f_{1}=f_{c}, f_{2}$

$=f_{1}, f_{3}=f_{m}$. check whether they satisfy the convergence criterion

If yes, all function values are very close, the minimum is found

If no, return to step 3 .

b. If $f_{c}>f_{h}$, fail to find a function value less than $f_{h}$. We have to reduce the size of simplex by letting

$X_{1}=X_{l}, X_{2}=X_{1}+0.5\left(X_{2}-X_{1,}\right), X_{3}=X_{1}+0.5\left(X_{3}-X_{l}\right)$

Then find corresponding function value $f_{1}, f_{2}$ and $f_{3}$. Then return to step 3 . 
9. If convergence, the position and value of maximum radiation heat flux are $\mathrm{X}_{1}$ and $-f_{1}$

10. The maximum radiation heat flux $\dot{q}_{\max }^{\prime \prime}(c)=-\mathrm{f}_{1}$

\subsubsection{Spatial Separation Distance between Buildings}

The condition of preventing fire spreading between two buildings

$$
\dot{\boldsymbol{q}}_{\text {max }}^{\prime \prime} \leq \dot{\boldsymbol{q}}_{\text {crit }}^{\prime \prime}
$$

Where:

$\dot{q}_{\max }^{\prime \prime}=$ Maximum radiation heat flux from fire buildings to the external wall of the adjacent building, $\left(\mathrm{W} / \mathrm{m}^{2}\right)$;

$\dot{q}_{c r i t}^{\prime \prime}=$ Critical ignition heat flux of the combustible on the external wall of the adjacent building, $\left(\mathrm{W} / \mathrm{m}^{2}\right)$.

Once the ignition heat flux of the adjacent building is known, letting the maximum radiation heat flux equals to the critical ignition heat flux, the minimum separation distance between fire building and its adjacent building can be found out by algorithms in Table 11-10. 
Table 11-10 Algorithms of calculation of separation distance between buildings

1. Input the critical ignition heat flux $\dot{q}_{c r i t}$

2. Input the tolerance of convergence criterion $\epsilon=10^{-9}$

3. Input the initial searching range of separation distance of two buildings $\left(c_{0}, c_{1}\right)$

4. Calculate $\dot{q}_{\max }^{\prime \prime}\left(c_{0}\right)$ and $\Delta \dot{q}_{0}^{\prime \prime}=\dot{q}_{\max }^{\prime \prime}\left(c_{0}\right)-\dot{q}_{c r i t}^{\prime \prime}$

5. Calculate $\dot{q}_{\max }^{\prime \prime}\left(c_{1}\right)$ and $\Delta \dot{q}_{1}^{\prime \prime}=\dot{q}_{\max }^{\prime \prime}\left(c_{1}\right)-\dot{q}_{c r i t}^{\prime \prime}$

6. Let $\mathrm{c}_{2}=0.5\left(\mathrm{c}_{0}+\mathrm{c}_{1}\right)$, calculate $\dot{q}_{\max }^{\prime \prime}\left(c_{2}\right)$ and $\Delta \dot{q}_{2}^{\prime \prime}=\dot{q}_{\max }^{\prime \prime}\left(c_{2}\right)-\dot{q}_{c r i t}^{\prime \prime}$

7. If $\left|\Delta \dot{q}_{2}^{\prime \prime}\right| \leq \epsilon$, convergence, the minimum separation distance between two buildings is $\mathrm{c}_{2}$

8. Otherwise

- If $\Delta \dot{q}_{0}^{\prime \prime} \times \Delta \dot{q}_{2}^{\prime \prime}<0$ and $\Delta \dot{q}_{1}^{\prime \prime} \times \Delta \dot{q}_{2}^{\prime \prime}>0$, let $\mathrm{c}_{0}=\mathrm{c}_{0}$ and $\mathrm{c}_{1}=\mathrm{c}_{2}$, return to step 4

- If $\Delta \dot{q}_{0}^{\prime \prime} \times \Delta \dot{q}_{2}^{\prime \prime}>0$ and $\Delta \dot{q}_{1}^{\prime \prime} \times \Delta \dot{q}_{2}^{\prime \prime}<0$, let $\mathrm{c}_{0}=\mathrm{c}_{2}$ and $\mathrm{c}_{1}=\mathrm{c}_{1}$, return to step 4

- otherwise, enlarge the initial searching range of separation distance $\left(c_{0}, c_{1}\right)$

The flow chart of the modeling of fire spread from the fire building to its adjacent building is presented by Figure 11-17 


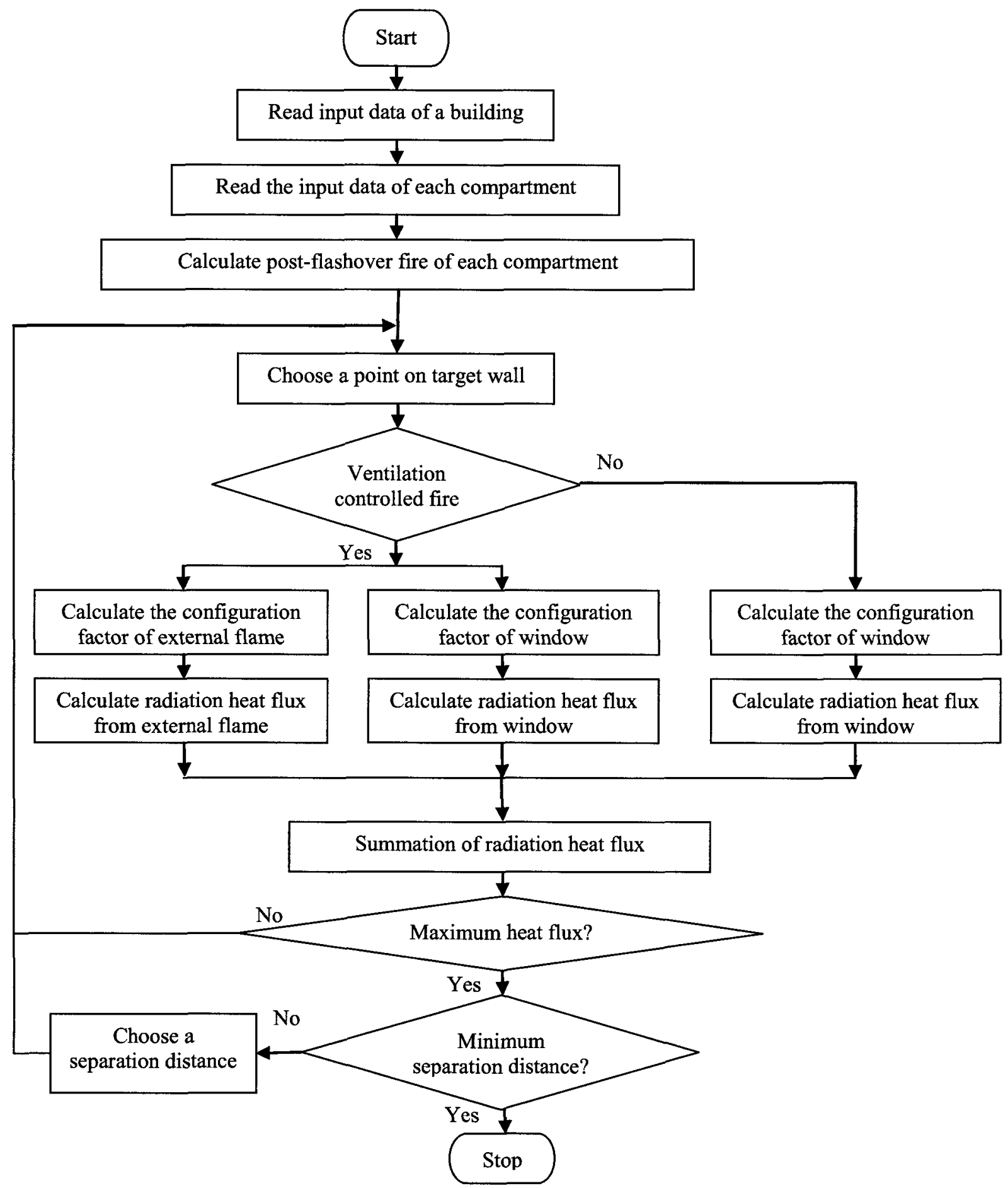

Figure 11-17 Flow char of modeling of fire spread to adjacent buildings 


\subsubsection{Example (11.3): Calculation of the separation distance between buildings based on radiation heat flux}

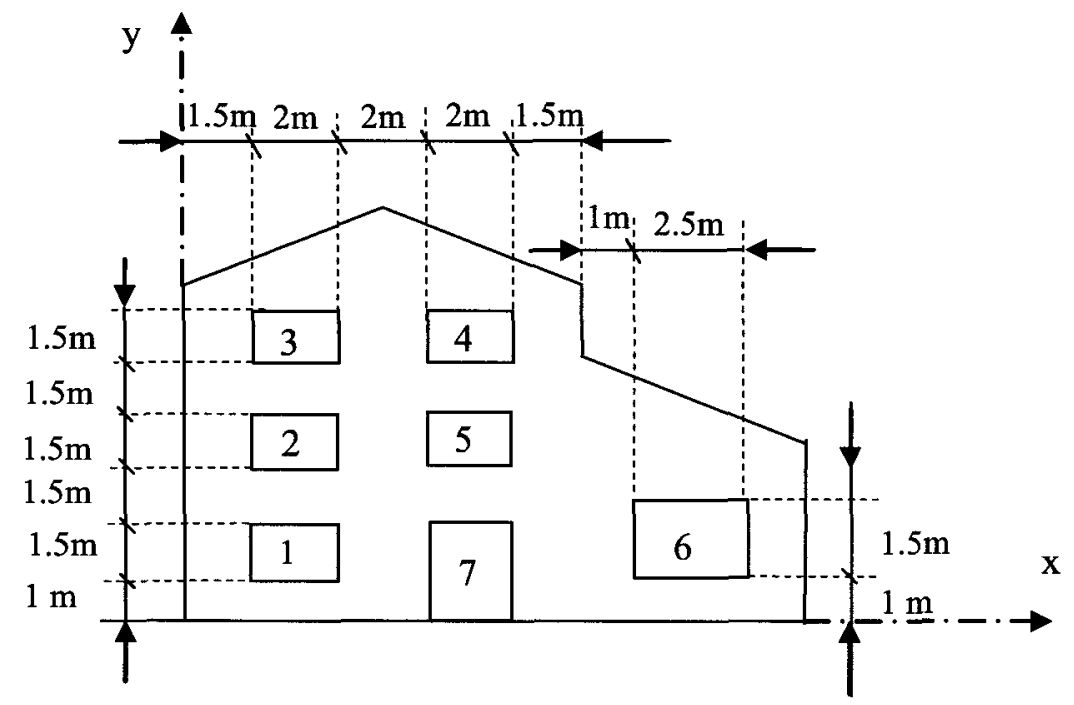

Figure 11-18 A building with irregular distribution of openings

A residential building with no combustible materials on its external wall will be built on a land lot. If fire occurs in this residential building, the fire may spread from this building to its adjacent building. On one of the external walls, there are six windows and one open door as shown in Figure 11-18. The critical ignition heat flux of the combustible material on the external wall of adjacent buildings is $12.5 \mathrm{~kW} / \mathrm{m}^{2}$.To protect the adjacent buildings from fire spread due to the radiation coming from the openings on the external wall of this building, calculate the minimum separation distance required between these two buildings if a fire starts in Compartment 1 of this new building. (This will yield a conservative time of fire spread to the adjacent building because at an exposure of $12.5 \mathrm{~kW} / \mathrm{m}^{2}$ it will take some time for the combustible materials of the exposed building to ignite) 
The dimensions of relative compartments and its openings are listed in Table 11-5. Other data used in this example are listed below:

- Ambient temperature: $20^{\circ} \mathrm{C}$

- Compartment:

The fire load follows a normal distribution. Fuel density: mean $=30.1 \mathrm{~kg} / \mathrm{m}^{2}$; standard deviation $(\mathrm{sd})=4.4 \mathrm{~kg} / \mathrm{m}^{2}{ }^{[25]}$.

Heat of combustion of fuel $\mathrm{H}_{\mathrm{ch}}=12.4 \mathrm{KJ} / \mathrm{g}^{\text {[27] }}$

Fire growth parameter: mean $=0.047 \mathrm{~kW} / \mathrm{s}^{2}$ (fast); $\mathrm{sd}=0.007 \mathrm{~kW} / \mathrm{s}^{2}$ (assumed).

- Window:

Material: common glass;

Fire resistance rating to $I S O 834$ fire: mean $=2 \mathrm{~min}, \mathrm{sd}=0.3 \mathrm{~min}$ (assumed).

- Door:

Material: wood;

Fire resistance rating to ISO834 fire: $\operatorname{mean}=10 \mathrm{~min}, \mathrm{sd}=1.5 \mathrm{~min}$ (assumed).

- Wall \& ceiling:

Material: Gypsum board $\sqrt{k \rho c}=0.742 \mathrm{~kJ} / \mathrm{m}^{2} \mathrm{~s}^{0.5} \mathrm{~K}^{[25]}$

Fire resistance rating to $\mathrm{ISO} 834$ fire: mean $=45 \mathrm{~min}, \mathrm{sd}=6.75 \mathrm{~min}$ (assumed).

- Floor:

Material: wood $\sqrt{k \rho c}=0.436 \mathrm{~kJ} / \mathrm{m}^{2} \mathrm{~s}^{0.5} K^{[25]}$ Steps of Solution: 
1) Calculation of simulated fire spread in the building Assume a fire starts in Compartment 1 on the first floor and the fire is reported to fire station only when flashover occurs. The time of the simulation of fire spread in the building starts at this moment $(\mathrm{t}=0)$. The detail results of simulation are described in Example (11.2). The relation of opening and post-flashover fire with time effect is summarized in Figure 11-19.

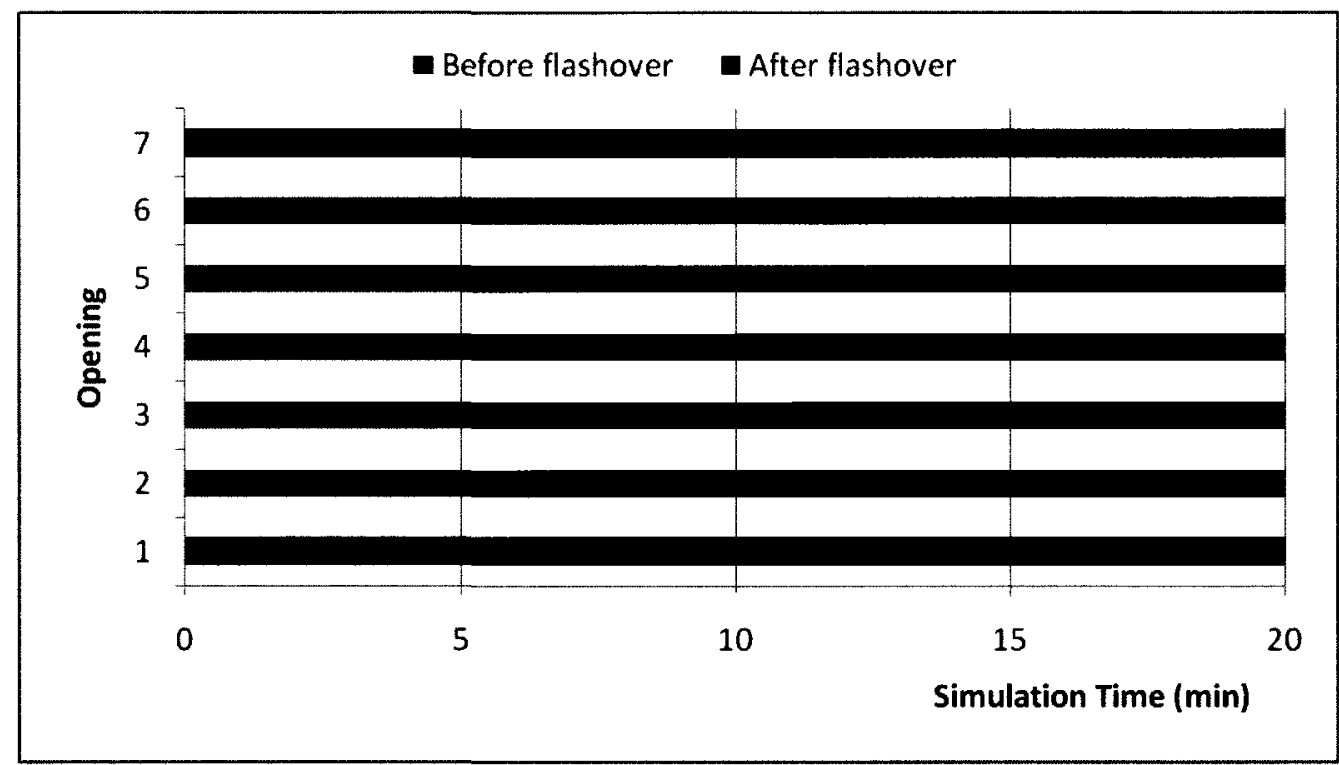

Figure 11-19 Relation between opening and post-flashover fire with time effect

2) Calculation of post-flashover fire for each compartment

Using the dimensions of the openings and compartments, the fire fuel density in the compartment, the output of post-flashover fire in each compartment can be calculated as seen in Table 11-11. 
Table 11-11 The output of post-flashover compartment fire

\begin{tabular}{|c|c|c|c|c|c|c|}
\hline \multirow{2}{*}{ Floor } & \multicolumn{2}{|c|}{ Compartment } & \multicolumn{3}{c|}{ Opening } & \\
\cline { 2 - 7 } & $\begin{array}{c}\text { No. of } \\
\text { compartment }\end{array}$ & $\begin{array}{c}\text { Compartment } \\
\text { temperature } \\
\left({ }^{\circ} \mathrm{C}\right)\end{array}$ & $\begin{array}{c}\text { No. Of } \\
\text { opening }\end{array}$ & $\begin{array}{c}\text { Window } \\
\text { temperature } \\
\left({ }^{\circ} \mathrm{C}\right)\end{array}$ & $\begin{array}{c}\text { Flame height } \\
\text { above opening } \\
(\mathrm{m})\end{array}$ & $\begin{array}{c}\text { Temperature of } \\
\text { opening radiator } \\
\left({ }^{\circ} \mathrm{C}\right)\end{array}$ \\
\hline \multirow{2}{*}{1} & 1 & 1068 & 1 & 1103 & 2.00 & 1103 \\
\cline { 2 - 7 } & 1 & 1068 & 7 & 910 & 2.42 & 1068 \\
\hline \multirow{2}{*}{2} & 3 & 950 & 6 & 1075 & 2.41 & 1075 \\
\cline { 2 - 7 } & 4 & 929 & 5 & 1049 & 2.81 & 1049 \\
\hline \multirow{2}{*}{3} & 5 & 929 & 3 & 1049 & 2.81 & 1049 \\
\hline
\end{tabular}

3) Calculation of the required minimum separation distance between two buildings

The following are used to calculate the radiation heat flux emitted from the fire building

- Compartments under post-flashover fire;

- Dimensions of openings;

- Temperatures of openings;

- Height of external flames above windows

- Emissivity of external flame;

- The critical ignition heat flux $=12.5 \mathrm{kw} / \mathrm{m}^{2}$; 
- Coefficients for searching maximum heat flux $(\alpha=1, \beta=0.5, \gamma=2)^{[56] \text {; }}$

- Initial searching range of separation distance between buildings;

- Initial searching coordinate in $x-y$ plane on selected target wall;

- Tolerance for convergence criterion $\epsilon=10^{-9}$.

By letting the maximum configuration factor to be equal to the critical configuration factor, the minimum separation distance between two buildings can be found as shown in Table 11-12 according to the fire spread process in the new building. If the fire fighter arrival time can be within 10 minutes, a $9.5 \mathrm{~m}$ separation distance is required between the new building and its adjacent buildings.

\subsection{Comparison separation distances required by the National Building Code of Canada with those calculated in Example (11.2) and Example (11.3)}

- This calculation is based on the National Building Code of Canada 2005 The National Building Code of Canada 2005 does not consider the time effect of fire spread within fire building. To compare the result calculated in the two examples above with those of the National Building Code of Canada 2005, the separation distance required between buildings is calculated according to the fire spread process in the fire building as shown in Figure 11-19. A sample of the calculation for the scenario where all compartments are in fully-developed fire phase is presented below. Total area of exposing building face $=101.25 \mathrm{~m}^{2}$ 
Table 11-12 Minimum separation distance required between two buildings (m)

\begin{tabular}{|c|c|c|c|c|c|c|}
\hline & Time & $<5 \mathrm{~min}$ & $5-6 \mathrm{~min}$ & $6-10 \mathrm{~min}$ & $10-11 \mathrm{~min}$ & $>11 \mathrm{~min}$ \\
\hline \multirow{3}{*}{$\begin{array}{c}\text { Emissivity of } \\
\text { external flame above } \\
\text { opening }\end{array}$} & 0.252 (Law) & 6.20 & 7.29 & 8.20 & 8.92 & 10.33 \\
\cline { 2 - 7 } & 0.394 (Beyreis) & 6.56 & 7.74 & 8.74 & 9.53 & 11.07 \\
\cline { 2 - 7 } & 0 (Ignore) & 5.46 & 6.96 & 9.23 & 10.08 & 11.69 \\
\hline
\end{tabular}


For the extreme scenario (all compartments are in the fully-developed fire phase), the aggregate area of unprotected opening on the external wall $=23.75 \mathrm{~m}^{2}$

Ratio of aggregate opening area to exposing building face area $=23.2 \%$

According to Table 8-4 (Table 9.10.14.4 in NBCC), the limiting distance $=8.0 \mathrm{~m}$

The separation distance between two buildings $=16 \mathrm{~m}$

Table 11-13 Separation distances calculated by NBCC and two models (m)

\begin{tabular}{|c|c|c|c|c|c|c|}
\hline & & $<5 \mathrm{~min}$ & $5-6 \mathrm{~min}$ & $6-10 \mathrm{~min}$ & $10-11 \mathrm{~min}$ & $>11 \mathrm{~min}$ \\
\hline NBCC & Residential & $2.4-3$ & 8 & 12 & 12 & 16 \\
\hline \multirow{3}{*}{$\begin{array}{c}\text { Configuration } \\
\text { factor (Severity) }\end{array}$} & $\begin{array}{c}\text { Normal } \\
\left(\mathrm{F}_{\text {crit }}=0.07\right)\end{array}$ & 5.27 & 6.18 & 6.97 & 7.57 & 8.75 \\
\cline { 2 - 7 } & $\begin{array}{c}\text { Hazardous } \\
\left(\mathrm{F}_{\text {crit }}=0.035\right)\end{array}$ & 7.99 & 9.38 & 10.61 & 11.60 & 13.56 \\
\hline \multirow{3}{*}{$\begin{array}{c}\text { Radiation } \\
\text { (Emissivity of } \\
\text { external flame) }\end{array}$} & 0.252 (Law) & 6.20 & 7.29 & 8.20 & 8.92 & 10.33 \\
\cline { 2 - 7 } & 0.394 (Beyreis) & 6.56 & 7.74 & 8.74 & 9.53 & 11.07 \\
\cline { 2 - 7 } & 0.519 or 0.820 & 6.96 & 8.20 & 9.23 & 10.08 & 11.69 \\
\cline { 2 - 7 } & 0 (Ignore) & 5.46 & 6.32 & 7.09 & 7.64 & 8.82 \\
\hline
\end{tabular}

- Comparison of the results calculated by the fire spread model between buildings based on configuration factor and radiation

From Table 11-13, it can be found that the results of separation distances calculated by the model of fire spread between buildings by configuration factor has the maximum value when the severity of the fire building is hazardous or minimum value when the severity of the fire building is normal. The values calculated by the model of fire spread between buildings using the configuration factor are very close to those calculated by the 
model of fire spread between buildings by radiation when the impact of external flame is ignored. The values calculated by the model of fire spread between buildings by radiation seem more reasonable compared with those calculated by the model of fire spread between buildings by configuration factor.

- Comparison of the results calculated by the two fire spread model with those required by NBCC 2005

From Table 11-13, it can be found that the separation distances required by NBCC 2005 are very different from those computed by the two models of fire spread between buildings. For the case with smaller ratio of aggregate opening area to the exposing building face area, the required separation distance between buildings is less than that calculated by the two models of fire spread between buildings. This may be due to the fact that NBCC only considers the ratio of aggregate opening area to the exposing building face area but not the size of a single opening. For the case with larger ratio of aggregate opening area to the exposing building face area, the required separation distance between buildings is much larger than that calculated by the two models of fire spread between buildings. The main problem of the NBCC requirements is that it mainly considers the ratio of the aggregate opening area to the exposing building face area and not the sizes of the openings and their distribution on the external wall. 


\section{Chapter 12 \\ Conclusion of the Study of Modeling Fire Spread between Buildings}

\subsection{Summary of the Study of Modeling Fire Spread between Buildings}

In this part of the thesis, a study of fire spread between buildings has been conducted. The main factor that causes fire spread between buildings is that the radiation heat flux received by the adjacent building exceeds the ignition heat flux of combustible material. Therefore, following work had been done to study the problem:

1. Twelve full-scale fire experiments were conducted to study the impact on characteristics of compartment fire by fire load and window size and the impact on radiation heat flux by different window sizes, separation distances and fire fuels. The contribution of the external flame to the radiation heat flux on a target wall was analyzed and the emissivity of external flame for each experiment was calculated. Then the modeling of the radiation on a target wall using the experimental data was conducted. Furthermore, a method for modeling the radiation heat flux on a target wall using the theory of post-flashover compartment fires is presented. 
2. Three types of basic relationships that exist between a rectangular opening and a parallel target point are presented. Corresponding formulae to calculate the configuration factor are derived. By summing the configuration factor for each window or opening to the target point, the configuration factor for buildings with multiple openings to a target points can easily be calculated even for buildings with irregular distribution of windows, different size of opening and recessed portions. The algorithms for searching for the position and value of the maximum configuration factor for a building to the external wall of its adjacent building are presented. A model for calculation of the acceptable separation distance between buildings based on configuration factor has been proposed. Once the severity of the hazardous conditions of buildings is known, the minimum separation distance between buildings could be easily found out by letting the maximum configuration factor equals to the critical configuration factor.

3. Based on the experimental results and modeling of radiation from compartment fires, a model of calculation of the separation distance between buildings based on radiation has been proposed. An example of the calculation is presented in which the results of the minimum acceptable separation distance between buildings are calculated for considering the impact by different values of emissivity. These results are compared with those calculated by the model of fire spread between buildings based on configuration factor. 


\subsection{Further Study}

In order to improve the modeling of fire spread from the fire building to be used in application as a method of performance-based fire safety design and become part of fire safety codes in the future, the following work should be conducted:

- The study of impact of fires with multiple compartments and multiple openings on radiation;

- The study of impact of wind on radiation;

- The study of impact of fuel type and size on emissivity;

- The study of formulae to calculate the room temperature, flame height above opening which can predict values closer to experimental results. 


\section{REFERENCES}

1. Ramachanandran G. Stochastic models of fire growth. SFPE handbook of fire protection engineering, 3rd ed. Section 3, Chapter 15, National Fire Protection Association, USA, 2002, 381-401.

2. Ramachanandran G. Non-deterministic modeling of fire spread, J. of Fire Prot. Engr. 3(2); 37-48; 1991.

3. Albini FA and rand S. Statistical consideration on the spread of fire. IDA research and engineering support division, Washington D.C., 1964

4. Thomas PH, Some possible statistic processes to the spread of fire. Internal Note No. 223, Fire research station, Borehamwood, Herts, UK, 1965

5. Benckert LG and Sternberg I. An attempt to find an expression for the distribution of fire damage amount, Transactions of the Fifteenth International Congress of Actuaries, $11 ; 288-294 ; 1957$

6. Mandelbrot B. Random walks, fire damage amount and other paretian risk phenomena, Operation Research, 12, 582-585, 1964.

7. Berlin GN. Managing the variability of fire behavior, Fire Technology, 16, 287$302,1980$.

8. Ramachanandran G. Stochastic modeling of fire growth, Fire Safety: Science and Engineering, ASTM STP 882, In: Harmathy, TZ, editor. American Society for Testing and Materials, 1985, 122-144. 
9. Aoki Y. Studies on probabilistic spread of fire, Research Paper No. 80, Building Research Institute, Japan, 1978.

10. Hori M. Theory of percolation and its applications. Nippon Tokeigakkai-shi, $3(19) ; 1972$

11. Tat MA. Stochastic modeling and optical control of compartment fires. Ph.D thesis, Victoria University of Technology at Australia, 1999

12. Ling W-C T. Williamson RB, Modeling of fire spread through probabilistic network. Fire Safety J 1986; 9; 287-300.

13. Platt DG, Elms DG, Buchanan AH. A probabilistic model of fire spread with time effects. Fire Safety J 1994; 22; 367-98.

14. Webb K, Dutcher CR. Fire spread model. Fire risk management program, institute for research in construction, NRCC, 2000.

15. Castillo E, Gutierrez JM, and Hadi AS. Expert systems and probabilistic network models. New York: Springer; 1997.

16. Williamson J, Bayesian nets and causality: philosophical and computational foundations, New York: Oxford University Press; 2005.

17. Jensen FV, An introduction to Bayesian networks, New York: Springer; 1996.

18. Murphy KP. Dynamic Bayesian networks: Representation, Inference, and Learning. Ph. D. dissertation. University of California; 2002

19. Cheng H, Hadjisophocleous GV. The Modeling of Fire Spread in Building by Bayesian Network, Fire Safety J, 2009; 901-908 
20. DiNenno PJ, SFPE handbook of fire protection engineering, 3rd ed. Section 3, National Fire Protection Association, USA, 2002.

21. Dreyfus SE, An appraisal of some shortest path algorithms, Opertions Research, Vol 17, 1969; 395-412

22. Babrauskas V., Estimating room flashover potential, Fire Technology, Vol 16, No.2, 1980

23. Harmathy TZ, A new look at compartment fires, Part I, Fire Technology, Vol. 8, No. 3, 1972, pp. 196-217

24. Harmathy TZ, A new look at compartment fires, Part II Journal: Fire Technology, Fire Technology, Vol. 8, No. 4, 1972, pp. 326-351

25. Harmathy TZ, Post-flashover fires - an overview of the research at the National Research Council of Canada (NRCC), 1970-1985, Fire Technology, Vol. 22, No. 3, 1986, pp. $210-233$

26. Law M, Fire safety of external building elements - the design approach, Engineering Journal, Second Quarter, American Institute of Steel Construction, pp. 59-74, 1978

27. Heselden AJM and Thomas PJ, Fully developed Fires in single compartment, CIB Report No. 20, Fire Research Note 923, Joint Fire Research Organization, Borehamwood, 1972 
28. Gaskin $\mathrm{J}$ and Yung D, Canadian and USA fire statistics for use in the risk-cost assessment model, Internal Report No. 637, national Research Council Canada, 1993

29. Yung DT, Hadjisophocleous GV and Proulx G, A Description of the probabilistic and deterministic modeling used in FiRECAM, International Journal on Engineering Performance-Based Fire Codes, Vol.1, No.1, 1999, pp. 18-26

30. Mehaffey JR, Designing wood-frame buildings for fire resistance, Wood and Fire Safety, 2000, pp201-209

31. Bevan RC and Webster CT, Investigation on building fires: Part 3, radiation from building, National Building Studies Technical Paper No. 5, London, 1950.

32. Shorter GW, McGuire JH, Hutcheon NB, and Legget RF, The St. Lawrence burns, Quarterly of the National Fire Protection Association, 53, (4), pp. 300-316, June 01,1960

33. Law M., Heat radiation from fires and building separation, Fire Research Technical Paper No. 5, H.M. Stationery Office, London, 1963.

34. Law M, Radiation from fires in a compartment, Fire Research technical Paper No. 20, Ministry of Technology and Fire office's Committee, 1968

35. Lin CY, Study of exposure fire spread between buildings by radiation, Journal of the Chinese Institute of Engineers, Vol. 23, No.4, pp.493-504, 2000 
36. Chen A and Francis J, Radiant heat flux to external surfaces from escaping and extrusive flashover flames, Proc. Instn. Mech. Engr, Vol. 217 Part C: J. Mechanical Engineering Science, pp247-256, 2003

37. Beyreis JR, Monsen HW and Abbasi AF, Properties of wood crib flames, Fire technology, 7(2), pp.145-155, 1971

38. Babrauskas V and Williamson RB, Post-flashover compartment fires: Basis of a theoretical model, Fire and Materials, Vol. 2, No. 2, 1978, pp. 39-53

39. Read RE, External fire spread: building separation and boundary distances, 1991

40. Law M and O'Brien T, Fire Safety of Bare External Structural Steel, Steel Construction Institute, 1981

41. Law M, A basis for the design of fire protection of building structures. Struct Eng $1983 ; 61: 25-33$

42. Barnett CR, Fire Separation between External Walls of Buildings, Fire Safety Science, Proceedings of the 2nd International Symposium (pp. 841-850), 1988

43. McGuire JH, Fire and the spatial separation of buildings, , Fire Technology, Vol. 1, No. 4, p. 278, 1965.

44. Williams-Leir G, Approximations for spatial separation, Fire Technology, Vol. 2, No. 2, pp. 136-45, 1966.

45. Williams-Leir G, Another approximation for spatial separation, Fire Technology, Vol. 6, No. 3, pp. 189-202, 1970. 
46. McGuire JH and Williams-Leir G, Fire and the spatial separation of buildings, Fire Fighting in Canada, Vol. 16, No. 3-4, pp. 3-6, 1972.

47. McGuire JH and Williams-Leir G, Spread of fire between buildings, Canadian Building Digest, 216, pp. 4, June, 1981.

48. NFPA, NFPA $80 A$ recommendation practice for protection of buildings from exterior fire exposures, National Fire Protection Association, Quincy, MA, 1996

49. Canadian Commission on Building and Fire Codes, National Building Code of Canada (2005), National Research Council of Canada, 2005

50. Moysey EB, Space separation for prevention of farm fire spread, Fire Technology, Vol. 1, No. 1, pp.62-68, 1965

51. Torvi D, Kashef A and Benichou N, FIERAsystem radiation to adjacent buildings Model (RABM): theory report, Research report No. 189, National Research Council Canada, March 2005.

52. Carlsson E and Olsson P, External fire spread to adjoining buildings - a literature review, 3rd International Conference on Performance-Based Codes and Fire Safety Design Methods, Lund University, Lund, Sweden, 2000.

53. Klopovic S and Turan OF, Flame venting externally during full-scale flashover fires: two sample ventilation cases, Fire Safety Journal, Vol. 31, 1998, pp117-142 54. Seigel, LG, the projection of flames from burning building, Fire Technology, Vol. 5 No. 1, pp. 43-51, 1969. 
55. Press WH, Teukolsky SA, Vetterling WT and Flannery BP, Numerical Recipes:

The art of scientific computing, third edition, Cambridge University, 2007

56. Bunday BD, Basic optimization methods, Edward Arnold, 1984. 


\section{Appendix A \\ The Analysis of Experiments of Radiation from Compartment Fires to Adjacent Buildings}

\section{A-1 Introduction to Fire Experiment}

In order to study the impact of external flames out of the window on the radiation distribution on a target wall and the emissivity of external flame, 12 full-scale experiments were conducted at the fire research laboratories of the National Research Council of Canada (NRCC). The size of the fire compartment was $5.95 \times 4.4 \times 2.75 \mathrm{~m}$ $(\mathrm{W} \times \mathrm{D} \times \mathrm{H})$. A wood-framed target wall was constructed with a size of $16^{\prime} \times 16^{\prime}(4.88 \times$ $4.88 \mathrm{~m}$ ) and placed away from the fire building at different separation distances. The window sizes of the fire compartment, separation distances between the fire building and the target wall, and fuel used in each experiment are reported in Table A-1. The distribution of instruments on the external wall of the fire building was the same in all tests as shown in Figure A-1. Due to the use of more radiometers and increasing of flame height above the window with the decreasing of window width, the distribution of instruments on the target wall was updated twice as shown from Figure A-2 to Figure A4. 
Table A-1 The matrix of the fire experiments

\begin{tabular}{|c|c|c|c|}
\hline Test & Fuel & Window $(\mathrm{W} \times \mathrm{H})(\mathrm{m})$ & Separation distance $(\mathrm{m})$ \\
\hline 1 & Propane & $2.55 \times 1.45$ & 3 \\
\hline 2 & Propane & $2.55 \times 1.45$ & 3.5 \\
\hline 3 & Propane & $2.55 \times 1.45$ & 4 \\
\hline 4 & Propane & $1.45 \times 1.45$ & 3 \\
\hline 5 & Propane & $1.45 \times 1.45$ & 3.5 \\
\hline 6 & Propane & $1.45 \times 1.45$ & 2.4 \\
\hline 7 & Propane & $1.10 \times 1.45$ & 3.5 \\
\hline 8 & Propane & $1.10 \times 1.45$ & 3 \\
\hline 9 & Propane & $1.10 \times 1.45$ & 4 \\
\hline 10 & Wood cribs 2"x4" & $1.10 \times 1.45$ & 3 \\
\hline 11 & Wood cribs 2"x4" & $1.45 \times 1.45$ & 3 \\
\hline 12 & Wood cribs 2"x2" & $2.55 \times 1.45$ & 3 \\
\hline
\end{tabular}

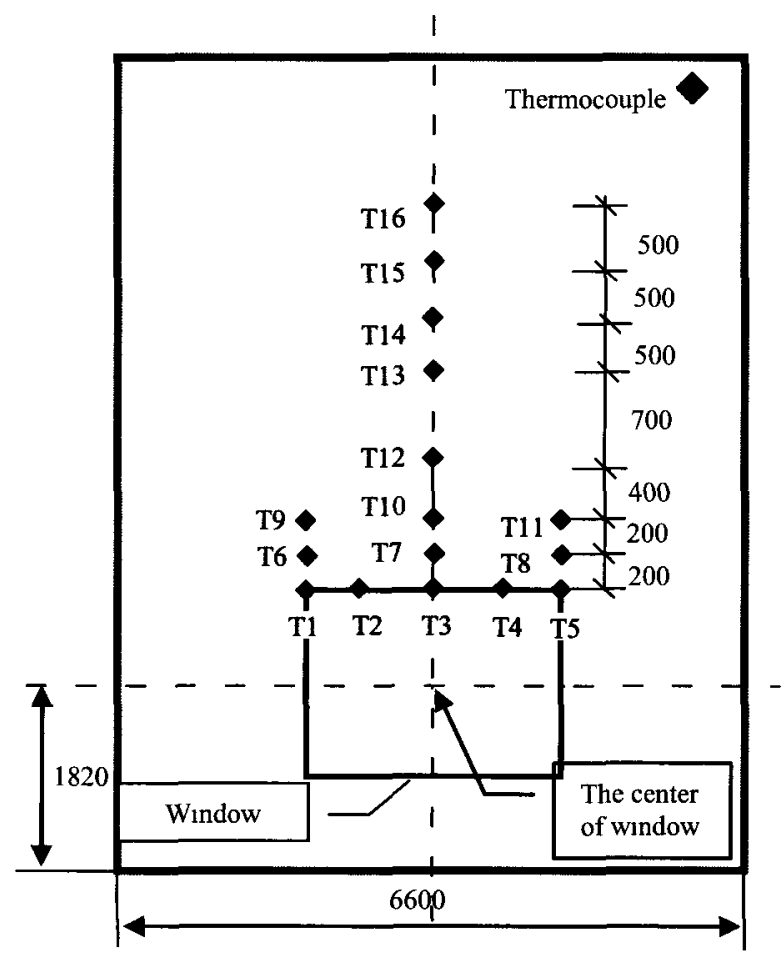

Figure A-1 Instrumentation on the external wall of fire building 


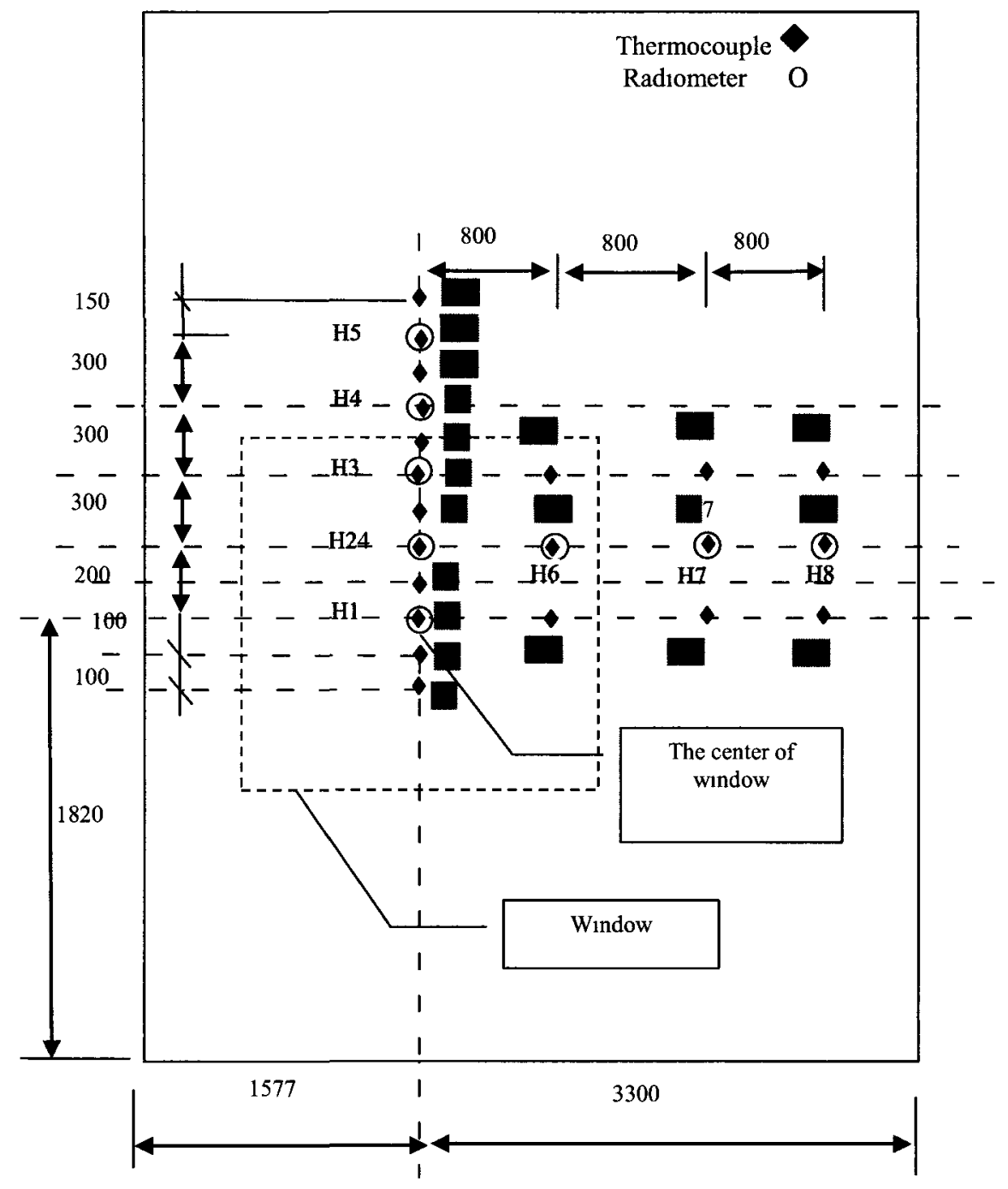

Figure A-2 Instrumentation on the target wall (Test 1-4) 


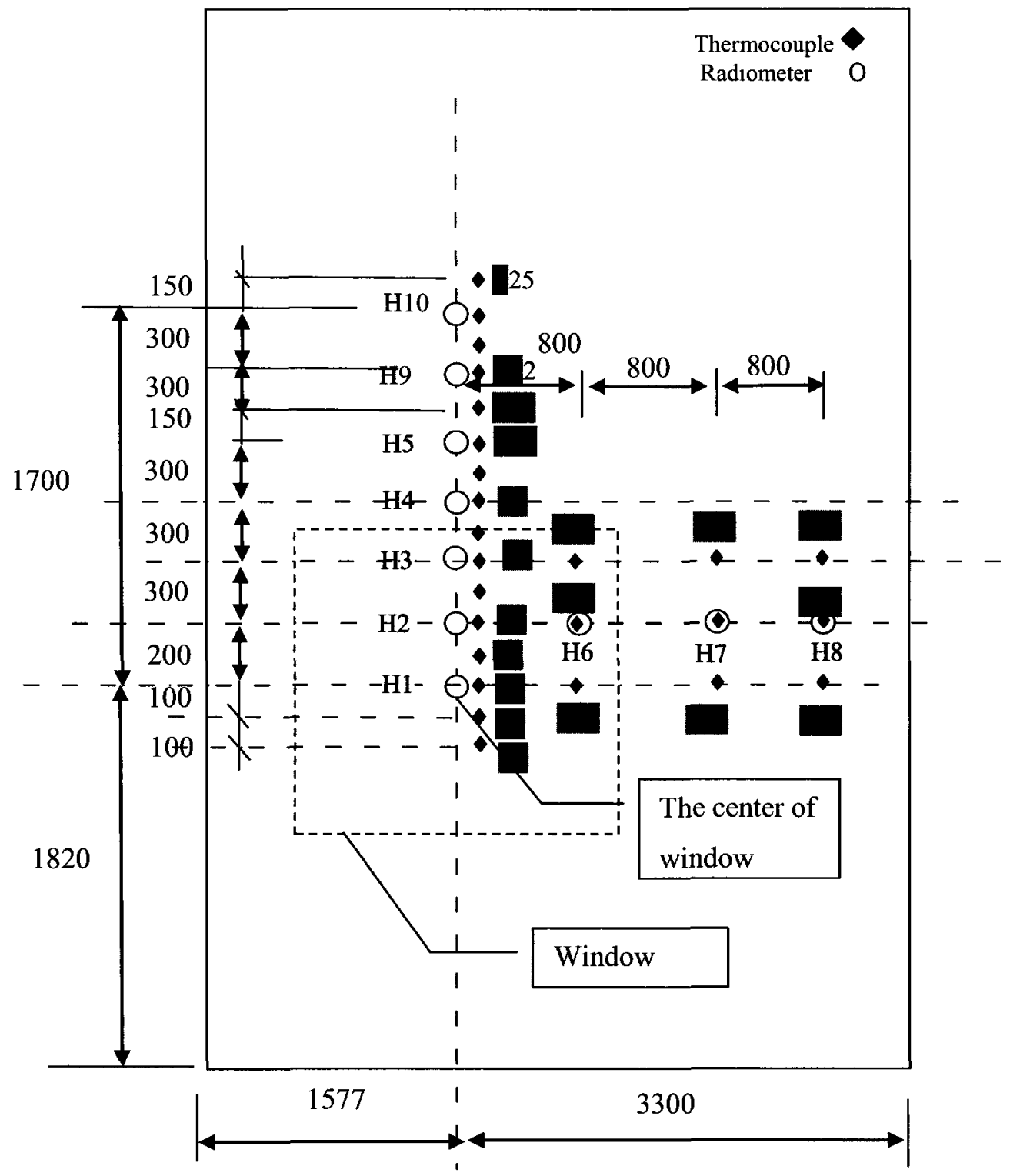

Figure A-3 Instrumentation on the target wall (Test 5) 


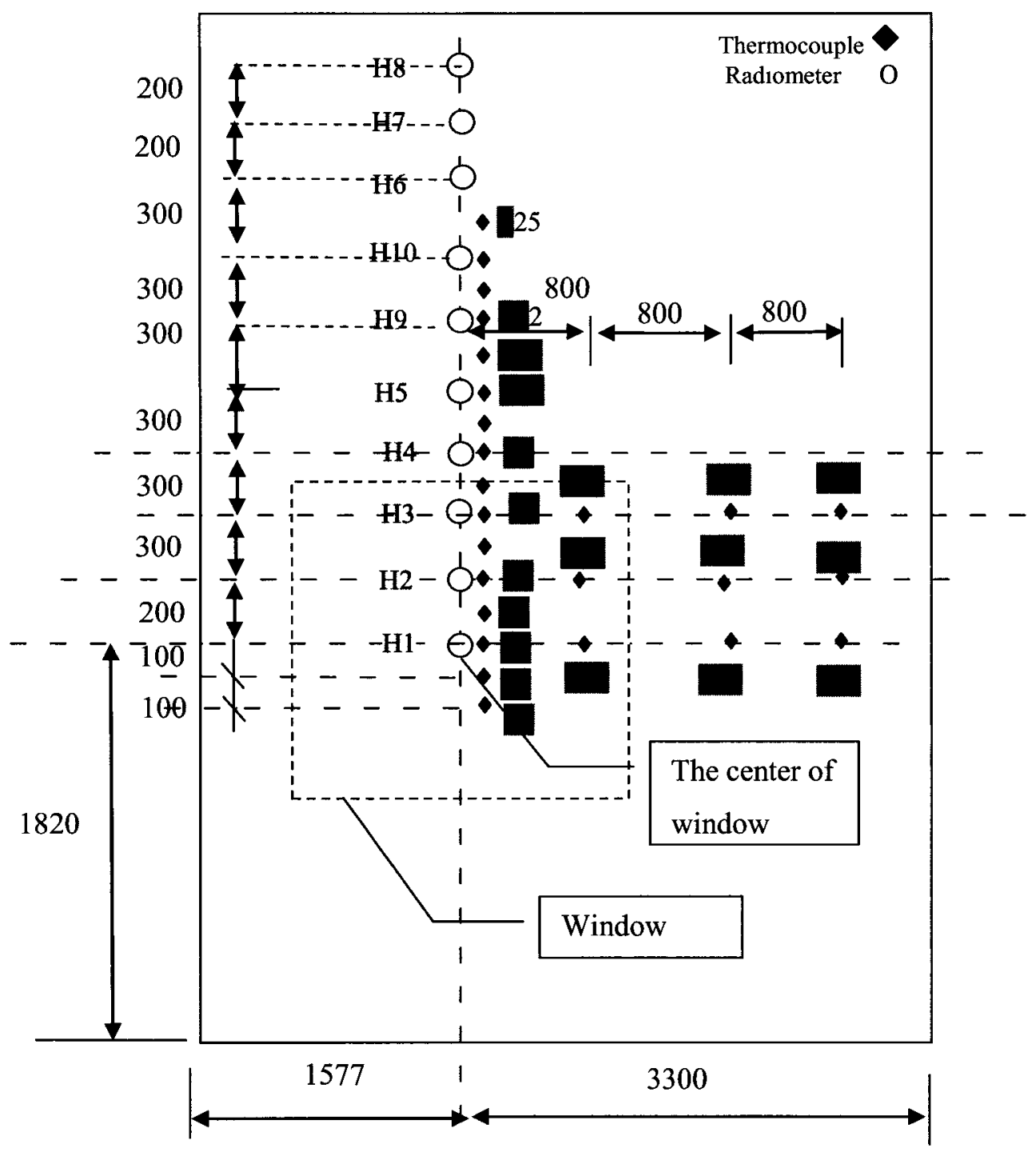

Figure A-4 Instrumentation on the target wall (Test 6-12) 


\section{A-2 Analysis of the Experimental Data}

In order to remove the noise inherent in experimental data, the initial experimental data were first smoothing after each experiment. A sample graph comparing the experimental data for temperature or heat flux with the data after smoothing is shown in Figure A-5. Then a period (around 5 minutes) of experimental data during fully-developed fire phase was chosen to do the analysis. By taking the average of each selected data, the value of temperature or heat flux at each point during post-flashover fire phase can be calculated.

\section{Test 1 (2.55x1.45 \& 3m, Propane)}

- A graph comparing the initial data with the data after smoothing for the temperature at the point T3 (shown in Figure A-1) on fire building or heat flux at the point $\mathrm{H} 1$ on the target wall (shown in Figure A-2) is plotted in Figure A-5.

- The thermal images of the fire building and target wall are shown in Figure A-6.

- Based on the graphs of heat flux on the target wall, the data after smoothing between 11:28:54 and 11:33:55 were chosen to do the experimental study of Test 1.

- By taking the average of the data selected, the value of temperature or heat flux at each point during post-flashover fire phase can be estimated.

- The temperature distribution and heat flux distribution at points on the target wall opposite the vertical centerline of the window are shown in Figure A-7. 


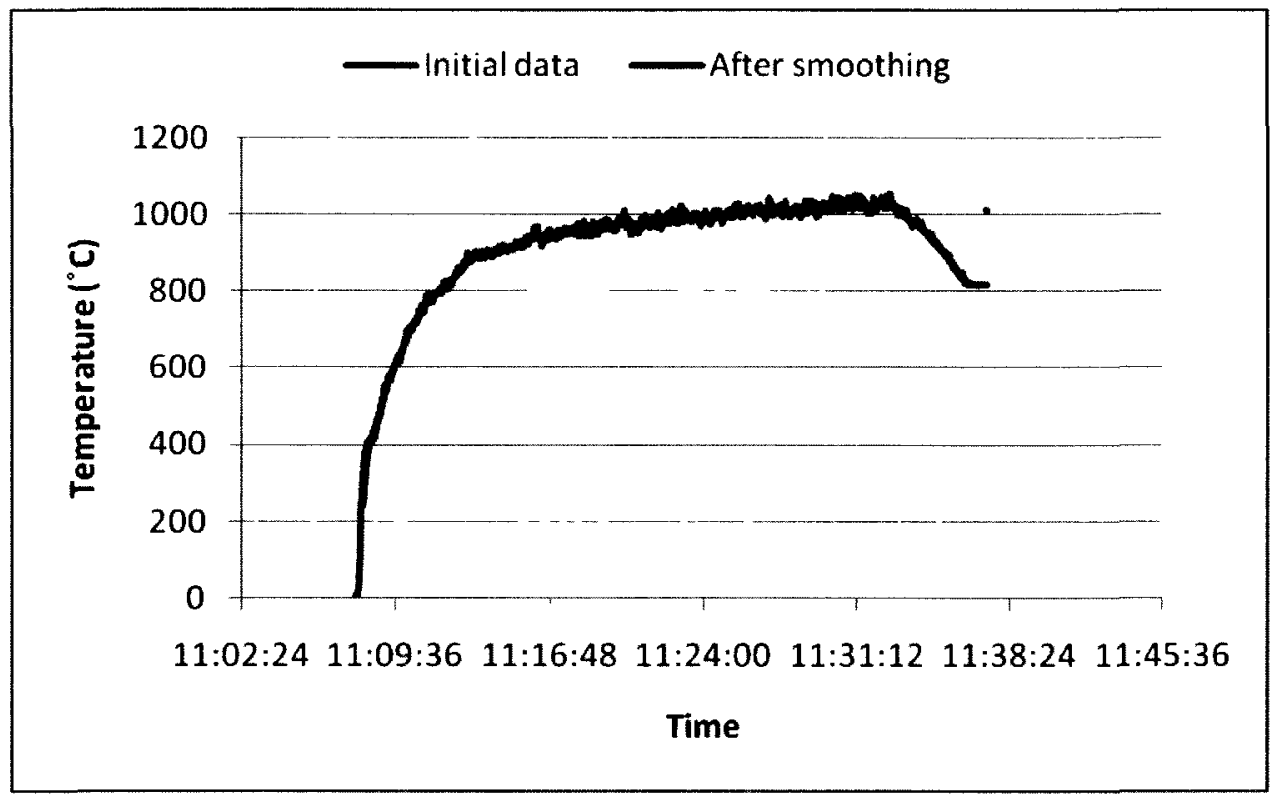

(a) Temperature at the point T3 on external wall of fire building

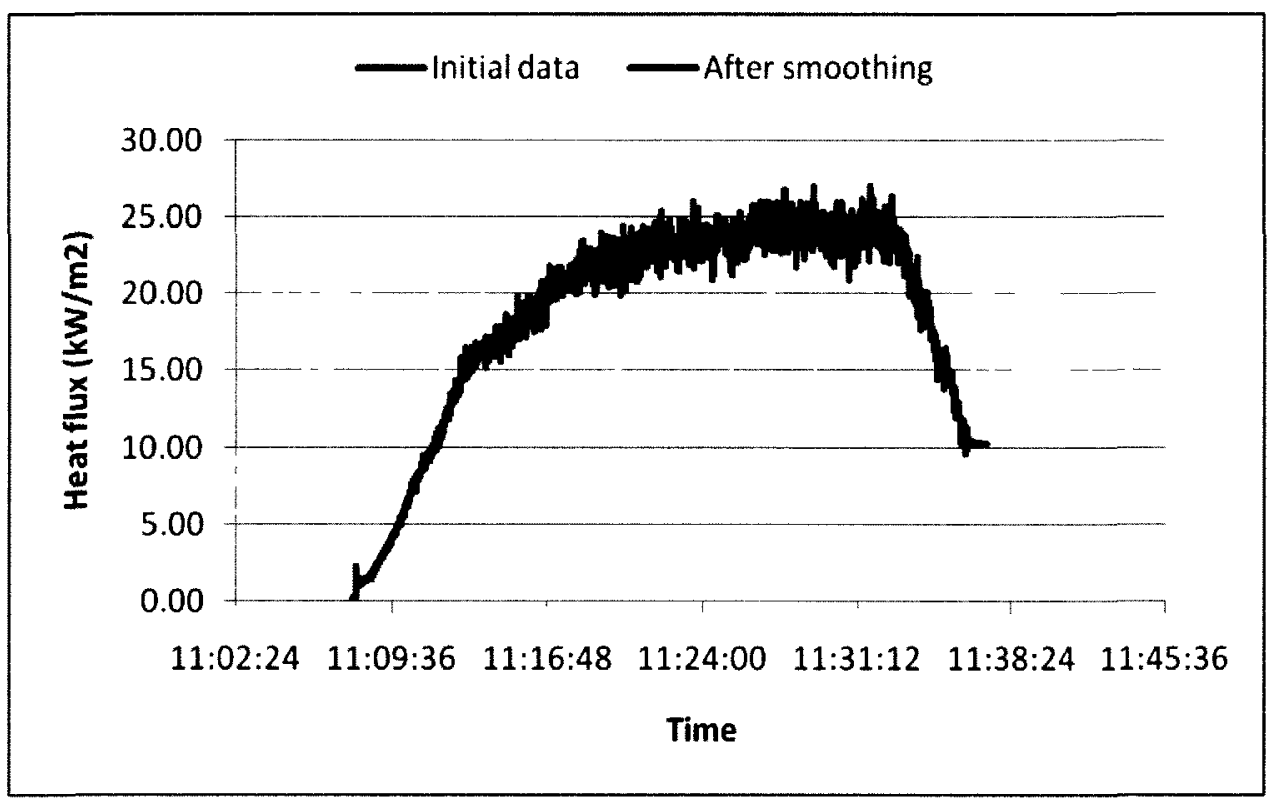

(b) Heat flux at the point $\mathrm{H} 1$ on target wall

Figure A-5 Sample of the experimental data before and after smoothing 

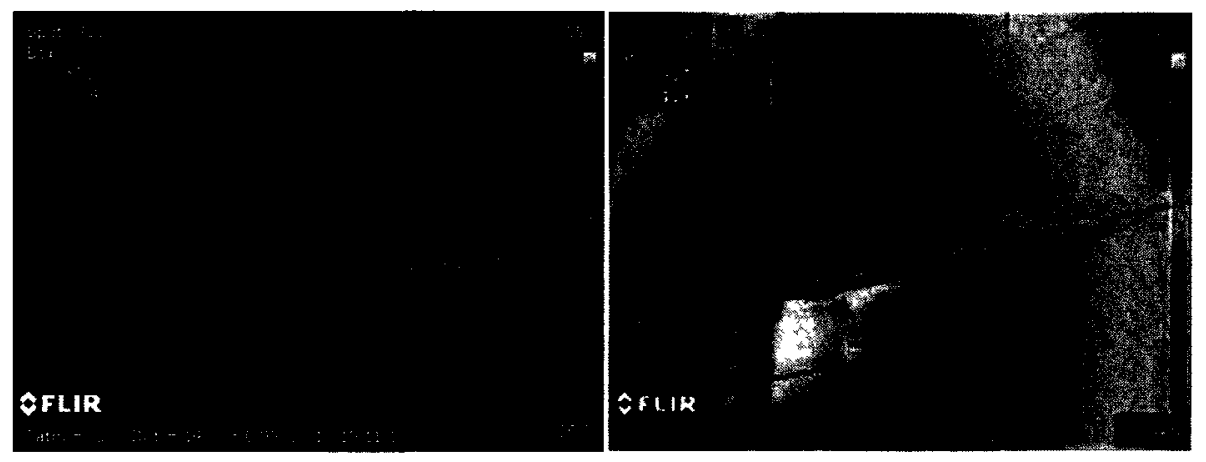

Figure A-6 Thermal image of fire building and target wall

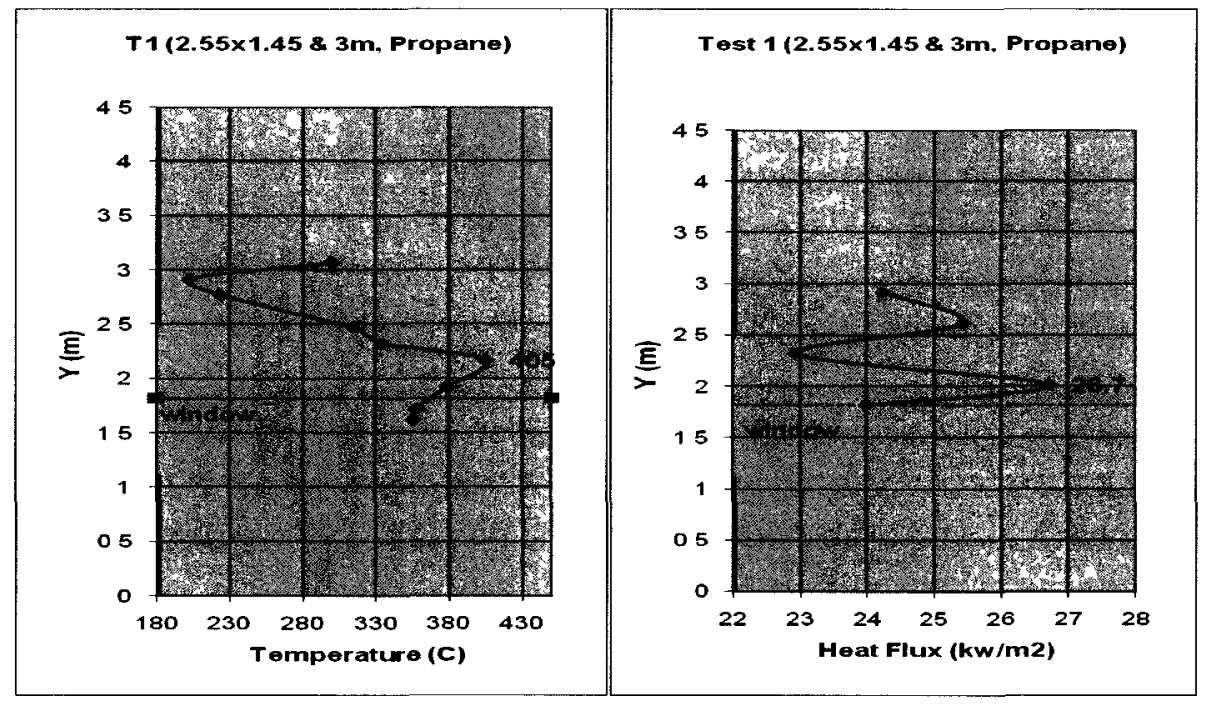

Figure A-7 Temperature distribution and heat flux distribution of target wall

- Based on the modeling in Chapter 10, the maximum flame temperature at the window was used as the temperature of window radiator. The average of the flame tip temperature and the temperature of window radiator was used as the temperature of the radiator of external flame. The intensities of radiation coming from window radiator and external flame radiator can be calculated. Then the 
emissivity of external flame radiator can be calculated by Equation (10.5) as shown in Table A-2.

Table A-2 Temperature, flame height, heat flux and emissivity

\begin{tabular}{|c|c|c|c|c|c|}
\hline & $\begin{array}{c}\text { Maximum } \\
\text { Temperature }\left({ }^{\circ} \mathrm{C}\right)\end{array}$ & Radiometer & $\begin{array}{l}\text { Heat flux } \\
\left(\mathrm{kW} / \mathrm{m}^{2}\right)\end{array}$ & $\begin{array}{l}\text { Emissivity of } \\
\text { external flame }\end{array}$ & $\begin{array}{c}\text { Average } \\
\text { emissivity }\end{array}$ \\
\hline Room & 1210 & $\mathrm{H} 1$ & 23.99 & 0.749 & \multirow{8}{*}{0.580} \\
\hline \multirow{2}{*}{$\begin{array}{c}\text { Flame } \\
\text { (at window) }\end{array}$} & \multirow{2}{*}{1021} & $\mathrm{H} 2$ & 26.71 & 0.945 & \\
\hline & & $\mathrm{H} 3$ & 22.94 & 0.501 & \\
\hline \multirow{3}{*}{$\begin{array}{c}\text { Flame } \\
\text { (50 cm above } \\
\text { window) }\end{array}$} & \multirow{3}{*}{ NA } & $\mathrm{H} 4$ & 25.43 & 0.699 & \\
\hline & & H5 & 24.22 & 0.650 & \\
\hline & & $\mathrm{H} 6$ & 19.68 & 0.418 & \\
\hline \multirow{2}{*}{$\begin{array}{l}\text { Flame height } \\
\text { above window }\end{array}$} & \multirow{2}{*}{$1.5 \mathrm{~m}$} & $\mathrm{H} 7$ & 19.30 & 1.242 & \\
\hline & & $\mathrm{H} 8$ & 6.41 & -0.561 & \\
\hline
\end{tabular}

\section{Test 2 (2.55x1.45 \& 3.5m, Propane)}

- The thermal images of the fire building and target wall are shown in Figure A-8.

- Based on the graphs of heat flux on the target wall, the data after smoothing between 13:39:43 and 13:44:43 were chosen to do the experimental study of Test 2.

- By taking the average of the data selected, the value of temperature or heat flux at each point during post-flashover fire phase can be estimated.

- The temperature distribution and heat flux distribution at the points on the target wall opposite vertical centerline of the window are shown in Figure A-9. 

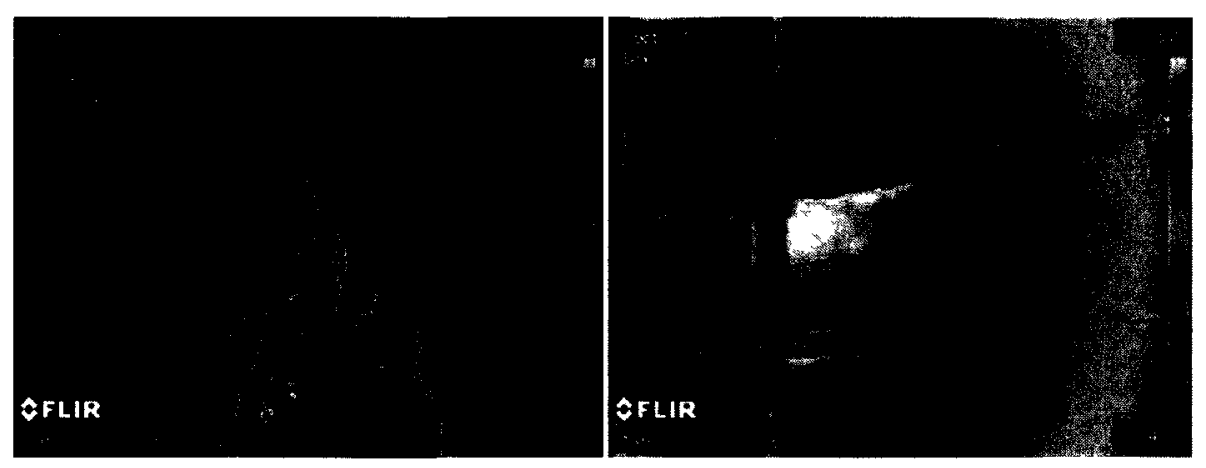

Figure A-8 Thermal image of fire building and target wall

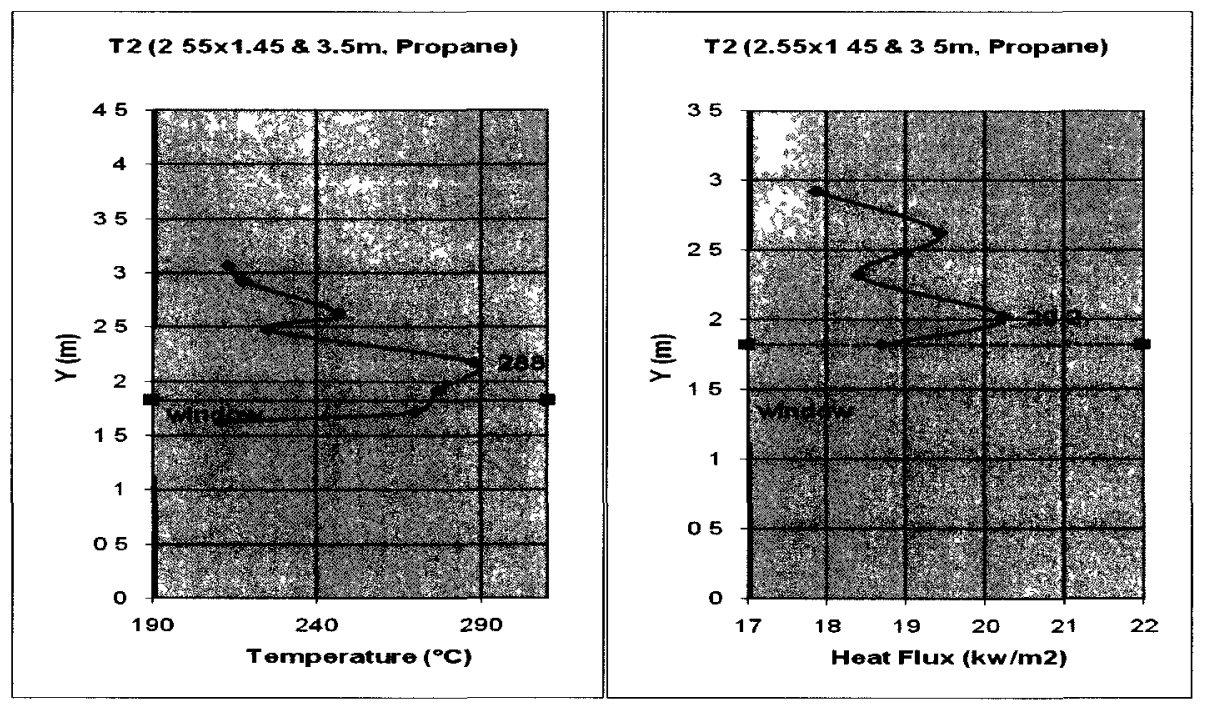

Figure A-9 Temperature distribution and heat flux distribution of target wall

- The maximum flame temperature (T1 to T5) at the window was used as the temperature of window radiator. The average of the flame tip temperature and the temperature of window radiator was used as the temperature of the radiator of external flame. The intensities of radiation coming from window radiator and external flame radiator can be calculated according to the modeling proposed in 
Chapter 10. Then the emissivity of external flame radiator can be calculated by Equation (10.5) as shown in Table A-3.

Table A-3 Temperature, flame height, heat flux and emissivity

\begin{tabular}{|c|c|c|c|c|c|}
\hline & $\begin{array}{c}\text { Maximum } \\
\text { Temperature }\left({ }^{\circ} \mathrm{C}\right)\end{array}$ & Radiometer & $\begin{array}{c}\text { Heat flux } \\
\left(\mathrm{kW} / \mathrm{m}^{2}\right)\end{array}$ & $\begin{array}{c}\text { Emissivity of } \\
\text { external flame }\end{array}$ & $\begin{array}{c}\text { Average } \\
\text { emissivity }\end{array}$ \\
\hline Room & 1215 & $\mathrm{H} 1$ & 18.70 & 0.540 & \\
\hline \multirow{2}{*}{$\begin{array}{c}\text { Flame } \\
\text { (at window) }\end{array}$} & 1047 & $\mathrm{H} 2$ & 20.23 & 0.683 \\
\cline { 3 - 5 } $\begin{array}{c}\text { Flame } \\
(50 \mathrm{~cm} \text { above } \\
\text { window) }\end{array}$ & $\mathrm{NA}$ & $\mathrm{H} 3$ & 18.40 & 0.438 & \multirow{2}{*}{0.428} \\
\cline { 3 - 5 } & \multirow{2}{*}{$\begin{array}{c}\text { Flame height } \\
\text { above window }\end{array}$} & $\mathrm{H} 4$ & 19.42 & 0.561 & \\
\cline { 3 - 5 } & $1.5 \mathrm{~m}$ & $\mathrm{H} 6$ & 16.52 & 0.394 & \\
\cline { 3 - 5 } & $\mathrm{H} 7$ & 15.54 & 0.864 & -0.527 \\
\hline
\end{tabular}

\section{Test 3 (2.55x1.45 \& 4m, Propane)}

- The thermal images of the fire building and target wall are shown in Figure A-10.

- Based on the graphs of heat flux on the target wall, the data after smoothing between 11:26:21 and 11:31:21 were chosen to do the experimental study of Test 3.

- By taking the average of the data selected, the value of temperature or heat flux at each point during post-flashover fire phase can be estimated.

- The temperature distribution and heat flux distribution at the points on the target wall opposite vertical centerline of the window are shown in Figure A-11. 


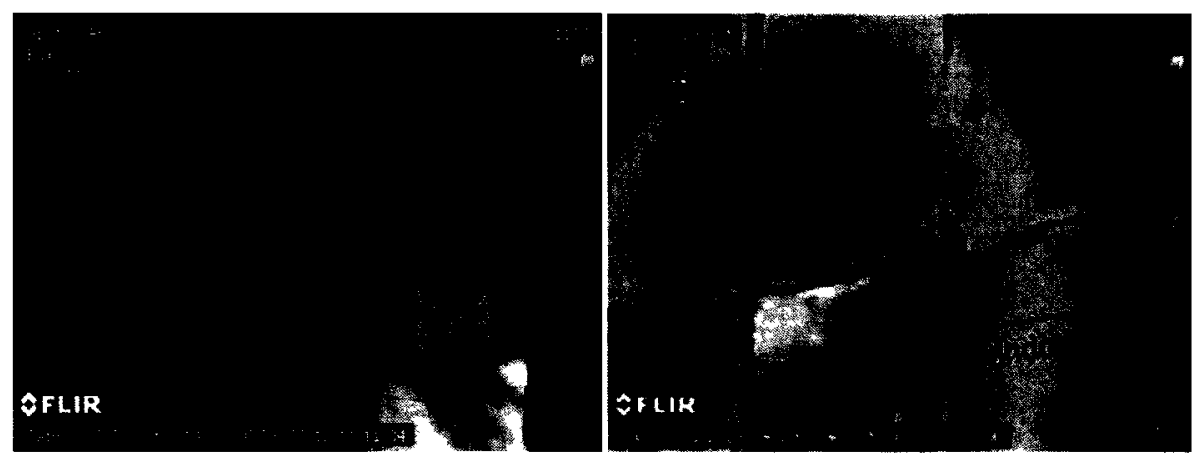

Figure A-10 Thermal image of fire building and target wall

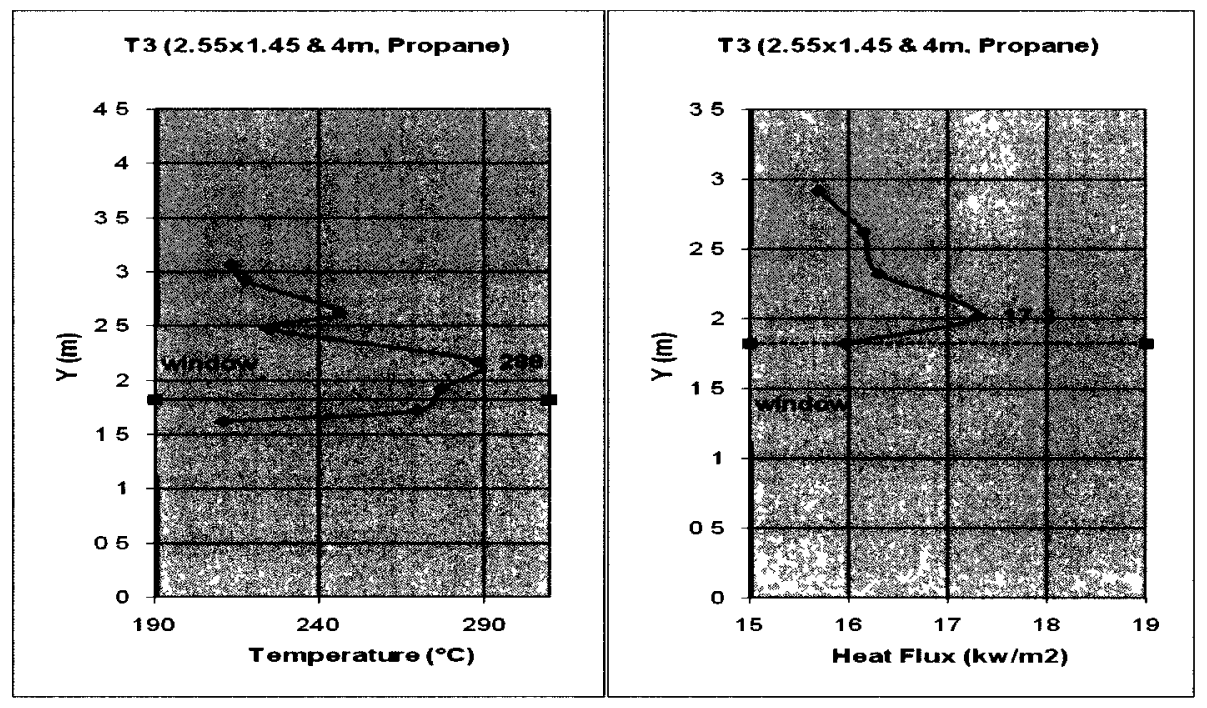

Figure A-11 Temperature distribution and heat flux distribution of target wall

- The maximum flame temperature (T1 to T5) at the window was used as the temperature of window radiator. The average of the flame tip temperature and the temperature of window radiator was used as the temperature of the radiator of external flame. The intensities of radiation coming from window radiator and external flame radiator can be calculated according to the modeling proposed in 
Chapter 10. Then the emissivity of external flame radiator can be calculated by Equation (10.5) as shown in Table A-4.

Table A-4 Temperature, flame height, heat flux and emissivity

\begin{tabular}{|c|c|c|c|c|c|}
\hline & $\begin{array}{c}\text { Maximum } \\
\text { Temperature }\left({ }^{\circ} \mathrm{C}\right)\end{array}$ & Radiometer & $\begin{array}{c}\text { Heat flux } \\
\left(\mathrm{kW} / \mathrm{m}^{2}\right)\end{array}$ & $\begin{array}{c}\text { Emissivity of } \\
\text { external flame }\end{array}$ & $\begin{array}{c}\text { Average } \\
\text { emissivity }\end{array}$ \\
\hline Room & 1205 & $\mathrm{H} 1$ & 15.97 & 0.546 & \\
\hline $\begin{array}{c}\text { Flame } \\
\text { (at window) }\end{array}$ & 1073 & $\mathrm{H} 2$ & 17.31 & 0.707 \\
\cline { 3 - 5 } $\begin{array}{c}\text { Flame } \\
(50 \mathrm{~cm} \text { above } \\
\text { window) }\end{array}$ & \multirow{2}{*}{810} & $\mathrm{H} 3$ & 16.31 & 0.537 & \multirow{2}{*}{0.475} \\
\cline { 3 - 6 } & \multirow{2}{*}{$\begin{array}{c}\text { Flame height } \\
\text { above window }\end{array}$} & $\mathrm{H} 4$ & 16.15 & 0.534 & \\
\cline { 3 - 6 } & $1.5 \mathrm{~m}$ & $\mathrm{H} 6$ & 16.14 & 0.703 & \\
\cline { 3 - 6 } & $\mathrm{H} 7$ & 13.55 & 0.768 & \\
\hline
\end{tabular}

\section{Test 4 (1.45x1.45 \& 3m, Propane)}

- The thermal images of the fire building and target wall are shown in Figure A-12.

- Based on the graphs of heat flux on the target wall, the data after smoothing between 13:40:30 and 13:46:00 were chosen to do the experimental study of Test 4.

- By taking the average of the data selected, the value of temperature or heat flux at each point during post-flashover fire phase can be estimated.

- The temperature distribution and heat flux distribution at the points on the target wall opposite vertical centerline of the window are shown in Figure A-13. 

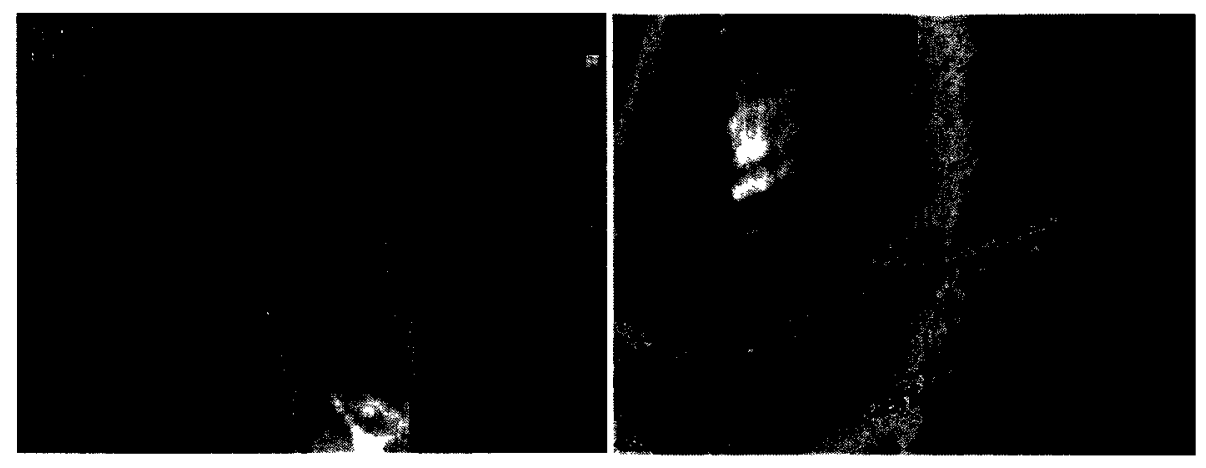

Figure A-12 Thermal image of fire building and target wall
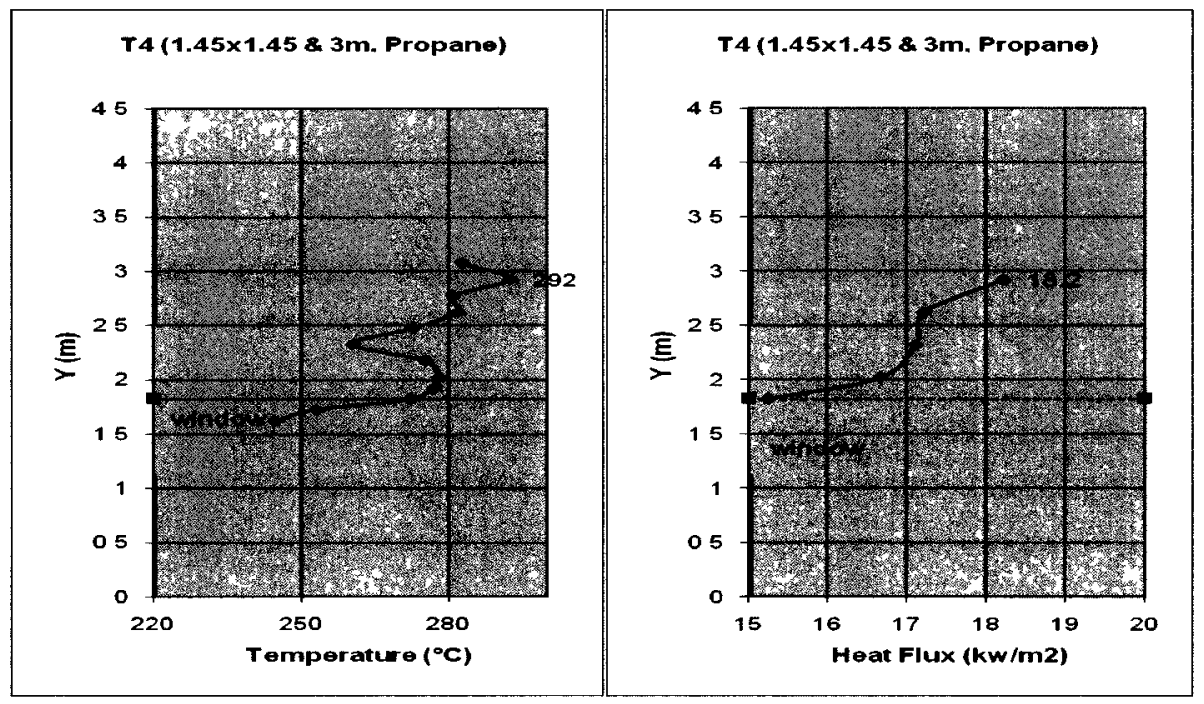

Figure A-13 Temperature distribution and heat flux distribution of target wall

- The maximum flame temperature (T1 to $\mathrm{T} 5$ ) at the window was used as the temperature of window radiator. Because the flame height was larger than 2 meters. According to the modeling in Chapter 10, the radiator of external flame is divided into two parts - the bottom part and upper part. The average of the temperature of window radiator and flame temperature at $50 \mathrm{~cm}$ above the soffit 
of window was used as the temperature of the bottom radiator of external flame.

The average of the temperature of the bottom radiator and flame tip temperature was used as the temperature of the bottom radiator of external flame. The intensities of radiation coming from window radiator and external flame radiator can be calculated. Then the emissivity of external flame radiator can be calculated by Equation (10.5) as shown in Table A-5.

Table A-5 Temperature, flame height, heat flux and emissivity

\begin{tabular}{|c|c|c|c|c|c|}
\hline & $\begin{array}{c}\text { Maximum } \\
\text { Temperature }\left({ }^{\circ} \mathrm{C}\right)\end{array}$ & Radiometer & $\begin{array}{l}\text { Heat flux } \\
\left(\mathrm{kW} / \mathrm{m}^{2}\right)\end{array}$ & $\begin{array}{l}\text { Emissivity of } \\
\text { external flame }\end{array}$ & $\begin{array}{l}\text { Average } \\
\text { emissivity }\end{array}$ \\
\hline Room & 957 & $\mathrm{H} 1$ & 15.24 & 0.492 & \multirow{8}{*}{0.515} \\
\hline \multirow{2}{*}{$\begin{array}{c}\text { Flame } \\
\text { (at window) }\end{array}$} & \multirow{2}{*}{993} & $\mathrm{H} 2$ & 16.66 & 0.538 & \\
\hline & & $\mathrm{H} 3$ & 17.11 & 0.489 & \\
\hline \multirow{3}{*}{$\begin{array}{c}\text { Flame } \\
(50 \mathrm{~cm} \text { above } \\
\text { window) }\end{array}$} & \multirow{3}{*}{991} & $\mathrm{H} 4$ & 17.22 & 0.455 & \\
\hline & & H5 & 18.22 & 0.495 & \\
\hline & & $\mathrm{H} 6$ & 15.18 & 0.612 & \\
\hline \multirow{2}{*}{$\begin{array}{l}\text { Flame height } \\
\text { above window }\end{array}$} & \multirow{2}{*}{$3.0 \mathrm{~m}$} & $\mathrm{H} 7$ & 11.87 & 0.855 & \\
\hline & & H8 & 4.67 & 0.186 & \\
\hline
\end{tabular}

\section{Test 5 (1.45x1.45 \& 3.5m, Propane)}

- The thermal images of the fire building and target wall are shown in Figure A-14.

- Based on the graphs of heat flux on the target wall, the data after smoothing between 10:19:52 and 10:24:52 were chosen to do the experimental study of Test 5. 

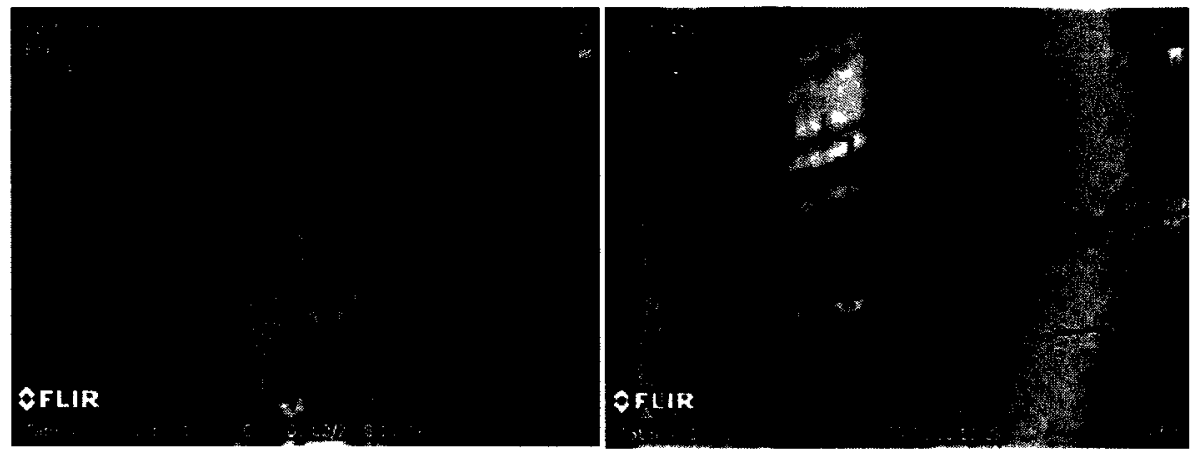

Figure A-14 Thermal image of fire building and target wall

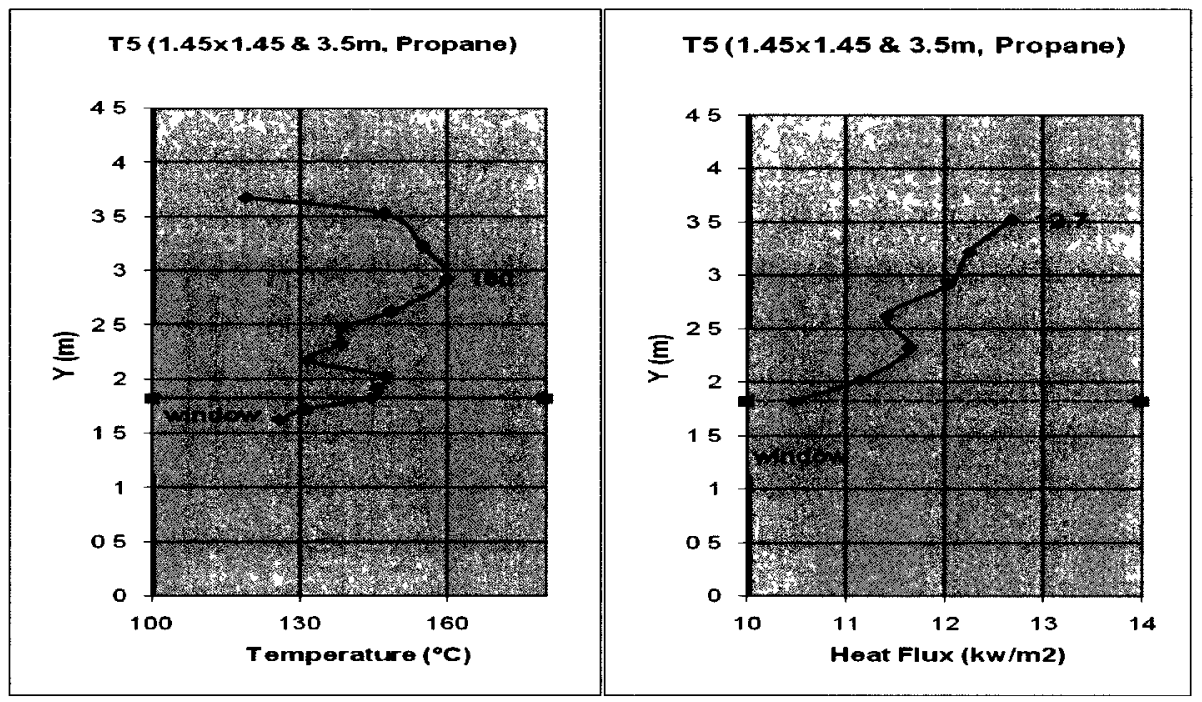

Figure A-15 Temperature distribution and heat flux distribution of target wall

- By taking the average of the data selected, the value of temperature or heat flux at each point during post-flashover fire phase can be estimated.

- The temperature distribution and heat flux distribution at the points on the target wall opposite vertical centerline of the window are shown in Figure A-15. 
- The maximum flame temperature (T1 to T5) at the window was used as the temperature of window radiator. Because the flame height was larger than 2 meters. According to the modeling in Chapter 10, the radiator of external flame is divided into two parts - the bottom part and upper part. The average of the temperature of window radiator and flame temperature at $50 \mathrm{~cm}$ above the soffit of window was used as the temperature of the bottom radiator of external flame. The average of the temperature of the bottom radiator and flame tip temperature was used as the temperature of the bottom radiator of external flame. The intensities of radiation coming from window radiator and external flame radiator can be calculated. Then the emissivity of external flame radiator can be calculated by Equation (10.5) as shown in Table A-6.

Table A-6 Temperature, flame height, heat flux and emissivity

\begin{tabular}{|c|c|c|c|c|c|}
\hline & $\begin{array}{c}\text { Maximum } \\
\text { Temperature }\left({ }^{\circ} \mathrm{C}\right)\end{array}$ & Radiometer & $\begin{array}{l}\text { Heat flux } \\
\left(\mathrm{kW} / \mathrm{m}^{2}\right)\end{array}$ & $\begin{array}{l}\text { Emissivity of } \\
\text { external flame }\end{array}$ & $\begin{array}{l}\text { Average } \\
\text { emissivity }\end{array}$ \\
\hline \multirow{2}{*}{ Room } & \multirow{2}{*}{918} & $\mathrm{H} 1$ & 10.46 & 0.431 & \multirow{10}{*}{0.498} \\
\hline & & $\mathrm{H} 2$ & 11.15 & 0.472 & \\
\hline \multirow{2}{*}{$\begin{array}{c}\text { Flame } \\
\text { (at window) }\end{array}$} & \multirow{2}{*}{985} & $\mathrm{H} 3$ & 11.64 & 0.475 & \\
\hline & & $\mathrm{H} 4$ & 11.41 & 0.430 & \\
\hline \multirow{3}{*}{$\begin{array}{c}\text { Flame } \\
\text { (50 } \mathrm{cm} \text { above } \\
\text { window) }\end{array}$} & \multirow{3}{*}{921} & $\mathrm{H} 5$ & 12.04 & 0.485 & \\
\hline & & $\mathrm{H} 6$ & 10.72 & 0.567 & \\
\hline & & $\mathrm{H} 7$ & 9.57 & 0.882 & \\
\hline \multirow{3}{*}{$\begin{array}{l}\text { Flame height } \\
\text { above window }\end{array}$} & \multirow{3}{*}{$3.0 \mathrm{~m}$} & $\mathrm{H} 8$ & 3.99 & 0.140 & \\
\hline & & $\mathrm{Hg}$ & 12.25 & 0.518 & \\
\hline & & $\mathrm{H} 10$ & 12.67 & 0.583 & \\
\hline
\end{tabular}




\section{Test $6(1.45 \times 1.45 \& 2.4 \mathrm{~m}$, Propane)}

- The thermal images of the fire building and target wall are shown in Figure A-16.
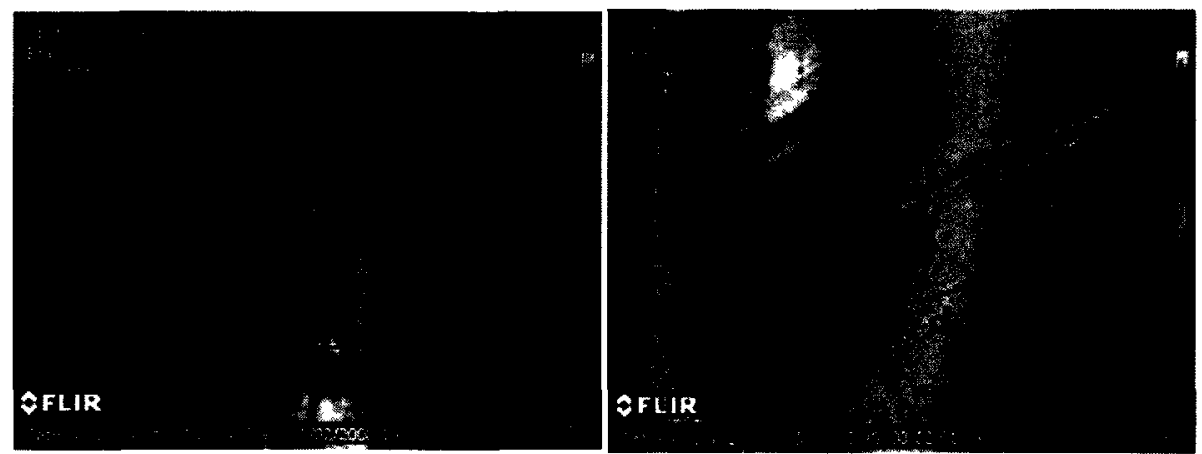

Figure A-16 Thermal image of fire building and target wall

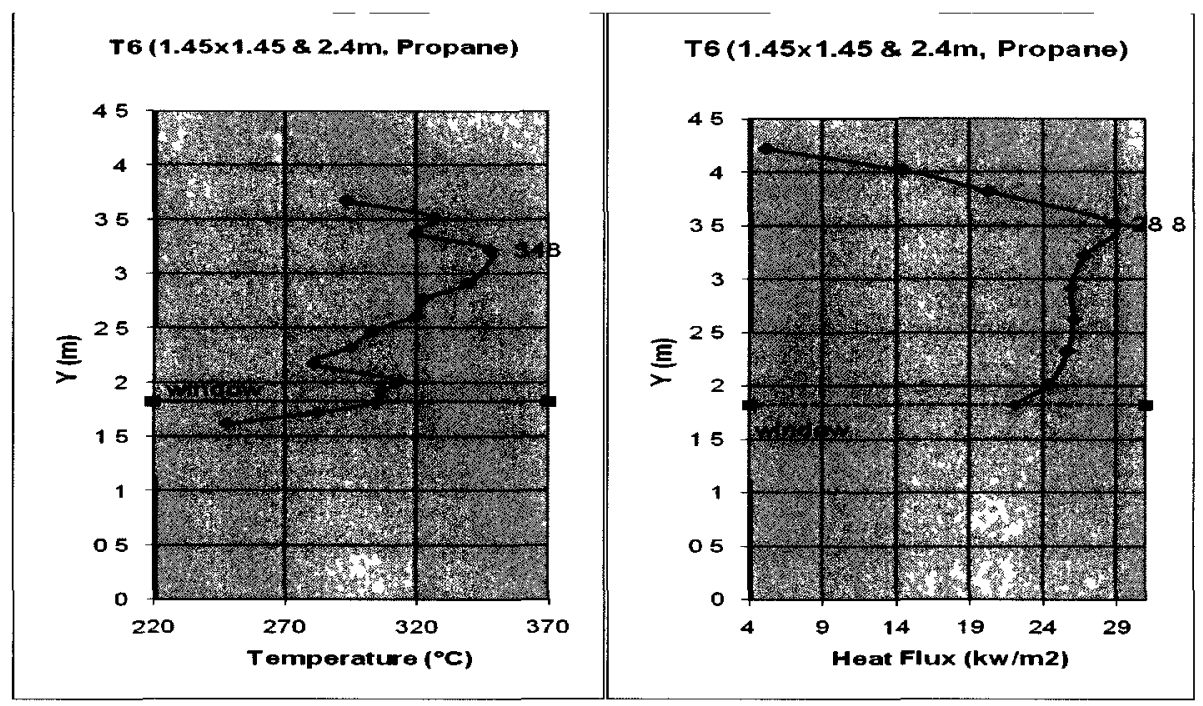

Figure A-17 Temperature distribution and heat flux distribution of target wall

By taking the average of the data selected, the value of temperature or heat flux at each point during post-flashover fire phase can be estimated.

- The temperature distribution and heat flux distribution at the points on the target wall opposite vertical centerline of the window are shown in Figure A-17. 
- The maximum flame temperature (T1 to T5) at the window was used as the temperature of window radiator. Because the flame height was larger than 2 meters. According to the modeling in Chapter 10, the radiator of external flame is divided into two parts - the bottom part and upper part. The average of the temperature of window radiator and flame temperature at $50 \mathrm{~cm}$ above the soffit of window was used as the temperature of the bottom radiator of external flame. The average of the temperature of the bottom radiator and flame tip temperature was used as the temperature of the bottom radiator of external flame. The intensities of radiation coming from window radiator and external flame radiator can be calculated. Then the emissivity of external flame radiator can be calculated by Equation (10.5) as shown in Table A-7.

Table A-7 Temperature, flame height, heat flux and emissivity

\begin{tabular}{|c|c|c|c|c|c|}
\hline & $\begin{array}{c}\text { Maximum } \\
\text { Temperature }\left({ }^{\circ} \mathrm{C}\right)\end{array}$ & Radiometer & $\begin{array}{l}\text { Heat flux } \\
\left(\mathrm{kW} / \mathrm{m}^{2}\right)\end{array}$ & $\begin{array}{l}\text { Emissivity of } \\
\text { external flame }\end{array}$ & $\begin{array}{l}\text { Average } \\
\text { emissivity }\end{array}$ \\
\hline \multirow{2}{*}{ Room } & \multirow{2}{*}{979} & $\mathrm{H} 1$ & 22.02 & 0.476 & \multirow{10}{*}{0.421} \\
\hline & & $\mathrm{H} 2$ & 24.38 & 0.543 & \\
\hline \multirow{2}{*}{$\begin{array}{c}\text { Flame } \\
\text { (at window) }\end{array}$} & \multirow{2}{*}{1022} & H3 & 25.67 & 0.496 & \\
\hline & & $\mathrm{H} 4$ & 26.04 & 0.453 & \\
\hline \multirow{3}{*}{$\begin{array}{c}\text { Flame } \\
\text { (50 } \mathrm{cm} \text { above } \\
\text { window) }\end{array}$} & \multirow{3}{*}{970} & H5 & 25.89 & 0.437 & \\
\hline & & $\mathrm{H} 6$ & 20.24 & 0.489 & \\
\hline & & $\mathrm{H} 7$ & 14.49 & 0.598 & \\
\hline \multirow{3}{*}{$\begin{array}{l}\text { Flame height } \\
\text { above window }\end{array}$} & \multirow{3}{*}{$3.0 \mathrm{~m}$} & $\mathrm{H8}$ & 5.21 & 0.418 & \\
\hline & & $\mathrm{H9}$ & 26.83 & 0.285 & \\
\hline & & $\mathrm{H} 10$ & 28.75 & 0.015 & \\
\hline
\end{tabular}


7. Test 7 (1.1x1.45 \& 3.5m, Propane)
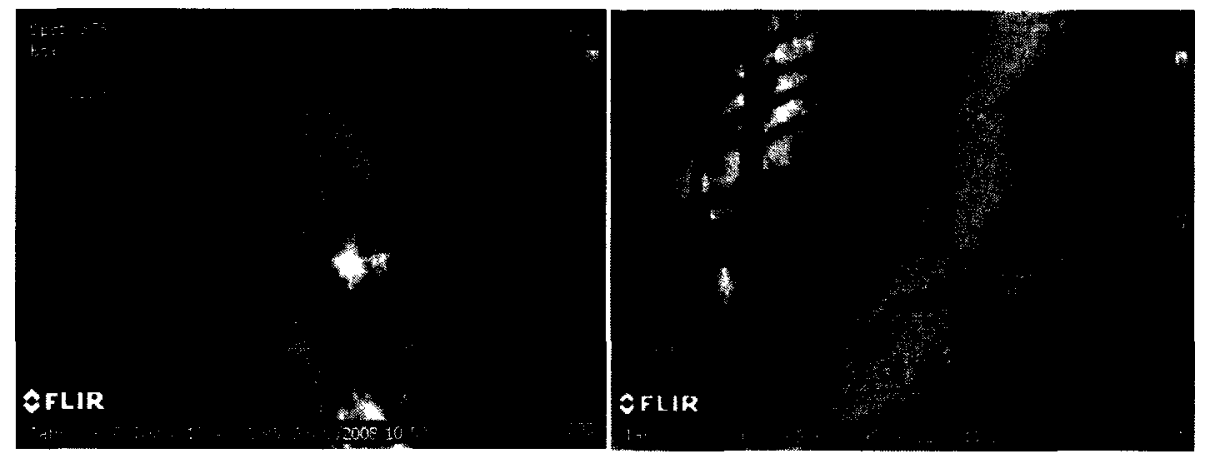

Figure A-18 Thermal image of fire building and target wall

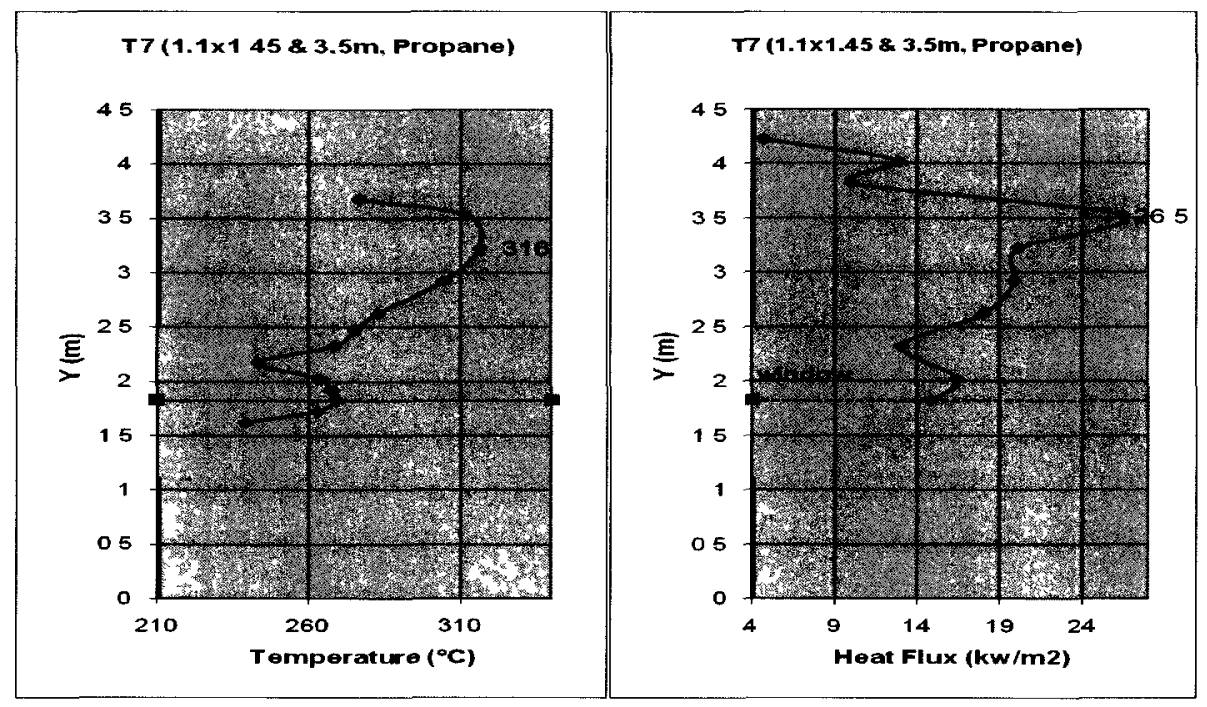

Figure A-19 Temperature distribution and heat flux distribution of target wall

- The thermal images of the fire building and target wall are shown in Figure A-18. 
- Based on the graphs of heat flux on the target wall, the data after smoothing between 11:08:14 and 11:13:15 were chosen to do the experimental study of Test 7.

- By taking the average of the data selected, the value of temperature or heat flux at each point during post-flashover fire phase can be estimated.

- The temperature distribution and heat flux distribution at the points on the target wall opposite vertical centerline of the window are shown in Figure A-19.

Table A-8 Temperature, flame height, heat flux and emissivity

\begin{tabular}{|c|c|c|c|c|c|}
\hline & $\begin{array}{c}\text { Maximum } \\
\text { Temperature }\left({ }^{\circ} \mathrm{C}\right)\end{array}$ & Radiometer & $\begin{array}{l}\text { Heat flux } \\
\left(\mathrm{kW} / \mathrm{m}^{2}\right)\end{array}$ & $\begin{array}{l}\text { Emissivity of } \\
\text { external flame }\end{array}$ & $\begin{array}{l}\text { Average } \\
\text { emissivity }\end{array}$ \\
\hline \multirow{2}{*}{ Room } & \multirow{2}{*}{879} & $\mathrm{H} 1$ & 14.84 & 1.186 & \multirow{10}{*}{0.892} \\
\hline & & $\mathrm{H} 2$ & 16.44 & 1.226 & \\
\hline \multirow{2}{*}{$\begin{array}{c}\text { Flame } \\
\text { (at window) }\end{array}$} & \multirow{2}{*}{976} & H3 & 13.09 & 0.731 & \\
\hline & & $\mathrm{H} 4$ & 18.04 & 1.055 & \\
\hline \multirow{3}{*}{$\begin{array}{c}\text { Flame } \\
(50 \mathrm{~cm} \text { above } \\
\text { window) }\end{array}$} & \multirow{3}{*}{968} & H5 & 19.86 & 1.097 & \\
\hline & & $\mathrm{H} 6$ & 10.04 & 1.051 & \\
\hline & & $\mathrm{H} 7$ & 12.88 & 1.423 & \\
\hline \multirow{3}{*}{$\begin{array}{l}\text { Flame height } \\
\text { above window }\end{array}$} & \multirow{3}{*}{$4.0 \mathrm{~m}$} & H8 & 4.77 & 0.415 & \\
\hline & & H9 & 20.08 & 0.605 & \\
\hline & & $\mathrm{H} 10$ & 26.46 & 0.130 & \\
\hline
\end{tabular}

- The maximum flame temperature (T1 to T5) at the window was used as the temperature of window radiator. Because the flame height was larger than 2 meters. According to the modeling in Chapter 10, the radiator of external flame is 
divided into two parts - the bottom part and upper part. The average of the temperature of window radiator and flame temperature at $50 \mathrm{~cm}$ above the soffit of window was used as the temperature of the bottom radiator of external flame. The average of the temperature of the bottom radiator and flame tip temperature was used as the temperature of the bottom radiator of external flame. The intensities of radiation coming from window radiator and external flame radiator can be calculated. Then the emissivity of external flame radiator can be calculated by Equation (10.5) as shown in Table A-8.

\section{Test 8 (1.1x1.45 \& 3m, Propane)}

- The thermal images of the fire building and target wall are shown in Figure A-20.

- Based on the graphs of heat flux on the target wall, the data after smoothing between 11:37:01 and 11:42:01 were chosen to do the experimental study of Test 8.

- By taking the average of the data selected, the value of temperature or heat flux at each point during post-flashover fire phase can be estimated.

- The temperature distribution and heat flux distribution at the points on the target wall opposite vertical centerline of the window are shown in Figure A-21.

- The emissivity of external flame radiator can be calculated by Equation (10.5) as shown in Table A-9. 


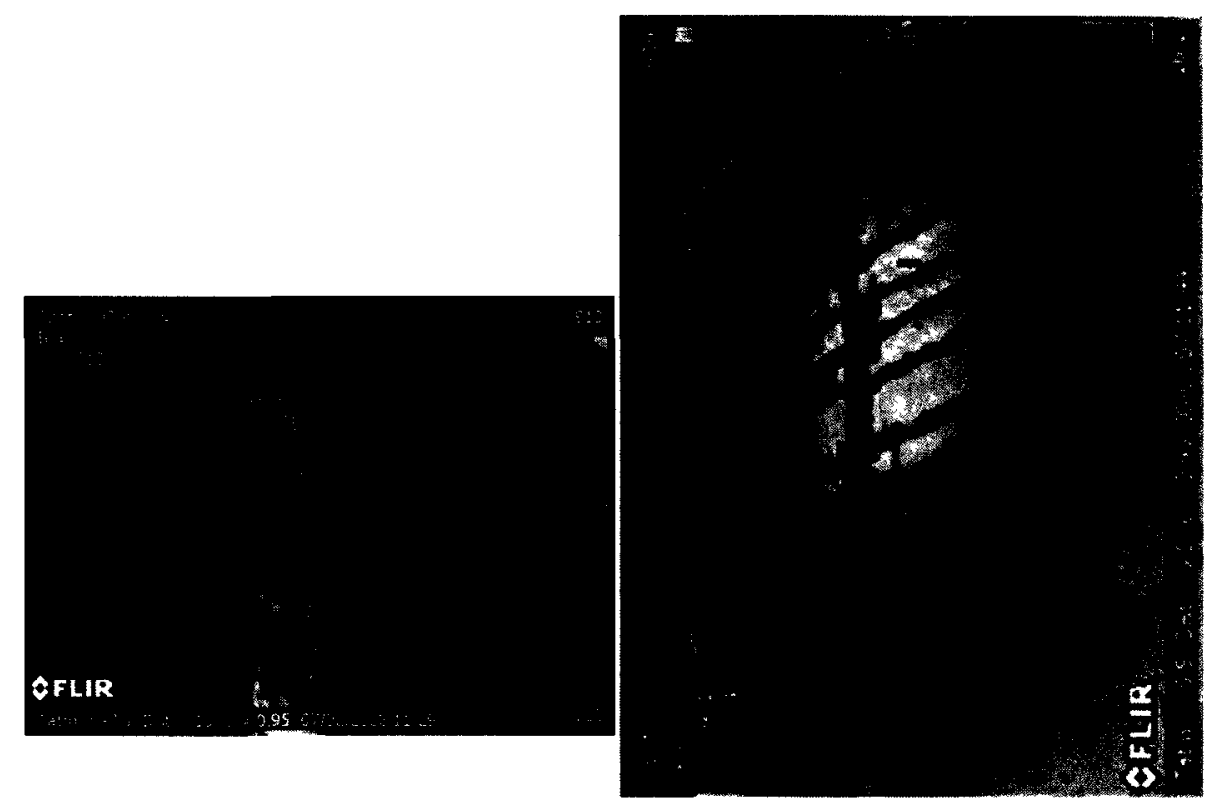

Figure A-20 Thermal image of fire building and target wall

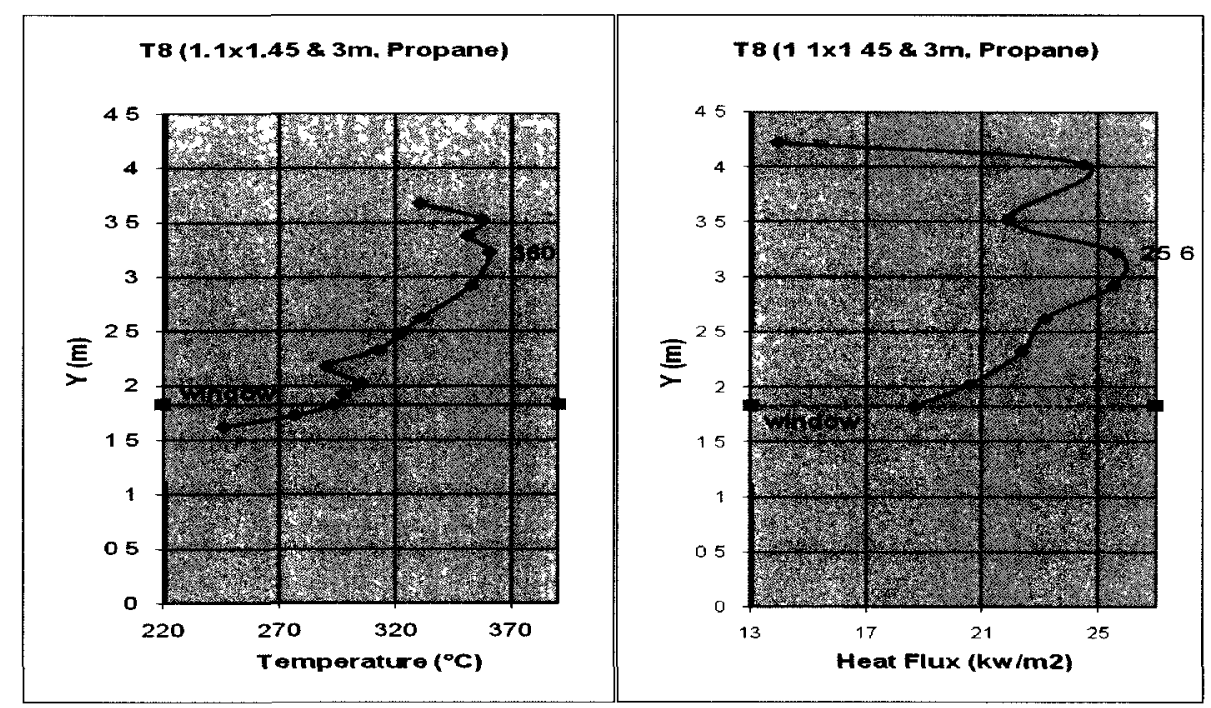

Figure A-21 Temperature distribution and heat flux distribution of target wall 
Table A-9 Temperature, flame height, heat flux and emissivity

\begin{tabular}{|c|c|c|c|c|c|}
\hline & $\begin{array}{c}\text { Maximum } \\
\text { Temperature }\left({ }^{\circ} \mathrm{C}\right)\end{array}$ & Radiometer & $\begin{array}{l}\text { Heat flux } \\
\left(\mathrm{kW} / \mathrm{m}^{2}\right)\end{array}$ & $\begin{array}{l}\text { Emissivity of } \\
\text { external flame }\end{array}$ & $\begin{array}{l}\text { Average } \\
\text { emissivity }\end{array}$ \\
\hline \multirow{2}{*}{ Room } & \multirow{2}{*}{873} & H1 & 18.65 & 0.940 & \multirow{10}{*}{0.808} \\
\hline & & $\mathrm{H} 2$ & 20.55 & 0.981 & \\
\hline \multirow{2}{*}{$\begin{array}{c}\text { Flame } \\
\text { (at window) }\end{array}$} & \multirow{2}{*}{1084} & $\mathrm{H} 3$ & 22.35 & 0.945 & \\
\hline & & $\mathrm{H} 4$ & 23.15 & 0.873 & \\
\hline \multirow{3}{*}{$\begin{array}{c}\text { Flame } \\
\text { (50 cm above } \\
\text { window) }\end{array}$} & \multirow{3}{*}{962} & $\mathrm{H} 5$ & 25.52 & 0.927 & \\
\hline & & $\mathrm{H} 6$ & 16.12 & 0.888 & \\
\hline & & $\mathrm{H} 7$ & 24.50 & 0.712 & \\
\hline \multirow{3}{*}{$\begin{array}{l}\text { Flame height } \\
\text { above window }\end{array}$} & \multirow{3}{*}{$4.0 \mathrm{~m}$} & $\mathrm{H} 8$ & 13.98 & 0.482 & \\
\hline & & $\mathrm{H} 9$ & 25.62 & 0.882 & \\
\hline & & $\mathrm{H} 10$ & 21.89 & 0.447 & \\
\hline
\end{tabular}

\section{Test 9 (1.1x1.45 \& 4m, Propane)}

- The thermal images of the fire building and target wall are shown in Figure A-22.

- Based on the graphs of heat flux on the target wall, the data after smoothing between 13:42:53 and 11:48:23 were chosen to do the experimental study of Test 9.

- By taking the average of the data selected, the value of temperature or heat flux at each point during post-flashover fire phase can be estimated. 


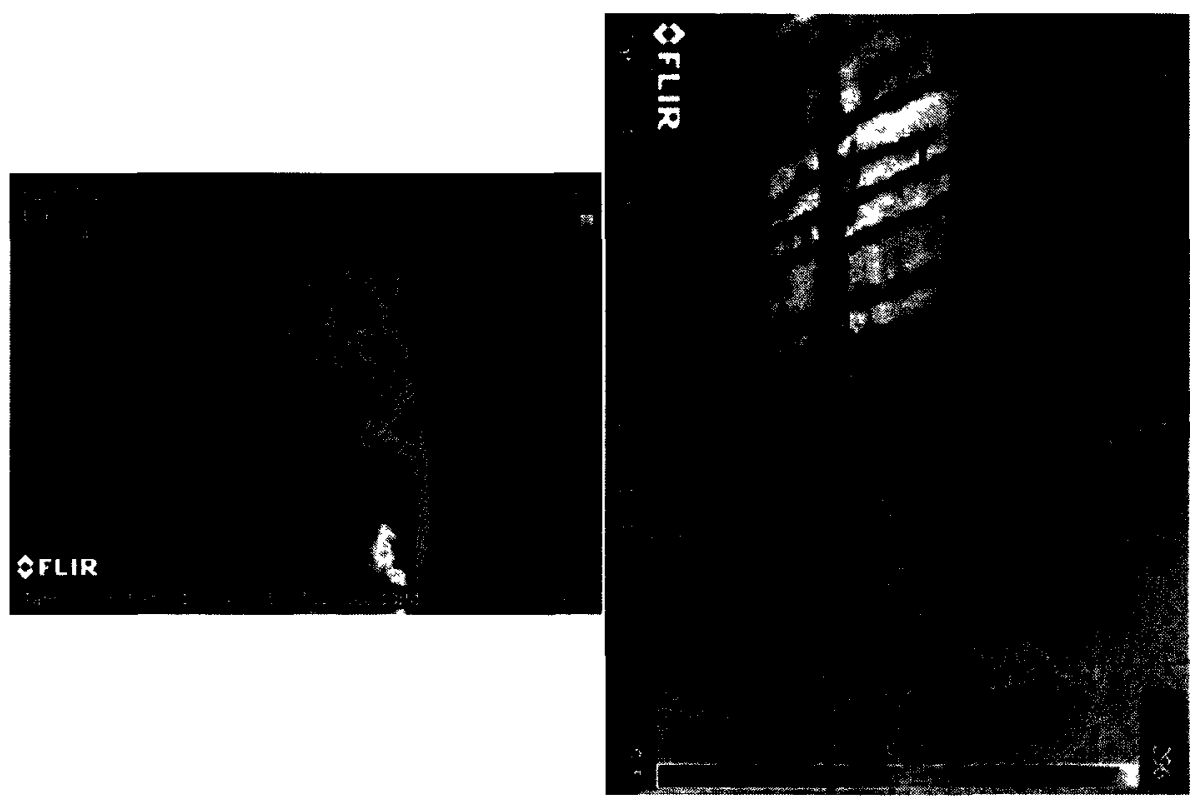

Figure A-22 Thermal image of fire building and target wall

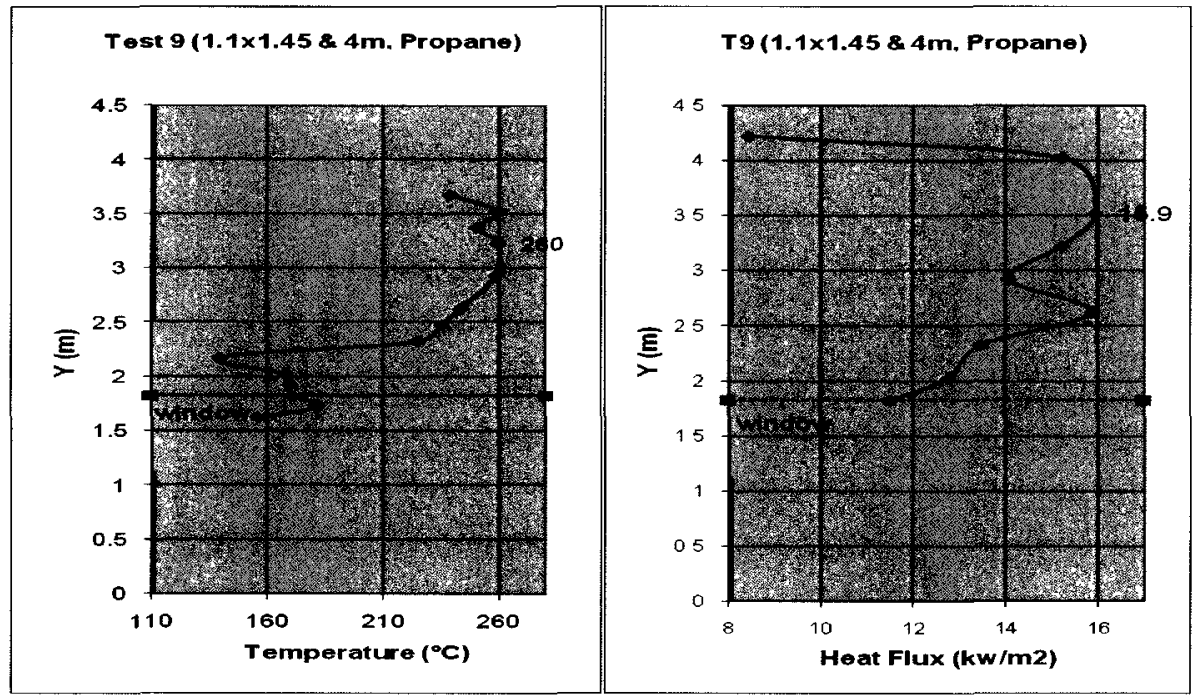

Figure A-23 Temperature distribution and heat flux distribution of target wall 
- The temperature distribution and heat flux distribution at the points on the target wall opposite vertical centerline of the window are shown in Figure A-23.

- The emissivity of external flame radiator can be calculated by Equation (10.5) as shown in Table A-10.

Table A-10 Temperature, flame height, heat flux and emissivity

\begin{tabular}{|c|c|c|c|c|c|}
\hline & $\begin{array}{c}\text { Maximum } \\
\text { Temperature }\left({ }^{\circ} \mathrm{C}\right)\end{array}$ & Radiometer & $\begin{array}{c}\text { Heat flux } \\
\left(\mathrm{kW} / \mathrm{m}^{2}\right)\end{array}$ & $\begin{array}{r}\text { Emissivity of } \\
\text { external flame }\end{array}$ & $\begin{array}{l}\text { Average } \\
\text { emissivity }\end{array}$ \\
\hline \multirow{2}{*}{ Room } & \multirow{2}{*}{875} & $\mathrm{H} 1$ & 11.50 & 0.934 & \multirow{10}{*}{0.922} \\
\hline & & $\mathrm{H} 2$ & 12.75 & 1.017 & \\
\hline \multirow{2}{*}{$\begin{array}{c}\text { Flame } \\
\text { (at window) }\end{array}$} & \multirow{2}{*}{1047} & $\mathrm{H} 3$ & 13.45 & 0.983 & \\
\hline & & $\mathrm{H} 4$ & 15.87 & 1.152 & \\
\hline \multirow{3}{*}{$\begin{array}{c}\text { Flame } \\
\text { (50 cm above } \\
\text { window) }\end{array}$} & \multirow{3}{*}{964} & H5 & 14.04 & 0.902 & \\
\hline & & $\mathrm{H} 6$ & 12.94 & 0.975 & \\
\hline & & $\mathrm{H} 7$ & 15.21 & 1.024 & \\
\hline \multirow{3}{*}{$\begin{array}{l}\text { Flame height } \\
\text { above window }\end{array}$} & \multirow{3}{*}{$4.0 \mathrm{~m}$} & H8 & 8.41 & 0.785 & \\
\hline & & $\mathrm{H} 9$ & 15.21 & 0.991 & \\
\hline & & $\mathrm{H} 10$ & 15.93 & 0.453 & \\
\hline
\end{tabular}

\section{Test $10\left(1.1 \times 1.45 \& 3 \mathrm{~m}\right.$, wood crib $\left.2 " x 4^{\prime \prime}\right)$}

- The thermal images of the fire building and target wall are shown in Figure A-24.

- Based on the graphs of heat flux on the target wall, the data after smoothing between 11:56:00 and 12:01:30 were chosen to do the experimental study of Test 10. 

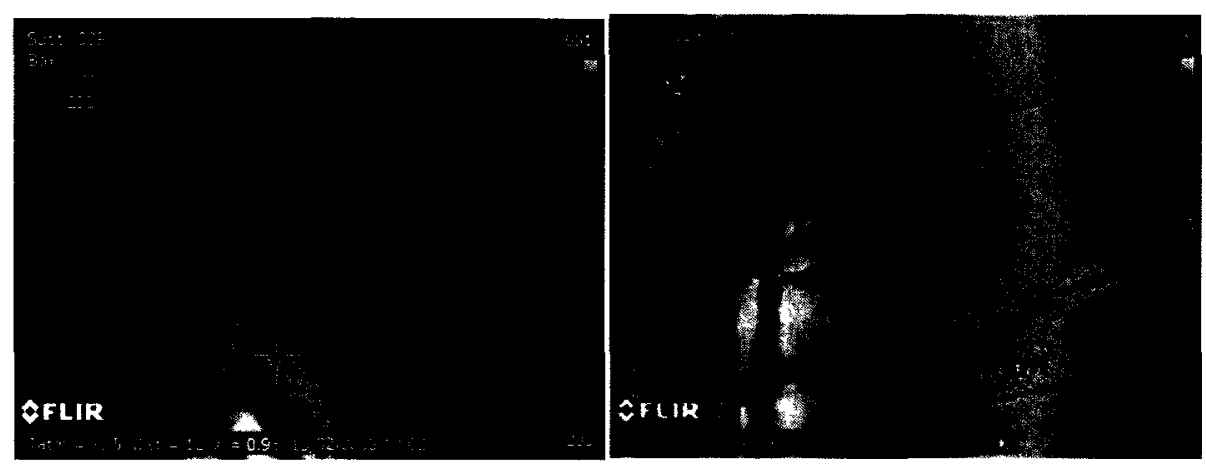

Figure A-24 Thermal image of fire building and target wall

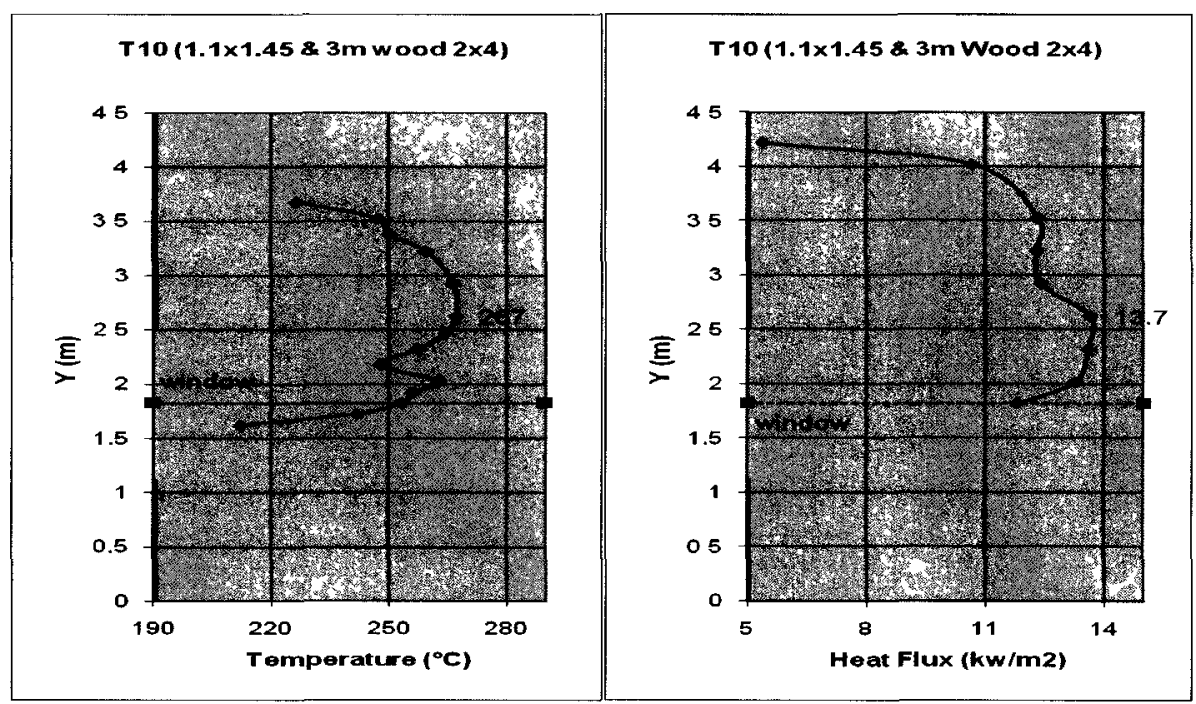

Figure A-25 Temperature distribution and heat flux distribution of target wall

- By taking the average of the data selected, the value of temperature or heat flux at each point during post-flashover fire phase can be estimated.

- The temperature distribution and heat flux distribution at the points on the target wall opposite vertical centerline of the window are shown in Figure A-25. 
- The emissivity of external flame radiator can be calculated by Equation (10.5) as shown in Table A-11.

Table A-11 Temperature, flame height, heat flux and emissivity

\begin{tabular}{|c|c|c|c|c|c|}
\hline & $\begin{array}{c}\text { Maximum } \\
\text { Temperature }\left({ }^{\circ} \mathrm{C}\right)\end{array}$ & Radiometer & $\begin{array}{r}\text { Heat flux } \\
\left(\mathrm{kW} / \mathrm{m}^{2}\right)\end{array}$ & $\begin{array}{l}\text { Emissivity of } \\
\text { external flame }\end{array}$ & $\begin{array}{l}\text { Average } \\
\text { emissivity }\end{array}$ \\
\hline \multirow{2}{*}{ Room } & \multirow{2}{*}{958} & $\mathrm{H} 1$ & 11.82 & 0.884 & \multirow{10}{*}{0.657} \\
\hline & & $\mathrm{H} 2$ & 13.28 & 0.965 & \\
\hline \multirow{2}{*}{$\begin{array}{c}\text { Flame } \\
\text { (at window) }\end{array}$} & \multirow{2}{*}{942} & H3 & 13.60 & 0.842 & \\
\hline & & $\mathrm{H} 4$ & 13.65 & 0.754 & \\
\hline \multirow{3}{*}{$\begin{array}{c}\text { Flame } \\
(50 \mathrm{~cm} \text { above } \\
\text { window) }\end{array}$} & \multirow{3}{*}{884} & H5 & 12.39 & 0.606 & \\
\hline & & $\mathrm{H} 6$ & 9.12 & 0.604 & \\
\hline & & $\mathrm{H} 7$ & 10.67 & 0.640 & \\
\hline \multirow{3}{*}{$\begin{array}{l}\text { Flame height } \\
\text { above window }\end{array}$} & \multirow{3}{*}{$3.0 \mathrm{~m}$} & H8 & 5.41 & 0.443 & \\
\hline & & $\mathrm{H9}$ & 12.30 & 0.605 & \\
\hline & & $\mathrm{H} 10$ & 12.36 & 0.226 & \\
\hline
\end{tabular}

\section{Test $11\left(1.45 \times 1.45 \& 3 \mathrm{~m}\right.$, wood crib $\left.2^{\prime \prime} \times 4^{\prime \prime}\right)$}

- The thermal images of the fire building and target wall are shown in Figure A-26.

- Based on the graphs of heat flux on the target wall, the data after smoothing between 11:41:04 and 11:46:04 were chosen to do the experimental study of Test 11.

- By taking the average of the data selected, the value of temperature or heat flux at each point during post-flashover fire phase can be estimated. 

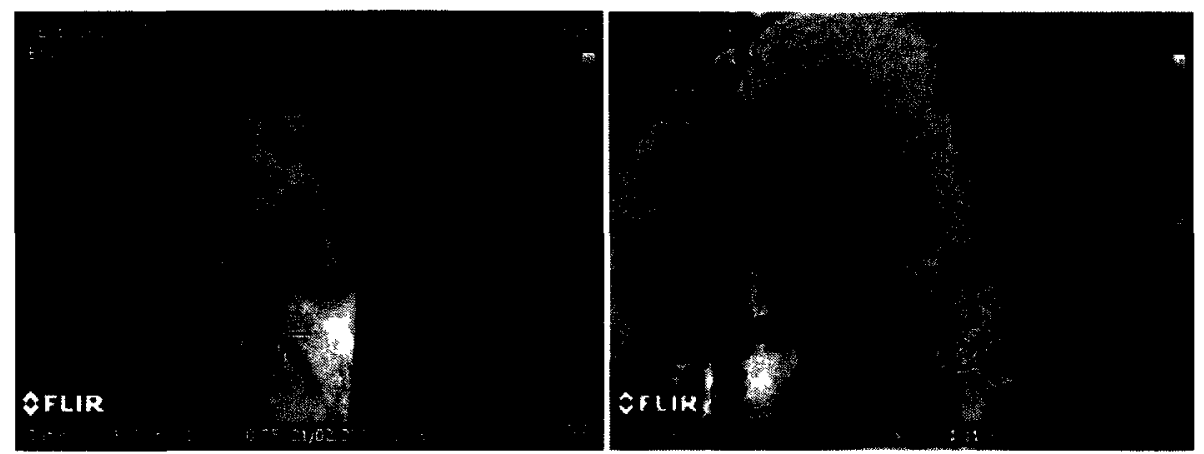

Figure A-26 Thermal image of fire building and target wall

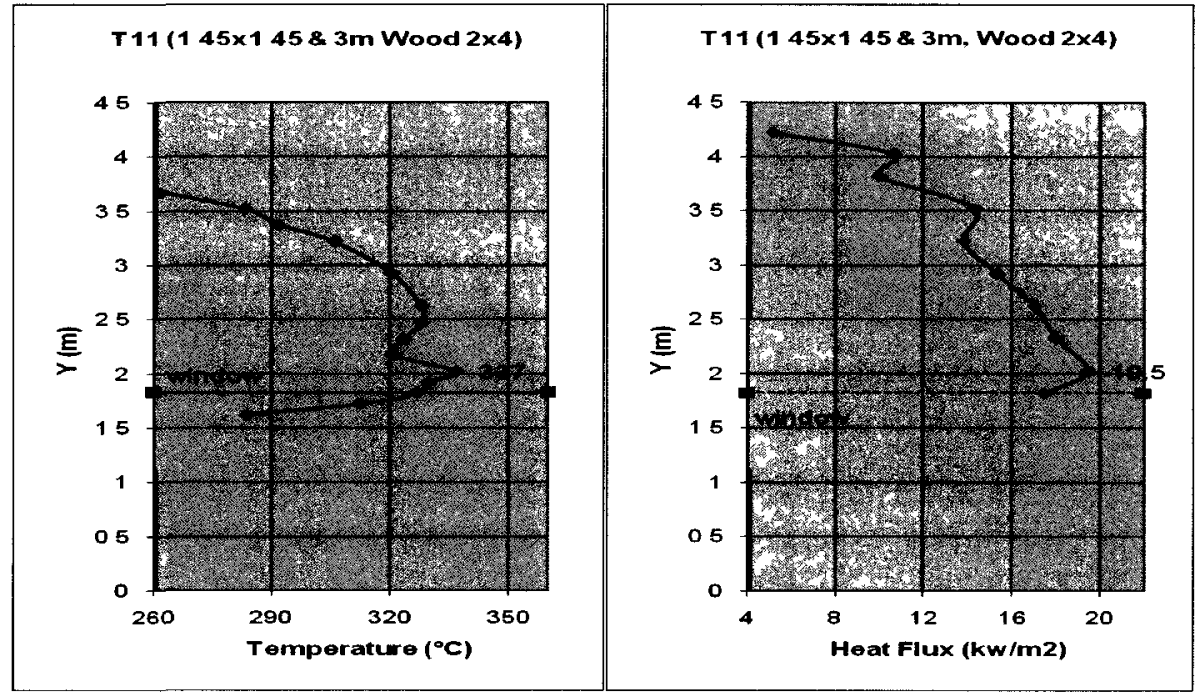

Figure A-27 Temperature distribution and heat flux distribution of target wall

- The temperature distribution and heat flux distribution at the points on the target wall opposite vertical centerline of the window are shown in Figure A-27.

- The emissivity of external flame radiator can be calculated by Equation (10.5) as shown in Table A-12. 
Table A-12 Temperature, flame height, heat flux and emissivity

\begin{tabular}{|c|c|c|c|c|c|}
\hline & $\begin{array}{c}\text { Maximum } \\
\text { Temperature }\left({ }^{\circ} \mathrm{C}\right)\end{array}$ & Radiometer & $\begin{array}{l}\text { Heat flux } \\
\left(\mathrm{kW} / \mathrm{m}^{2}\right)\end{array}$ & $\begin{array}{l}\text { Emissivity of } \\
\text { external flame }\end{array}$ & $\begin{array}{c}\text { Average } \\
\text { emissivity }\end{array}$ \\
\hline \multirow{2}{*}{ Room } & \multirow{2}{*}{1083} & $\mathrm{H} 1$ & 17.49 & 1.045 & \multirow{10}{*}{0.607} \\
\hline & & $\mathrm{H} 2$ & 19.45 & 1.151 & \\
\hline \multirow{2}{*}{$\begin{array}{c}\text { Flame } \\
\text { (at window) }\end{array}$} & \multirow{2}{*}{1010} & $\mathrm{H} 3$ & 18.04 & 0.824 & \\
\hline & & $\mathrm{H} 4$ & 17.06 & 0.669 & \\
\hline \multirow{3}{*}{$\begin{array}{c}\text { Flame } \\
\text { (50 cm above } \\
\text { window) }\end{array}$} & \multirow{3}{*}{846} & H5 & 15.34 & 0.530 & \\
\hline & & $\mathrm{H} 6$ & 9.97 & 0.458 & \\
\hline & & $\mathrm{H} 7$ & 10.65 & 0.557 & \\
\hline \multirow{3}{*}{$\begin{array}{l}\text { Flame height } \\
\text { above window }\end{array}$} & \multirow{3}{*}{$2.5 \mathrm{~m}$} & $\mathrm{H} 8$ & 5.18 & 0.328 & \\
\hline & & $\mathrm{H9}$ & 13.81 & 0.437 & \\
\hline & & $\mathrm{H} 10$ & 14.31 & 0.072 & \\
\hline
\end{tabular}

\section{Test $12\left(2.55 \times 1.45 \& 3 \mathrm{~m}\right.$, wood crib $\left.2^{\prime \prime} \times 2^{\prime \prime}\right)$}

- The thermal images of the fire building and target wall are shown in Figure A-28.

- Based on the graphs of heat flux on the target wall, the data after smoothing between 11:41:04 and 11:46:04 were chosen to do the experimental study of Test 12.

- By taking the average of the data selected, the value of temperature or heat flux at each point during post-flashover fire phase can be estimated.

- The temperature distribution and heat flux distribution at the points on the target wall opposite vertical centerline of the window are shown in Figure A-29. 
- The emissivity of external flame radiator can be calculated by Equation (10.5) as shown in Table A-13.
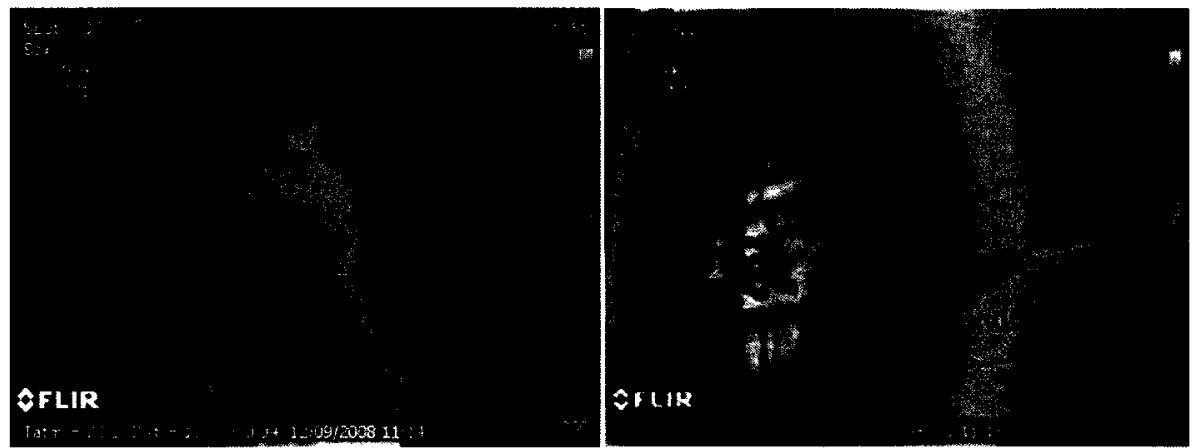

Figure A-28 Thermal image of fire building and target wall

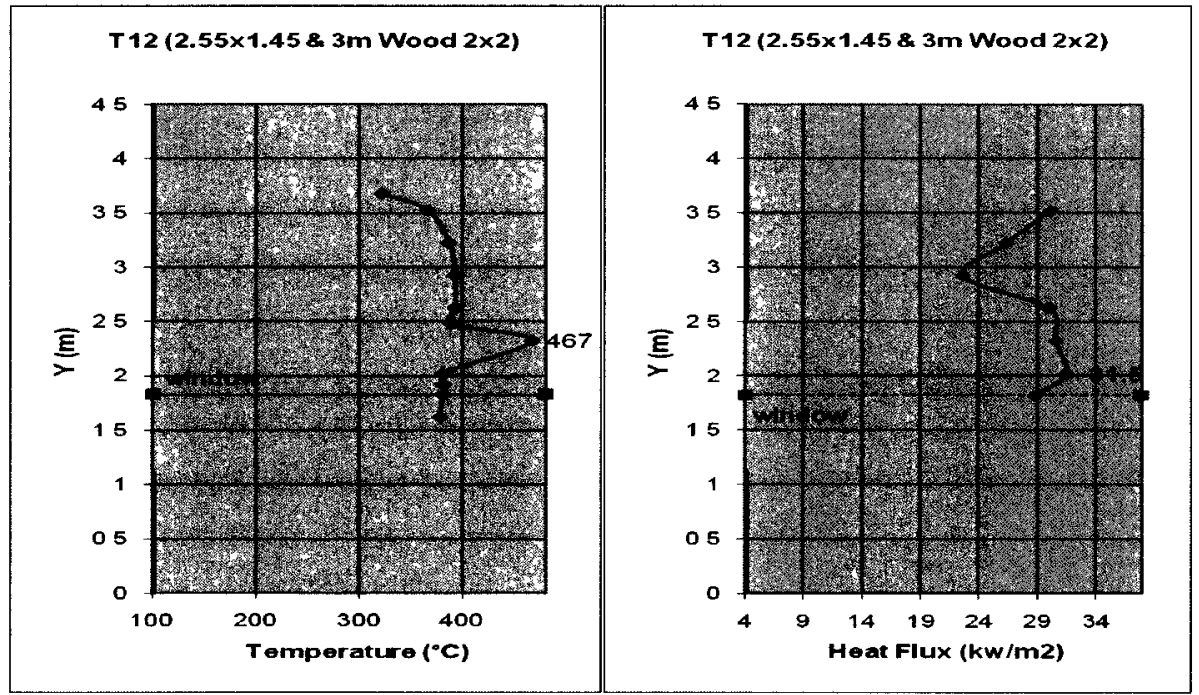

Figure A-29 Temperature distribution and heat flux distribution of target wall 
Table 13 A-Temperature, flame height, heat flux and emissivity

\begin{tabular}{|c|c|c|c|c|c|}
\hline & $\begin{array}{c}\text { Maximum } \\
\text { Temperature }\left({ }^{\circ} \mathrm{C}\right)\end{array}$ & Radiometer & $\begin{array}{l}\text { Heat flux } \\
\left(\mathrm{kW} / \mathrm{m}^{2}\right)\end{array}$ & $\begin{array}{l}\text { Emissivity of } \\
\text { external flame }\end{array}$ & $\begin{array}{l}\text { Average } \\
\text { emissivity }\end{array}$ \\
\hline \multirow{2}{*}{ Room } & \multirow{2}{*}{1050} & $\mathrm{H} 1$ & 28.79 & 0.460 & \multirow{10}{*}{0.629} \\
\hline & & $\mathrm{H} 2$ & 31.47 & 0.545 & \\
\hline \multirow{2}{*}{$\begin{array}{c}\text { Flame } \\
\text { (at window) }\end{array}$} & \multirow{2}{*}{1079} & $H 3$ & 30.59 & 0.439 & \\
\hline & & $\mathrm{H} 4$ & 29.98 & 0.400 & \\
\hline \multirow{3}{*}{$\begin{array}{c}\text { Flame } \\
\text { (50 cm above } \\
\text { window) }\end{array}$} & \multirow{3}{*}{956} & H5 & 22.56 & 0.171 & \\
\hline & & H6 & 40.95 & 0.335 & \\
\hline & & $\mathrm{H} 7$ & 26.73 & 0.495 & \\
\hline \multirow{3}{*}{$\begin{array}{l}\text { Flame height } \\
\text { above window }\end{array}$} & \multirow{3}{*}{$3.2 \mathrm{~m}$} & H8 & 16.80 & 1.309 & \\
\hline & & $\mathrm{H} 9$ & 26.39 & 1.056 & \\
\hline & & $\mathrm{H} 10$ & 30.16 & 1.084 & \\
\hline
\end{tabular}

